UNIVERSIDADE DE SÃO PAULO

INSTITUTO DE GEOCIÊNCIAS

\title{
INVESTIGAÇÃO GEOFÍSICA DO ALTO ESTRUTURAL DE ANHEMBI - SP
}

\author{
Francisco de Assis Cavallaro \\ Orientador: Prof. Dr. Jorge Kazuo Yamamoto \\ Co-Orientador:Prof. Dr. José Domingos Faraco Gallas
}

TESE DE DOUTORAMENTO

Programa de Pós-Graduação em Recursos Minerais e Hidrogeologia

Versão Corrigida

SÃO PAULO

2013 


\section{UNIVERSIDADE DE SÃO PAULO \\ INSTITUTO DE GEOCIÊNCIAS}

\section{INVESTIGAÇÃO GEOFÍSICA DO ALTO ESTRUTURAL DE ANHEMBI - SP}

\section{Francisco de Assis Cavallaro}

Orientador: Prof. Dr. Jorge Kazuo Yamamoto

Co-Orientador: Prof. Dr. José Domingos Faraco Gallas

\section{TESE DE DOUTORAMENTO}

Programa de Pós-Graduação em Recursos Minerais e Hidrogeologia

SÃO PAULO

2013 
Ficha catalográfica preparada pelo Serviço de Biblioteca e Documentação do Instituto de Geociências da Universidade de São Paulo

Cavallaro, Francisco de Assis

Investigação geofísica do Alto Estrutural de Anhembi-SP / Francisco de Assis Cavallaro. - São Paulo, 2013.

148 p. : il.

Tese (Doutorado) : IGc/USP

Orient.: Yamamoto, Jorge Kazuo

Co-orient: Gallas, José Domingos Faraco

1. Bacia do Paraná: Métodos potenciais 2. Gravimetria 3. Geiseritos 4. Formação Teresina 5. Arenito asfáltico I. Título 
À Edna Toshika,

minha esposa e a meus filhos Heitor e Arthur 
"Impossível é apenas uma grande palavra usada por gente fraca que prefere viver no mundo como está em vez de usar o poder que tem para mudá-lo. Impossível não é um fato, é uma opinião. Impossível não é uma declaração, é um desafio. Impossível é hipotético. Impossivel é temporário. Impossível é nada."

Muhammad Ali 


\section{AGRADECIMENTOS}

Meus sinceros agradecimentos a todos que de alguma forma contribuíram para a realização e conclusão deste trabalho.

Em especial, gostaria de agradecer ao Prof. Dr. Jorge Kazuo Yamamoto, orientador, e ao Prof. Dr. José Domingos Faraco Gallas, co-orientador, pela oportunidade, confiança em meu trabalho e pela amizade durante todo o período da pesquisa.

Agradeço também ao Samuel Pedro Egídio, Paulo Rodrigues de Lima e Reynaldo Pena Castelon pelos trabalhos de campo realizados ao longo de vários meses.

À Prof. Maria Irene Bartholomeu Raposo pelos trabalhos de coleta de amostras e medições de susceptibidade e MRN em laboratório.

Ao Prof. Dr. Antonio Roberto Saad pela revisão e orientação da estratigrafia e tectônica da Bacia do Paraná, pela paciência e momentos de convívio, poucos, porém intensos.

Ao Prof. Paulo Roberto dos Santos pela colaboração durante o desenvolvimento dos trabalhos e empréstimo de referências bibliográficas.

Ao Prof. Dr. Wladimir Shukowsky e ao Prof. Dr. Carlos Alberto Mendonça pela orientação e discussão com relação aos métodos potenciais.

A Lucas Cavallaro Lin pela revisão do texto, Carlos Arbieto Carrasco e Enos Nobuo Sato por todas as discussões e testes e a amizade.

A meus amigos que participaram ativamente do processo: ao Antônio Tadashi Kikuda, Roberto Zanon, Fabrício Bau Dalmas e Sidney Schaberle Goveia. À Elaine Aparecida Sinfronio pelos trabalhos de laboratório.

Ao pessoal das bibliotecas do IGc e IAG - USP pela paciência e ajuda, exemplar, dada a minha pessoa. Da mesma forma, agradeço a secretaria de pós, Magali e Leonardo, e a equipe da gráfica.

A meus amigos da Provida Andreas, Tânia, Vera, Ivan, Nilton, Ariovaldo, Renato, Rosa Maria, Nilva, Maria Helena pela amizade, força e incentivo ao meu trabalho.

Ao Sr. Rios pela pela amizade, pela alegria de estar junto, conduzindo como um pai a mim e a minha família.

Finalmente, agradeço à Fundação de Amparo à Pesquisa do Estado de São Paulo FAPESP - que por meio do Auxílio à Pesquisa - Processo FAPESP 2009/50923-2 - permitiu a realização dos trabalhos de campo. 


\section{ÍNDICE}

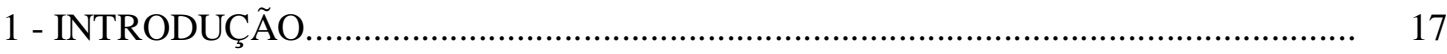

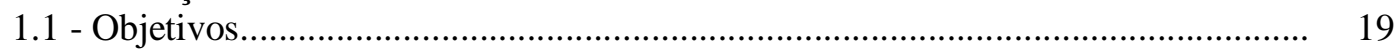

1.2- Justificativas................................................................................................ 19

2 - GEOLOGIA REGIONAL.................................................................................. 20

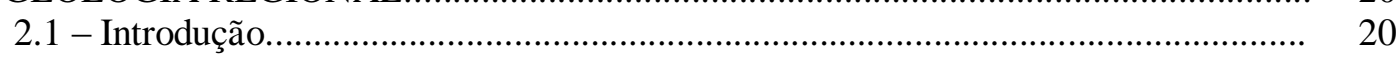

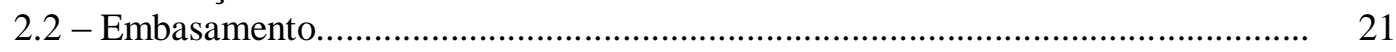

2.3 - Sedimentação e estratigrafia da Bacia do Paraná.................................................... 25

2.4 - Caracterização Estrutural da Bacia do Paraná...................................................... 30

3- GEOLOGIA DA ÁREA DE ESTUDO................................................................... 36

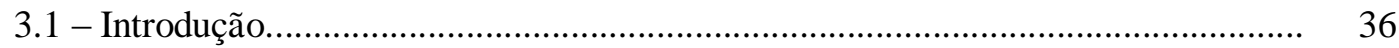

3.2 - Aspectos geomorfológicos da área de estudo..................................................... 38

3.3 - Principais litotipos presentes na área de estudo................................................... 41

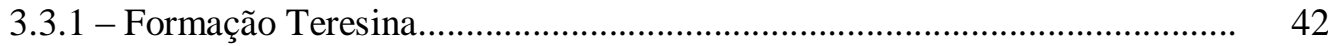

3.3.2 - Formação Pirambóia ....…………………………………………………… 46

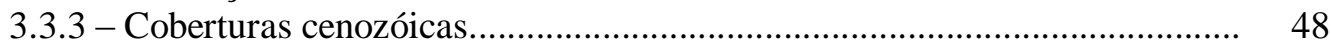

3.3.4 - Aluviões................................................................................................ 49

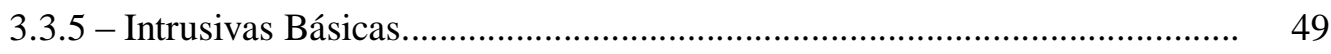

3.3.6 - Litotipos em sub-superfície.................................................................... 49

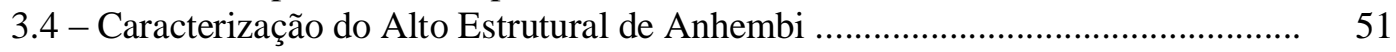

4 - FUNDAMENTAÇÃO TEÓRICA........................................................................ 57

4.1 - Método gravimétrico terrestres........................................................................ 57

4.1.1 - Tratamento dos Dados........................................................................... 58

4.1.1.1 - Correção de Marés...................................................................... 59

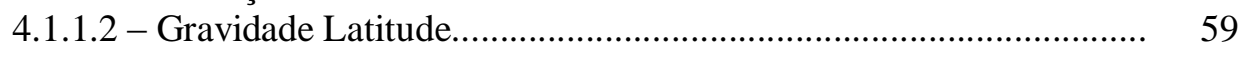

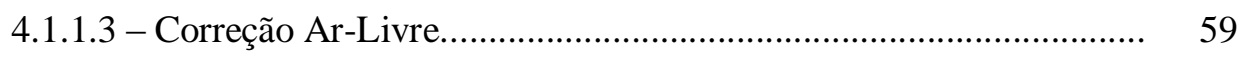

4.1.1.4 - Correção de Bouguer....................................................................... 60

4.1.1.5 - Correção do terreno....................................................................... 60

4.2 - Método magnetométrico terrestre....................................................................... 62

4.2.1 - Tratamento dos Dados........................................................................... 62

4.2.1.1 - Variação diurna........................................................................... 63

4.3 - Medições das propriedades físicas das rochas....................................................... 64

4.3.1 - Densidade de massa............................................................................. 64

4.3.2 - Medidas de Susceptibilidade Magnética e Magnetização Remanescente

Natural (MRN) ……………………………………………………….... 65

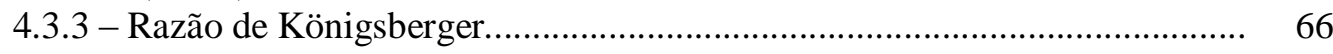

4.4 - Transformações lineares dos dados geofísicos.................................................... 68

4.4.1 - Introdução............................................................................................. 68

4.4.2 - Filtros utilizados................................................................................. 69

4.4.2.1 - Espectro de Potência ponderado Radialmente................................. 69

4.4.2.2 - Filtro-Passa Banda...………………………………………….... 70

4.4.2.3 - Filtro Cosseno Direcional................................................................ 71

4.4.2.4 - Filtro Butterworth........................................................................... 71

4.4.2.5 - Filtro Derivada Vertical............................................................. 72

4.4.3 - Continuação para cima............................................................................... 72

4.4.4 - Redução ao polo.................................................................................... 72

4.4.5 - Sinal Analítico ........................................................................................ 73

4.4.5.1 - Inclinação do Sinal Analítico - ISA …………………………….... 75

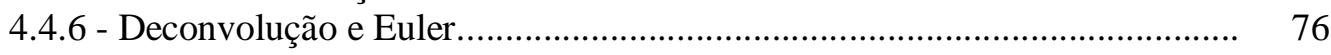

4.4.7 - Modelagem Gravimétrica Direta 21/2D ................................................. 77 


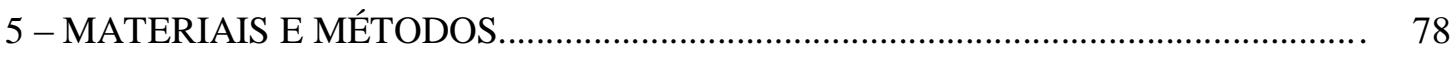

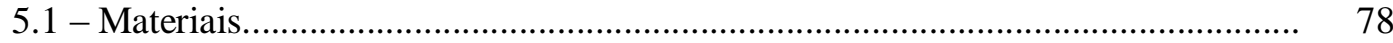

5.1.1 - Áreas de estudo - localização.................................................................... 78

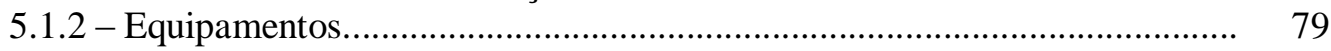

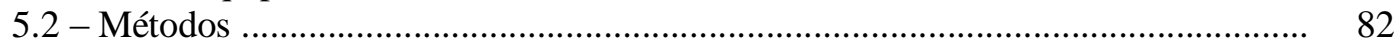

5.2.1 - Transferência de g absoluto ................................................................. 82

5.2.2 - Levantamento Planialtimétrico ........................................................... 83

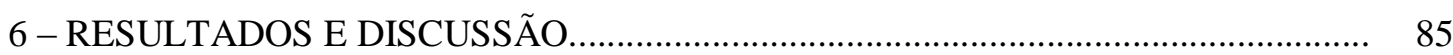

6.1 - Resultado obtidos em laboratório ........................................................... $\quad 85$

6.1.1 - Densidade de massa.............................................................................. 85

6.1.2 - Magnetização Remanecente Natural e Susceptibilidade ................................. 86

6.2 - Levantamento gravimétrico de semi-detalhe....................................................... 88

6.2.1 - Mapa Bouguer do levantamento de semi-detalhe .................................... 89

6.2.2 - Espectro de Potência aplicado aos dados gravimétricos de semi-detalhe... 91

6.2.3 - Filtro Butterworth aplicado aos dados gravimétricos de semi-detalhe....... 94

6.2.4 - Resultados do filtro Butterworth - parâmetro regional - aplicados aos dados gravimétricos de semi-detalhe ........................................................ 95

6.2.5 - Resultados do filtro Butterworth - parâmetro residual - aplicados aos dados gravimétricos de semi-detalhe ..................................................... 105

6.2.6 - Deconvolução de Euler aplicado aos dados gravimétricos de semidetalhe ........................................................................................... 106

6.3 - Levantamento magnetométrico de semi-detalhe .............................................. 109

6.3.1 - Mapa do Campo Magnético Total - CMT ............................................ 110

6.3.2 - Espectro de potência aplicado aos dados magnetométricos de semidetalhes

6.3.3 - Filtro Butterworth aplicado aos dados magnetométricos de semidetalhe

6.3.4 - Resultados dos filtros aplicados aos dados magnetométricos de semidetalhe

6.3.5 - Deconvolução de Euler aplicado aos dados magnetométricos de semidetalhe

6.4 - Levantamento gravimétrico de detalhe...................................................... 123

6.4.1 - Mapa de Bouguer de detalhe............................................................. 123

6.4.2 - Espectro de Potência aplicado aos dados gravimétricos de detalhe......... 123

6.4.3 - Filtro Butterworth aplicado aos dados gravimétricos de detalhe............. 124

6.4.4 - Deconvolução de Euler aplicado aos dados gravimétricos de detalhe .... 127

6.5 - Levantamento magnetométrico de detalhe ....................................................... 129

6.5.1 - Mapa do Campo Magnético Total - CMT - de detalhe ............................ 129

6.5.2 - Espectro de potência aplicado aos dados magnetométricos de detalhes.. 130

6.5.3 - Filtro Butterworth aplicado aos dados magnetométricos de detalhe....... 132

6.5.4 - Resultados dos filtros aplicados aos dados magnetométricos de detalhe 134

6.5.5 - Deconvolução de Euler aplicado aos dados magnetométricos de detalhe

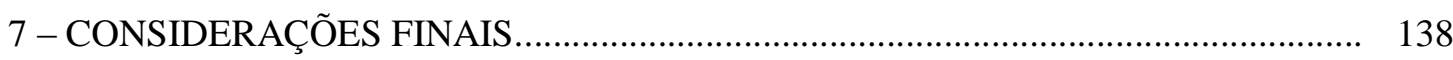

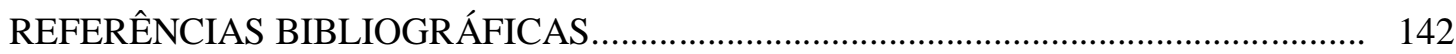




\section{ÍNDICE DE FIGURAS}

\section{Capítulo 2}

Figura 2.1 - Localização da bacia do Paraná.

Figura 2.2 - Seção geológica NW-SE da Bacia do Paraná representando as principais formações e grupos.

Figura 2.3 - Estrutura do embasamento da Bacia do Paraná. No detalhe, arcabouço geotectônico regional para o domínio sul-ocidental do Gondwana. Setas indicam o movimento convergente entre o continente e a litosfera do Panthalassa.

Figura 2.4 - Delimitação do Bloco Paranapanema através de dados gravimétricos, segundo Mantovani et al. (2005, p.18). (1) Crátons: São Francisco (SF), Amazônico, LA- Luís Alves, RP- Rio de La Plata. (2) Principais blocos Pré-Brasilianos retrabalhados (embasamento Paleozóico e Arqueano). (3) Arcos magmáticos Brasilianos Neoproterozóicos: MR- Mara Rosa - Goiás, AR- Arenópolis, SM- Terreno Serra do Mar (Arcos Rio Negro e Rio Doce), SG- Socorro Guaxupé, PE- Pelotas. (3) Cinturões de rochas Supracrustais indiferenciadas. (4) Mapa gravimétrico do embasamento.

Figura 2.5 - Mapa de anomalia Bouguer da Bacia do Paraná. Foram utilizados dados terrestres disponíveis para a Bacia (ANP, 2010). Estão representados: a profundidade do embasamento, em metros e contorno dos limites da Bacia do Paraná.

Figura 2.6 - Mapa geológico simplificado da Bacia do Paraná, seus principais elementos tectônicos e acidentes geográficos

Figura 2.7 - Carta estratigráfica da Bacia do Paraná.

Figura 2.8 - A Bacia do Paraná é condicionada principalmente por estruturas de direção NE relacionadas ao Cinturão de Cisalhamento Ribeira (Neoproterozóico - Cambriano Superior) e pelo Cinturão de Cisalhamento Transbrasiliano. Seu depocentro tem aproximadamente $6000 \mathrm{~m}$ de profundidade.

Figura 2.9 - Lineamentos estruturais propostos por Soares (1991).

Figura 2.10 - Mapa magnético residual da Bacia do Paraná, ilustrando as principais assinaturas magnéticas (ANP, 2010).

Figura 2.11 - Unidades geológicas e principais alinhamentos estruturais da Bacia do Paraná no Estado de São Paulo. Unidades Geológicas:

Figura 2.12 - Mapa gravimétrico residual gerado por Quintas (1995, p. 116), subtraído os sedimentos e rochas ácidas. Os pontos na cor lilás representam a posição das alcalinas e as linhas na cor roxa os limites da Bacia do Paraná. As linhas brancas os limites dos prováveis blocos litosféricos dispostos em horst e graben.

Figura 2.13 - Interpretação Geofísica das feições tectônicas da bacia do Paraná com os Alinhamentos estruturais propostos por Soares (1991) sobrepostos. Na parte central pode-se observar um alto gravimétrico positivo.

\section{Capítulo 3}

Figura 3.1 - Mapa geológico do Alto Estrutural de Anhembi com lineamentos representados e identificados. Estão também representados as ocorrências: de arenito asfáltico, entrela em amarelo, cones silicosos (geseritos) em pontos em vermelho e a localização do 1AB-1-SP, ponto em verde. Em detalhe é delimitado a área de estudo.

Figura 3.2 - Mapa Geomorfológico do Estado de São Paulo, modificado de IPT (1981).

Figura 3.3 - Esquema simplificado do padrão de relevo da área de estudo (modificado de IPT, 1981).

Figura 3.4 (A) Mapa de drenagem. Em vermelho, as principais anomalias de drenagem. Nota-se, entre os rios Alambari e dos Remédios, uma anomalia com padrão anelar e radial de drenagem, os sinais positivos indicam as áreas de alto estrutural. Os pontos verdes indicam os afloramentos de um dique de rocha básica. (B) Curvas de isovalor com interpretação morfoestrutural e indicação das anomalias observadas em (A). As estrelas indicam ocorrência de arenito asfáltico. (C) Representação tridimensional de altos e baixos morfoestruturais com indicação das ocorrências de arenito asfáltico. Os tons de verde indicam baixo estrutural e os tons de marrom e cinza indicam alto estrutural. Notar que as ocorrências se encontram nas regiões entre altos e baixos estruturais. 
Coordenadas UTM em metros; M.C. $-51^{\circ}$, SAD69.

Figura 3.5 - Coluna estratigráfica simplificada da seção Permo-Triássica da área do Alto de Anhembi.

Figura 3.6 - Litoestratigrafia do Grupo Passa Dois para os estados do Paraná e São Paulo.

Figura 3.7 - Foto ilustrativa da Fm. Teresina: siltitos com intercalações de arenitos finos a muito finos com estruturas de aleitamento rítmicas evidenciadas pelas estruturas tipo "flaser".

Figura 3.8 - Foto ilustrativa da Fm. Teresina: espessas camadas de siltito maciço.

Figura 3.9 - Foto ilustrativa de ondas da Fm. Teresina: marcas de ondas, próximo a cidade Anhembi- SP (IPT, 1979).

Figura 3.10 - Ocorrência silexito na Fm. Teresina observado em campo, nas margens leste e oeste do córrego do Retiro (cota 515 metros), a montante do mesmo córrego (cota 530 metros).

Figura 3.11 - Mapa de localização da área de ocorrência dos geiseritos, com coordenadas em UTM, aflorando. No detalhe, observam-se os pontos das ocorrências de cones silicosos e em detalhe um cone.

Figura 3.12 - Foto ilustrativa dos contatos das Formações Pirambóia, Teresina (base) e cobertura cenozóica (topo). Rodovia SP-147, próximo à cidade de Anhembi.

Figura 3.13 - Foto ilustrativa da ocorrência do regolito fóssil brechado da base da Fm. Pirambóia (IPT, 1979).

Figura 3.14 - Foto ilustrativa de depósito de cascalho da cobertura cenozoica, localizada na área de estudo.

Figura 3.15 - Perfil do poço pioneiro exploratório 1-AB-1-SP, da Petrobras, com os principais litotipos da área de estudo (modificado de IPT, 2005, p. 180).

Figura 3.16 - Caracterização do Alto estrutural de Anhembi. Contorno estrutural do topo da Fm. Teresina, em verde, sobre modelo numérico de terreno sombreado, iluminação de $45^{\circ}$, elevação de $45^{\circ}$. As principais falhas e lineamentos na área de estudo, em vermelho, assim como os altos estruturais, dois perfis geológico, segmentos em preto, ocorrência de cones silicosos, em lilás, poço exploratório 1-AB-1-SP, triângulo invertido em laranja e ocorrência de arenito asfáltico, estrela em amarelo estão identificados (compilado de IPT, 1979, mapas 2 e 7; Araujo et al., 2006, p. 55).

Figura 3.17 - Perfil N-S (AB), modificado de IPT (1979).

Figura 3.18 - Perfil NW-NE (CD), modificado de IPT (1979).

Figura 3.19 - Mapa de Contorno Estrutural da Formação Teresina na região do Alto de Anhembi sobre modelo numérico de terreno sombreado. As linhas contínuas indicam o contorno estrutural com valores em metros acima do nível do mar. A área de afloramento da Fm. Teresina está em rosa e a represa de Barra Bonita em azul. As estrelas vermelhas representam as ocorrências de arenito asfáltico e as linhas tracejadas são as principais falhas e lineamentos utilizados na interpretação do contorno estrutural. (modificado de Araujo et al., 2006, p. 55).

Figura 3.20 - Mapa geológico com lineamentos e falhas interpretados com imagem de satélite Landsat 7. As falhas foram também identificadas através de levantamento de campo. $\mathrm{O}$ ponto de amostragem de diabásio, para datação, assinalado com estrela vermelha (modificado de Araújo et al., 2006, p.51).

Figura 3.21 - Mapa geológico e estrutural do Estrutural de Anhembi. Segundo IPT, 1979. Estão também representados lineamentos e falhas interpretadas e identificadas em campo (IPT, 2005, p. 166)

\section{Capítulo 4}

Figura 4.1 - Correçães de elevação de numa determinada estação. A) Ar livre - estação localizada numa altura $h$ sobre o datum; B) Bouguer, sendo a área hachurada uma placa de rocha de espessura $h$ que se estende ao infinito lateralmente; C) Correção de terreno para um relevo não plano.

Figura 4.2 - Gradícula típica usada para o cálculo de correção de terreno.

Figura 4.3 - (a) Intensidade do campo geomagnético flutuando num intervalo de amplitude de 10-30 nT em período de um dia, apresentados em varias latitudes, e (b) Variação da intensidade do campo horizontal durante uma tempestade magnética (modificado de Kearey \& Brooks, 2002, p. 290).

Figura 4.4 - Dispositivo para se medir a massa, por imersão, das amostras coletas

Figura 4.5 - Espécimes identificados e orientados, prontos para serem medidas. 
Figura 4.6 - Soma vetorial mostrando as relações de magnetização induzida $\left(J_{i}\right)$, remanescente $\left(J_{r}\right)$ e total $(J)$.

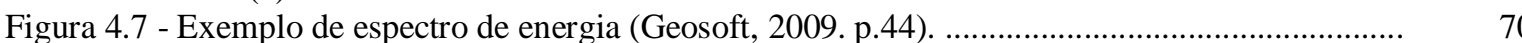

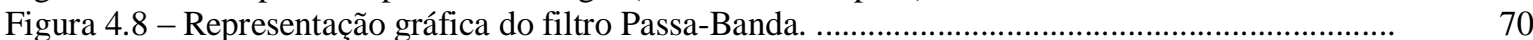

Figura 4.9 - Representação gráfica do filtro Cosseno Direcional. ...................................................... 71

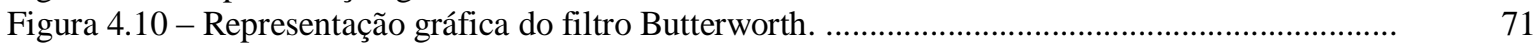

Figura 4.11 - Representação gráfica do filtro Continuação para Cima. ............................................ 72

Figura 4.12 - Exemplo do principal atributo de ASA: máximos nas bordas e mínimos relativos nos centros dos corpos, representado por um prisma em profundidades diferentes.

Figura 4.13 - Representação geometrica de ASA, ISA, derivadas e suas formulações (simplificado de Ferreira et al, 2010).

Figura 4.14 - Exemplo de aplicação da técnica ISA: máximos nos centros dos corpos, representados em um prisma, com magnetização reduzida ao polo, em profundidades diferentes. ........

\section{Capítulo 5}

Figura 5.1 - Mapa de localização da área de estudo, retângulo em linhas azuis e em vermelho podese observar o município de Anhembi, onde se localiza o Alto Estrutural de Anhembi. ....

Figura 5.2 - Console Overhauser (GSM-19) com sensor e cabo.

Figura 5.4 - GPS Trimble - Conjunto com coletor de dados receptor (5700 L1 e L2) e antenas. .........

Figura 5.5 - Magnetômetro SPINNER JR6 conectado a computador do Laboratório de anisotropia magnética - LAM's.

Figura 5.6 - Equipamento Kappabridge LLY-4S - magnetic susceptibility do Laboratório de anisotropia magnética - LAM's.

Figura 5.7 - Estação gravimétrica de Laranjal Paulista, de onde foi feita a transferência de ' $g$ ' absoluto para a área de estudo.

Figura 5.8 - Ponto na área de estudo (igreja matriz de Anhembi) para onde foi transferido o valor de ' $g$ ' absoluto de Laranjal Paulista.

Figura 5.9 - Imagem ilustrativa de correção de posicionamento da base fixa do Trimble R3 GPS System (ID: b-26-04-c) utilizando o software do fabricante, Trimble $\AA$ Business Center - TBC.

Figura 5.10 - Imagem ilustrativa da correção de posicionamento dos pontos medidos. São listadas todas as bases processadas, especificando as precisões horizontais e verticais. A bandeira vermelha indica problemas com as correções.

\section{Capítulo 6}

Figura 6.1 - Levantamento gravimétrico realizado no Domo de Anhembi com 3486 estações.

Figura 6.2- Diagrama ilustrativo da obtenção do mapa de Bouguer, levantamento de detalhe, e produtos derivados.

Figura 6.3 - Mapa de anomalia bouguer da área de estudo com estações de medidas gravimétricas. A área assinalada no retângulo azul corresponde a área de ocorrência dos geiseritos.

Figura 6.4 - Gráfico do espectro de potência radialmente ponderado gerado a partir do mapa de bouguer do levantamento de semi-detalhe, com indicação das profundidades médias das fontes.

Figura 6.5 - Exemplo de aplicação do filtro Butterworth ao espectro de potência do levantamento de semi-detalhe e seu respectivo valor de corte (linhas azuis). O espectro resultante é mostrado na linha de cor vermelha. O intervalo de corte foi 0.0 a $0.17 \mathrm{rad} / \mathrm{km}$ para profundidades maiores que 1800 metros, aproximadamente.

Figura 6.6 - Mapa filtrado do levantamento de semi-detalhe, sombreado, iluminação de $45^{\circ}$, elevação de $45^{\circ}$, com profundidade maior que 1800 metros. (A) - Embasamento com contorno estrutural da Fm. Teresina e falhas segundo IPT (1979, mapa 2). (B) Embasamento sobreposto pela integração dos sistemas de falhas de IPT (2005) e Araújo et al. (2006).

Figura 6.7 - Mapa residual gravimétrico, sombreado, iluminação de $45^{\circ}$, elevação de $45^{\circ}$, determinado pelo intervalo de 0.01 a $0.5 \mathrm{rad} / \mathrm{km}$. Dois perfis estão representados: $\mathrm{AB}$ e CD. Eles foram modelados utilizando o programa GRAVMAG.

Figura 6.8 - Perfil geológico CD pelo IPT (1979) modelado pelo programa GRAMAG. 
Figura 6.10 - Mapa continuado para cima (1000 metros) do mapa residual gravimétrico, determinado pelo intervalo de 0.01 a $0.5 \mathrm{rad} / \mathrm{km}$ (figura 6.11 ), com curvas de contorno, intervalo de $0.2 \mathrm{mGal}$. Também está representado o poço pioneiro exploratório 1-AB-1SP da Petrobras (triângulo amarelo invertido) e são traçados mais dois perfis EF e GH, cruzando o Alto Estrutural de Anhembi.

Figura 6.11 - Perfil EF modelado pelo programa GRAMAG do mapa continuado para cima à 1000 metros (Figura 6.14).

Figura 6.12 - Perfil GH modelado pelo programa GRAMAG do mapa continuado para cima à 1000 metros (Figura 6.14).

Figura 6.13 - Mapa da inclinação do sinal analítico - ISA, sombreado, iluminação de $45^{\circ}$, elevação de $45^{\circ}$, aplicado ao mapa gravimétrico resultante da aplicação do filtro Passa-Banda, para profundidades maiores que 1800 metros com sobreposição do rio Tietê.

Figura 6.14 (A) - Mapa residual gravimétrico, sombreado, iluminação de $45^{\circ}$, elevação de $45^{\circ}$, com profundidade menor que 1800 metros, aproximadamente. O poço pioneiro exploratório 1-AB-1-SP da Petrobras está representado com triângulo amarelo. Em branco é mostrado estruturas com formato anelar. (B) - Curvas de isovalor com interpretação morfoestrutural na área de estudo (modificado de Araujo et al., 2006, p. 56).

Figura 6.15 - Mapa da $1^{\mathrm{a}}$ derivada vertical, sombreado, iluminação de $45^{\circ}$, elevação de $45^{\circ}$, do mapa residual gravimétrico (Figura 6.5.14-A), sobreposto por sistema de falhas de IPT (1979 e 2005, p.166), em preto e Araújo et al. (2006, p. 51), em marrom.

Figura 6.16 - Soluções de Euler calculado com base nos dados da figura 6.3.15, sobrepostas ao sistema de falhas de e lineamentos de IPT (1979 e 2005, p.166) em preto e Araújo et al. (2006, p. 51) em marrom.

Figura 6.17 - Levantamento magnetométrico realizado no Alto Estrutural de Anhembi com 15.868 medidas, sobreposto ao mapa de acessos na área de estudo.

Figura 6.18 - Diagrama ilustrativo da obtenção do mapa de Campo Magnético Total - CMT, levantamento de semi-detalhe, e produtos derivados.

Figura 6.19 - Mapa do campo magnético total - CMT, sobreposto aos pontos de medida do levantamento de semi-detalhe. Área de ocorrência dos geiseritos está demarcada pelo retângulo azul, levantamento de detalhe.

Figura 6.20 - Espectro de potência do levantamento de semi-detalhe, com indicações das profundidades médias das fontes e seus respectivos valores de cortes.

Figura 6.21 - Mapa do campo magnético residual - CMR, sombreado, iluminação de $45^{\circ}$, elevação de $45^{\circ}$.

Figura 6.22 - Mapa redução ao polo, sombreado, iluminação de $45^{\circ}$, elevação de $45^{\circ}$, sobreposto pelo contorno estrutural da Fm. Teresina e o sistema de falhas de IPT (1979 e 2005, p. 166) e Araújo et al. (2006, p. 51).

Figura 6.23 - Mapa de Amplitude do Sinal Analítco - ASA, sombreado, iluminação de $45^{\circ}$, elevação de $45^{\circ}$, sobreposto pelo contorno estrutural da Fm. Teresina e o sistema de falhas de IPT (1979, mapa 2) e Araújo et al. (2006, p .55). O circulo em branco indica uma possível estrutura anelar no Alto Estrutural de Anhembi.

Figura 6.24 - Mapa ISA do cos-seno direcional, sombreado, iluminação de $45^{\circ}$, elevação de $45^{\circ}$, com direção N45E, com base no mapa de redução ao polo, sobreposto pelo sistema de falhas de IPT (1979, mapa 2 e 2005, p. 166), linhas em preto, e Araújo et al. (2006, p. 51), linhas em marrom.

Figura 6.25 - Mapa ISA do cosseno direcional, sombreado, iluminação de $45^{\circ}$, elevação de $45^{\circ}$, com direção N45W, com base no mapa de redução ao polo, sobreposto pelo sistema de falhas IPT (1979 e 2005, p. 166), linhas em preto, e Araújo et al. (2006, p. 51), linhas em marrom.

Figura 6.26 - Mapa de Amplitude do Sinal Analítico - ASA, sombreado, iluminação de 45, elevação de $45^{\circ}$, sobreposto ao sistema de falhas de IPT (1979 e 2005, p. 166), linhas em preto, e Araújo et al. (2006, p. 51), linhas em marrom.

Figura 6.27 - Mapa de redução ao polo sobreposto à localização de ocorrência do arenito asfáltico, ponto pretos. sombreado, iluminação de $45^{\circ}$, elevação de $45^{\circ}$, sobreposto ao sistema de falhas de IPT (1979 e 2005, p. 166), linhas em preto, e Araújo et al. (2006, p. 51), linhas em marrom.

Figura 6.28 - Soluções de Euler calculado com base nos dados da Figura 6.26, sobrepostas ao sistema de falhas de IPT (1979, mapa 2 e 2005, p. 166), linhas em preto, e Araújo et al. (2006, p. 51), linhas em marrom.

Figura 6.29 - Diagrama ilustrativo da obtenção do mapa de Bouguer, do levantamento de detalhe, e 
seus produtos derivados.

Figura 6.30 - Mapa de anomalia bouguer com 768 estações (em azul) na área de afloramento dos cones silicosos (polígonos em verde).

Figura 6.31 - Espectro de potência do levantamento de detalhe, com indicações das profundidades médias das fontes.

Figura 6.32 - Mapa residual gravimétrico, sombreado, iluminação de $45^{\circ}$, elevação de $45^{\circ}$, com sobreposição de ocorrência de cones silicosos, em preto, e córrego do Retiro, linha azul.

Figura 6.33 - Mapa residual gravimétrico, sombreado, iluminação de $45^{\circ}$, elevação de $45^{\circ}$, com sobreposição das soluções de Euler e principais lineamentos gravimétricos reconhecidos, linhas na cor marrom, na área de estudo. Linha em preto indica falha determinada por Araújo et al. (2006).

Figura 6.34 - Diagrama ilustrativo da obtenção do mapa CMT, levantamento de detalhe, e seus produtos derivados.

Figura 6.35 - Mapa do campo magnético total - CMT, sobreposto aos pontos de medida do levantamento de detalhe com 3.479 estações (em vermelho) na área de ocorrência dos geiseritos (polígonos em verde).

Figura 6.36 - Espectro de potência do levantamento de detalhe, com indicações das profundidades médias das fontes e seus respectivos valores de cortes, linhas azuis e espectro resultante, linha vermelha.

Figura 6.37 - Mapa do campo magnético residual - CMR, sombreado, iluminação de $45^{\circ}$, elevação de $45^{\circ}$.

Figura 6.38 - Mapa redução ao polo, sombreado, iluminação de $45^{\circ}$, elevação de $45^{\circ}$, sobreposto por falha determinada por Araújo et al. (2006, p.55), segmento na cor preta, pela localização da área de ocorrência dos cones silicosos, sequência de pontos pretos, cortado pelo córrego do Retiro, segmento em azul. Os segmentos em marrom representam principais lineamentos magnetométricos reconhecidos neste mapa.

Figura 6.39 - Mapa Amplitude do Sinal Analítico - ASA, sombreado, iluminação de $45^{\circ}$, elevação de $45^{\circ}$, sobreposto por falha determinada por Araújo et al. (2006, p. 55), segmento na cor preta, pela localização da área de ocorrência dos cones silicosos, sequência de pontos pretos, cortado pelo córrego do Retiro, segmento em azul. Os segmentos em marrom representam principais lineamentos magnetométricos reconhecidos neste mapa.

Figura 6.40 - Representação das soluções da deconvolução de Euler sobreposto ao mapa de Amplitude do Sinal Analítico - ASA, sombreado, iluminação de $45^{\circ}$, elevação de $45^{\circ}$, e por falha determinada por Araújo et al. (2006, p. 55).

\section{Capítulo 7}

Figura 7.1 - Diagrama ilustrativo dos resultados obtidos.

Figura 7.2 - Modelo de limite de blocos estruturais de Etchebehere et al. (2007). Falhas e fraturas observadas em superfície refletem as descontinuida existentes no embasamento.

Figura 7.3 - Modelo genérico de um sistema hidrotermal em profundidade, que poderia representar a gênese dos geiseritos (Matos, 1995, p.75). As setas indicam um possível padrão de circulação de água no sistema. Neste modelo não houve preocupação com a geometria das falhas e com a proporcionalidade. 


\section{ÍNDICE DE TABELAS}

\section{Capítulo 6}

Tabela 6.1 - Susceptibilidade de amostras de rochas da área de estudo.

Tabela 6.2 - Valores de MRN das amostras de rochas da área de estudo.

Tabela 6.3 - Direção média da área de estudo. $\mathrm{N}=$ Número de vetores, $\mathrm{R}=$ intensidade do vetor e $\mathrm{k}=$ parâmetro de precisão.

Tabela 6.4 - Estatística descritiva do espectro da Figura 6.4.

Tabela 6.5 - Distribuição das profundidades, em porcentagem na deconvolução de Euler.

Tabela 6.6 - Estatística descritiva do espectro da Figura 6.20.

Tabela 6.7 - Distribuição das profundidades, em porcentagem na deconvolução de Euler.

Tabela 6.8 - Estatística descritiva do espectro da figura 6.31.

Tabela 6.9 - Distribuição das profundidades, em porcentagem na deconvolução de Euler.

Tabela 6.10 - Estatística descritiva do espectro da figura 6.36.

Tabela 6.11 - Distribuição das profundidades, em porcentagem na deconvolução de Euler. 


\section{ÍNDICE DE QUADROS}

\section{Capítulo 3}

Quadro 3.1 - Síntese da geologia da área de estudo.

\section{Capítulo 4}

Quadro 4.1 - Resumo de índices estruturais simples em um campo potencial

\section{Capítulo 6}

Quadro 6.1 - Densidades medidas na área de estudo e adjacências. 


\section{RESUMO}

Cavallaro, F. A. Investigação geofísica do Alto Estrutural de Anhembi - SP. 2013. 148p. Tese - Instituto de Geociências da Universidade de São Paulo, São Paulo. 2013.

Nesse trabalho são apresentados os resultados de levantamentos gravimétricos e magnetométricos feitos no Alto Estrutural de Anhembi, SP. Para a área total, foi adotada a escala de semi-detalhe, enquanto que, para a área de ocorrência de geiseritos, os levantamentos foram feitos em escala de detalhe. O Alto Estrutural de Anhembi registra dois eventos geológicos importantes durante a evolução da Bacia Sedimentar do Paraná, ou seja, uma intensa atividade geotermal no final do Permiano que produziu milhares de geiseritos, bem como a migração e o transporte do óleo da Formação Irati armazenados em arenitos da Formação Pirambóia causados pela intrusão de diques e sills associados ao vulcanismo da Formação Serra Geral. Esses reservatórios são agora arenitos asfálticos que afloram na borda da estrutura circular, mostrando que eles estão localizados na base da Formação Pirambóia. O levantamento gravimétrico de semi-detalhe mostra uma anomalia positiva na direção NW-SE superposta ao rio Tietê, que indica uma forte correlação com o Lineamento Tietê. Esta é a prova de que, durante a sedimentação das formações do final do Permiano, havia um alto estrutural separando as formações Serra Alta, Teresina e Rio do Rasto a sul do rio Tietê, da Formação Corumbataí a norte do mesmo rio. Além disso, a anomalia gravimétrica residual também mostra uma feição aproximadamente circular coincidindo com a área de afloramentos da Formação Teresina no centro do Alto Estrutural de Anhembi. O padrão e forma da anomalia gravimétrica residual confirmam que as rochas do embasamento estão dispostas em blocos escalonados resultados do efeito dominó. $\mathrm{Na}$ realidade, a estrutura das rochas do embasamento é reproduzida na superfície por falhas e lineamentos. Levantamentos de semidetalhe não mostram qualquer possível rocha ígnea como fonte de calor sob a área dos geiseritos. Os resultados sugerem que uma possível falha ao longo do córrego do Retiro tenha servido como conduto principal para a água quente vindo do embasamento. A fonte de calor está associada com a deformação dúctil ocorrida no interior da crosta e do manto superior.

Palavras-chave: Bacia do Paraná; Geiseritos; Permiano; Formação Teresina; Arenito Asfáltico. 


\begin{abstract}
Cavallaro, F. A. Geophysical research of High Structural Anhembi - SP. 2013. 148p. Tese - Instituto de Geociências da Universidade de São Paulo, São Paulo. 2013.
\end{abstract}

In this work results from gravity and magnetic surveys done on Anhembi Structural High, SP, are presented. For whole area a large scale surveying was adopted while for outcropping area of geyserites both gravity and magnetic surveys were done at a small scale. This structural high records two important geological events during the evolution of the Paraná Sedimentary Basin, that is, an intense geothermal activity in Late Permian that produced thousands of geyserites, and migration and transport of oil from the Irati formation trapped into sandstones of the Pirambóia Formation caused by intrusion of sills and dykes associated with the Serral Geral volcanism. These reservoirs are now tar sand deposits that outcrop in the border of the circular structure showing that they are located in the bottom of the Piramboia Formation. Gravity survey at large scale shows a positive anomaly in NW-SE direction matching the Tietê river which indicates a strong association with Tietê Lineament. This is the proof that during sedimentation of Late Permian formations there was a structural high along this lineament separating Serra Alta, Teresina and Rio do Rasto formations occurring southern Tietê river from the Corumbatai formation that occurs only northern this river. Moreover, residual gravity anomaly also shows an approximately circular feature matching the outcropping area of the Teresina formation in the center of the structural high. The pattern and shape of this residual gravity anomaly also confirms that the basement rocks are broken into blocks laying each other such as domino effect. Actually, the structure of the basement rocks is reproduced on the ground by faults and lineaments. Small scale surveys do not show any possible igneous rock as heat source under the area of geyserites. Results suggest that a possible fault existed along the Retiro river served as the main conduct for hot water coming from the basement. The heat source is associated with ductile deformation occurred under the crust and upper mantle.

Key-words: Paraná Basin; Geiserites; Permian; Tersina Formation; Tar Sandstone. 


\section{CAPITULO 1}

\section{INTRODUÇÃO}

Os altos estruturais localizados na porção nordeste da Bacia Sedimentar do Paraná, dentre os quais o Alto Estrutural de Anhembi, SP, são feições geológicas singulares uma vez que os mesmos constituem testemunhos da evolução tectônica em que a região foi submetida. Essas estruturas são frutos da reativação de zonas de fraquezas herdadas do embasamento précambriano, sendo estas relativamente comuns em bacias intracratônicas. A análise destes altos estruturais, em suas várias fases de atividade, tem grande importância para o entendimento da evolução tectônica e sedimentar da Bacia do Paraná, pois desempenham importante papel controlador e modificador de sua seção sedimentar.

Há vários estudos relativos a estas estruturas nos quais o objetivo foi determinar o condicionamento geológico-estrutural e tectônico das mesmas. Estes estudos variam desde levantamentos de campo em semi-detalhe, como mapeamento geológico (e.g. Soares, 1974; IPT, 1979 e 2005), estudos termocronológicos (e.g. Godoy et al., 2006), evolução tectônica (e.g. Sousa, 2002), inclusões fluidas (Nomura, 2012) e arenito asfáltico (e.g. Araújo et al., 2006; Thomas filho et al., 2008), assim como em grande escala (e.g. Soares, 1974 e Soares et al., 1996; Riccomini, 1995 e 1997; Araújo et al., 2005) levando em conta aspectos gerais da Bacia do Paraná, estimulados principalmente pelo incentivo à procura de alvos exploratórios para hidrocarbonetos e mais recentemente, para estocagem de gás natural (IPT, 2005). Em contrapartida, há uma carência em estudos geofísicos com resolução de semi-detalhe e de detalhe, o que permitiria um melhor entendimento das feições geológicas que constituem estas estruturas e suas relações com a as estruturas da bacia de forma geral, como sugerem alguns autores já citados (e.g. Thomas filho et al., 2008).

O Alto Estrutural de Anhembi localiza-se no cruzamento das zonas de falhas: Jacutinga (PT-3 de Soares, 1991) e do Lineamento do Tietê (Saad, 1977 e Coimbra et al. 1977) caracterizam-se pelo afloramento de rochas Eopermianas da Fm. Teresina na porção central da estrutura, circundada por rochas Triássicas (Eojurrásico - Triassíco) da Fm. Pirambóia. Este alto estrutural guarda o registro de dois eventos importantes da evolução da

Bacia do Paraná. O primeiro evento trata do registro de uma intensa atividade hidrotermal ocorrida no Permiano Superior registrada por meio de cones silicosos, ou geseiritos 
(Yamamoto et al., 2005). O segundo evento está relacionado à Fm. Serra Geral, manisfestando-se na forma de ocorrência de Arenito asfáltico (Araújo et al., 2006).

Em vista do interesse despertado pelas feições geológicas especiais e únicas, no caso da ocorrência de milhares de geiseritos e dos afloramentos de arenitos asfálticos, procedeu-se levantamentos gravimétricos e magnetométricos terrestres, conforme os resultados apresentados e interpretados neste trabalho. 


\section{1 - Objetivos}

Esta pesquisa tem por objetivo a investigação geofísica do Alto Estrutural de Anhembi, SP e vizinhanças, utilizando gravimetria e magnetometria com a finalidade de se ampliar o entendimento entre a relação da feição dômica com a estruturação do embasamento, visando a:

- Comprovar a existência de uma possível anomalia gravimétrica positiva relacionada à morfoestrutura identificada por Araujo et al. (2006);

- Identificar uma rocha ígnea rasa que tenha atuado como possível fonte de calor, no Permiano superior, na gênese dos geiseritos de Anhembi;

- Localizar as fontes de anomalias magnéticas, diques e sills, e estudar suas relações com o Alto Estrutural de Anhembi e sistemas de falhas, identificados por IPT (1979 e 2005) e Araújo et al. (2006), bem como com as ocorrências conhecidas de arenitos asfálticos mapeadas por Araújo (2003);

\section{2 - Justificativas}

O Alto Estrutural de Anhembi tem sido alvo de estudos geológicos e estruturais desde a década de 1970. Vários estudos de diferentes tipos foram realizados em Anhembi com o objetivo de determinar o condicionamento geológico-estrutural e tectônico desse alto estrutural. Entretanto, há uma carência de estudos geofísicos com resolução de semi-detalhe e de detalhe. Este trabalho visa suprir esta carência, proporcionando maiores subsídios para um melhor entendimento das feições geológicas que constituem esta estrutura e suas relações com a estruturação regional da Bacia do Paraná. 


\section{CAPÍTULO 2}

\section{GEOLOGIA REGIONAL}

\section{1 - Introdução}

Caracterizada como uma bacia intracratônica (Milani et al., 2007), a Bacia do Paraná tem uma área aproximada de $1.500 .000 \mathrm{~km}^{2}$, abrangendo os estados de Mato Grosso, Mato Grosso do Sul, Goiás, Minas Gerais, São Paulo, Paraná, Santa Catarina e Rio Grande do Sul; o norte e noroeste do Uruguai; além de parte da Argentina e Paraguai (Figura 2.1). Sua sedimentação teve início no CambrianoOrdoviciano, cuja seção sedimentar paleozoica pode ser dividida em três sequências tectonosedimentares: Ordoviciano-Devoniano, EocarboníferoPermiano e NeojurássicoEocretáceo limitadas por inconformidades (Zalán et al., 1991). Fúlfaro et al. (1982) descrevem, para a transição Permotriássica, uma mudança do nível de base regional. Neste período, segundo esses autores, um mar raso (Teresina/Corumbataí) é ocupado por dunas litorâneas (Pirambóia) e, posteriormente, por dunas de um deserto continental (Botucatu). Para Fúlfaro et al. (1982), esta mudança ocorreu, em princípio, devido ao levantamento dos Andes Meridionais e à movimentação

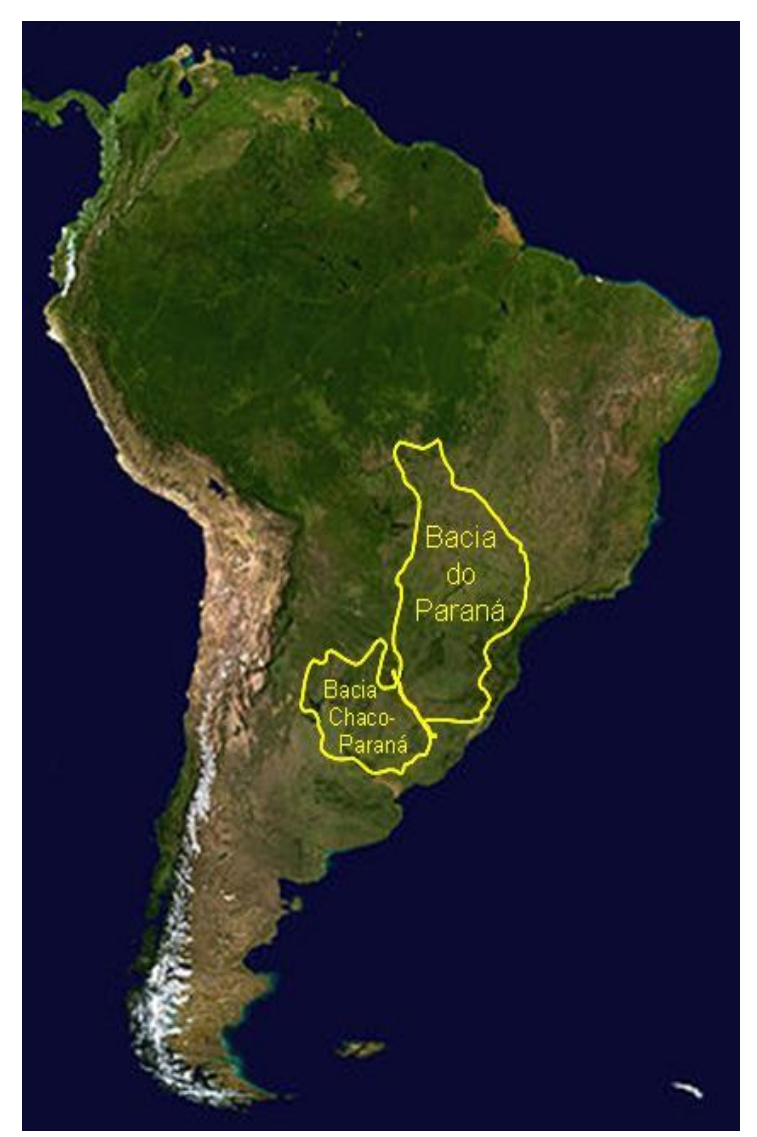

Figura 2.1 - Localização da Bacia do Paraná. (http://pt.wikipedia.org/wiki/Bacia_do_Parana) Acessado em 03/2013. tectônica positiva do assoalho da Bacia do Paraná. Em toda a Bacia do Paraná, segundo Zalán et al. (1991), dois estilos estruturais principais estão presentes: deformações associadas a intrusões ígneas e deformações associadas a reativações de elementos tectônicos lineares com direção NE e NW.

O lado leste da bacia passou por modificações intensas durante sua história, fruto da forte erosão em suas bordas, causada pela tectônica ascendente pós-Paleozóica, marginal ao 
Rifte do Atlântico Sul (Milani et al., 2007). Estima-se em até 2500 metros de remoção sedimentar neste flanco da bacia (Zanotto, 1993 apud Milani et al., 2007). A Bacia do Paraná é preenchida por um pacote sedimentar-magmático com espessura máxima de aproximadamente de 7000 metros, sendo seu depocentro coincidente, geograficamente, com a calha do rio Paraná (Milani et al., 2007). A Figura 2.2 mostra uma seção geológica NW-SE, onde a bacia se encontra bem preservada.

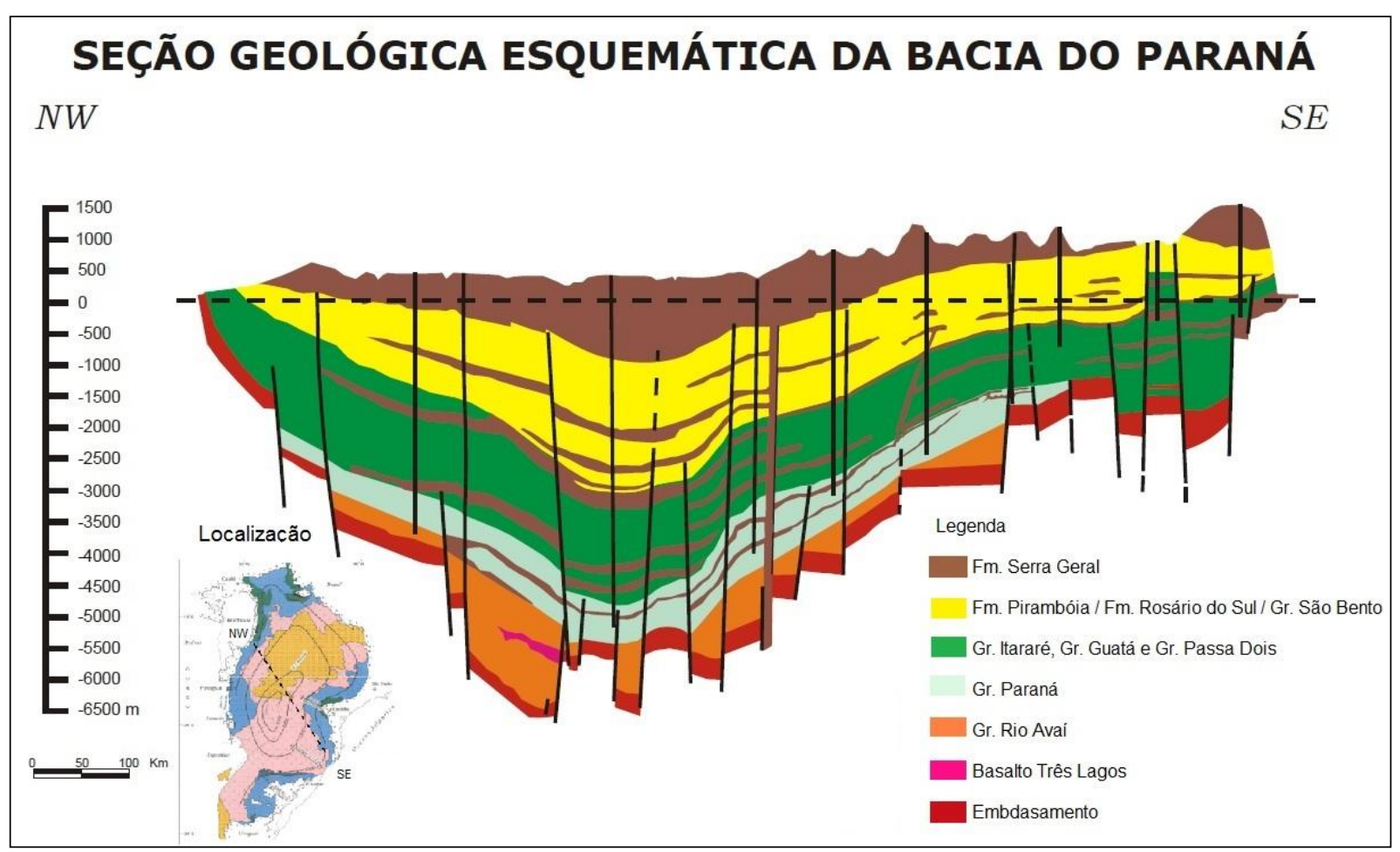

Figura 2.2 - Seção geológica NW-SE da Bacia do Paraná representando as principais formações e grupos (modificado de Milani e Zalán, 1999).

\section{2 - Embasamento}

Ao se analisar o embasamento aflorante da bacia, é possível prever uma continuação das entidades geotectônicas citadas anteriormente por baixo das rochas sedimentares. Neste contexto, Cordani et al. (1984), com base em dados de poços que atingiram o embasamento, sugerem a existência de um núcleo cratônico no centro da bacia, ao redor do qual se desenvolveram as faixas móveis descritas, posteriormente, por Zalán et al. (1990).

Milani \& Ramos (1998) apresentam uma interpretação semelhante à de Zalán et al. (1990), mas igualmente baseada nas porções do embasamento aflorante e com um núcleo cratônico central (Figura 2.3), denominado de Rio Paranapanema. Estes autores interpretam 
também outras porções cratônicas, como as do Rio Aporé, do Triângulo Mineiro e de Guaxupé, cercados de faixas móveis como a de Apiaí, Rio Paraná e Paraguai-Araguaia. Estas porções cratônicas e faixas móveis representam zonas de fraqueza crustais, cujo arcabouço estrutural, por meio de sucessivas reativações, possibilitou controlar a maior parte da evolução estratigráfico-estrutural da Bacia do Paraná.

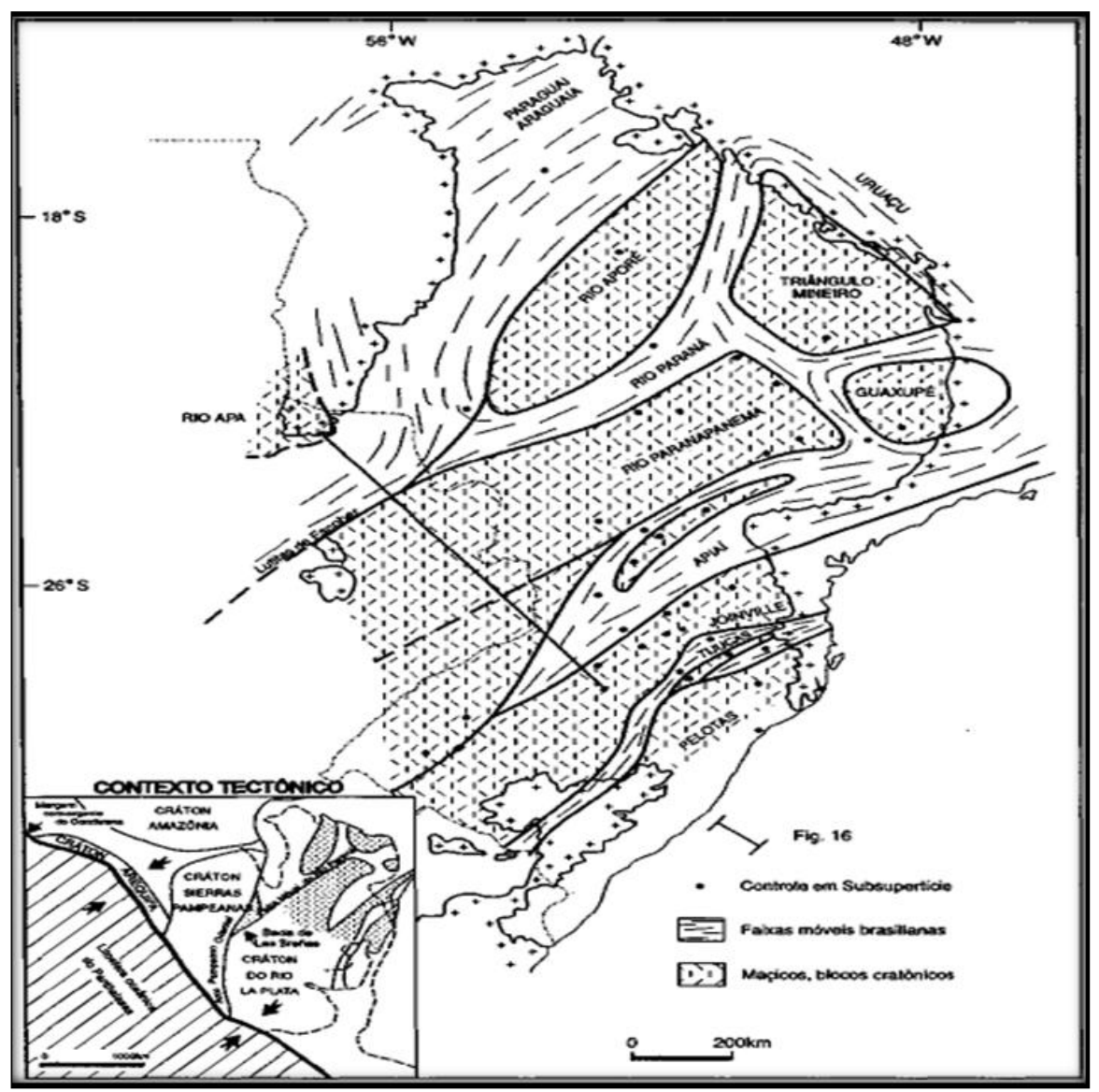

Figura 2.3 - Estrutura do embasamento da Bacia do Paraná. No detalhe, arcabouço geotectônico regional para o domínio sul-ocidental do Gondwana. Setas indicam o movimento convergente entre o continente e a litosfera do Panthalassa (Milani \& Ramos, 1998).

Quintas (1995) e Mantovani et al. (2005) confirmaram, mais recentemente, a existência de um núcleo cratônico central, sob a Bacia do Paraná. Estes autores também o delimitaram, com base em análise de dados gravimétricos de Quintas (1995). Os quais foram processados com o intuito de retirar as influências das anomalias relativas às fontes profundas (manto) e das camadas sedimentares da bacia (fontes superficiais). O produto deste processamento foi o mapa gravimétrico residual, que indicou as descontinuidades do embasamento da bacia. Desta forma, estes autores interpretaram, a partir de dados geofísicos, a existência de um núcleo cratônico central à bacia, denominando-o de Bloco Paranapanema, com uma área de grande anomalia positiva, segundo a direção NE-SW (Figura 2.4). Em um 
mapa de anomalia Bouguer atualizado (Figura 2.5), no qual são considerados dados levantados por: IAG-USP, IBGE, ON, CPRM e UFPR (ANP, 2010), esta estrutura fica bem evidenciada.

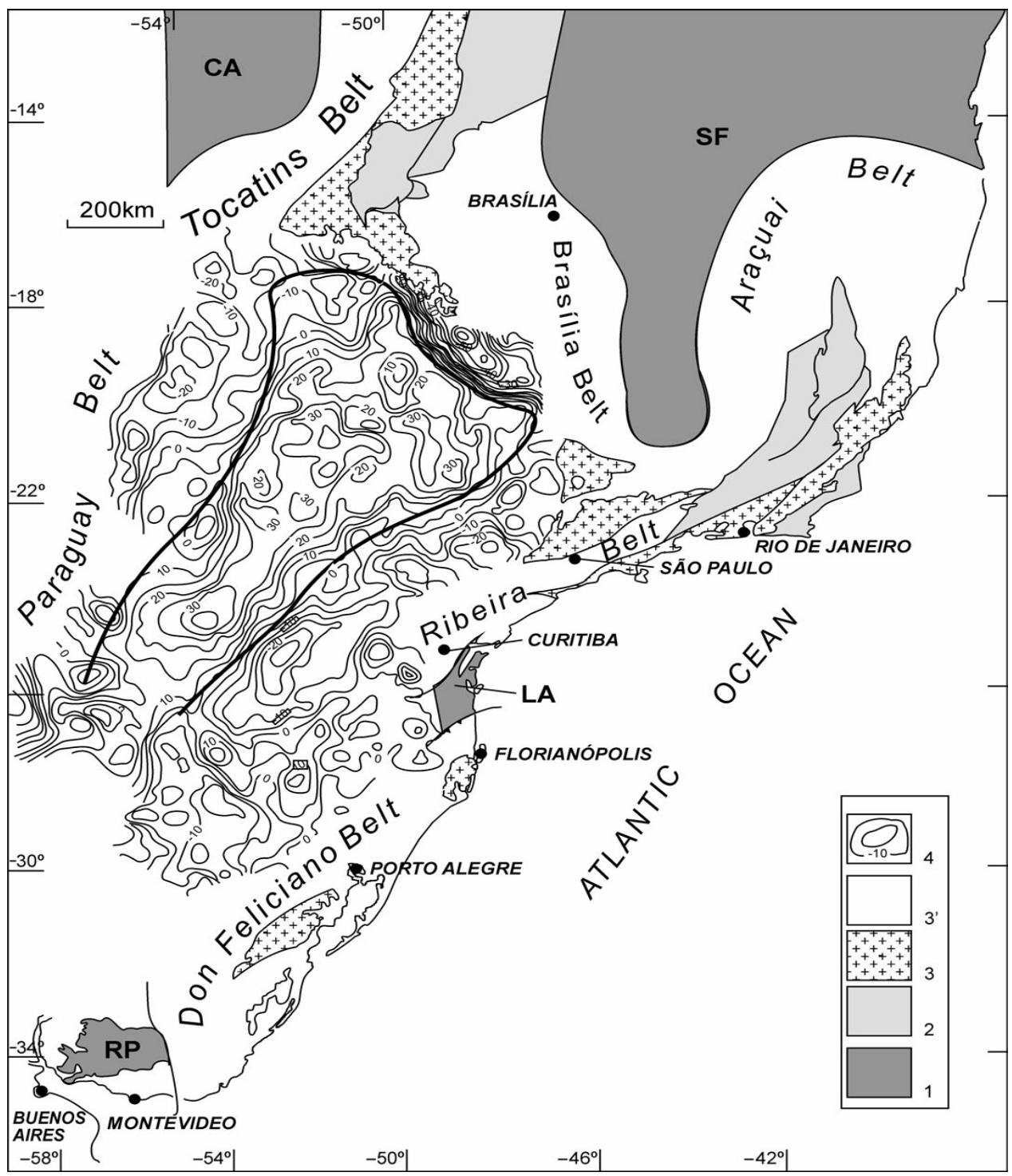

Figura 2.4 - Delimitação do Bloco Paranapanema através de dados gravimétricos, segundo Mantovani et al. (2005, p.18). (1) Crátons: São Francisco (SF), Amazônico, LA- Luís Alves, RP- Rio de La Plata. (2) Principais blocos Pré-Brasilianos retrabalhados (embasamento Paleozóico e Arqueano). (3) Arcos magmáticos Brasilianos Neoproterozóicos: MR- Mara Rosa - Goiás, AR- Arenópolis, SM- Terreno Serra do Mar (Arcos Rio Negro e Rio Doce), SG- Socorro Guaxupé, PE- Pelotas. (3) Cinturões de rochas Supracrustais indiferenciadas. (4) Mapa gravimétrico do embasamento. 


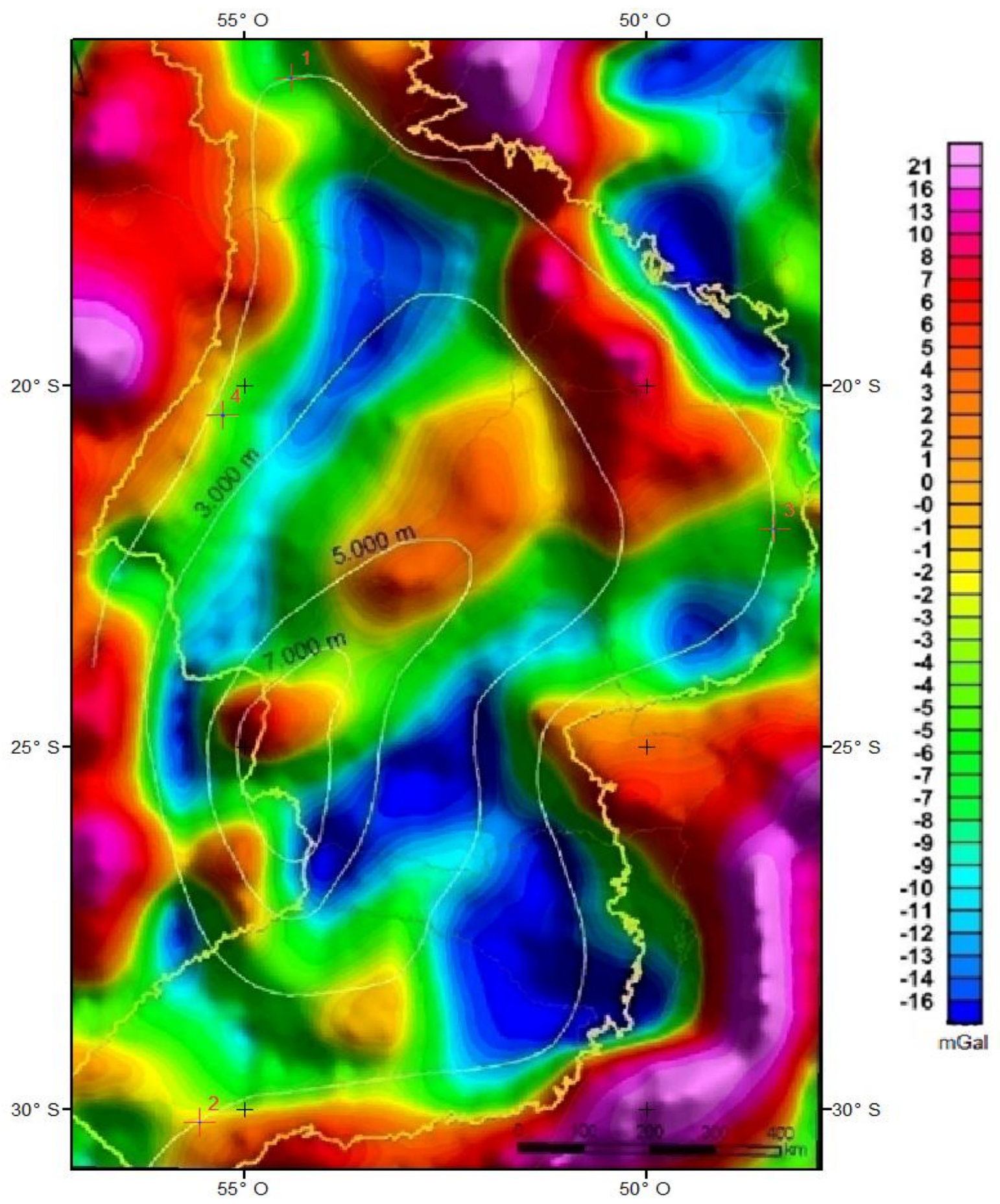

Figura 2.5 - Mapa de anomalia Bouguer da Bacia do Paraná. Foram utilizados dados terrestres disponíveis para a Bacia (ANP, 2010). Estão representados: a profundidade do embasamento, em metros e o contorno dos limites da Bacia do Paraná. 


\section{3 - Sedimentação e estratigrafia da Bacia do Paraná}

Em território brasileiro, a evolução sedimentar da Bacia do Paraná, segundo Milani et al. (2007), é descrita em seis ciclos de subsidência, ou seis unidades aloestratigraficas de segunda ordem, responsáveis pela deposição de seis supersequências deposicionais, seguindo a concepção de (Figura 2.6) Vail et al. (1977, apud Milani et al., 2007). De acordo com Milani et al. (2007), há relação entre ciclos de criação de espaço deposicional na área intracratônica com eventos ocorridos na borda ativa do Gondwana. Estas supersequências estão dispostas na forma de pacotes rochosos e compreendem um intervalo de 450 a $65 \mathrm{Ma}$, sendo que, em uma grande parte deste tempo reconhecem-se hiatos deposicionais que as separam (Figura 2.7), segundo Milani et al. (2007).

As supersequências descritas por Milani et al. (2007) são: Rio Ivaí (OrdovicianoSiluriano), Paraná (Devoniano), Gondwana I (Carbonífero-Eotriássico), representadas por sucessões sedimentares, definindo os grandes ciclos transgressivo-regressivos paleozóicos. Gondwana II (Meso a Neotriássico), Gondwana III (Neojurássico-Eocretáceo), Bauru (Neocretáceo) correspondem a pacotes de sedimentos continentais e rochas ígneas associadas (Figura 2.7).

A sedimentação da Bacia do Paraná, na área brasileira, tem inicio com a deposição da Supersequência do Rio Ivaí durante Ordoviciano-Siluriano, com características transgressivas, contendo inúmeros depocentros com direção NE-SW (Milani et al., 2007). Segundo estes autores, é o primeiro ciclo de sedimentação fanerozóico sobre o embasamento cratônico após eventos da orogenia Brasiliana.

Segundo Milani et al. (2007), a supersequência Paraná, sequência de idade Devoniana, tem como principal característica uniformidade faciológica proeminente em toda área de ocorrência. Possui geometria tabular e representa o segundo ciclo transgressivo-regressivo do registro estratigráfico da Bacia do Paraná (Milani et al., 2007). Os depósitos da Fm. Furnas (Eodevoniano), com assinatura característica transgressiva, estão sobrepostos pelos pelitos da base da Fm. Ponta Grossa, formação esta que documenta a primeira grande inundação do ciclo Devoniano (Assine, 1996 apud Milani et al. 2007).

Durante a sedimentação carbonífera, representada pela Sequência Gondwana I, ocorreram profundas alterações tanto tectônicas quanto climáticas (Milani et al. 2007). Segundo estes autores, materializa o ciclo transgressivo-regressivo completo, resultado do avanço e posterior recuo do Panthalassa sobre a parte interna do Gondwana. Neste período ocorreram vários processos tectônicos, reativando grandes lineamentos da bacia, causados 
pela orogenia San-Rafaélica, de idade permiana-triásica (Milani, 1997, apud Milani et al., 2007). Segundo Milani et al. (2007), no final do Permiano e durante o Mesozoico, há um progressivo isolamento da Bacia em relação às incursões marinhas no lado oeste, assumindo, assim, o caráter de bacia intracratônica. Com o aprisionamento da bacia no árido interior continental em tempo mesozoico, há formação de desertos que a recobrem totalmente e às regiões vizinhas, durante o Neojurássico/Eucretácio, representadas pela Fm. Botucatu (Milani et al., 2007).

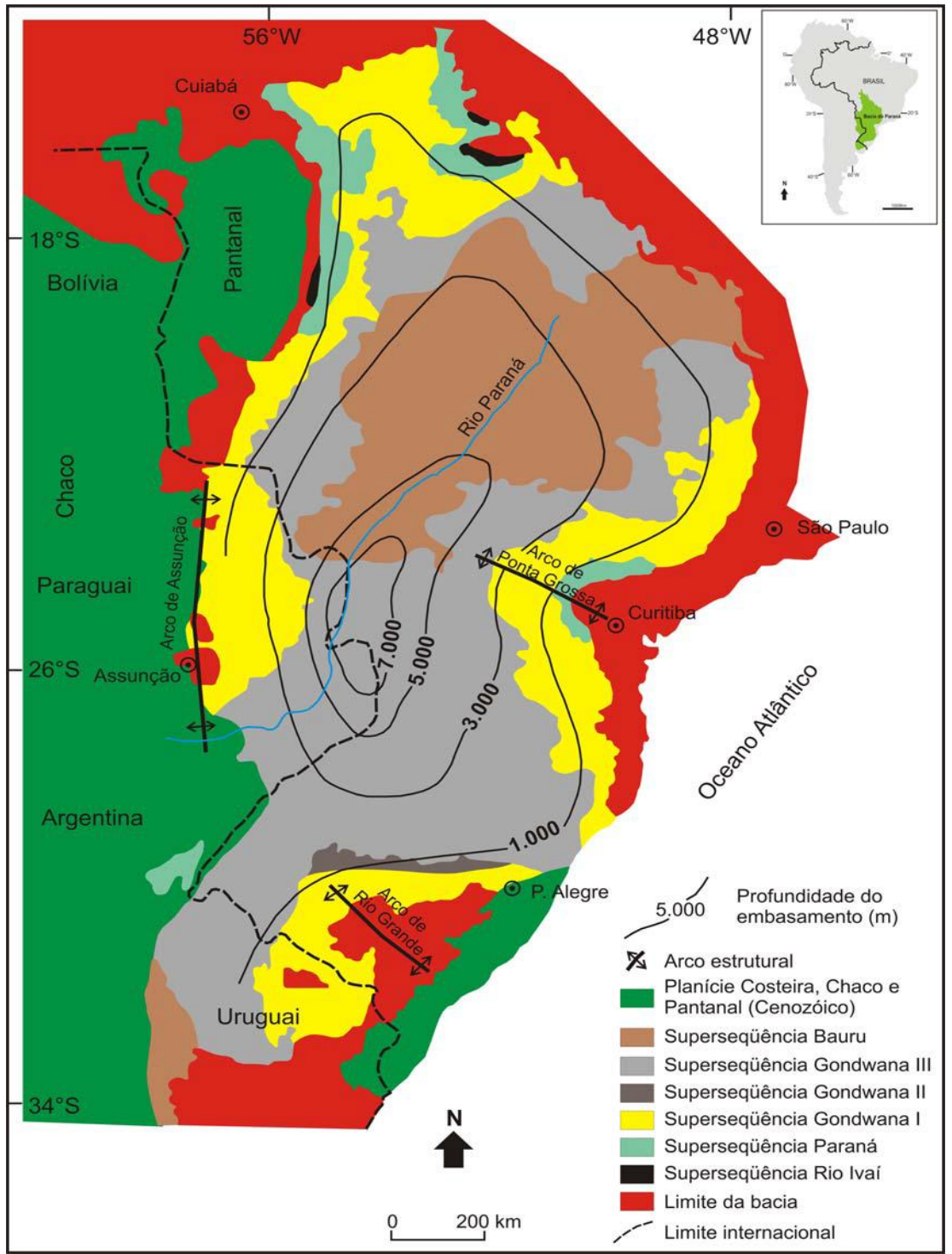

Figura 2.6 - Mapa geológico simplificado da Bacia do Paraná, seus principais elementos tectônicos e acidentes geográficos (modificado de Milani, 1997 apud Silva, 2006, p.13). 


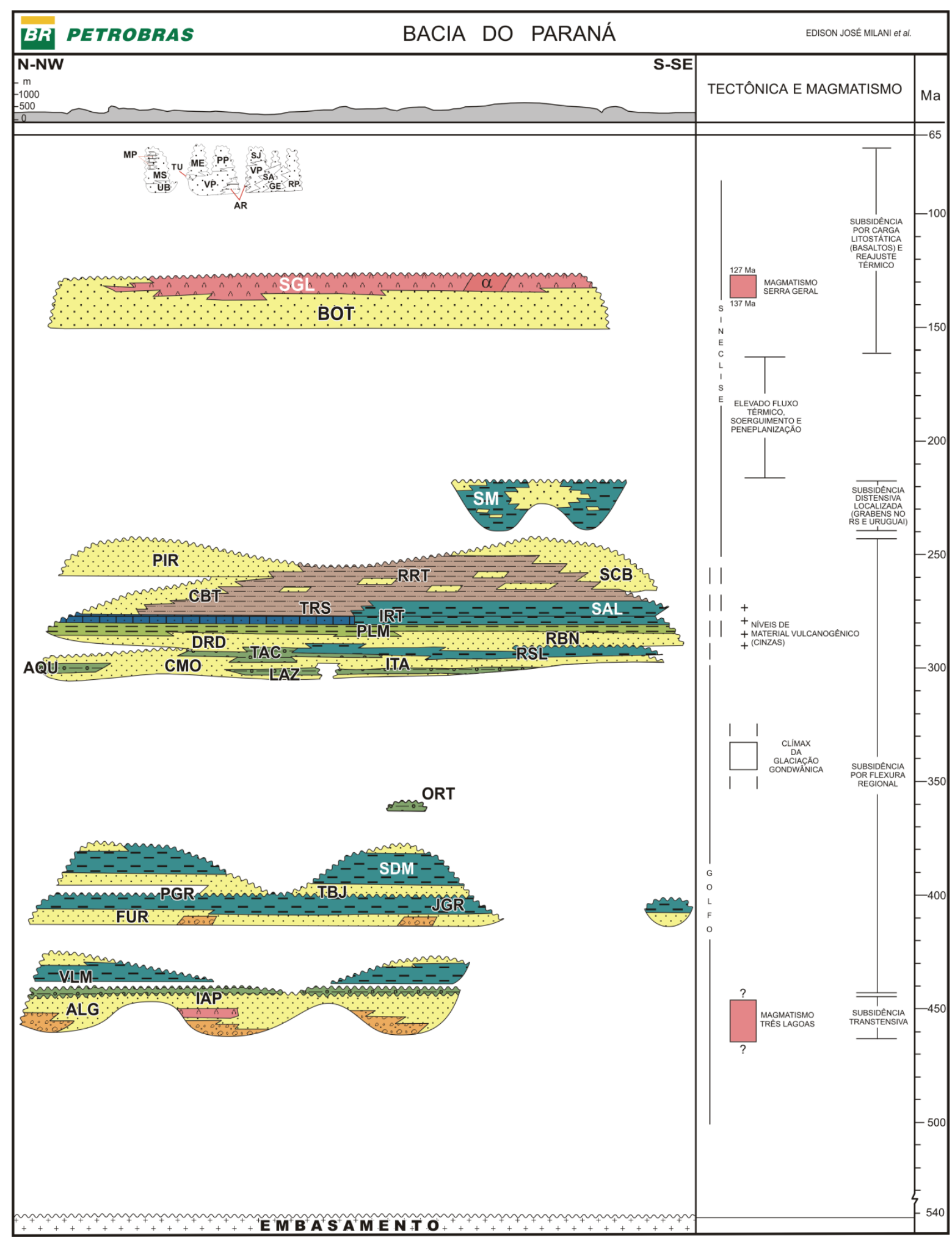

Figura 2.7 - Carta estratigráfica da Bacia do Paraná (Milani et al., 2007, p. 287).

Esta supersequência contém o maior volume sedimentar da Bacia do Paraná com uma espessura máxima da ordem de 2500 metros, incluindo os pacotes sedimentares representados por: Grupo Itararé, Fm. Aquidauana, Grupo Guatá, Grupo Passa Dois e Formações Pirambóia e Saga do Cabral (Milani et al., 2007). É muito pesquisada por apresentar interesses 
econômicos, por exemplo, ocorrência de carvão e urânio na Fm. Rio Bonito e do play petrolífero Irati/Pirambóia (Milani et al., 2007). Segundo esses autores, a Fm. Irati é importante, pois resulta de uma forte restrição à circulação de águas entre o oceano Panthalassa e o interior do Gondwana, culminando em ambiente hipersalino na bacia interior. Esta restrição favorece o acúmulo de carbonatos e evaporitos na parte norte e de folhelhos betuminosos na parte sul da bacia, com alto grau de conteúdo orgânico, qualificando-os como um potencial gerador de hidrocarbonetos (Hachiro, 1991, p. 80). O processo de sedimentação do Grupo Passa Dois, posterior ao da Fm. Serra Alta, ocorreu seguindo a tendência regressiva regional, sendo a sedimentação dominada por sistemas continentais. Processos acumulativos de sedimentos ligados à ação de marés na Fm. Teresina são substituídos por um complexo progradacional de red beds (Lavina, 1988 apud Milani et al., 2007) da Fm. Rio do Rastro, tendo, em geral, uma direção de desenvolvimento de noroeste para sudeste. A Fm. Pirambóia aflora principalmente na porção nordeste da bacia, nos estados de São Paulo e Paraná, com ampla área de ocorrência (Landim et al., 1980 e Assine et al., 2004). Predominam estratificações cruzadas de médio porte, mas também as de baixo ângulo ou até plano paralela. Estas estruturas são caracterizadas por depósitos de dunas e interdunas úmidas, sendo que o intervalo inferior até partes intermediárias por grandes lençóis de areia. Nas partes superiores, apresentam dunas de médio à grande porte, isto é, apresenta aridez nas proximidades do topo da formação (Brighetti, 1994, p.8). Esta tendência mostra-se, principalmente, no centro-leste do estado de São Paulo, segundo esta autora. Este paleoambiente foi classificado como sistema flúvio-eólico por Caetano Chang \& Wu (1995). Este processo representa a finalização da deposição da Supersequência Gondwana I.

A Supersequência Gondwana II é restrita à porção sul do paleocontinente Gondwana, região que sofreu uma distensão generalizada no Triássico, e representa uma sedimentação acumulada em bacias do tipo graben (Milani et al., 2007). Segundo esses autores, durante o Mesozoico, a forte atuação da erosão, em larga escala, sobre o substrato da bacia, reflete como a mais pronunciada lacuna de seu registro estratigráfico, acumulando sobre sua superfície extensos campos de dunas a partir do final do Jurássico.

De acordo com Milani et al. (2007), a Supersequência Gondwana III inicia-se no registro estratigráfico onde se posiciona a sedimentação eólica da Fm. Botucatu e as rochas básicas da Fm. Serra Geral. Considerando o pacote sedimentar suprabasáltico, este intervalo estratigráfico corresponde ao Grupo São Bento (Schneider et al. 1974).

Na Bacia do Paraná, o evento magmático Serra Geral caracteriza-se como uma espessa cobertura de lava, com acúmulo próximo de 2000 metros no Pontal de Paranapanema - SP 
(Milani et al. 2007). De forma geral, a Fm. Serra Geral é composta por basaltos toleíticos e andesitos basálticos, ocorrendo quantidades subordinadas de riolitos e ridacitos (Peate, 1997). Renne et al. (1997) chegaram à idade de $134.7 \pm 1$ Ma para as intrusões basálticas. Tuner et al. (1994) e Stewart et al. (1996) caracterizam, em termos geocronológicos (datações ${ }^{40} \mathrm{Ar} /{ }^{39} \mathrm{Ar}$ ), a variedade de tipos magmáticos apresentado por Peate (1997). Segundo Tuner et al. (1994), as idades resultantes para o evento Serra Geral estão entre 137 e $127 \mathrm{Ma}$, sendo que diques com direção NW-SE (Arco de Ponta Grossa) com idades entre 134,1 a 130,5 Ma e os de direção NE-SW (rodovia Rio-Santos) com idades entre 133,3 a 129,4 Ma. Thiede \& Vasconcelos (2010) reanalisaram as amostras de Tuner et al. (1994) e Stewart et al. (1996) e determinam uma idade para as intrusões de $134.7 \pm 1 \mathrm{Ma}$, confirmando o resultado de Renne et al. (1997). Sugerem que a duração deste evento foi menor que 1,2 Ma, contrariando estudos anteriores.

Este período marca o término de eventos de sedimentação extensiva dentro da bacia, assim como importantes alterações crustais, como reativação de grandes lineamentos estruturais com direção NW-SE e tectônica ascensional na borda leste da bacia (Godoy et al., 2006).

Após término do magmatismo, ocorreu subsidência provocada pelo acúmulo de espessas camadas de lavas basálticas, definido uma depressão sobre este pacote onde viria se acumular a Supersequência Bauru (grupos Bauru e Caiuá) no Neocretácio (Soares, 1991; Quintas, 1995, p.101). A deposição na Bacia Bauru deu-se em um ambiente semi-árido, mais úmido próximo das margens e de deserto em seu interior (Milani et al., 2007). O substrato basáltico foi soterrado progressivamente por uma extensa camada de areia, com pequenas dunas e lamitos, durante o avanço da sedimentação (Milani et al., 2007). Entre as bordas da Bacia Bauru e a periferia do deserto interior Caíua, seguindo o eixo central da calha elíptica na direção NE a SE, formou-se um sistema de drenagem regional (Milani et al., 2007). Durante o período de deposição, ocorreram dois intervalos de eventos intrusivos alcalinas: o primeiro entre 87-90 Ma e a segundo entre 70-60 Ma (Almeida \& Melo, 1981). 


\section{4 - Caracterização estrutural da Bacia do Paraná}

Segundo Zalán et al. (1991), a Bacia do Paraná possui dois estilos estruturais predominantes: deformações devidas a intrusões ígneas e aquelas associadas a reativações de alinhamentos com direção NE e NW (Figura 2.8). Entre as estruturas NW, destacam-se os lineamentos: Tietê, Barra Bonita-Itu, Paranapanema, a Falha Santo Anastácio, o Lineamento de Guapiara e o Arco da Ponta Grossa. Na borda leste, destacam-se lineamentos estruturais de direção NE como a Falha de Jacutinga, as Zona de falha Blumenau - Soledade e LancinhaCubatão e a Zona de Cisalhamento Ribeira (Zalán et al. (1991) e CPRM, 2001).

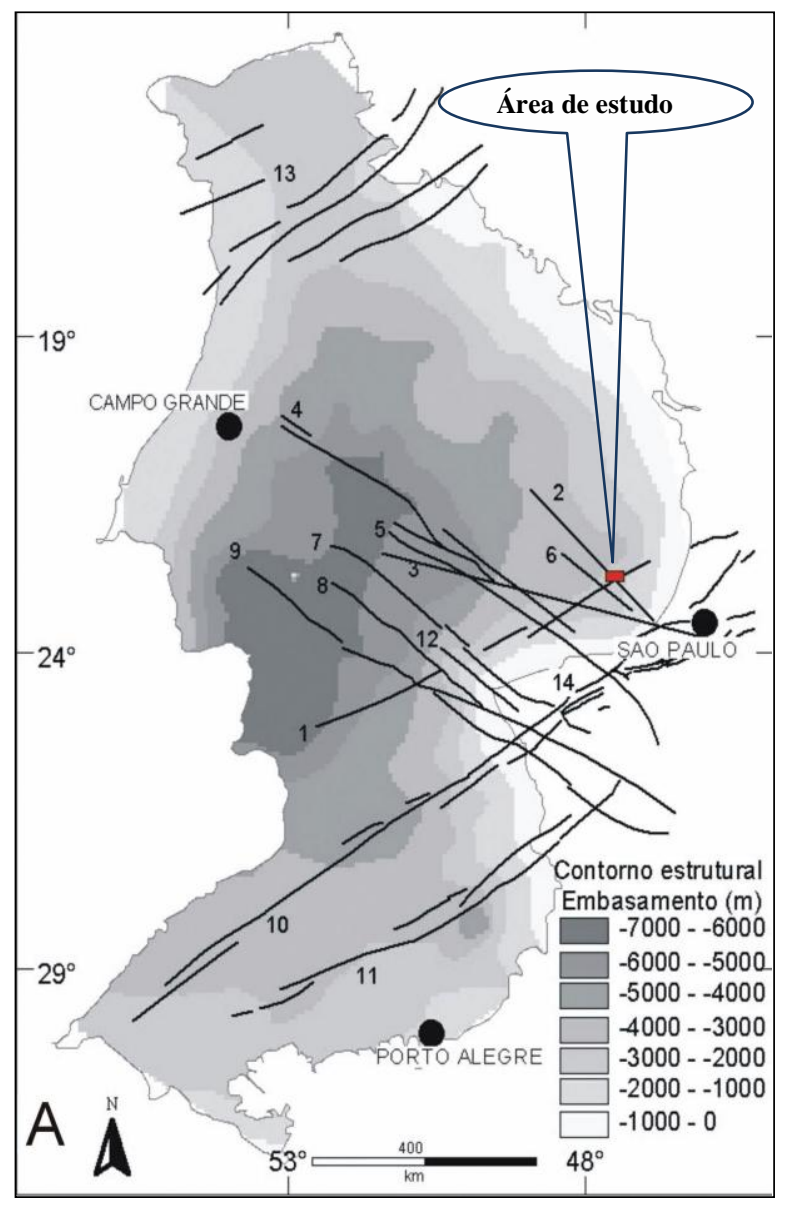

Figura 2.8 - A Bacia do Paraná é condicionada principalmente por estruturas de direção NE relacionadas ao Cinturão de Cisalhamento Ribeira (Neoproterozóico - Cambriano Superior) e pelo Cinturão de Cisalhamento Transbrasiliano. A subsidência fanerozóica foi controlada principalmente pela reativação das estruturas $\mathrm{NE}$ relacionadas ao embasamento. No Mesozóico, a ativação de estruturas de direção NW formou importantes falhas nesta direção. A área de estudo está representada pelo pequeno retângulo vermelho a oeste de São Paulo. 1 Falha de Jacutinga. 2 - Lineamento Tietê. 3 Lineamento Paranapanema. 4 - Falha de Guapiara. 5 Falha Santo Anastácio. 6 - Lineamento Barra Bonita Itu. 7 - Falha São Jerônimo -Curiúva. 8 - Falha Rio Alonzo. 9 - Falha Cândido de Abreu - Campo Mourão. 10 - Zona de Falha Lancinha - Cubatão. 11 - Zona de Falha Blumenau -Soledade. 12 - Arco de Ponta Grossa. 13 - Zona de Cisalhamento Transbrasiliano. 14 - Zona de Cisalhamento Ribeira. Estruturas compiladas de Zalán et al. (1991) e CPRM (2001).

Soares (1991) reconhece cinco direções de lineamentos tectônicos principais na Bacia do Paraná (N25E), Pitanga (N60E), Rio Ivaí (N45W), Rio Piriqui (N70W) e Goioxim (N20W) (Figura 2.9). 


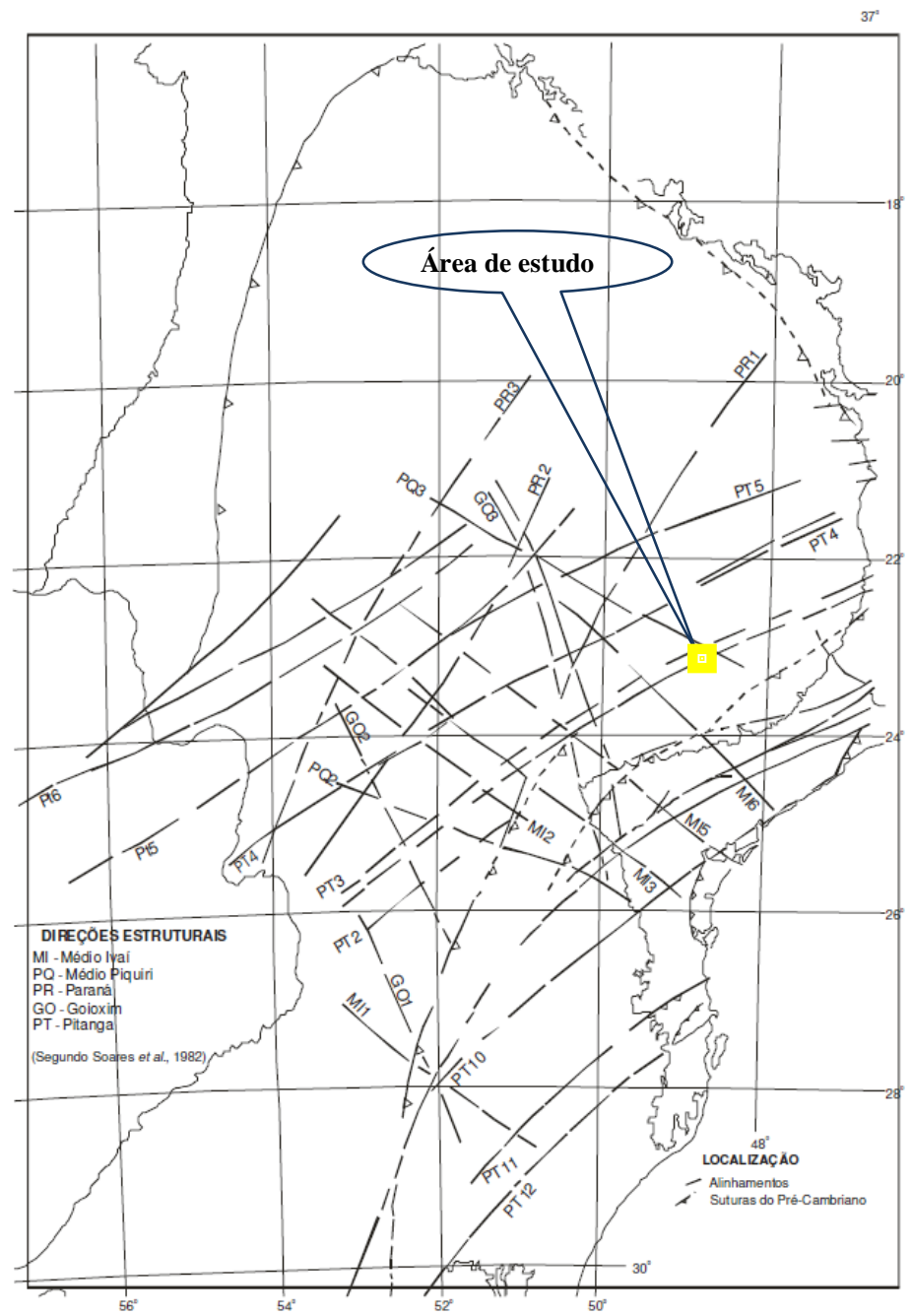

Figura 2.9 - Lineamentos estruturais propostos por Soares (1991).

Segundo Soares (1991):

- A direção PT - N55-45E (Pitanga) é a mais importante em termos de intensidade e densidade; corresponde à transcorrência principal, reativada paralelamente ao sistema de transcorrência sudeste (Cubatão, Jacutinga, Major Gercino etc.), com cinemática horária;

- A direção - PR -N25-45E (Paraná) é bastante desenvolvida e corresponde a um leque de falhas de empurrão de alto ângulo até falhas mistas (fraturas P, do sistema Lancinha);

- As direções - PQ -N70W (Piquiri) e MI - N45W (Ivaí) correspondem às fraturas extensionais do sistema de transcorrência Neoproterozoico.

Estas direções se apresentam na forma de diversos alinhamentos estruturais, que, no geral, apresentam sistemas NE-SW, NW-SE e, de uma maneira menos frequente, na direção 
E-W, e são decorrentes de reativações de estruturas preexistentes no embasamento da bacia, sendo paralelas a grandes feições estruturais formadas durante o Ciclo Brasiliano (Soares, 1991). Segundo esse autor, estas estruturas apresentam maior propensão à deformação rúptil, bem como condicionaram a geração e reativação de novas descontinuidades. No Mesozoico, os alinhamentos NW-SE propiciaram e condicionaram a colocação de sills e diques de diabásio (magmatismo Serra Geral) e a ocorrência de corpos alcalinos (Soares, 1991). A maioria destes lineamentos possui assinatura magnética bem marcada (Figura 2.10).

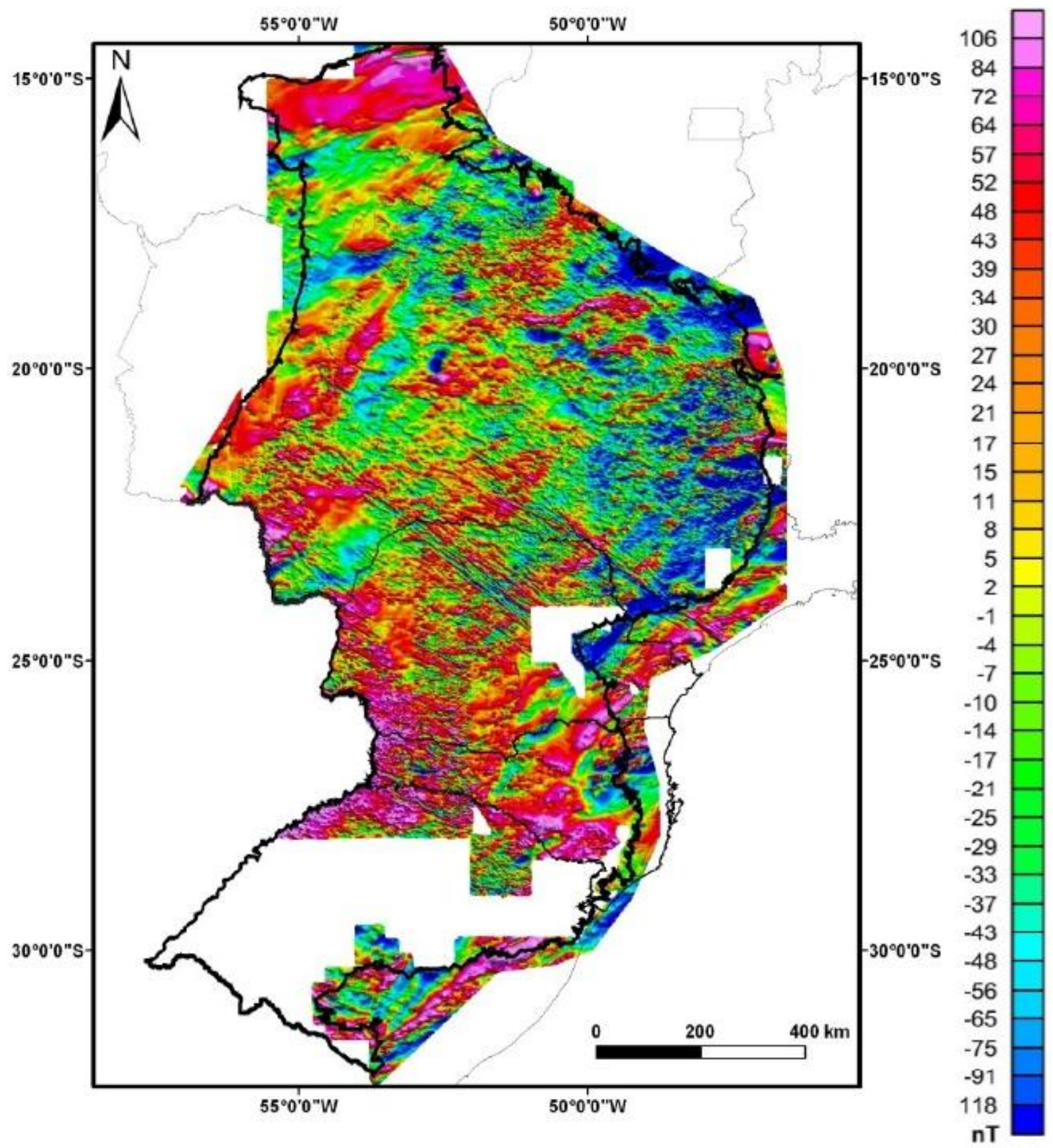

Figura 2.10 - Mapa magnético residual da Bacia do Paraná, ilustrando as principais assinaturas magnéticas (ANP, 2010). 
Riccomini (1995, p.30) descreve vários lineamentos (Figura 2.11) no Estado de São Paulo, sendo os principais: lineamentos do Rio Paranapanema, Rio Moji-Guaçu, Rio Tietê (NW-SE) e o prolongamento da zona de Falha de Jacutinga (NE-SW). O Alto Estrutural de Anhembi localiza-se entre o lineamento do Tietê (I), Barra Bonita - Itu (VI) e Falha de Jacutinga (III). Segundo Riccomini et al. (2005), a Falha de Jacutinga teve grande influência na formação do arcabouço estrutural da área do Domo de Pitanga, associando-lhe diques clásticos arenosos injetados por fraturas, de forma ascendente, formados durante a reativação do lineamento no Permotriássico.

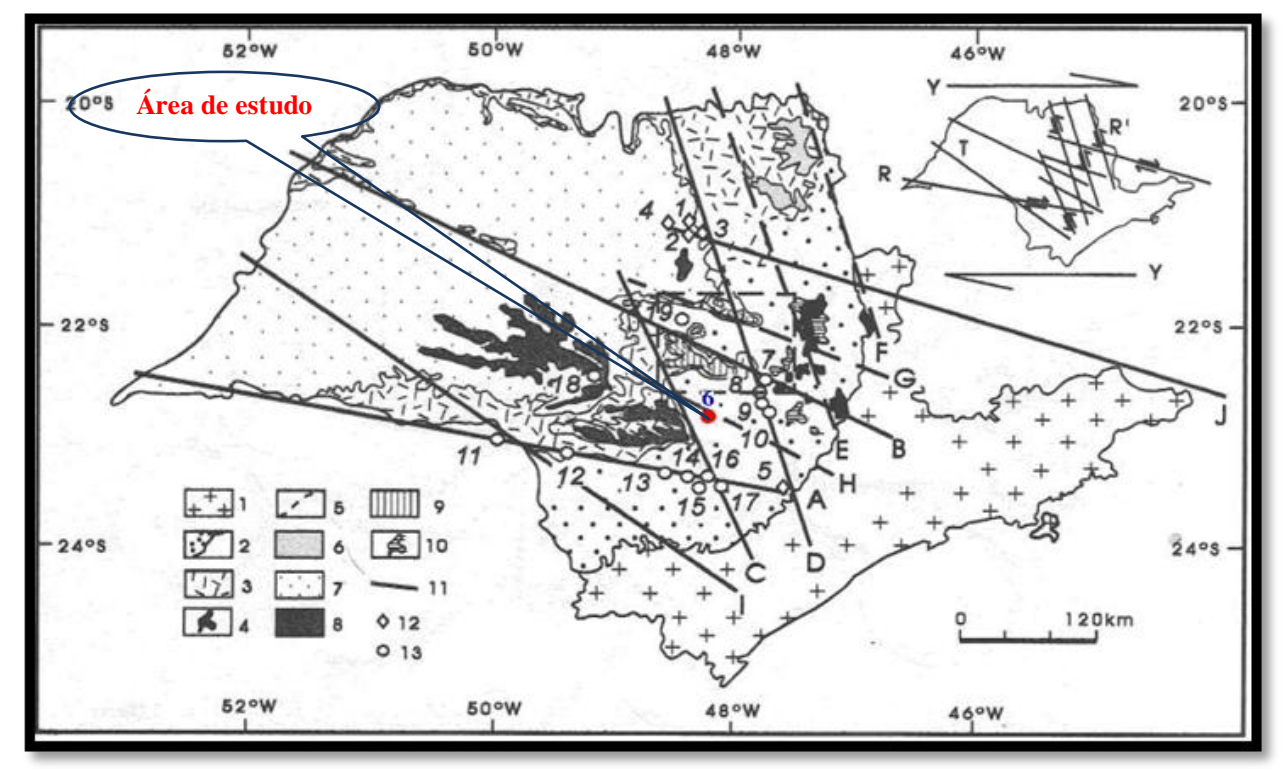

Figura 2.11 - Unidades geológicas e principais alinhamentos estruturais da Bacia do Paraná no Estado de São Paulo. Unidades Geológicas: 1. Substrato Pré-Cambriano, em parte recoberto por sedimentos cenozóicos; 2. Terrenos paleozóicos e mesozóicos da Bacia do Paraná, subjacentes aos derrames superiores da Formação Serra Geral; 3. Rochas vulcânicas da Formação Serra Geral; 4. Sills de diabásio; 5. Contato aproximado entre 2 e 3; 6. Depósitos rudáceos da região de Franca-Pedregulho; 7. Grupos Caiuá e Bauru, não diferenciados; 8. Formação Marília, Grupo Bauru; 9. Formação Itaqueri; 10. Formação Rio Claro e depósitos correlatos. 11. Alinhamentos Estruturais: A - Rio Paranapanema; B - Tietê; C - Ibitinga - Botucatu; D - Rio Mogi - Guaçu; E - Ribeirão Preto - Campinas; F - Rifaina-São João da Boa Vista; G - São Carlos - Leme; H - Barra Bonita - Itu; I Guapiara; J - Cabo Frio; 12. Manifestações Alcalinas: 1 - Taiúva; 2 - Aparecida do Monte Alto; 3 - Jaboticabal; 4 - Piranji; 5 - Ipanema/Araçoiaba da Serra; 13. Altos Estruturais: 6 - Domo de Anhembi-Piapara; 7 - Estrutura de Pitanga; 8 - Domo de Artemis; 9 - Horst Pau d'Alho; 10 - Domo de Jibóia; 11 - Domo de Jacarezinho ;12 Domo da Neblina; 13 - Domo de Jacu; 14 - Estrutura Dômica de Carlota Prenz; 15 - Domo de Rio Grande; 16 Domo de Jacutinga; 17 - Domo de Guarda; 18 - Astroblema de Piratininga; 19 - Domo de Jacaré-Guaçu (Ricomini 1997, modificado).

Quintas (1995, p.116), processando e analisando dados gravimétricos existentes, interpretou várias descontinuidades presentes no embasamento da bacia, por meio de mapa gravimétrico residual (Figura 2.12). Esta autora destaca a presença de um bloco com características cratônicas alinhado segundo a direção NE-SW. 


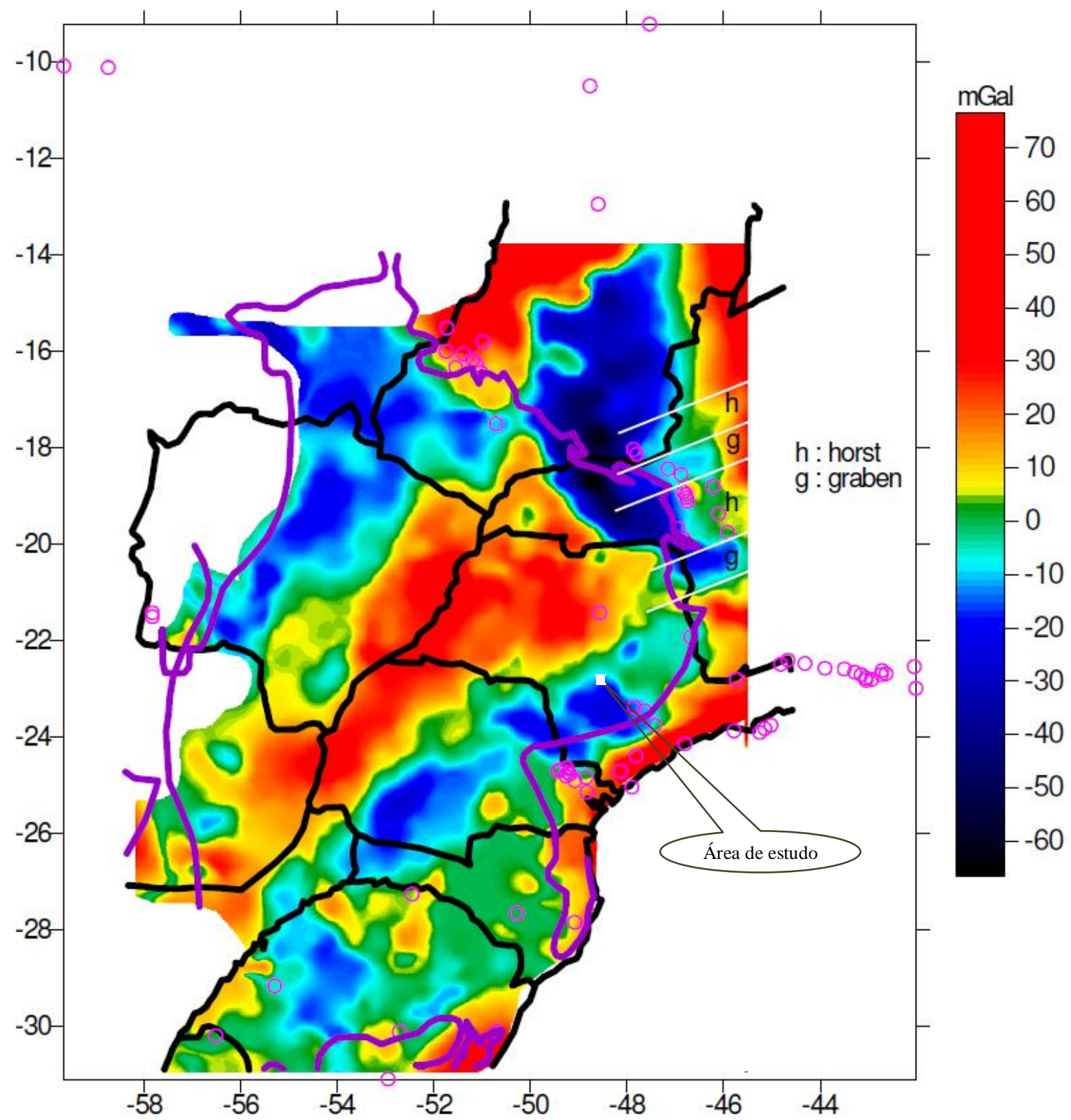

Figura 2.12 - Mapa gravimétrico residual gerado por Quintas (1995, p. 116), subtraído as rochas sedimentares e rochas ácidas. Os pontos na cor lilás representam a posição das rochas alcalinas e as linhas na cor roxa os limites da Bacia do Paraná. As linhas brancas representam os limites dos prováveis blocos litosféricos dispostos em horst e graben (modificado por Rugenski, 2006, p.24).

Mantovani et al. (2005) retomaram o trabalho de Quintas (1995) e, ao estudarem as características gravimétricas (anomalia positiva), sugeriram que este bloco possuía caráter cratônico e o denominaram de "Bloco Paranapanema". Além disto, as anomalias negativas, baixos gravimétricos, que circundam o Bloco Paranapanema, foram interpretadas como continuidade das faixas móveis Ribeira, Brasília, Dom Feliciano e Paraguai Araguaia (Figura 2.13). Ao sobrepor o mapa dos alinhamentos proposto por Soares (1991), mostrado na Figura 2.9, com o mapa interpretado por Quintas (1995, p.116), Figura 2.12, e compará-los com a 
interpretação proposta por Riccomini (1995, p.30), Figura 2.11, podem-se notar várias semelhanças entre os resultados obtidos, de certa forma, confirmando-os em grande parte (Figura 2.13).

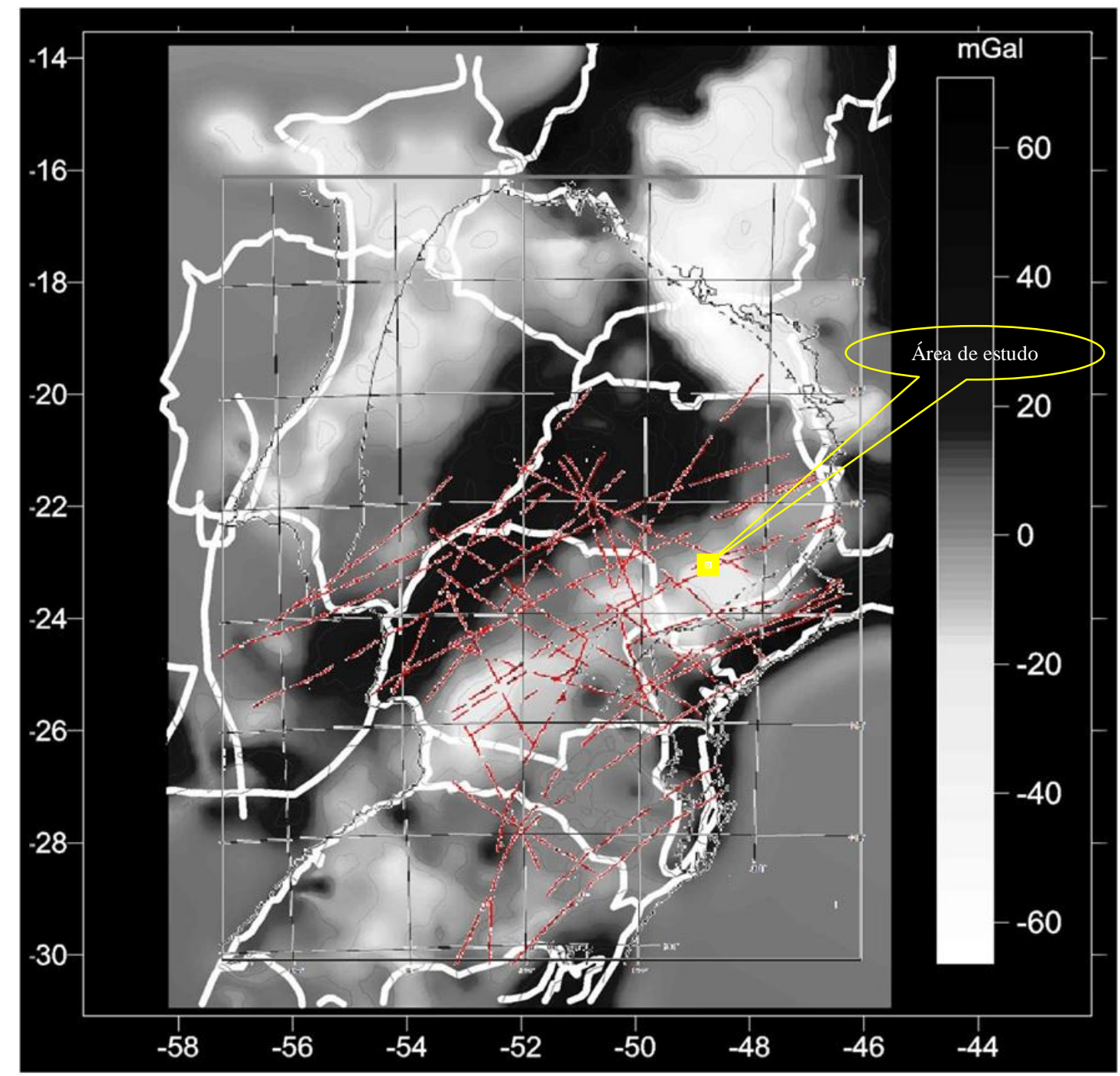

Figura 2.13 - Interpretação geofísica das feições tectônicas da Bacia do Paraná com os alinhamentos estruturais propostos por Soares (1991) sobrepostos. Na parte central pode-se observar um alto gravimétrico positivo (modificado de Mantovani et al., 2005, p.21). 


\section{CAPÍTULO 3}

\section{GEOLOGIA DA ÁREA DE ESTUDO}

\section{1 - Introdução}

O Alto Estrutural de Anhembi situa-se no cruzamento de dois grandes lineamentos regionais, na parte norte da Zona de Falha de Jacutinga (Soares et al., 1996), direção NE, com o lineamento Tietê (Saad, 1977, p. 79; Coimbra et al. 1977), direção NW. Nas proximidades do Alto Estrutural de Anhembi, existem outros altos estruturais, como Pitanga, Pau d'alho e Artemis, possivelmente relacionados à reativação de estruturas herdadas do embasamento, principalmente a Zona de Falha de Jacutinga (Ricomini, 1995, p.26).

Saad (1977, p.76) descreve o Lineamento Tietê como resultado de um estudo, baseado em uma série de evidências de ordem estratigráfica, sedimentológica, estrutural e geomorfológica. Segundo este autor, esta estrutura teria idade Pré-cambriana, sofrendo sucessivas reativações do Paleozoico ao Cenozoico, com comportamento tectônico variado durante este período. Northfleet et al. (1969) sugerem, através de mapas de porcentagens de areia da Fm. Ponta Grossa, uma região menos negativa correspondente ao Lineamento Tietê. Saad (1977, p.96), analisando os mapas de isópacas do sub-grupo Itararé e do ciclo Irati-Serra Alta, conclui que o Lineamento Tietê sofreu inversão tectônica, transformando-se em uma calha deposicional no primeiro caso e soerguimento no segundo, servindo de borda para a sedimentação neste ciclo. A reativação só teria ocorrido a partir da sedimentação da Fm. Rio do Rastro, após uma quiescência aparente durante a deposição da Fm. Teresina, segundo este mesmo autor.

O Alto Estrutural de Anhembi caracteriza-se pelo afloramento de rochas Eopermianas da Fm. Teresina na porção central da estrutura, circundada por rochas Triássicas (Eojurrásico - Triassíco) da Fm. Pirambóia, áreas hachuradas, representadas na Figura 3.1. Os sedimentos Terciários e quaternários estão representados em tons de amarelo. A represa de Barra Bonita (rio Tietê) é mostrada cortando toda a área de estudo. Estão também representadas as ocorrências de geiseritos (circulo vermelho), arenito asfáltico (estrela verde) e poço pioneiro de exploração da Petrobras: 1-AB-1-SP (triângulo invertido amarelo). Esta figura é uma síntese dos trabalhos de IPT (1979) e Araújo (2006, p. 55). 


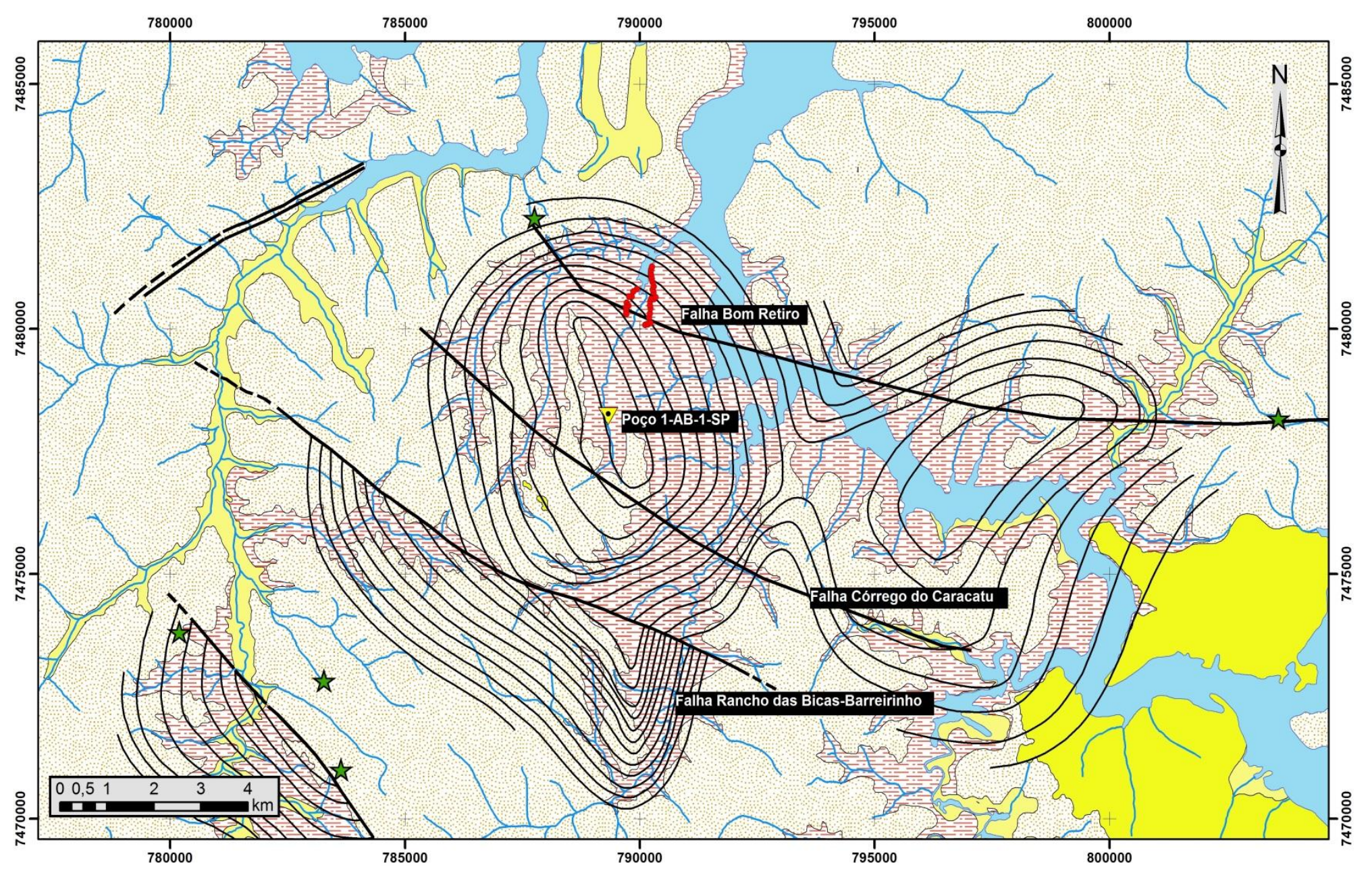

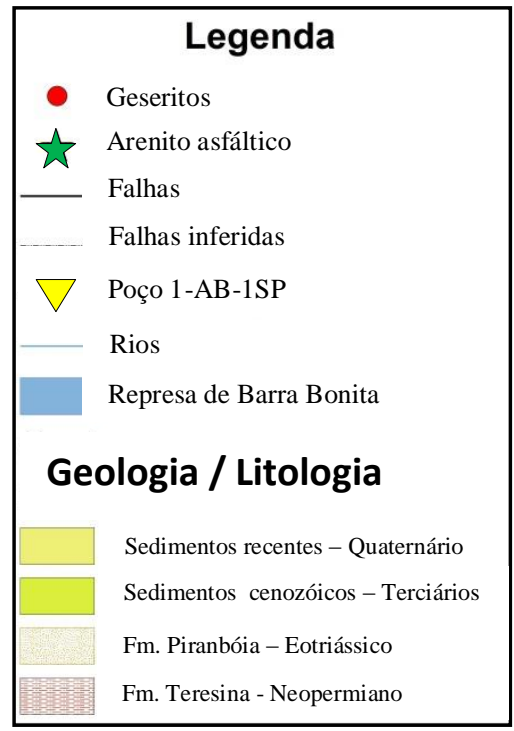

Figura 3.1 - Mapa geológico do Alto Estrutural de Anhembi com lineamentos representados e identificados. Estão também representados as ocorrências: de arenito asfáltico, entrela em verde, cones silicosos (geseritos) em pontos em vermelho e a localização do poço 1-AB-1-SP, triângulo invertido em amarelo (compilado de Araújo, 2006, p. 55 e IPT, 1979). 


\section{2 - Aspectos geomorfológicos da área de estudo}

De acordo com o mapa geomorfológico elaborado pelo IPT (1981), o Estado de São Paulo está dividido nas seguintes Províncias Geomorfológicas: Planalto Atlântico, Província Costeira, Depressão Periférica, Cuestas Basálticas e Planalto Ocidental (Figura 3.2).

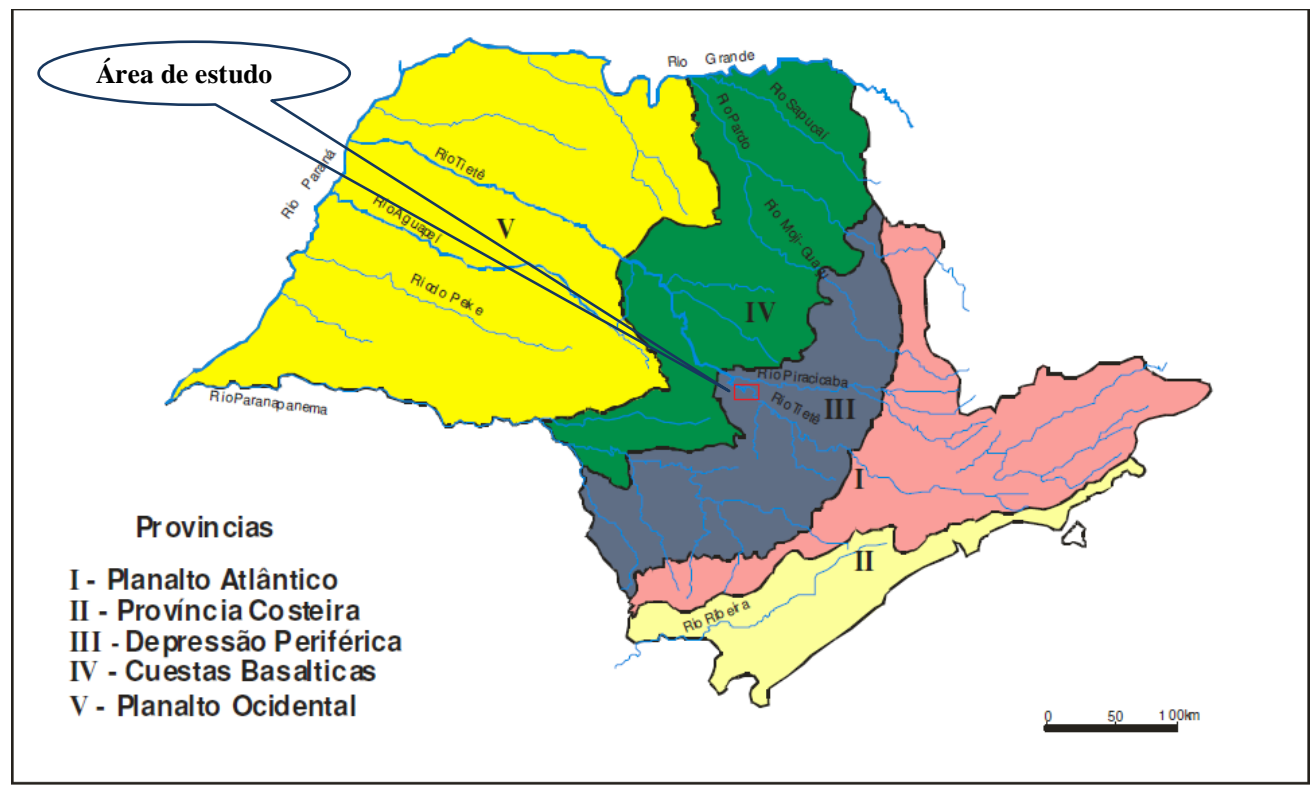

Figura 3.2 - Mapa Geomorfológico do Estado de São Paulo, modificado de IPT (1981).

A Província Depressão Periférica, onde está localizada a área de estudo, caracteriza-se por um relevo rebaixado em relação ao Planalto Atlântico e o Planalto Ocidental. Nesta província, afloram as unidades Paleozoicas da Bacia da Paraná. Suas características distintivas devem-se ao mergulho das camadas sedimentares da borda para o centro da bacia e pela presença dos derrames basálticos, permitindo o avanço da erosão e a forma de um escarpado, denominada por cuestas basálticas, limítrofe à depressão gerada (Penteado, 1976, p.13). As cuestas basálticas são sustentadas pelos derrames (Figura 3.3) sotopostos às unidades de idades Triássica, basicamente arenitos eólicos - muitos susceptíveis à erosão.

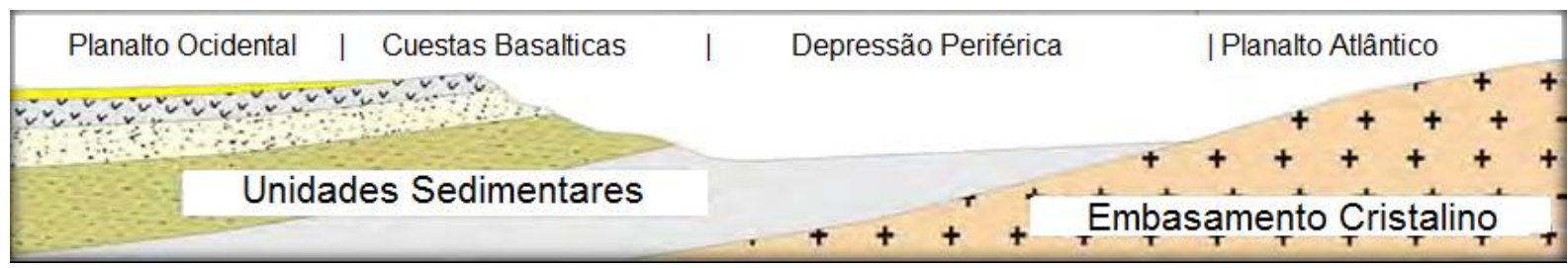

Figura 3.3 - Esquema simplificado do padrão de relevo da área de estudo (modificado de IPT, 1981). 
As formas de relevo da área de estudo (Figura 3.3), cuja topografia está relacionada com litologia das formações aflorantes, distinguem-se por dois tipos principais de forma (IPT, 1979. p. 4):

O relevo típico da Fm. Pirambóia se caracteriza por chapadões tabuliformes com encostas escalonadas, possuindo grandes extensões de areias sobre superfícies aplainadas nas cotas mais altas da região e ao longo das áreas elevadas dos cursos de água de maior expressão.

- A forma de relevo observada na Fm. Teresina é a de colinas suaves com encostas em degraus, onde se podem observar quebras positivas do relevo, causadas por leitos de calcário e sílex, que dão esta forma. Esta forma apresenta-se nas partes mais baixas da área de estudo, próximas a cidade de Anhembi e do rio Tietê.

As drenagens (Figura 3.4) também refletem as formações as quais estão encaixadas. Na Fm. Pirambóia, por exemplo, as drenagens são retilíneas e esparsas, enquanto que, na Fm. Teresina, o padrão se torna dendrítico e mais denso com cursos maiores, do tipo meandrante. A área de estudo é cortada pelo rio Tietê, cujo curso é em direção a noroeste, na direção regional de mergulho das camadas sedimentares. No entanto, a melhor caracterização da anomalia que define o Alto Estrutural de Anhembi é observada nas áreas dos rios Alambari e Remédios, pois apresentam curvaturas sub-paralelas aos contornos da estrutura, assim como a disposição radial, a partir do centro da estrutura, configurada pelos afluentes da margem direita do rio Alambari, ao norte de Piapara (IPT, 1979. p.5, Araújo, 2003. p. 30, Araújo et al., 2006. p. 56). 

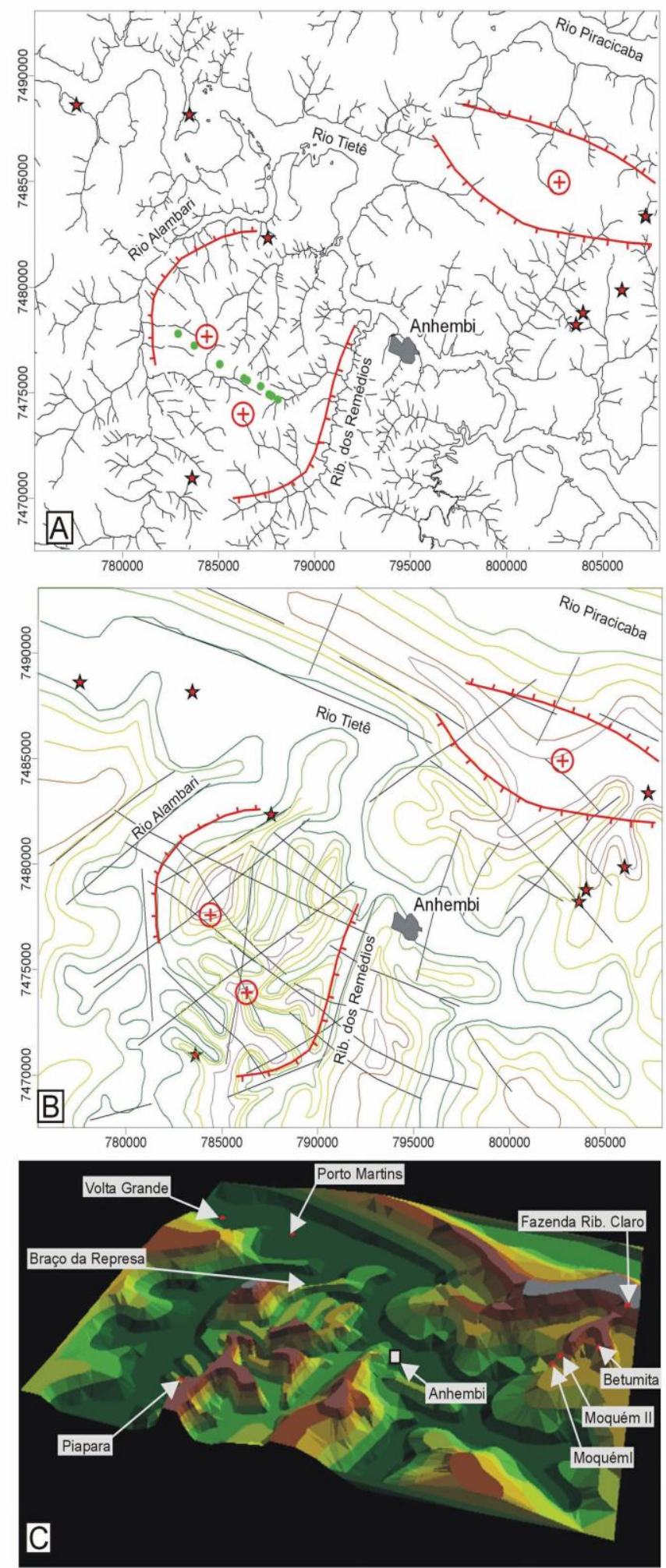

Figura 3.4: (A) Mapa de drenagem. Em vermelho, as principais anomalias de drenagem. Nota-se, entre os rios Alambari e dos Remédios, uma anomalia com padrão anelar e radial de drenagem, os sinais positivos indicam as áreas de alto estrutural. Os pontos verdes indicam os afloramentos de um dique de rocha básica. (Araújo et al., 2006. p.56).

(B) Curvas de isovalor com interpretação morfoestrutural e indicação das anomalias observadas em (A). As estrelas indicam ocorrência de arenito asfáltico. (Araújo et al., 2006. p.56)

(C) Representação tridimensional de altos e baixos morfoestruturais com indicação das ocorrências de arenito asfáltico. Os tons de verde indicam baixo estrutural e os tons de marrom e cinza indicam alto estrutural. Notar que estas ocorrências se encontram nas regiões entre altos e baixos estruturais. Coordenadas UTM em metros; M.C. -51º, SAD69 (Araújo et al., 2006. p.56). 


\section{3 - Principais litotipos presentes na área de estudo}

Os principais litotipos aflorantes encontrados na área de estudo são apresentados de forma resumida no Quadro 3.1 e descritos a seguir. A distribuição em mapa das unidades aflorantes pode ser visualizada na Figura 3.1. A Figura 3.5 apresenta de forma simplificada a coluna estratigráfica de unidades sedimentares (Araujo et al., 2006. p.52) do intervalo Permiano ao Triássico, aflorantes na área de estudo.

Os hiatos observados na coluna estratigráfica possivelmente estão relacionados à orogenia San Rafaélica (La Ventana - Cabo) do Permiano Superior e ao inicio da fragmentação continental (Milani \& Zalán, 1999, p.203).

Quadro 3.1: síntese da geologia da área de estudo:

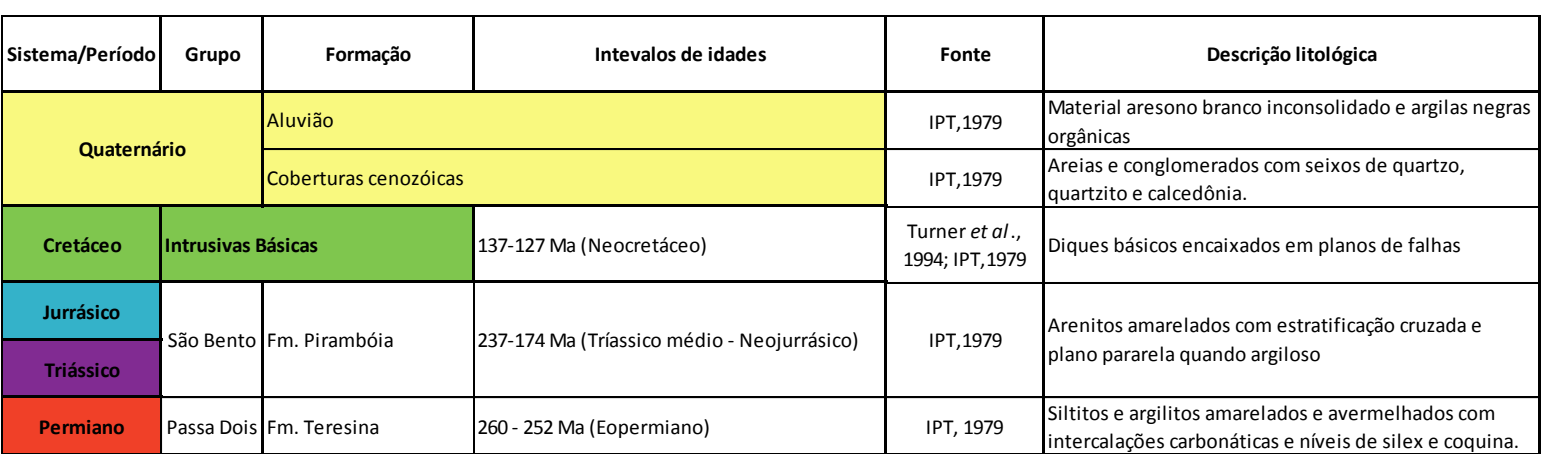

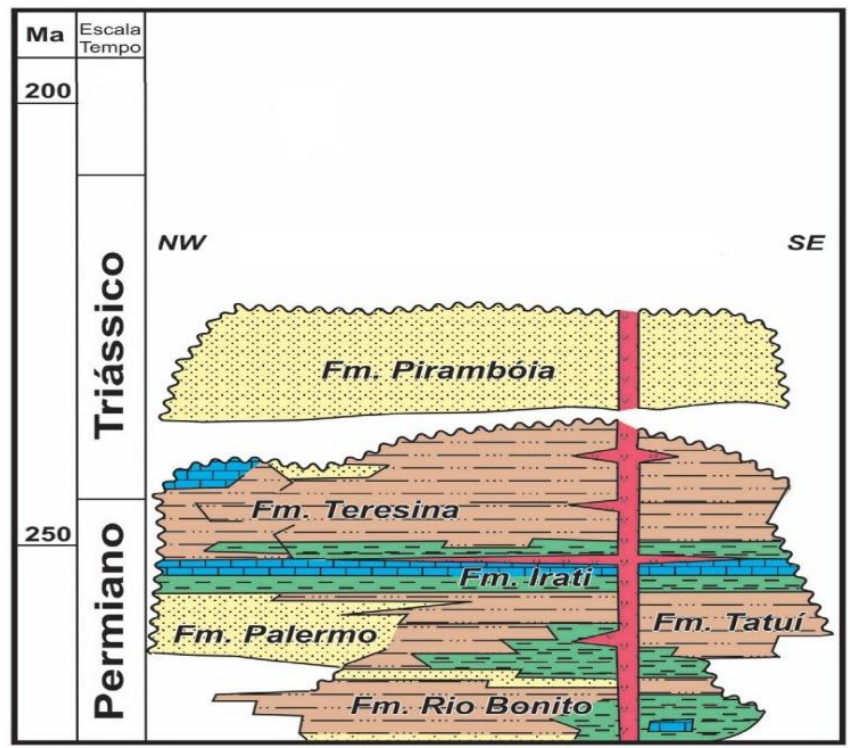

Figura 3.5 - Coluna estratigráfica simplificada da seção Permo-Triássica da área do Alto de Anhembi (simplificado de Araújo, 2006. p.52). 


\subsection{1 - Formação Teresina}

Gordon Jr (1947, apud Milani et al., 2007) subdivide a Formação Estrada Nova nos membros Serra Alta (membro inferior) e Teresina (membro superior). O Membro Serra Alta corresponderia aos 30 a 40 metros superiores da Formação Irati de White (1908, apud DNPM, 1988, p.180), enquanto que o Membro Teresina seria composto por arenitos finos ou calcários arenosos e calcários oolíticos parcial ou inteiramente. Schneider et al. (1974) subdividiram o Grupo Passa Dois nas formações: Irati, Serra Alta, Teresina e Rio do Rasto, nas porções central e sul da Bacia do Paraná. Ao norte do lineamento do rio Tietê, nos estados de São Paulo, Mato Grosso e Goiás, o Grupo Passa Dois se constitui das formações Irati e Corumbataí (Figura 3.6).

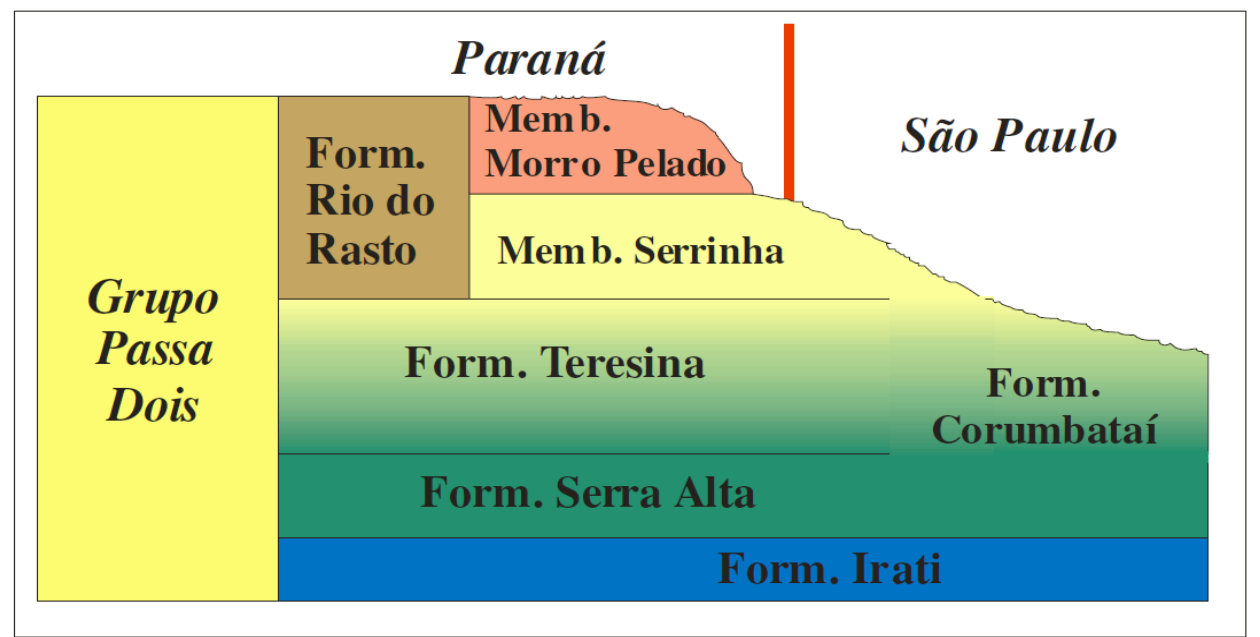

Figura 3.6 - Litoestratigrafia do Grupo Passa Dois para os estados do Paraná e São Paulo (Meglhioratti, 2006, p.3).

Segundo Schneider et al. (1974), Zaine (1980), Petri \& Coimbra (1982) e Sousa et al. (1991), a Fm. Teresina se depositou em ambiente marinho raso, com planícies de maré, porém, de acordo com Holz et al . (2010), esta formação é produto de sistema deposicional de offshore influenciado por tormentas a planície costeira com uma contribuição baixa de carbonatos.

A Formação Teresina, em sua porção centro-sul do Estado de São Paulo, está entre as formações Serra Alta e Pirambóia, com contato transicional entre as formações Teresina e Serra Alta, conforme descrito por Rohn (2001) e Meglhioratti (2006, p.4). O contato entre o Grupo Passa Dois e a Formação Pirambóia é discordante para Soares (1973) e Caetano-Chang (1993), e concordante, de acordo com Matos (1995, p.68), Giannini et al. (2004) e Milani et al. (2007). O equivalente estratigráfico das formações: Serra Alta, Rio do Rasto e Teresina é a 
fomação Corumbataí, a qual está restrita ao norte e nordeste da Bacia do Paraná, pelo Lineamento Tietê (Schneider et al., 1974).

As rochas da Fm. Teresina são compostas por sedimentos clásticos finos e calcíferos de coloração marrom a amarelo pálido, de forma geral, siltitos com intercalações de arenitos finos a muito finos, com estruturas de aleitamento rítmicas evidenciadas pelas estruturas tipo "flaser", lenticulares e onduladas (IPT, 1979. p. 6), mostradas nas Figuras 3.7, 3.8, 3.9. Isoladamente, são descritos níveis de siltito maciço, lamitos e bancos de calcário bioclástico e oolítico associados a níveis de silexito, Figura 3.10. O contato superior da Fm. Teresina com a Fm. Pirambóia é descrito na área como discordante e está representado por paleosolos brechados com fragmentos de siltitos e sílex da unidade sotoposta. São descritos fósseis de lamelibrânquios, ostracódeos, restos de peixes, restos de vegetais e palinomorfos os quais indicam a idade relativa da deposição como sendo no Eopermiano e atribuem a origem da formação como em ambiente marinho raso, em condições climáticas oxidantes, sob influência de marés (IPT, 1979, p. 7). A espessura da Fm. Teresina é de aproximadamente 280-330 metros na parte central na borda leste da Bacia do Paraná (Holz et al., 2010).

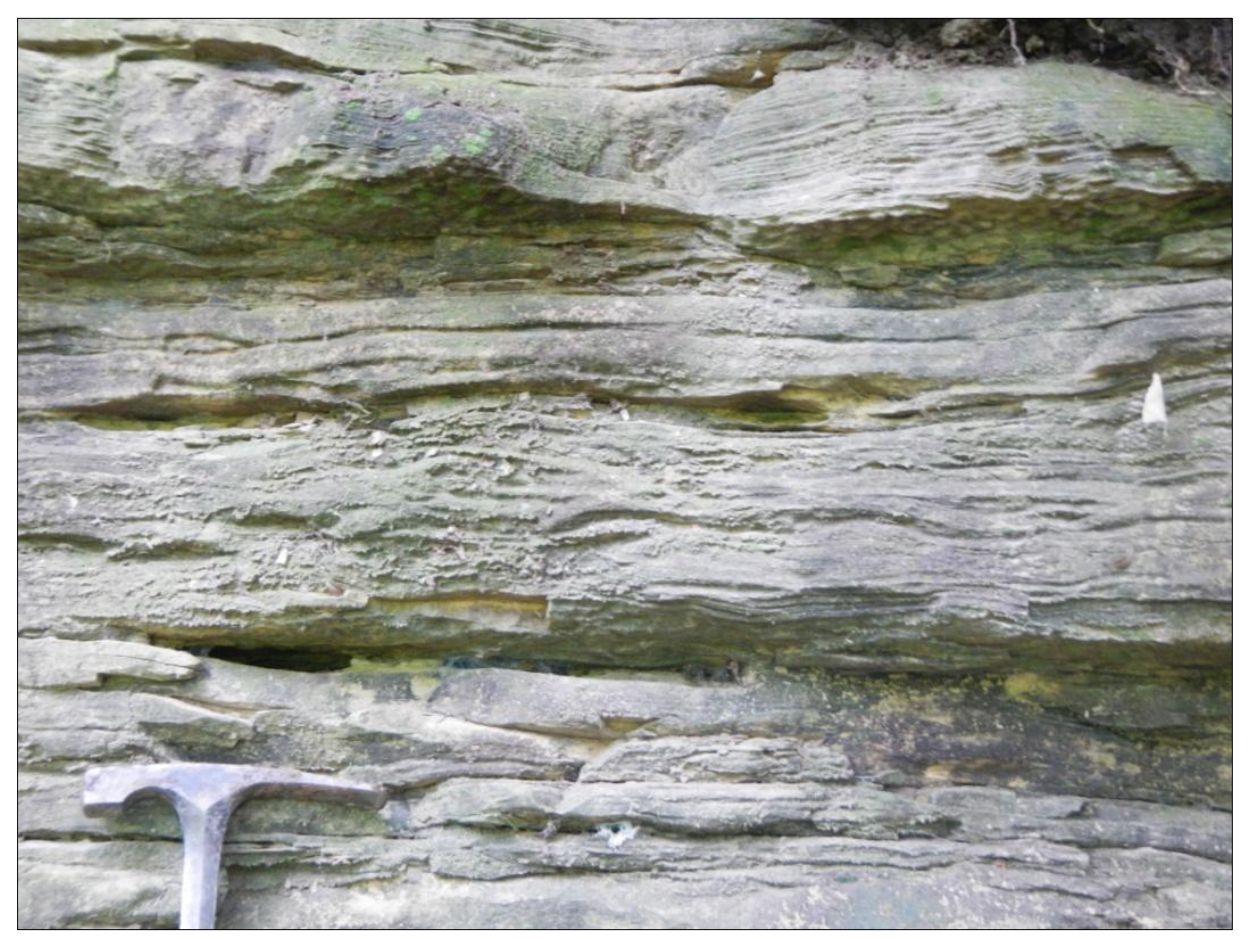

Figura 3.7 - Foto ilustrativa da Fm. Teresina: siltitos com intercalações de arenitos finos a muito finos com estruturas de aleitamento rítmicas evidenciadas pelas estratificações onduladas encontrados na área de estudo. 


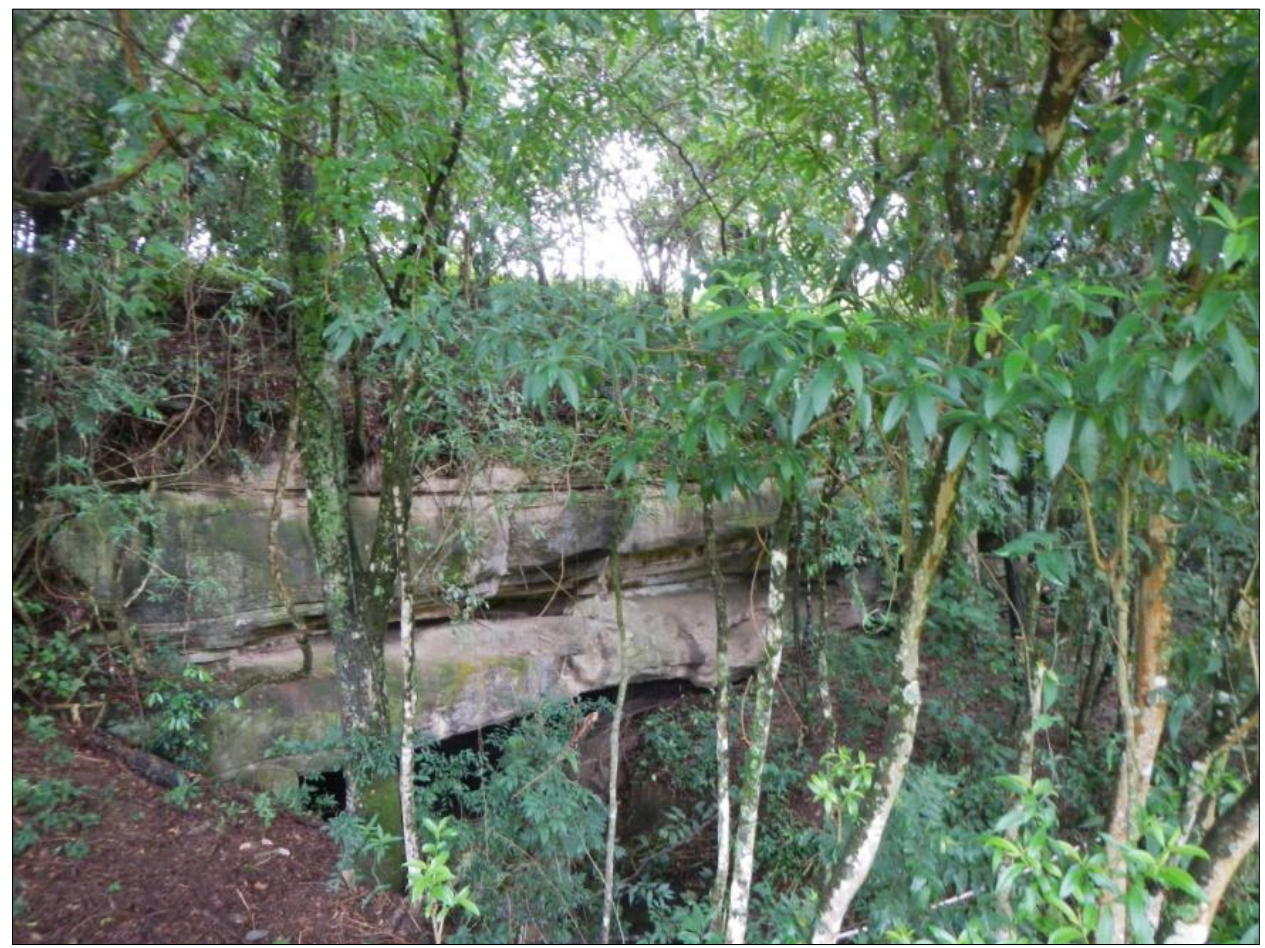

Figura 3.8 - Foto ilustrativa da Fm. Teresina: espessas camadas de siltito maciço dentro da área de estudo.

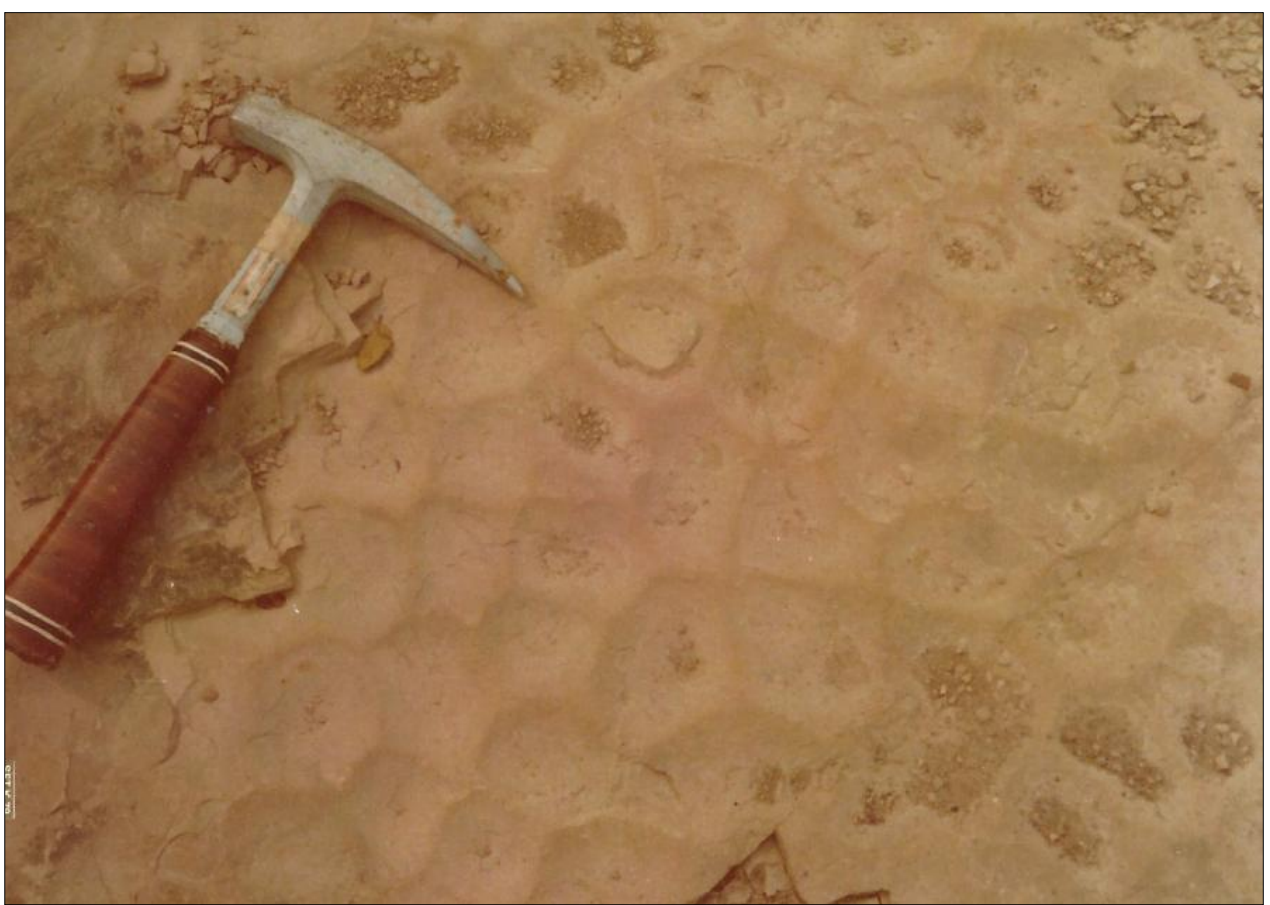

Figura 3.9 - Foto ilustrativa de ondas da Fm. Teresina: marcas de ondas, próximo a cidade Anhembi- SP (IPT, 1979). 


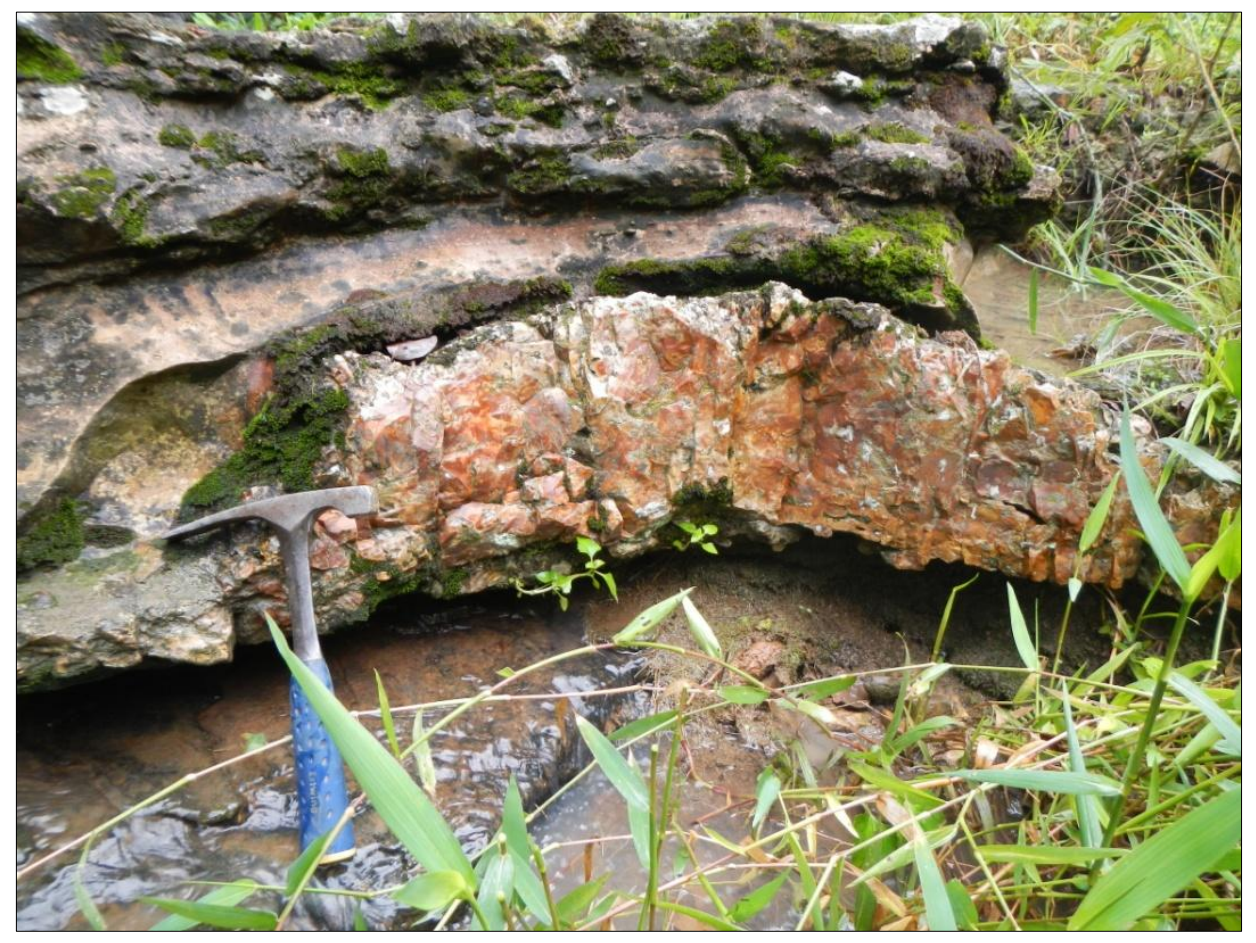

Figura 3.10 - Ocorrência silexito na Fm. Teresina observado em campo, nas margens leste e oeste do córrego do Retiro (cota 515 metros), a montante do mesmo córrego (cota 530 metros).

Uma ocorrência singular nesta formação são os cones silicosos. Localizados a noroeste da cidade de Anhembi - SP, foram também identificados mais de 4500 cones silicosos (Figura 3.11), resultantes de uma intensa atividade hidrotermal (Yamamoto et al., 2005). Segundo estes autores, trata-se do mais importante registro conhecido de atividade hidrotermal do período Permiano, não só pela quantidade, como também pela densidade, pois eles foram mapeados dentro de uma área de apenas $1,5 \mathrm{~km}^{2}$ e, sobretudo, pela singular preservação.

Os cones silicosos desenvolveram-se simultaneamente à sedimentação do topo da Formação Teresina (Yamamoto et al., 2005). Estes autores concluíram que essa ocorrência deva ter sido formada em um ambiente subaquático, pois não apresentam as características daquelas observadas nos gêisers modernos. Esses corpos apresentam uma morfologia homogênea, sendo a grande maioria de forma cônica, ao contrário dos geiseritos modernos. Entretanto, existem alguns corpos silicosos que não têm a forma cônica e podem ter sido desenvolvidos completamente emersos. 


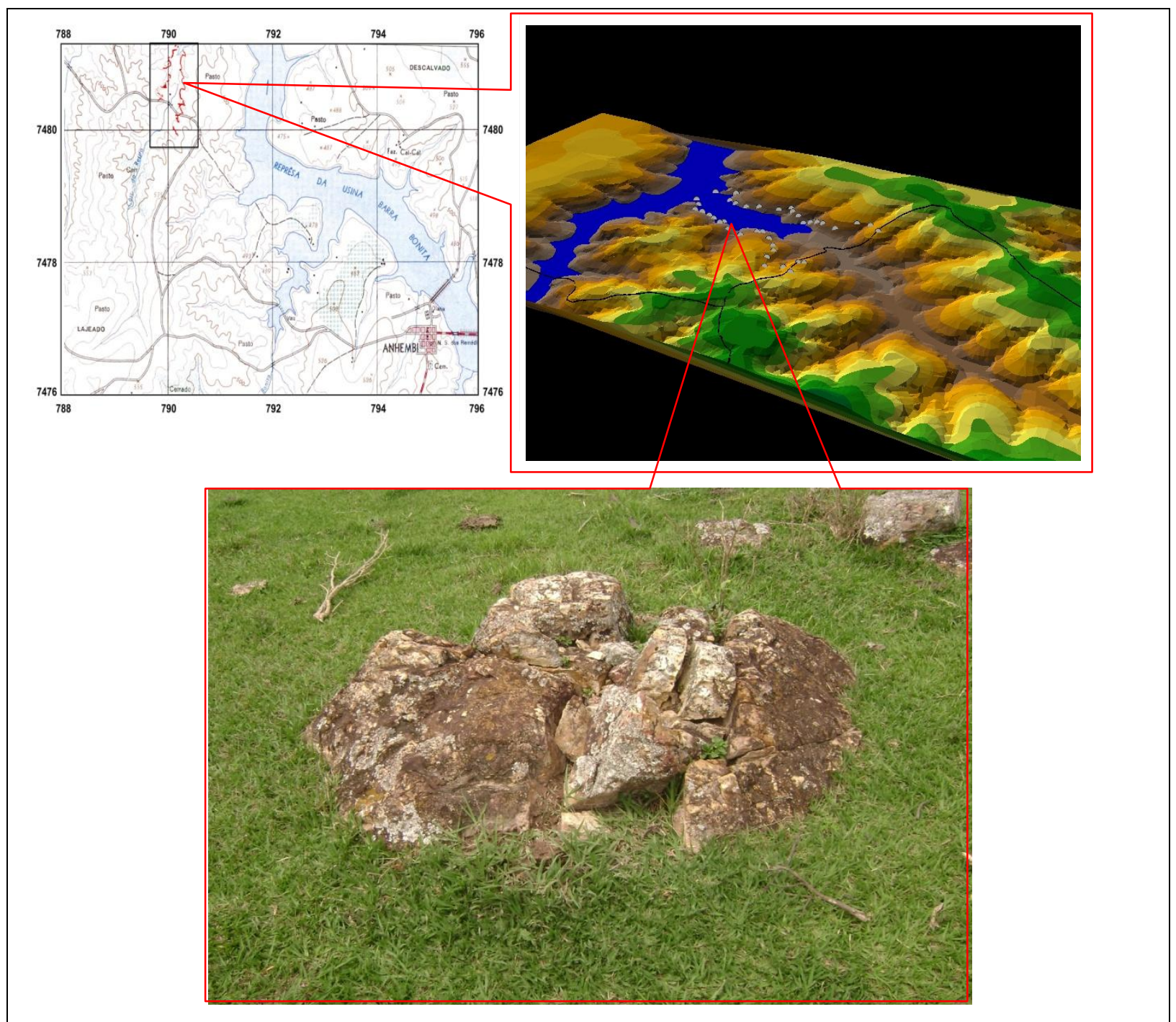

Figura 3.11 - Mapa de localização da área de ocorrência dos geiseritos, com coordenadas em UTM, aflorando. No detalhe, observam-se os pontos das ocorrências de cones silicosos e em detalhe um cone.

\subsection{2 - Formação Pirambóia}

As rochas da formação Pirambóia são essencialmente constituídas por arenitos finos a médios de coloração amarela, e localmente há descrições de ocorrências de coloração avermelhada ou rosada e esverdeada (IPT, 1979. p.6). Estas rochas possuem teor variável de argila e apresentam estratificação cruzada planar de porte pequeno a médio e estratificação plana- paralela usualmente em associação com sedimentos finos (argilitos, lamitos) de cores que variam de tons claros a amarelo, roxo, vermelho e verde (Landim et al., 1980). Esta formação tem ambiente deposicional caracterizado como uma associação de depósitos eólicos de dunas, interdunas e lençóis de areia, entremeados por depósitos fluviais subordinados (Assine \& Soares 1995; Caetano Chang \& WU, 1995). A idade provável da deposição 
sedimentar desta formação situa-se entre o Triássico Médio e o Jurássico Inferior (Soares, 1973, p.59 e Landim et al., 1980).

$\mathrm{Na}$ área de estudo, esta formação aflora em grande parte desta e tem seu contato basal determinado nas adjacências de Anhembi-Piapara com maior espessura verificada com cerca de 80 metros (IPT, 1979, p.8). A Fm. Pirambóia está sobreposta à Fm. Teresina (Figura 3.12) em discordância com contato marcado pela presença de regolito fóssil brechado (Figura 3.13), com fragmentos angulosos da Fm. Teresina. Esta formação caracteriza-se na área de estudo por acumular óleo, na forma de arenito asfáltico (Thomaz Filho, 1982, Araújo et al., 2003, p. 27 e Thomaz Filho et al., 2008, p. 132), onde se podem observar várias ocorrências em seu entorno, como foi mostrado na figura 3.1.

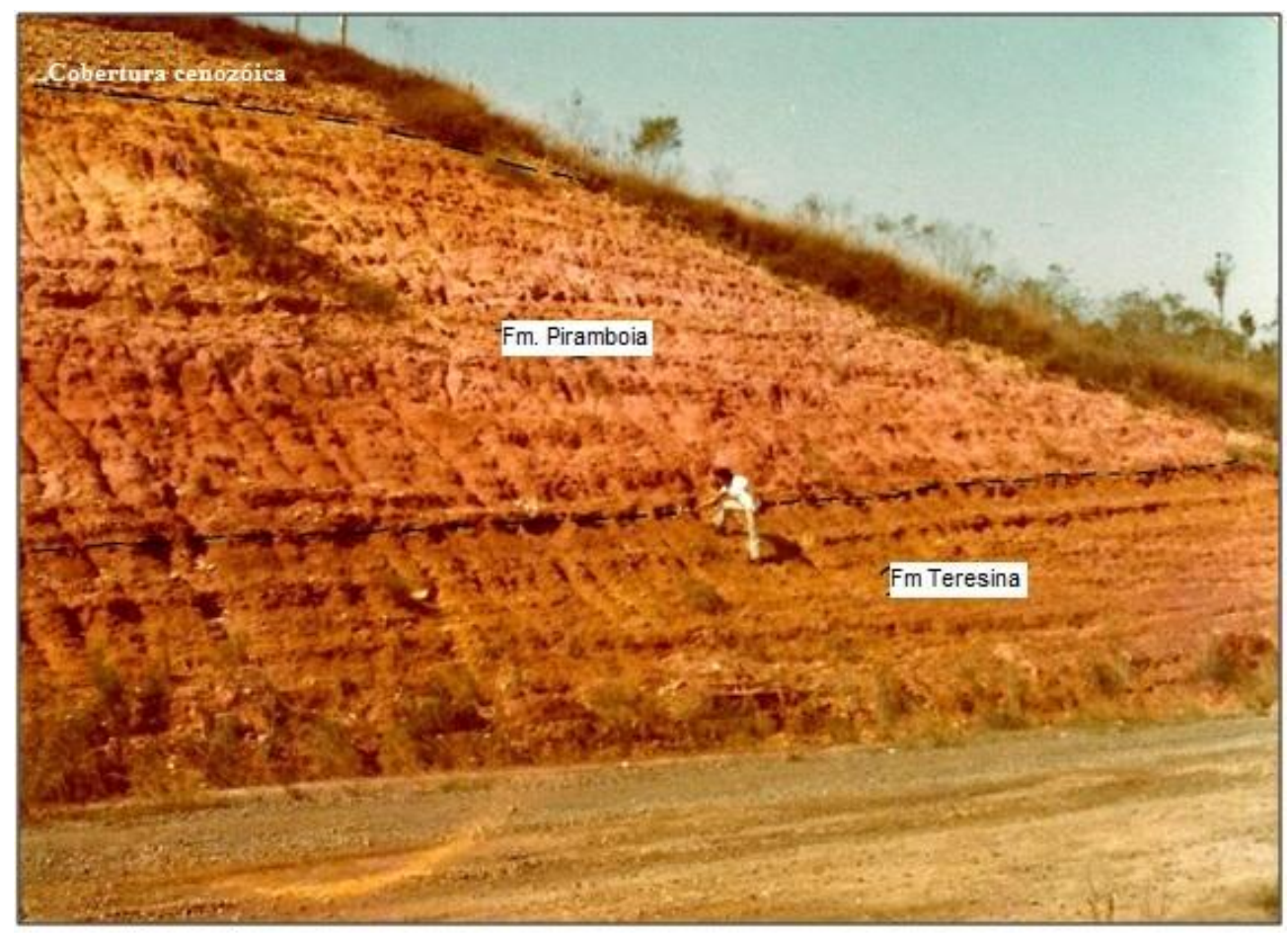

Figura 3.12 - Foto ilustrativa dos contatos das Formações Pirambóia, Teresina (base) e cobertura cenozóica (topo). Rodovia SP-147, próximo a cidade de Anhembi (modificado de IPT, 1979). 


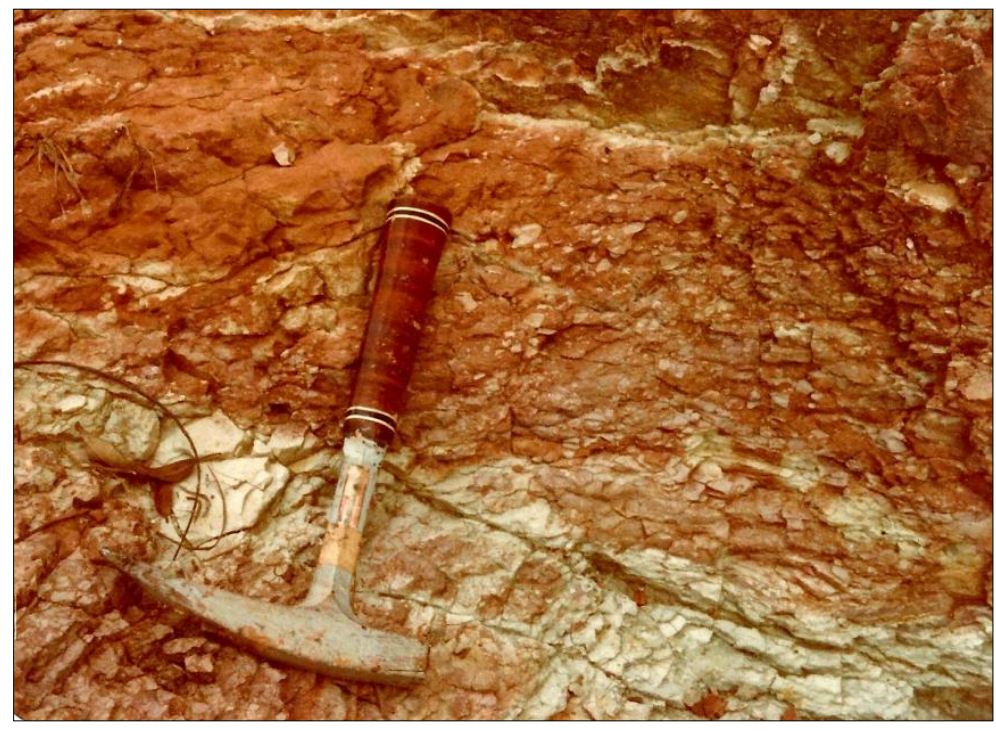

Figura 3.13 - Foto ilustrativa da ocorrência do regolito fóssil brechado da base da Fm. Pirambóia (IPT, 1979).

\subsection{3 - Coberturas cenozóicas}

As coberturas cenozóicas compreendem areias e conglomerados com seixos de quartzo, quartzito e calcedônia (Figura 3.14), sem estrutura definida, têm espessura máxima em torno de 10 metros e afloram como pequenas manchas esparsas em diversos pontos da área de estudo com presença marcante em área a sudeste de Anhembi, às margens da represa de Barra Bonita, com afloramentos da ordem de $30 \mathrm{~km}^{2}$ (IPT, 1979, p. 9). Têm contato discordante com as unidades mais antigas com conglomerado basal. Soares \& Landim (1976) atribuem a idade desta unidade ao Quaternário e indicam uma origem continental a partir de depósitos colúvio-aluvionares.

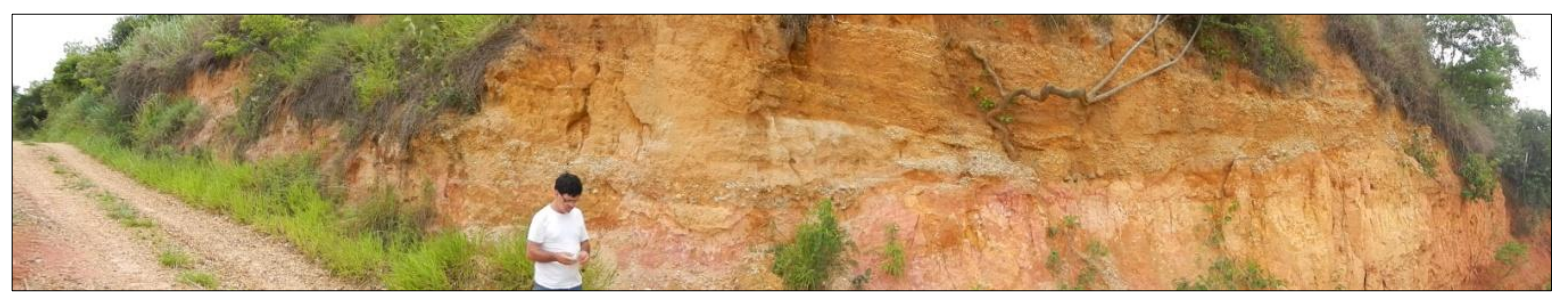

Figura 3.14 - Foto ilustrativa de depósito de cascalho da cobertura cenozoica, localizada na área de estudo. 


\subsection{4 - Aluviões}

Aluviões presentes na área de estudo são compostos, essencialmente, por areias e cascalhos inconsolidados que apresentam sua distribuição espacial ao longo de vales e planícies de inundação dos principais cursos d'água.

\subsection{5 - Intrusivas Básicas}

As rochas intrusivas básicas presentes na área são reflexos do diastrofismo que atuou na Bacia do Paraná desde o Neojurrásico ao início do Terciário e estão relacionadas ao vulcanismo gerador da Formação Serra Geral (IPT, 1979, p.8).

Caracterizam-se por intrusões de diques de diabásio, soleiras e derrames de basalto, basaltos andesíticos de filiação toleítica, com porções subordinadas de riodacitos e riolitos da Fm. Serra Geral (Peate, 1997).

Os diques que afloram na área de estudo são relacionados à Fm. Serra Geral em um intervalo entre 137 a 127 Ma, segundo Turner et al. (1994, p. 339). Segundo estes autores, estes diques com idades mais jovens estão a sul e leste e as mais velhas a norte e oeste da bacia. A datação de um dique de diabásio mais próxima é a de Porto Martins, mostrado mais à frente na figura 3.13, NW do Alto Estrutural de Anhembi com idade $134 \pm 2$ Ma (Araújo, 2003, p. 110). Idade concordante com a encontrada por Thiede \& Vasconcelos (2010, p. 747).

\subsection{6 - Litotipos em Sub-superfície}

$\mathrm{Na}$ área de estudo, as informações de litotipos, em sub-superfície, foram obtidas através da descrição do perfil composto do poço pioneiro exploratório 1-AB-1-SP da Petrobras. Sua localização foi apresentada na figura 3.1 (geográfica: Lat. 22 48' 37,2" e Lon. $48^{\circ} 10^{\prime}$ 58,8" e UTM: 7478200 - norte, 789650 - leste, em metros). A figura 3.15 mostra, de forma simplificada, os tipos de rochas constituintes do pacote sedimentar e suas respectivas espessuras. Também estão descritas as formações observadas no perfil. Os litotipos encontrados são: arenito, lamito/siltito, folhelho, diamictito e destacando-se duas camadas de diabásio ( $(\mathrm{ill}$ ), em um total de 200 metros de espessura, aproximadamente. Segundo a descrição do perfil, o embasamento cristalino é encontrado a 1650 metros de profundidade. Porém, o perfil o descreve como quartzito, uma rocha não necessariamente pertencente ao embasamento cristalino. 


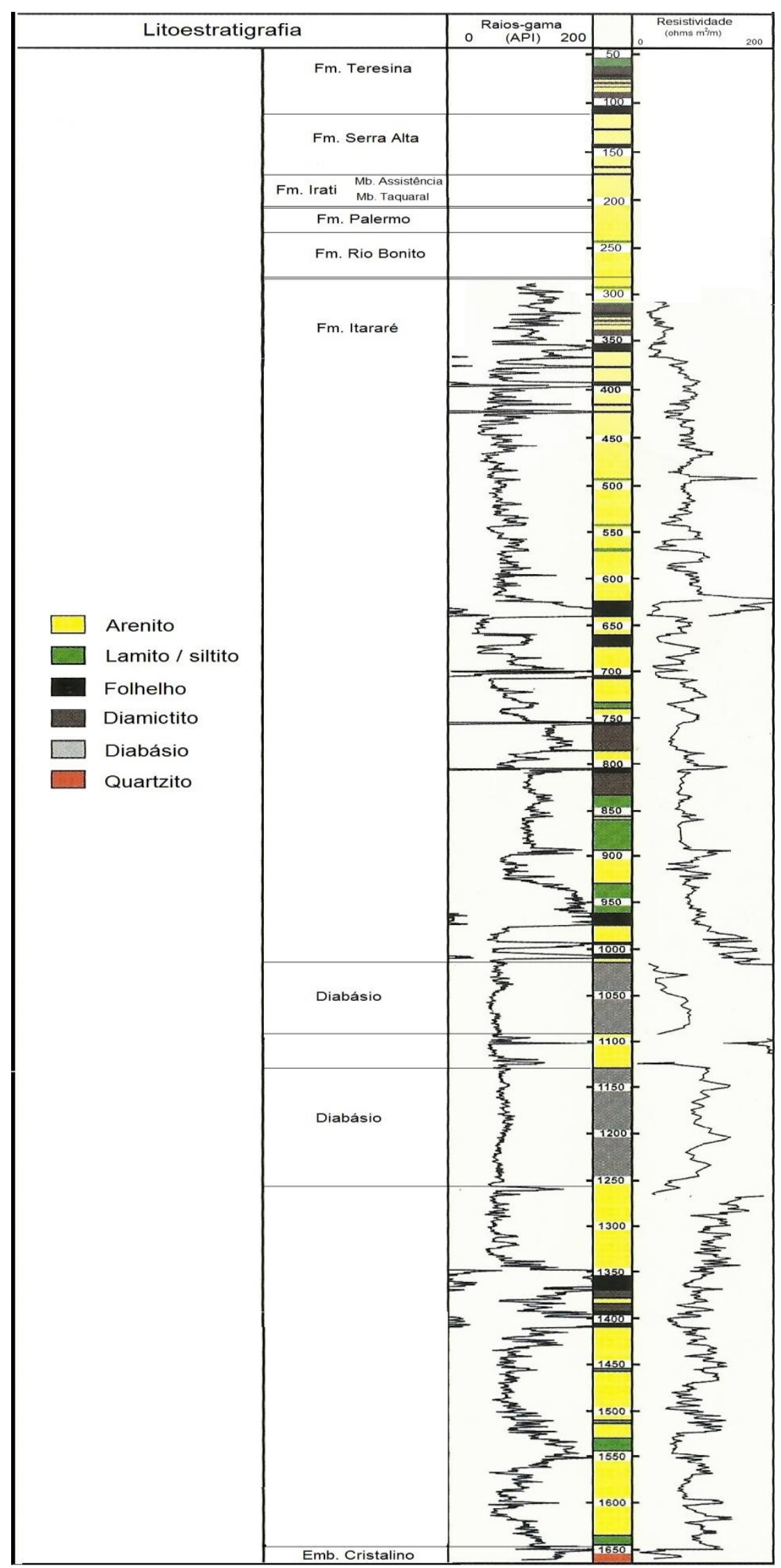

Figura 3.15 - Perfil do poço pioneiro exploratório 1-AB-1-SP, da Petrobras, com os principais litotipos da área de estudo (modificado de IPT, 2005, p. 180). 


\section{4 - Caracterização do Alto Estrutural de Anhembi}

Vários estudos foram realizados na Alto Estrutural de Anhembi e em seu entorno. Muitos deles visavam, a princípio, à utilização do arenito asfáltico e, depois, em função de sua potencialidade, a ser um depósito de óleo. Dentre estes estudos, destacam-se o realizado por Soares (1974) e o pelo IPT (1979), que caracterizaram as estruturas de Anhembi e Piapara. IPT (1979) realizou mapeamento geológico, na escala 1:25.000. Desta forma, foi confeccionado o mapa de contorno estrutural da superfície de discordância Teresina Pirambóia e dois cortes estruturais e geológicos (Figuras 3.16, 3.17 e 3.18). As cotas topográficas na área variam de 437 a 652 metros e os contatos entre as formações Pirambóia e Teresina variam de 465 até 540 metros. Para esta caracterização, IPT $(1979$, p. 8) usou como premissa as observações regionais de campo que indicaram que o topo da Fm. Teresina, na época da deposição Pirambóia, era uma superfície aplainada.

Esta estrutura foi subdividida em três estruturas menores (IPT, 1979, p. 10):

Alto de Piapara: associado a um falhamento de gravidade, tendo a direção NW e rejeito de aproximadamente de 80 metros. Encaixado no plano de falha existe um dique de diabásio descontinuo. O fechamento da estrutura é em torno de 50 metros;

$>$ Alto de Anhembi-Norte: possui a maior área da estrutura. Subdivide-se em duas feições dômicas ligadas por um baixo estrutural com a forma de sela. Na parte sul localiza-se o bloco baixo da falha que deu origem à estrutura de Anhembi-Sul. Possui uma área de $3 \mathrm{~km}^{2}$, aproximadamente, tendo o seu menor eixo aproximadamente $8 \mathrm{~km}$ e o de maior próximo a $17 \mathrm{~km}$ (direção WNW) com fechamento de 60 metros;

Alto de Anhembi-Sul: Também está associado com falhamento de gravidade, direção NW e rejeito de cerca de 30 metros. Apresenta dique de diabásio descontínuo ao longo do plano de falha. O fechamento da estrutura é em torno de 55 metros.

Estas estruturas rúpteis pós-deposicionais, destacando-se as fraturas presentes nos siltitos da Fm. Teresina e as bandas de deformação nos arenitos Pirambóia, foram interpretadas (IPT, 1979, p.9) como estruturas que foram geradas por eventos mesozoicos, embora a reativação de estruturas permianas também seja considerada. 


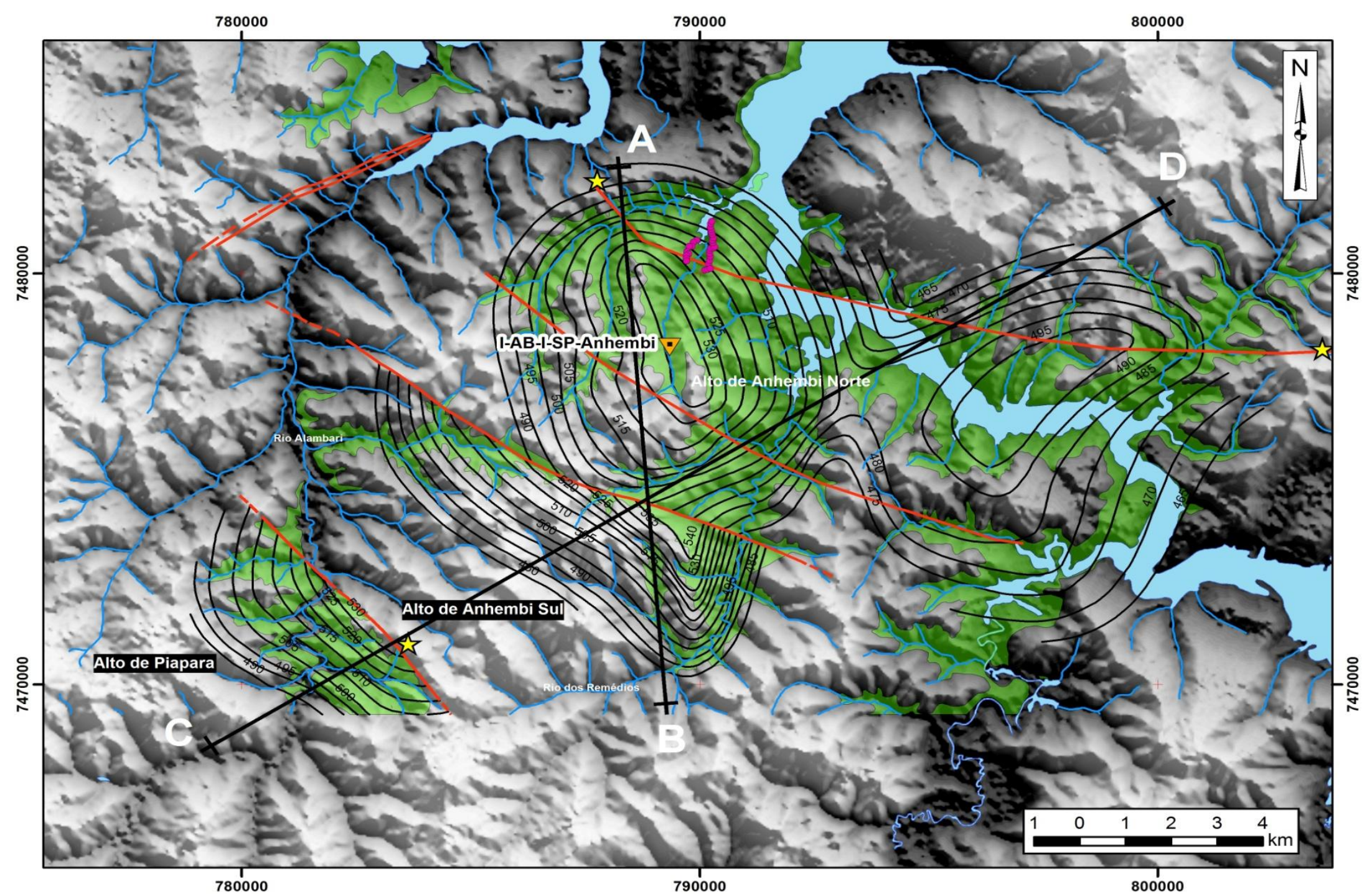

Figura 3.16 - Caracterização do Alto Estrutural de Anhembi. Contorno estrutural da Fm. Teresina, em verde, sobre modelo numérico de terreno sombreado, iluminação de $45^{\circ}$, elevação de $45^{\circ}$. As principais falhas e lineamentos na área de estudo, em vermelho, assim como os altos estruturais, dois perfis geológico, segmentos em preto, ocorrência de cones silicosos, em lilás, poço exploratório 1-AB-1-SP, triângulo invertido em laranja e ocorrência de arenito asfáltico, estrela em amarelo estão identificados (compilado de IPT, 1979; Araújo et al., 2006, p. 55). 


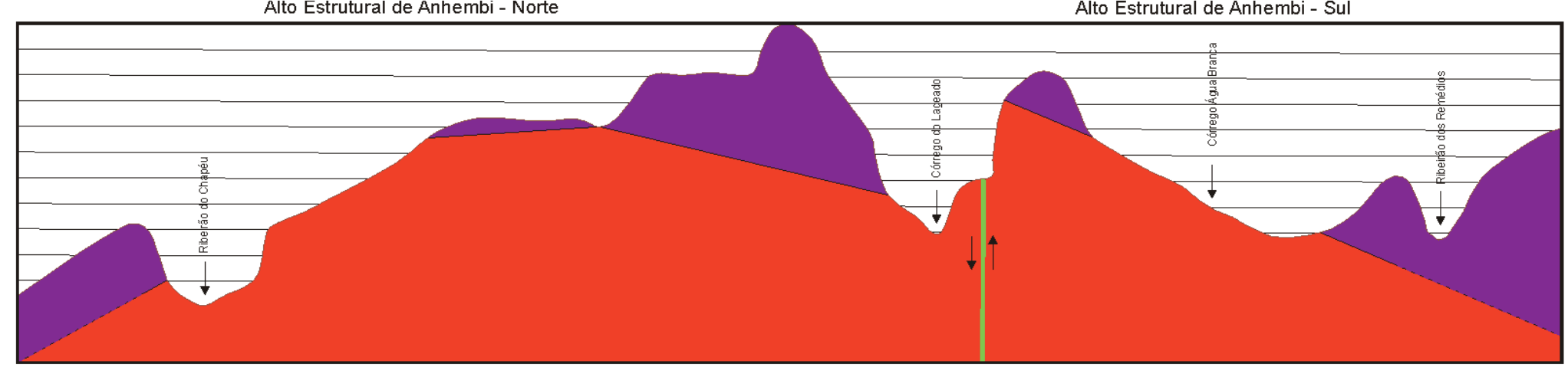

A

B

Figura 3.17 - Perfil N-S (AB), modificado de IPT (1979)

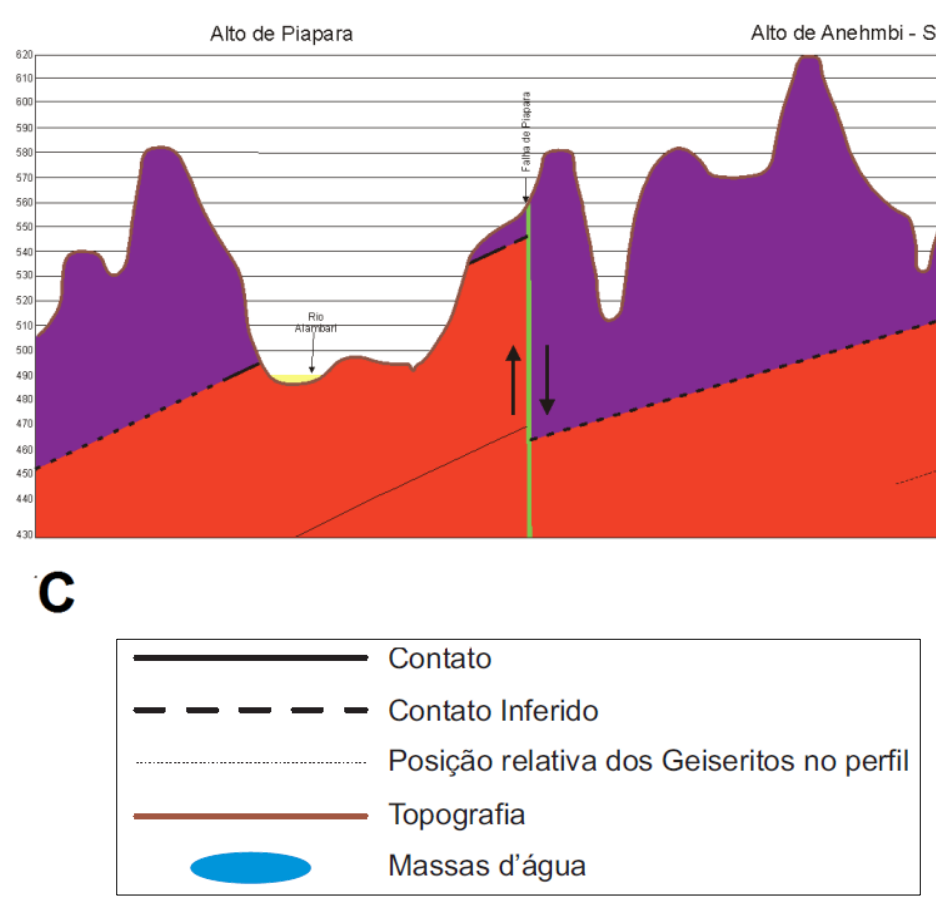

Figura 3.18 - Perfil NW-NE (CD), modificado de IPT (1979)

\begin{tabular}{|c|c|c|c|c|}
\hline & |dade & & Formação/Intevalos de idades & Descrição litológica \\
\hline \multirow{2}{*}{\multicolumn{2}{|c|}{ Quaternário }} & & Aluvião & Material aresono branco inconsolidado e argilas negras \\
\hline & & \multicolumn{2}{|r|}{ Coberturas cenozóicas } & $\begin{array}{l}\text { Areais e conglomerados com seixos de quartzo, quartzito } \\
\text { e calcedônia. }\end{array}$ \\
\hline \multicolumn{2}{|r|}{ Cretáceo } & Intrusivas Básicas & $127-137 \mathrm{Ma}$ (Neocretáceo) & Diques básicos encaixados em plan os de falthas \\
\hline Triássico & Grup São Bento & Fm. Pirambóia & 174 - 237 Ma (Tríassico médio - Neojurrásico) & $\begin{array}{l}\text { Arenitos amarelados com estratificaçăo cruzada e plano } \\
\text { pararela quando argilloso }\end{array}$ \\
\hline Permiano & Passa Dois & Fm. Teresina & & $\begin{array}{l}\text { siltitos e argilitos amarelados e avermelhados com } \\
\text { intercalagoes carbonáticas e niveis de silex e coquina. }\end{array}$ \\
\hline
\end{tabular}


Araújo et al. (2006) ampliaram o conhecimento da área de estudo confeccionando um novo mapa de contorno estrutural da Fm. Teresina a partir de levantamentos de campo (Figura 3.19). Estes autores interpretaram o arcabouço estrutural através de análise morfoestrutural, modelo digital de terreno, aeromagnetometria e sensoriamento remoto. Confirmaram em campo falhas oblíquas sinistrais $\mathrm{N} 50^{\circ}-60^{\circ} \mathrm{W}$, as quais têm características transtensionais, inclusive com algumas intrusões ígneas básicas ao longo da direção principal (Figura 3.20). Entre essas, destaca-se a intrusão de um dique de extensão quilométrica ao longo da Falha Rancho das Bicas-Barreirinho (Figura 3.19 e 3.20), com bloco baixo para nordeste Araujo et al. (2006). As falhas NE também foram confirmadas como sinistrais em duas direções preferenciais $\left(\mathrm{N} 20^{\circ} \mathrm{E}\right.$ e $\left.\mathrm{N} 50^{\circ} \mathrm{E}\right)$, por esses autores. Araújo (2003, p. 110) datou amostras de diabásio na parte noroeste da área de estudo, Porto Martins (figura 3.20), determinado a idade de $134 \pm 2$ Ma.

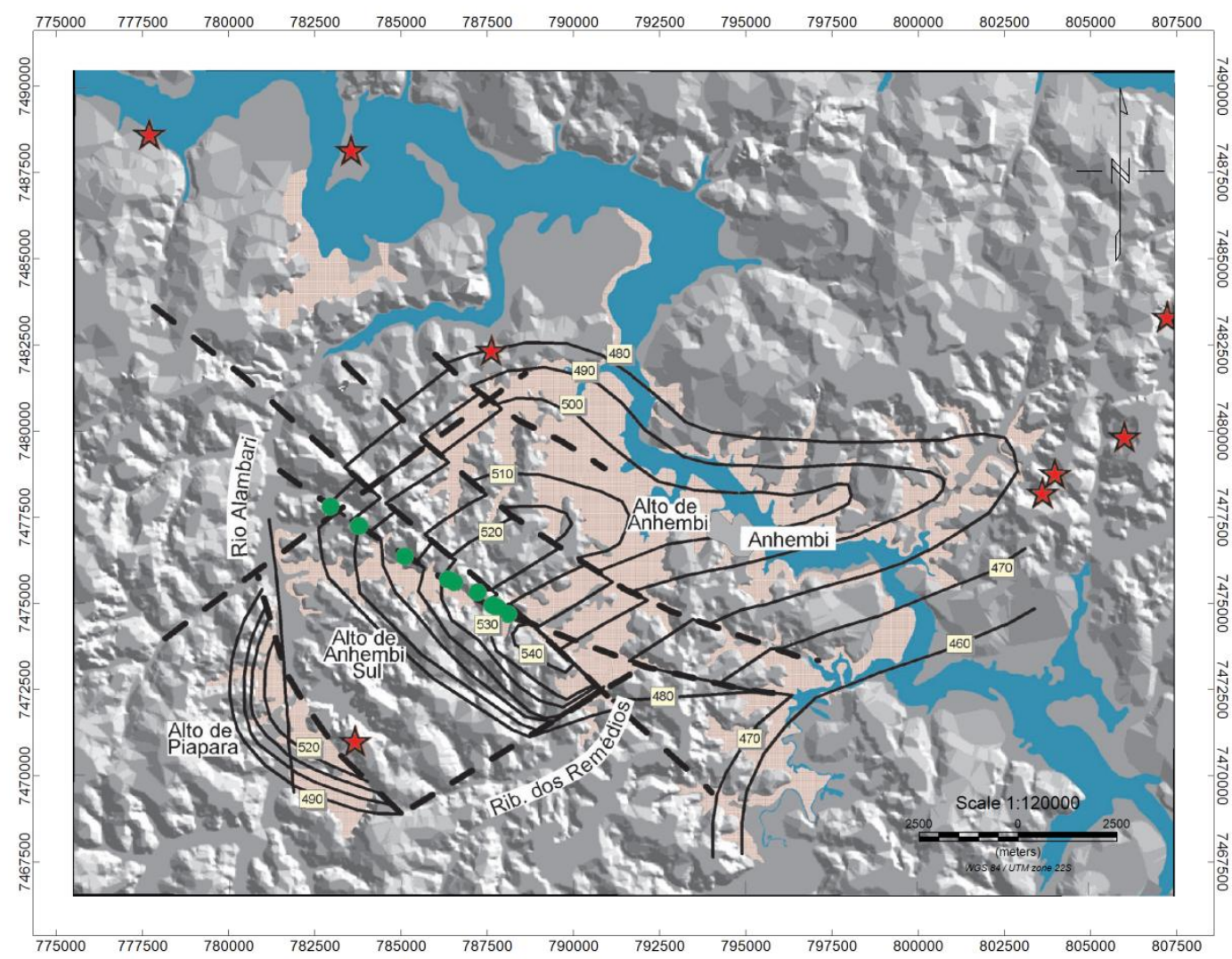

Figura 3.19 - Mapa de Contorno Estrutural da Formação Teresina na região do Alto de Anhembi sobre modelo numérico de terreno sombreado. As linhas contínuas indicam o contorno estrutural com valores em metros acima do nível do mar. A área de afloramento da Fm. Teresina está em rosa e a represa de Barra Bonita em azul. As estrelas vermelhas representam as ocorrências de arenito asfáltico e as linhas tracejadas são as principais falhas e lineamentos utilizados na interpretação do contorno estrutural. (modificado de Araújo et al., 2006, p. 55). 

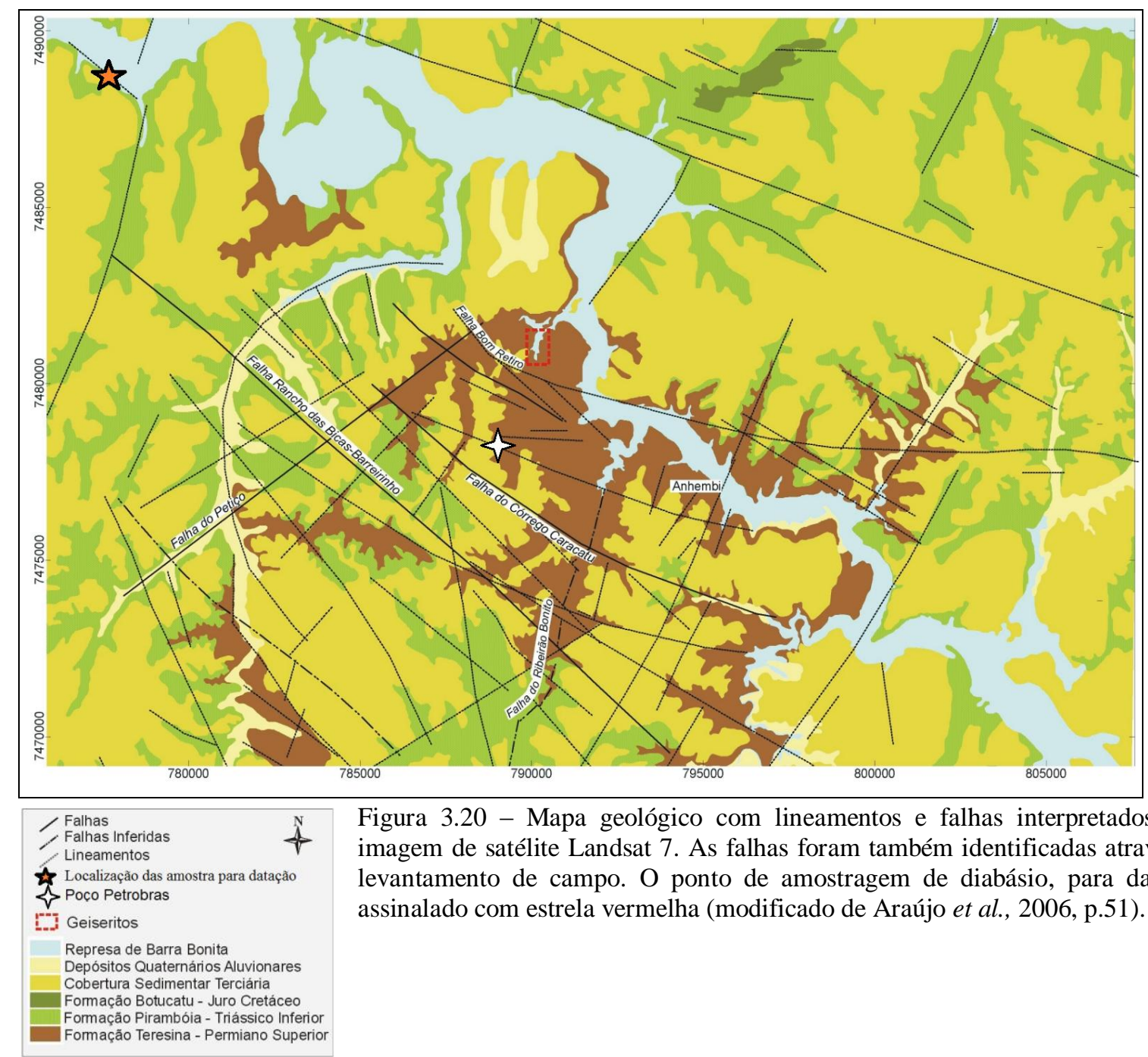

Figura 3.20 - Mapa geológico com lineamentos e falhas interpretados com imagem de satélite Landsat 7. As falhas foram também identificadas através de levantamento de campo. O ponto de amostragem de diabásio, para datação, assinalado com estrela vermelha (modificado de Araújo et al., 2006, p.51).

Com uma abordagem diferente das anteriores, IPT retornou à área de estudo e sugeriu a ambiência geológica como propícia à armazenagem de gás natural (IPT, 2005). Trabalhando de forma mais restrita ao alto estrutural e procurando determinar possíveis armadilhas, rochas reservatórios e selantes, mapeou as estruturas presentes na área (Figura 3.21). Descreve o Alto Estrutural de Anhembi como um alto regional ENE-WSW, de primeira grandeza, cortado por sistemas N30-50W e N20-30E, com padrão escalonado, constituindo-se por quadro altos de segunda ordem: Anhembi Norte, Anhembi Sul, Anhembi Leste e Piapara.

Segundo IPT (2005), os altos de Anhembi Leste e Anhembi Sul compreendem horts com direção N40W e NS a NNW, respectivamente, e eles são limitados pelas falhas do Rancho das Bicas e do Barreirinho em suas margens. O Alto de Piapara é caracterizado por um bloco basculado contra a falha de Piapara. O Alto de Anhembi Norte, descrito pelo IPT (2005), compreende ao sítio onde está locado o poço pioneiro exploratório 1-AB-1-SP da Petrobras, próximo à falha do Caracatu. 
IPT (2005) interpreta o Alto Estrutural de Anhembi como uma megadobra de arrasto, sendo associada a ela uma falha transpressional de direção N50-60E, tendo mergulho para SE. Constituído por sistemas escalonados, tipo dominó, devido à segmentação em altos menores, na direção N30-50W e N20-30E, principalmente, com característica transtrativa e megulho SW.

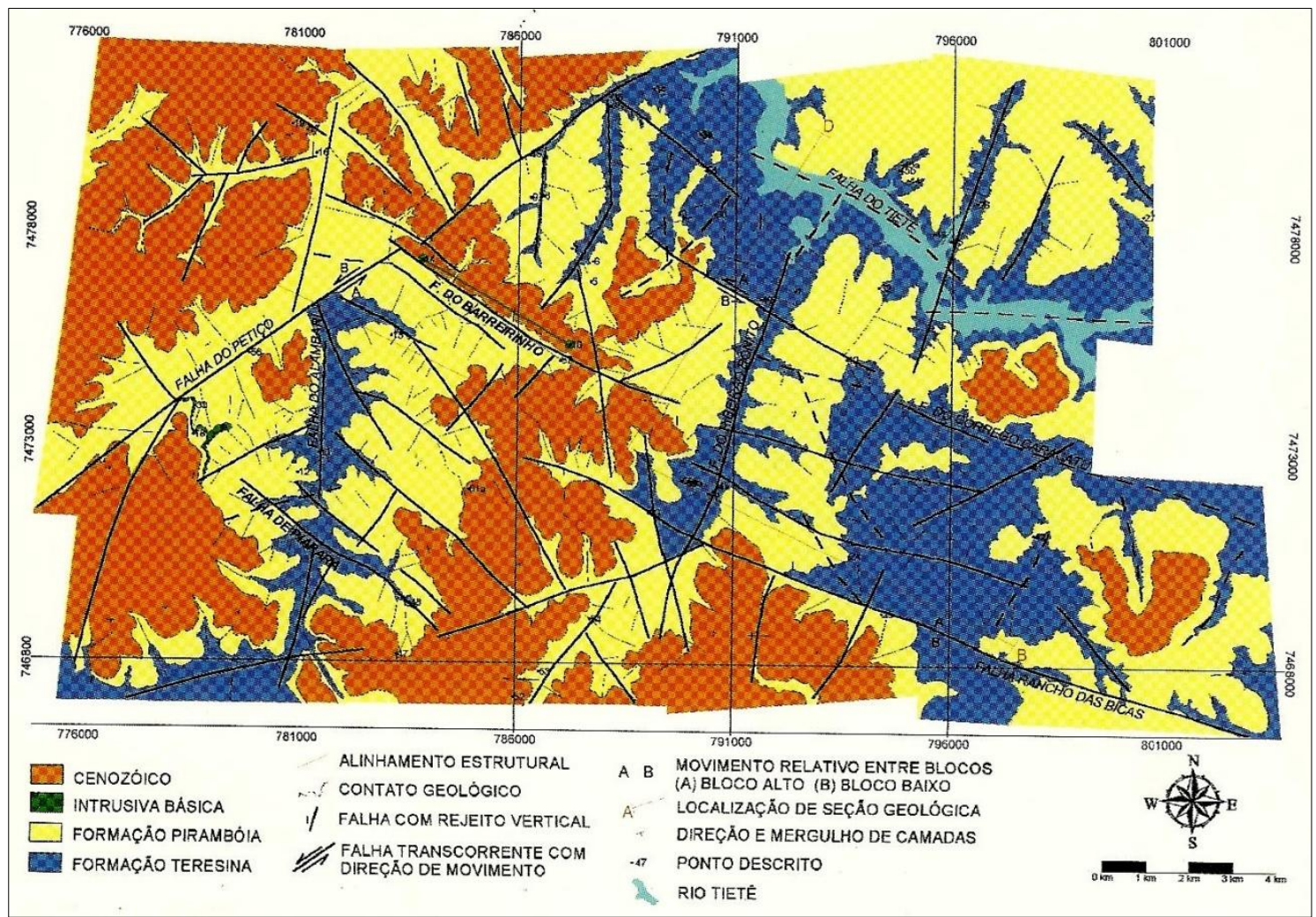

Figura 3.21 - Mapa geológico do Alto Eestrutural de Anhembi, segundo IPT (1979). Estão também representados lineamentos e falhas interpretadas e identificadas em campo (IPT, 2005, p. 166). 


\section{CAPÍTULO 4}

\section{FUNDAMENTAÇÃO TEÓRICA}

\section{1 - Método gravimétrico terrestre}

Gravidade é à força de atração entre massas. Em termos geofísicos, esta é a força devido à massa integrada de toda a Terra, que age sobre o mecanismo do instrumento de medição. Se a Terra fosse uma esfera prefeita e homogênea, o campo gravitacional apenas dependeria da distância do centro do planeta (Fowler, 2001, p.166). Porém, na prática, a Terra é um elipsóide ligeiramente irregular e abaulado. Isto significa que o campo gravitacional na superfície é mais forte nos polos do que no equador (Telford et al., 1990, p.10). A distribuição de massa (densidade) é também desigual, particularmente na crosta terrestre rígida. Esta particularidade causa a variação da gravidade de valores esperados, calculados com base em um esferóide de revolução, para valores anômalos conforme a posição da medição varia. Estas variações são expressas como anomalias gravimétricas (Fowler, 2001, p.167). O mapeamento destas feições nos fornece informações importantes da estrutura da Terra, porém, anomalias gravimétricas ocorrem somente quando existe contraste de densidades dentro da Terra e, desta forma, levantamentos gravimétricos são úteis apenas no caso em que a estrutura investigada envolve corpos de diferentes densidades (Luiz \& Silva, 1995, p.130).

Rochas sedimentares geralmente são menos densas que rochas ígneas e metamórficas (Telford et al., 1990, p.15). A ampla gama de densidades de rochas sedimentares é principalmente devida a variações em porosidade, sendo que a natureza dos fluidos, que preenchem os espaços porosos, também afeta o valor da densidade (Kearey \& Brooks, 2002, p. 247). De maneira geral, a densidade aumenta com a profundidade. O contraste de densidades entre formações sedimentares adjacentes em campo é raramente maior que 0,25 $\mathrm{g} / \mathrm{cm}^{3}$ em grandes e médias profundidades (Telford et al., 1990, p.17). Geralmente, rochas ígneas básicas são mais densas que as ácidas. 


\subsection{1 - Tratamento dos Dados}

O processamento de dados gravimétricos constitui-se em um conjunto de procedimentos (correções) aplicados aos dados com objetivo de inferir as estruturas geológicas de sub-superfície, eliminando as variações do campo gravitacional terrestre que não sejam devidas às diferenças de densidade no interior da Terra. Estes procedimentos são chamados de correções gravimétricas, sendo que os valores resultantes são denominados anomalias gravimétricas (Kearey \& Brooks, 2002, p. 241). A magnitude da gravidade depende de cinco fatores: latitude, elevação proximidades do ponto de medição, marés terrestres, e variação de densidades em sub-superfície. Estações com diferentes elevações são corrigidas em três etapas (Figura 4.1) (Kearey \& Brooks, 2002, p. 241):

1) Correção Ar livre - trabalha com a variação da distância da estação ao centro da terra.

2) Correção Bouguer - trata o efeito gravitacional das rochas entre a estação e o datum.

3) Correção do terreno - corrige os efeitos do relevo topográfico não plano nas vizinhanças da estação.

Como o interesse da prospecção gravimétrica são as anomalias relacionadas à variação de densidades em sub-superfície, todos os outros devem ser eliminados.

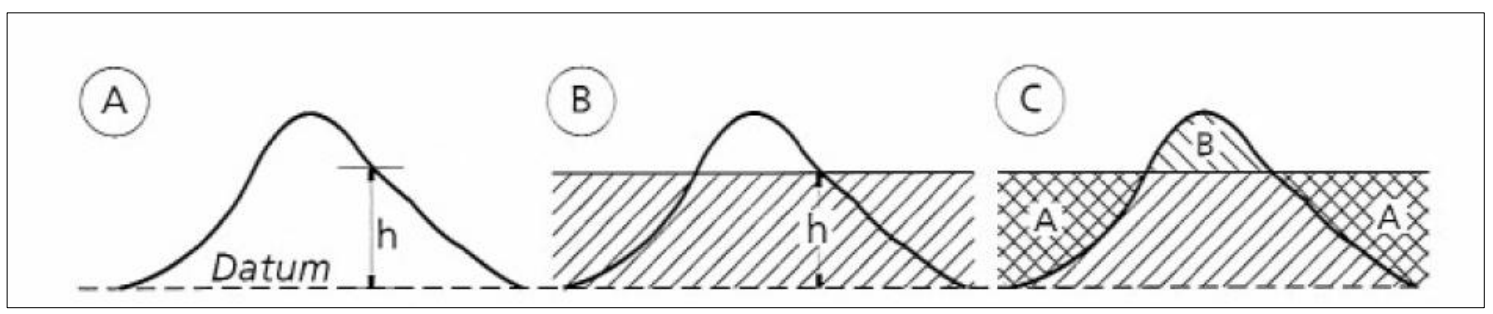

Figura 4.1 - Correções de elevação de numa determinada estação. A) Ar livre - estação localizada numa altura $h$ sobre o datum; B) Bouguer, sendo a área hachurada uma placa de rocha de espessura $h$ que se estende ao infinito lateralmente; C) Correção de terreno para um relevo não plano (Kearey \& Brooks, 2002, p. 243).

Principais fatores contribuintes a atração gravitacional.

$\mathrm{G}_{\mathrm{obs}}=\mathrm{LATITUDE}+$ ELEVAÇÃO + MARÉS + INTERFACE CROSTA MANTO + GEOLOGIA.

As principais correções utilizadas são: 


\subsubsection{1 - Correção de Marés}

Os instrumentos para medir a gravidade em prospecção geofísica são tão sensíveis que respondem à atração gravitacional do Sol e da Lua e registram as variações periódicas na atração causada por movimentos da Terra com respeito a esses corpos (Kearey \& Brooks, 2002, p. 245). O efeito decorrente destas forças é a deformação da crosta terrestre, causando alteração da elevação na estação em alguns centímetros, alterando, assim, sua distância ao centro da Terra (Kearey \& Brooks, 2002, p. 246). A Terra irá deformar-se de diferentes maneiras em diferentes locais, dependendo da elasticidade da crosta e do efeito da maré sobre os oceanos (Luiz \& Silva, 1995, p.137). A magnitude dessas alterações varia com a latitude, a hora do dia, o mês, o ano, mas o ciclo de marés completo é acompanhado pela variação na gravidade de aproximadamente de 0.2 a 0.3 mGal (Luiz \& Silva, 1995, p.137).

\subsubsection{2 - Gravidade Latitude}

Como mencionado anteriormente, esta correção relaciona a força centrífuga da Terra com o achatamento do esferóide. De acordo com a Geodétic Reference System 1967 (Telford et al., 1990, p.10), é dada pela fórmula:

$$
g_{\phi}=978.031846\left(1+0.005278895 \operatorname{sen}^{2} \phi-0.000023462 \operatorname{sen}^{4} \phi\right) \text {, }
$$

onde, $g$ é a gravidade em $\mathrm{mGal}$ e $\phi$ é a latitude em graus. A anomalia é obtida pela subtração entre o valor observado e o calculado.

$$
\Delta g_{\phi}=g_{o b s}-g_{\phi},
$$

sendo o valor de $g_{\text {obs }}$ aquele lido no gravímetro e corrigido dos efeitos de maré.

\subsubsection{3 - Correção Ar Livre}

Esta correção se destina a compensar os efeitos da variação de altitude das estações em relação a uma superfície equipotencial, geóide (Telford et al., 1990, p.11). Desta forma, os dados adquiridos são reduzidos a uma superfície de referência ou geóide que é coincidente com o nível médio dos mares. As altitudes utilizadas nesta correção são as ortométricas, 
normais à superfície do geóide. A anomalia gravitacional ar livre simples é calculada pelo uso da seguinte formula (Telford et al., 1990, p.11):

$$
g_{f a}=g_{o b s}-g_{\phi}+3.086 H \mu m s^{-2}
$$

onde: $g_{\text {obs }}$ é a gravidade observada;

$g_{\phi} \quad$ é a gravidade normal sobre o elipsóide à latitude estipulada;

$H$ é a altitude da medição acima do geóide.

\subsubsection{4 - Correção Bouguer}

A correção Bouguer considera o efeito de atração das massas existentes entre o gravímetro e o geóide (Telford et al., 1990, p.12), assumindo a crosta como uma placa de extensão lateral infinita (platô de Bouguer). É dada por:

$$
g_{B}=2 \pi G \rho h=0.1119 h,
$$

onde $\rho$ é a densidade do material crustal.

Quando a densidade é desconhecida, costuma-se utilizar o valor $\rho=2,67 \mathrm{~g} / \mathrm{cm}^{3}$ (Hinze, 2003), obtendo-se a relação acima, $\operatorname{com} h$ dado em metros e a correção em mGal.

\subsubsection{5 - Correção do terreno}

A correção de terreno é aplicada às irregularidades da superfície terrestre nas vizinhanças do ponto de medida. Montanhas acima do nível do ponto de medida exercem uma atração ascendente sobre o gravímetro, enquanto vales exercem o efeito oposto sobre as medições. Existem diversos métodos para o cálculo da correção de terreno, todos os quais exigem um conhecimento detalhado do relevo nas proximidades de cada ponto de medição, conhecimento esse provido pelo modelo digital do terreno ou mapas topográficos precisos (Kearey \& Brooks, 2002, p. 244). O procedimento mais conhecido para a correção de terreno é a divisão da área em compartimentos cuja elevação média é comparada com a elevação do ponto de medição. Isto pode ser efetuado atualmente por meio computacional (Geosoft, 2006, p. 39). O formato mais comum utilizado para estes compartimentos é usando círculos concêntricos e linhas radiais definindo setores cujas áreas aumentam com a distância ao ponto 
de medição (Figura 4.2). Para este caso, o efeito gravitacional de um único setor é calculado pela seguinte equação (Telford et al., 1990, p. 13):

$$
\partial g_{T}(r, \theta)=G \rho \theta\left\{\left(r_{0}-r_{i}\right)+\left(r_{i}^{2}+\Delta z^{2}\right)^{\frac{1}{2}}-\left(r_{0}^{2}+\Delta z^{2}\right)^{\frac{1}{2}}\right\}
$$

onde $G$ é a constante gravitacional, $\rho$ é a densidade do material, $\theta$ é o ângulo de abertura do setor em radianos, $\Delta z=\left|z_{s}-z_{a}\right|$, sendo que $z_{s}$ é a elevação da estação e $z_{a}$ é a elevação média do setor, $r_{0}$ e $r_{i}$ são os raios interno e externo do setor.

A correção de terreno $\Delta g_{T}$ é a soma da contribuição de todos os setores (Telford et al., 1990, p. 13):

$$
\Delta g_{T}=\sum_{r} \sum_{\theta} \partial g_{T}(r, \theta)
$$

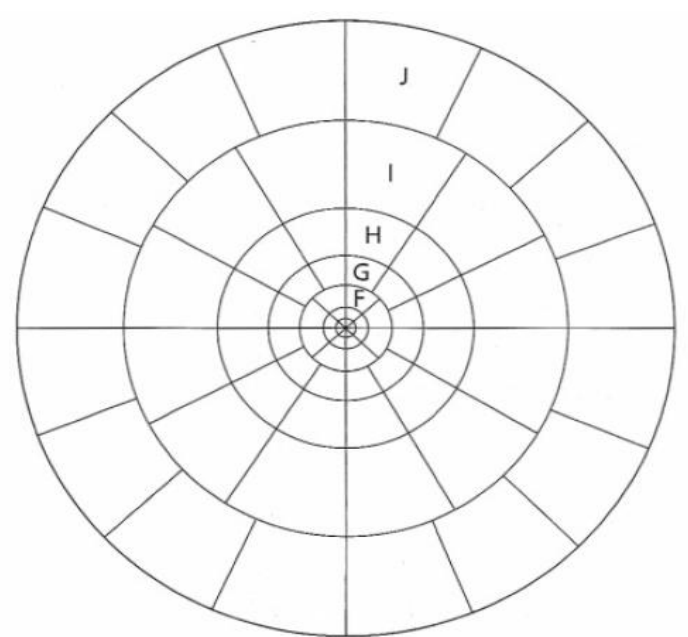

Figura 4.2 - Gradícula típica usada para o cálculo de correção de terreno (Kearey \& Brooks, 2002, p. 244). 


\section{2 - Método Magnetométrico Terrestre}

A prospecção magnética dos diversos ambientes geológicos da superfície da Terra baseia-se na medida do Campo Magnético Terrestre. Esse campo potencial tem origem no núcleo do planeta e pode ser considerado, numa primeira aproximação, como sendo dipolar (Telford et al., 1990, p. 131). No entanto, quando fazemos medidas, percebemos que existem alguns distúrbios neste campo, tratados na geofísica como anomalias magnéticas. A origem dessas anomalias está relacionada à presença de minerais magnéticos na crosta terrestre e, portanto, ao arcabouço geológico de interesse exploratório. Esses minerais correspondem a um pequeno número de óxidos de ferro e titânio, sendo mais comum a magnetita (Telford et al., 1990, p. 127). A presença desses minerais nas rochas está associada aos ambientes em que elas foram geradas e aos processos que sofreram durante a evolução geológica. Mapeando-se, portanto, a distribuição desses minerais na superfície terrestre, é possível inferir sobre as características litológicas e estruturais de uma determinada região (Luiz \& Silva, 1995, p.270).

$\mathrm{Na}$ exploração mineral, os minérios encontram-se associados a diversos corpos e estruturas geológicas com assinaturas magnéticas bastante peculiares. Como exemplo pode-se citar as formações ferríferas bandadas que apresentam comumente forte magnetização remanescente (Gunn et al., 1998). Já na exploração de petróleo, a magnetometria é aplicada nas primeiras etapas de análise da bacia sedimentar com o objetivo de reconhecer as dimensões, profundidades, estruturas e intrusões. As rochas sedimentares apresentam geralmente baixa suscetibilidade magnética, no entanto as rochas do embasamento cristalino e de possíveis intrusões possuem maior quantidade de minerais magnéticos e, dessa forma, constituem as fontes das principais respostas magnéticas (Luiz \& Silva, 1995, p.269).

\subsection{1 - Tratamento dos Dados}

$\mathrm{Na}$ etapa do pré-processamento, são feitas correções e filtragens para eliminar os efeitos das interferências causadas por fontes não geológicas. Um dos procedimentos mais importantes é a retirada do campo de origem profunda com a utilização de um modelo matemático, normalmente o International Geomagnetic Reference Field (IGRF). Após esta correção, o campo resultante representa anomalias de fontes crustais, situadas acima da superfície de Curie (Kearey \& Brooks, 2002, p.291). 


\subsubsection{1 - Variação diurna}

A variação diurna é de ordem de 20 a 60 nT, num período de 24 horas em dias nornais, sendo caracterizada por altas frequências, e sua fonte está relacionada com correntes elétricas na ionosfera que são controlada pela atividade solar (Figura 4.3a) (Lowrie, 2007, p. $307)$.

A variação diurna afeta diretamente os levantamentos geofísicos. Deve-se reconhecer esta variação para que se possa removê-la antes da interpretação (Lowrie, 2007, p. 307).

Esta variação é caracterizada por ocorrer em pulsos de curto período de tempo da ordem de dezenas de minutos e por ter grandes amplitudes acima de 1000 nT (Figura 4.3b). A fonte desta variação está relacionada à atividade explosiva na superfície do sol. As atividades mais intensas podem ser observadas em todo o globo, podendo perdurar por muitos dias. Levantamentos magnéticos que visam à exploração não devem ser efetuados nestes períodos, pois podem produzir anomalias inexistentes (Lowrie, 2007, p. 307).
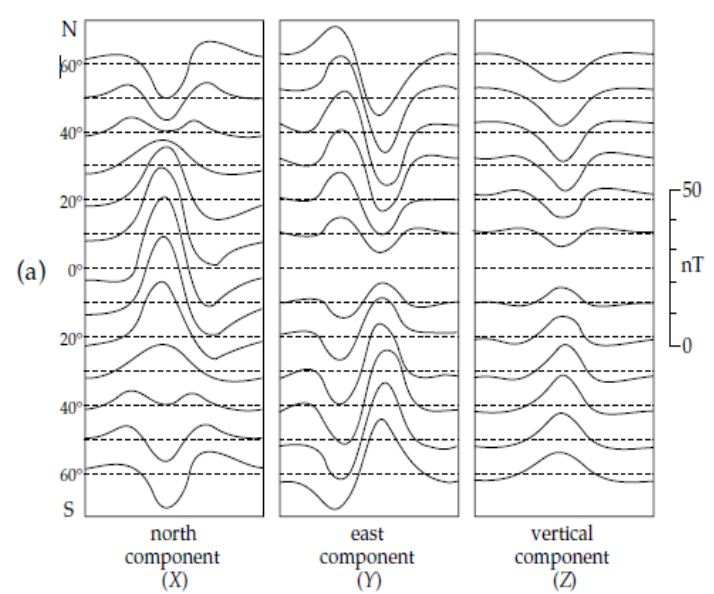
intensity Macquarie observatory 16.2 .1958

(b)

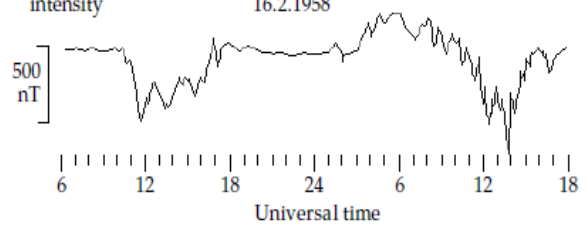

Figura 4.3 - (a) Intensidade do campo geomagnético flutuando num intervalo de amplitude de 10-30 nT em período de um dia, apresentados em varias latitudes, e (b) Variação da intensidade do campo horizontal durante uma tempestade magnética (Lowrie, 2007, p. 308). 


\section{3 - Medições das propriedades físicas das rochas}

\subsection{1 - Densidade de massa}

Foi utilizado para este procedimento o método da Balança Hidrostática (http://lqes.iqm.unicamp.br/images/vivencia_lqes_meprotec_densidade_arquimedes.pdf, acessado em maio de 2012). Este procedimento visa a uma estimativa, do ponto de vista petrofísico, dos limites de contraste de densidades das interfaces dos diferentes tipos de rochas presentes na área de estudo. Estes valores de densidades são parâmetros importantes na construção de modelos geofísicos estruturais. As amostras de rochas levadas ao laboratório são pesadas no ar e na água. A densidade pode ser estimada por meio da expressão (conforme referência acima):

$$
\rho=\frac{P_{a r}}{P_{a r}-P_{a g}}
$$

onde $P_{a r}$ e $P_{a g}$ representam o peso da amostra no ar e na água.

Esta forma de cálculo dá bons resultados para rochas ígneas e metamórficas inalteradas. Porém para rochas sedimentares, com elevada porosidade, em que a densidade não depende só dos constituintes minerais, como também da quantidade de água presentes nos poros, utilizou-se a expressão (conforme referência mencionada anteriormente):

$$
\rho=\frac{P_{s}}{\left(P_{p a r}-P_{p_{H_{2} O}}\right)-\left(\left(\left(P_{p a r}-P_{a g}\right) / x\right)\right)}
$$

Onde:

$\rho=$ densidade na base seca $\left(\mathrm{g} / \mathrm{cm}^{3}\right) ;$

$P_{\mathrm{s}}=$ peso da amostra seca na estufa $(\mathrm{g})$;

$P_{p a r}=$ peso da amostra parafinada $(\mathrm{g})$;

$P_{p_{H_{2} \mathrm{O}}}=$ peso da amostra parafinada imersa na água $(\mathrm{g})$;

$x=$ Fator de correção do peso da parafina contida no sistema $\left(1-\left(\left(P_{p a r}-P_{s}\right) / P_{p a r}\right)\right)$.

Determina-se o peso das amostras in natura, em seguida elas são secadas numa estufa elétrica, ajustada para temperaturas variáveis na faixa de 100 a $120^{\circ} \mathrm{C}$, por um período de 10 horas. Retiradas da secagem, as amostras são imersas em parafina derretida e pesadas novamente, obtendo o $P_{\text {par }}$. A amostra parafinada é acondicionada num dispositivo de maneira que fique totalmente submersa em água e, ao mesmo tempo, não toque nas paredes 
do vasilhame que contém o volume de água (Figura 4.4 - A e B). O peso da amostra parafinada submersa é $P_{p_{H_{2}} \mathrm{O}}$.

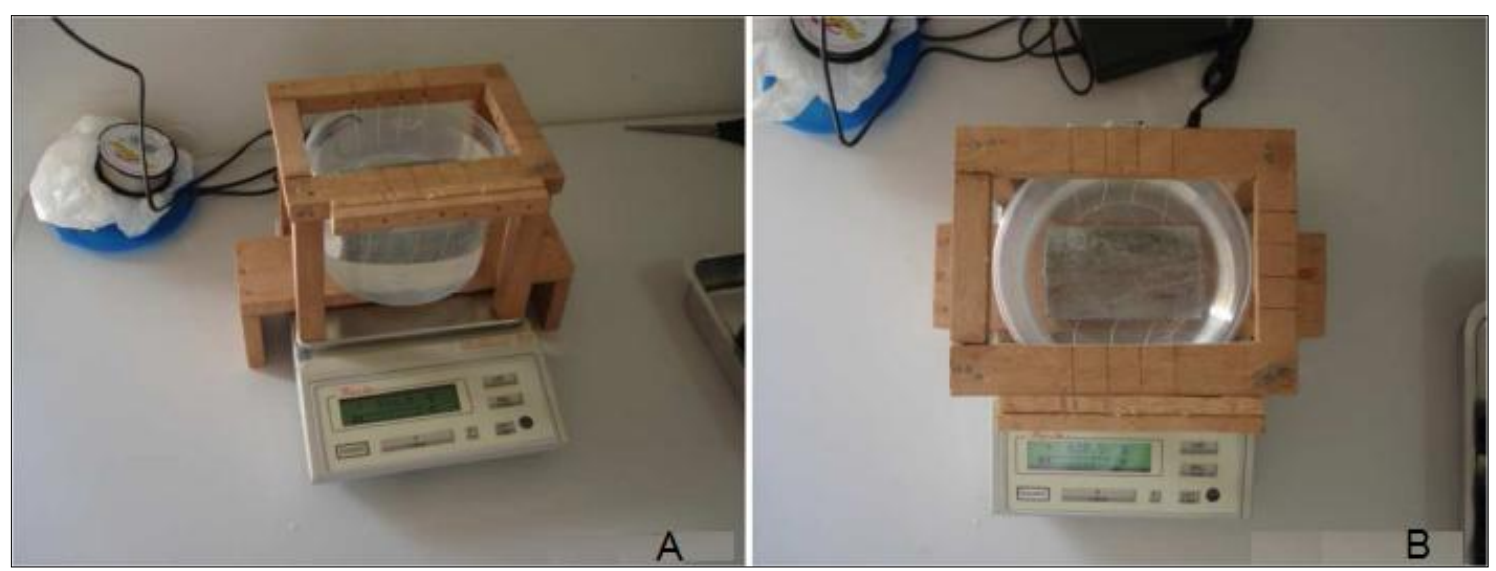

Figura 4.4 - Dispositivo para se medir a massa, por imersão, das amostras coletadas.

\subsection{2 - Medidas de Susceptibilidade Magnética e de Magnetização} Remanescente Natural (MRN).

Neste trabalho, foram medidas a susceptibilidade magnética e a magnetização remanescente natural - MRN das amostras de diabásio coletadas em campo. A coleta foi efetuada com o auxílio de uma perfuratriz portátil movida à gasolina. As amostras foram coletadas em 3 sítios, sendo que somente um estava em in situ e, portanto neste caso, as amostras foram orientadas, visando a obtenção da direção da MRN. A orientação das amostras foi feita com bússolas magnética e solar. Dessa forma, foram extraídos cilindros com $2.5 \mathrm{~cm}$ de diâmetro. Estes cilindros foram cortados em espécimes de $2.2 \mathrm{~cm}$ de altura (Figura 4.5) e colocados em equipamentos específicos: medidor de susceptibilidade magnética Kappabridge KLY-4S (Guide, 2004) e magnetômetro do tipo Spinner e JR6 (Manual, 2004) para as medidas da MRN (ambos da Agico, República Tcheca). As medidas foram realizadas no Laboratório de Anisotropia Magnética e de Magnetismo de Rocha do Instituto de Geociências da Universidade de São Paulo. Um total de 15 espécimens foram medidos para suscetibilidade magnética e 7 espécimens para obtenção para MRN. Estas medidas foram utilizadas no cálculo da razão de Königsberger e na aplicação da redução ao polo. 


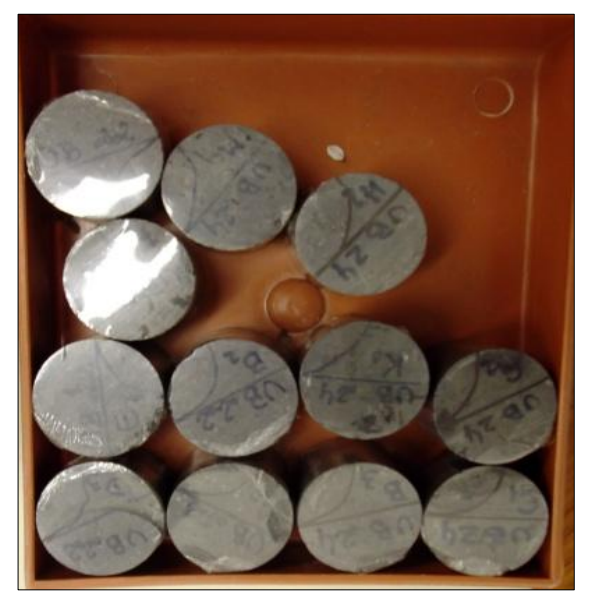

Figura 4.5 - Espécimes identificados e orientados, prontos para serem medidas.

As direções médias foram calculadas utilizando a estatística de Fisher (Butler, 1992, p. 136), que considera todos os $N$ vetores de intensidade igual a um e a média das direções $\vec{S}$

igual à soma vetorial $\vec{R}$ de todos os $N$ vetores dividido pela sua intensidade $R(\vec{S}=\vec{R} / R)$. Este procedimento sugere estatísticas para definir o agrupamento dos pontos e a confiabilidade da direção média obtida. O parâmetro de precisão $k$ define a dispersão das direções sobre uma esfera de raio unitário. A estatística $k$ (para $N>3$ ) é dada pela equação $k=(N-1 / N-R)$ (Butler, 1992, p. 139). As direções estarão agrupadas se $N$ estiver próximo de $R$, para valores altos de $k$. Se a dispersão for muito grande, $R$ será muito menor que $N$, então o parâmetro $k$ será baixo. O outro parâmetro levado em consideração é ângulo $\alpha_{95} \cong 140^{\circ} / \sqrt{k N}$ (Butler, 1992, p. 138), que representa duas vezes o desvio padrão da média numa projeção esférica. O procedimento utilizado para a soma vetorial da magnetização induzida com a remanescente é descrita por Butler (1992. p. 138).

\subsection{3 - Razão de Königsberger}

A magnetização existente nas rochas é consequência da presença na sua composição de minerais magnéticos (Kearey \& Brooks, 2002, p. 277). Esta magnetização é a soma vetorial da componente magnetização induzida $\left(J_{\mathrm{i}}\right)$, produzida pelo campo magnético atual, 
com a remanescente natural $\left(J_{\mathrm{r}}\right)$, incorporada pela rocha através de sua história geológica (Kearey \& Brooks, 2002, p. 279), ou seja, $J=J_{i}+J_{\mathrm{r}}$ (Figura 4.6).

No Brasil, a intensidade do campo magnético é menor em relação a outras regiões do planeta (Cordani \& Shukowski, 2009) devido à Anomalia do Atlântico Sul (Hartmann \& Pacca, 2009), dando à remanescente natural maior importância em relação à magnetização induzida. Desta forma, em interpretação magnética é importante a estimativa da remanescente natural para que a resposta teórica seja compatível com a anomalia observada. Esta estimativa é de muita importância às técnicas de Redução ao Polo e Sinal Analítico (Cordani \& Shukowski, 2009). Estas técnicas têm como característica simplificar a interpretação das anomalias magnéticas, pois as centralizam em relação às fontes (Baranov, 1957 e Nabighian, 1972, 1984).

As intensidades das magnetizações induzidas e remanescentes podem ser expressas em termos da razão de Königsberger $\left(Q=J_{r} / J_{i}\right)$. Estas intensidades podem ter diferentes direções e magnitudes. A orientação de $J$ influencia a forma da anomalia magnética e a sua magnitude e amplitude (Kearey \& Brooks, 2002, p. 279).

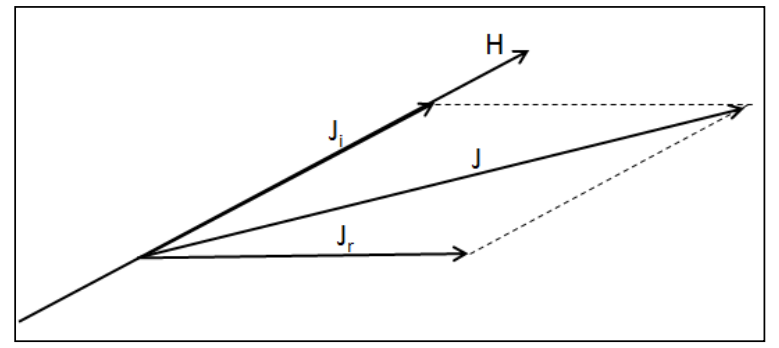

Figura 4.6 - Soma vetorial mostrando as relações de magnetização induzida $\left(J_{i}\right)$, remanescente $\left(J_{r}\right)$ e total $(J)$ (Kearey \& Brooks, 2002, p. 279). 


\section{4 - Transformações lineares dos dados geofísicos}

\subsection{1 - Introdução}

A principal aplicação dos métodos potenciais em geofísica é a interpretação das anomalias gravimétricas e magnéticas em termos de estrutura geológica em sub-superfície (Luiz \& Silva, 1995, p. 115 e 204). Em especial, na interpretação procura-se determinar os parâmetros dos corpos causadores das anomalias, quais sejam suas formas, localização, densidade e/ou susceptibilidade (Luiz \& Silva, 1995, p. 115 e 204).

As transformações dos potenciais gravimétrico e magnético são atualmente importantes ferramentas auxiliares de interpretação, pois permitem examinar os dados existentes sob diferentes aspectos que realçam as feições diretamente associadas aos corpos causadores, facilitando a elaboração e a verificação de modelos estruturais (Paterson \& Reeves, 1985). A aplicação de transformações funcionais a campos potenciais geofísicos teve início com os trabalhos de Bateman (1946), nos quais foi mostrada a possibilidade de continuação analítica de potenciais. A aplicação prática da continuação analítica a medidas magnéticas foi apresentada por Peters (1949). Os trabalhos de Henderson \& Zietz (1949), Elkins (1951) e Rosenbach (1953) estabeleceram o uso da derivada vertical segunda em interpretações gravimétrica e magnética. Baranov (1957) introduziu a transformação do potencial gravimétrico equivalente, de acordo com o teorema de Poisson. Bhattacharyya (1965) apresentou um novo formalismo para o cálculo de transformações de potenciais em termos de série de Fourier, que permite não só o cálculo das transformações da continuação analítica e de derivadas verticais de qualquer ordem, como também a redução ao polo de anomalias magnéticas.

O desenvolvimento do algoritmo da transformada rápida de Fourier (FFT) (Cooley \& Tuckey, 1965) deu novo impulso ao estudo de transformações de potenciais no domínio da frequência. Gunn (1974) publicou um estudo compreensivo de transformações utilizando a técnica da transformada de Fourier e seguida Baranov (1975) dá um tratamento rigoroso e sistemático das transformações de potenciais.

Este desenvolvimento permitiu a criação de um leque de técnicas que auxiliam na interpretação dos dados, como, por exemplo, a análise de espectro de potência que separa e caracteriza as fontes rasas das profundas, estimando as profundidades destas, podendo também ser usada para a separação regional/residual e a eliminação, ou atenuação de ruídos de alta frequência. Outras técnicas que podem ser utilizadas são: deconvolução de Euler, Sinal 
Analítico - SA, análise espectral (filtragens passa-alta, passa baixa, passa-banda), continuação para cima, derivadas, redução ao polo - RTP - entre outras. Uma interpretação quantitativa também pode ser realizada através de modelagem, técnica esta que envolve estimativas das propriedades físicas de susceptibilidades e densidades das rochas.

\subsection{2 - Filtros utilizados}

\subsubsection{1 - Espectro de Potência Ponderado Radialmente}

O espectro de potência ponderado radialmente, ou simplesmente espectro de energia, de uma função $[\mathrm{f}(\mathrm{x})],|\mathrm{F}(\mathrm{k})|^{2}$, pode ser expresso na equação de energia total:

$E=\int_{-\infty}^{\infty}|F(k)|^{2} d k$, onde $k=2 \pi / \lambda$ é o número de onda (proporcional à frequência) e $\lambda$ é o comprimento de onda (Blakely, 1996, p.261). Pode-se expandir esta função para duas variáveis $\left(x\right.$ e $y$ ) e os termos $k$ e $\lambda$ representados por $k_{x}, k_{y}, \lambda_{x}$ e $\lambda_{y}$, respectivamente (Blakely, 1996, p.261).

A profundidade das fontes anômalas pode ser estimada, utilizando o espectro de energia com a eguinte expressão (Spector \& Grant, 1970):

$$
h=-s / 4 \pi
$$

sendo $s$ a declividade numa parte específica do espectro.

A Figura 4.7 representa de um espectro de energia típico (Geosoft, 2009, p. 44), onde se pode dividir e aproximá-lo por segmentos de retas. Número de onda baixo considera-se como representação de fontes mais profundas, enquanto em números de ondas mais elevados refletem o ruído nos dados e os intermediários fontes mais rasas (Spector \& Grant, 1970). Os valores da função situados após o número de onda de Nyquist apresentam falseamento (aliasing) (Kearey \& Brooks, 2002, p. 34, Geosoft, 2009. p. 45), isto é, incorporam frequências altas sem resolução nas frequências baixas, assim, não podendo ser detectadas se seus comprimentos de onda forem menores que o dobro do espaçamento entre pontos amostrados (Kearey \& Brooks, 2002, p. 34). Estes valores devem ser eliminados, pois representam ruído. 


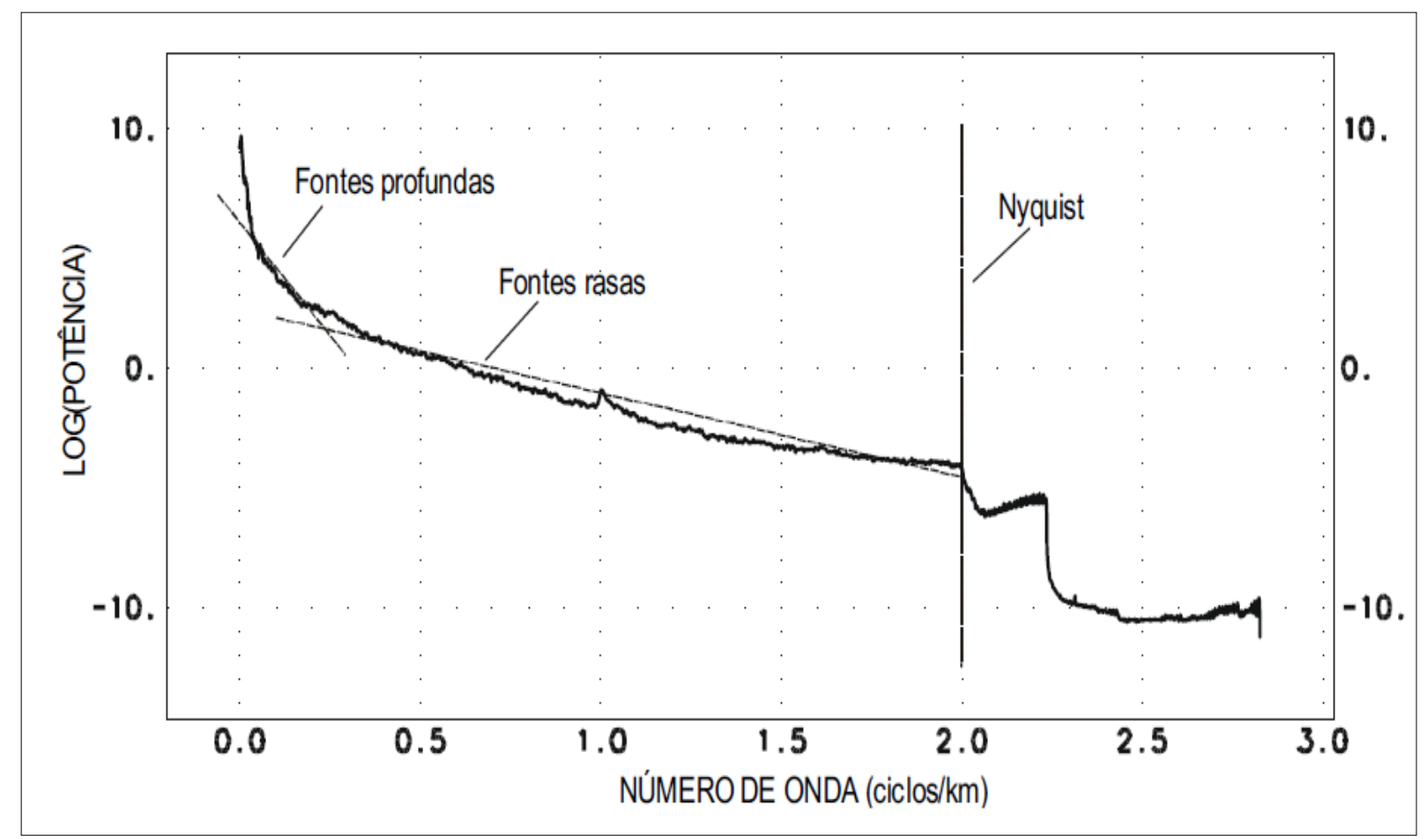

Figura 4.7 - Exemplo de espectro de energia (Geosoft, 2009. p.44).

\subsubsection{2 - Filtro Passa-Banda}

O filtro passa-banda é usado para selecionar intervalos de números de onda (Figura 4.8), porém, na aplicação desse filtro pode-se gerar ringing (fenômeno de Gibbs) (Geosoft, 2009. p.49). O operador possui a seguinte forma (Geosoft, 2009. p.56):

$\mathrm{L}(k)=0$, para $k<k_{I}$

$\mathrm{L}(k)=\mathrm{L}(k)$, para $k>=k_{l}$

onde, $k_{0}$ é o menor número de onda para o corte e $k_{l}$ o maior número de onda para o corte.

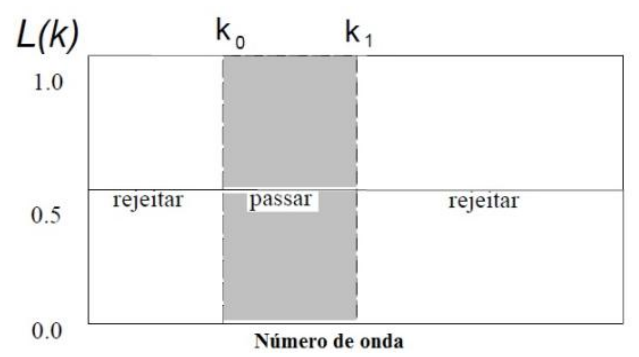

Figura 4.8 - Representação gráfica do filtro Passa-Banda (modificado de Geosoft, 2009. p.56). 


\subsubsection{3 - Filtro Co-seno Direcional}

Este operador matemático é utilizado para passar/remover feições direcionais de um grid (Figura 4.9). A função cosseno torna este operador suave de tal forma que o efeito de ringing (fenômeno de Gibbs) não cause problemas (Geosoft, 2009. p 60). O operador possui duas formas (Geosoft, 2009. p.60):

$L(\theta)=\left|\cos ^{n}(\alpha-\theta+\pi / 2)\right| \rightarrow$ direção $\alpha$ rejeitada

$L(\theta)=1-\left|\cos ^{n}(\alpha-\theta+\pi / 2)\right| \rightarrow$ direção $\alpha$ que passou

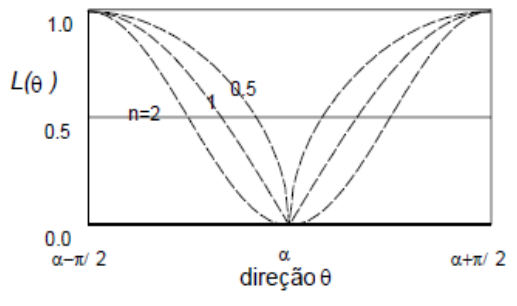

Figura 4.9 - Representação gráfica do filtro Cosseno Direcional (Geosoft, 2009. p.60).

onde, $\alpha$ é a direção do operador, em graus (em relação ao norte), $n$ é o grau da função co-seno (padrão é 2) e $\theta$ é a direção do número de ondas.

\subsubsection{4 - Filtro Butterworth}

Este operador possui desempenho muito bom quando aplicado como passa-alta ou passa-baixa, pois pode-se controlar o pendente do rolamento, fixando, apenas, $k$ central (Figura 4.10). O fenômeno de Gibbs, se houver, pode ser controlado pelo grau do operador, normalmente reduzindo seu valor (Geosoft, 2009, p. 57). O operador tem a seguinte forma (Geosoft, 2009, p. 57):

$$
L(k)=\frac{1}{\left[1+k / k_{c}\right]^{2}}
$$

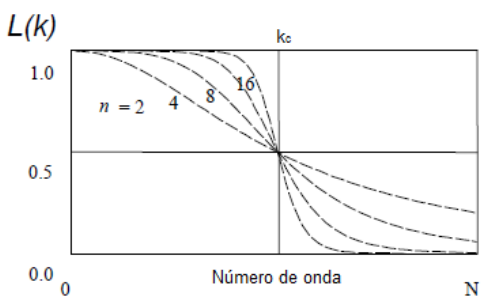

Figura 4.10 - Representação gráfica do filtro Butterworth. (Geosoft, 2009. p.57).

onde $k_{c}$ é o número de onda central do operador e no grau da função do operador. 


\subsubsection{5 - Filtro Derivada Vertical}

Comprimentos de ondas curtos (fontes rasas) são ampliados e o processo é inverso em relação aos comprimentos longos, sendo, assim, um filtro passa-alta. De uma forma geral, este filtro acentua os gradientes nas bordas de corpos rasos (Geosoft, 2009, p. 63).

$$
\begin{aligned}
L(r)=r^{n}, \text { onde } r & =\text { número de onda }(\mathrm{rad} / \mathrm{metro}) \text { e } n=\mathrm{a} \text { ordem da } \\
& \text { diferenciação. }
\end{aligned}
$$

\subsection{3 - Continuação para cima}

Atua como um filtro de limpeza, semelhante ao filtro passa-alta com a vantagem de não produzir grandes efeitos laterais não necessitando de processo para corrigi-lo (Figura 4.11). É muito utilizado para remover ou minimizar ruídos e efeitos de fontes rasas em grids (Geosoft, 2009. p.59).

$$
\begin{aligned}
& L(r)=e^{-h r}, \text { onde, } \\
& h \text { é a altura, em metros, para aplicação filtro } \\
& \text { em relação ao ponto de medida; } \\
& r \text { é o número de onda, rad/metros. }
\end{aligned}
$$

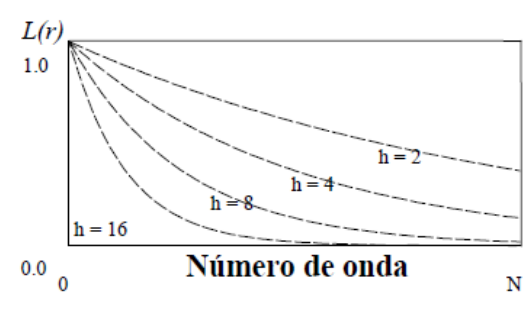

Figura 4.11 - Representação gráfica do filtro Continuação para Cima (Geosoft, 2009. p.59).

\subsection{4 - Redução ao Polo}

A direção e a inclinação do campo magnético variam ao longo da superfície da Terra por causa da característica dipolar do mesmo, produzindo diferentes padrões em relação à variação da latitude. É um complicador ao processamento e análise dos dados, porém este problema pode ser contornado aplicando um artifício matemático, operador redução ao polo (Baranov, 1957), que transforma os dados de qualquer latitude para uma latitude cuja inclinação é $90^{\circ}$. Isto implica que a magnetização induzida tenha direção vertical, análoga ao campo gravitacional (Luiz \& Silva, 1995, p.249). O operador redução ao polo é aplicado ao Campo Magnético anômalo utilizando algoritmo de Philips (2007), no domínio da frequência 
com coordenadas polares, levando em consideração apenas magnetização induzida $\left(M_{\mathrm{i}}\right)$ e é dada pela seguinte equação, em coordenadas polares (Li, 2008):

$$
L(\theta)=\frac{1}{\left[\sin \left(I_{a}\right)+i * \cos (I) * \cos (D-\theta)\right]^{2}} \text {, se }(|I a|<|I|) \text { então } I a=I
$$

Onde $I$ é a inclinação magnética, $D$ é a declinação magnética e $I a$, a inclinação para correção de amplitude que nunca deve ser menor que $I$ e $\theta$. O uso deste operador é desaconselhável a baixas latitudes magnéticas, pois nestas latitudes são observadas fortes feições na direção do campo magnético. Isto ocorre devido à correção de amplitude (Li, 2008). Como este operador só se utiliza da magnetização induzida $\left(J_{i}\right)$, uma alternativa é a utilização da direção da magnetização total $(J)$. Como há normalmente a presença de magnetização remanescente $\left(J_{r}\right)$ e esta, tendo uma intensidade forte, pode afetar a interpretação dos dados magnéticos e gerar erros na detecção da forma ou tamanho das fontes (Kearey \& Brooks, 2002, p. 279), é importante conhecer a direção da magnetização total. Para estimar a direção da magnetização total foram realizadas medidas em laboratório da direção da magnetização remanescente de amostras orientadas da região de estudo. Também formam feitas medidas de susceptibilidade magnética para melhor caracterização magnética dos dados coletados.

\subsection{5 - Sinal Analítico}

A amplitude sinal analítico (ASA) é considerado uma boa ferramenta para a localização das bordas de corpos que possuem contraste magnético, trazendo informações relevantes sobre a sua geometria (Nabighian, 1972). Para anomalias do campo potencial em 2D e 3D, os gradientes horizontal e vertical geralmente formam um par de sinais analíticos, posicionando os valores máximos do sinal analítico resultante sobre os limites dos corpos ou estruturas geológicas (Nabighian, 1984). Um exemplo pode visto na Figura 4.12, onde está representado um prisma com seu sinal analítico em três diferentes profundidades, crescente da esquerda para a direita. Pode-se observar o principal atributo do ASA: máximos nas bordas e mínimos relativos nos centros do corpo (Ferreira et al., 2010).

Podemos definir uma estimativa para o mergulho das fontes anômalas e também para o contraste da susceptibilidade magnética, utilizando a fase do sinal analítico. Este 
procedimento foi utilizado por Thurston e Smith (1997), em uma extensão da teoria do sinal analítico complexo (Nabighian, 1972).

Há vários métodos de realces na literatura com o objetivo de delinear os limites das fontes das anomalias para facilitar a interpretação. Neste trabalho é utilizada a técnica denominada Inclinação do Sinal Analítico - ISA (Miller \& Singh, 1994). Este método é representado na Figura 4.13.

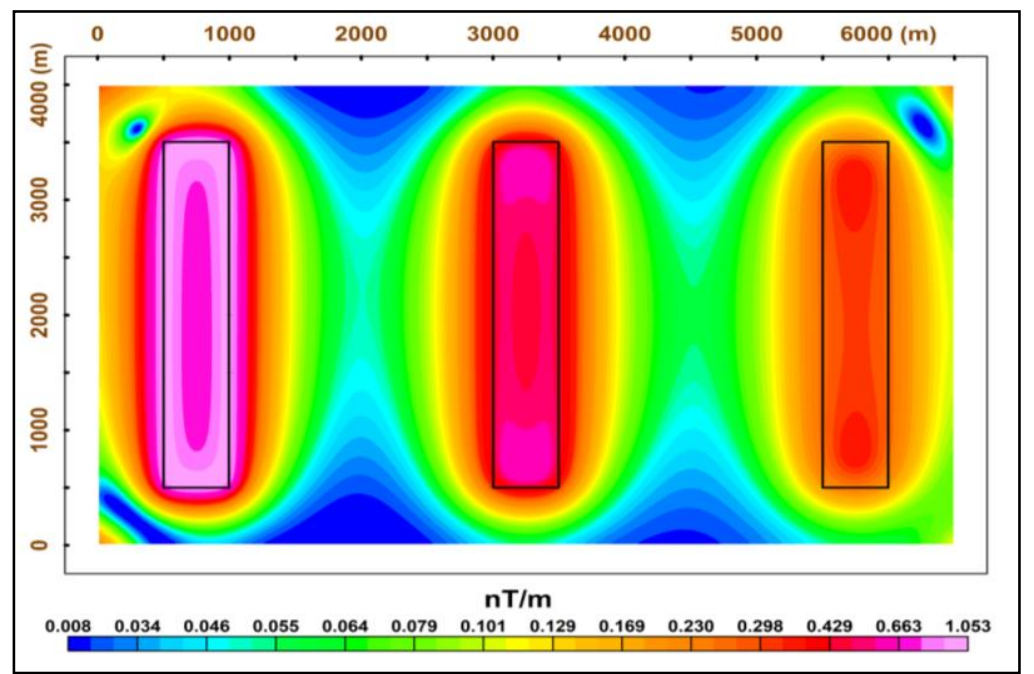

Figura 4.12 - Exemplo do principal atributo de ASA: máximos nas bordas e mínimos relativos nos centros dos corpos, representado por um prisma em profundidades diferentes (Ferreira et al., 2010).

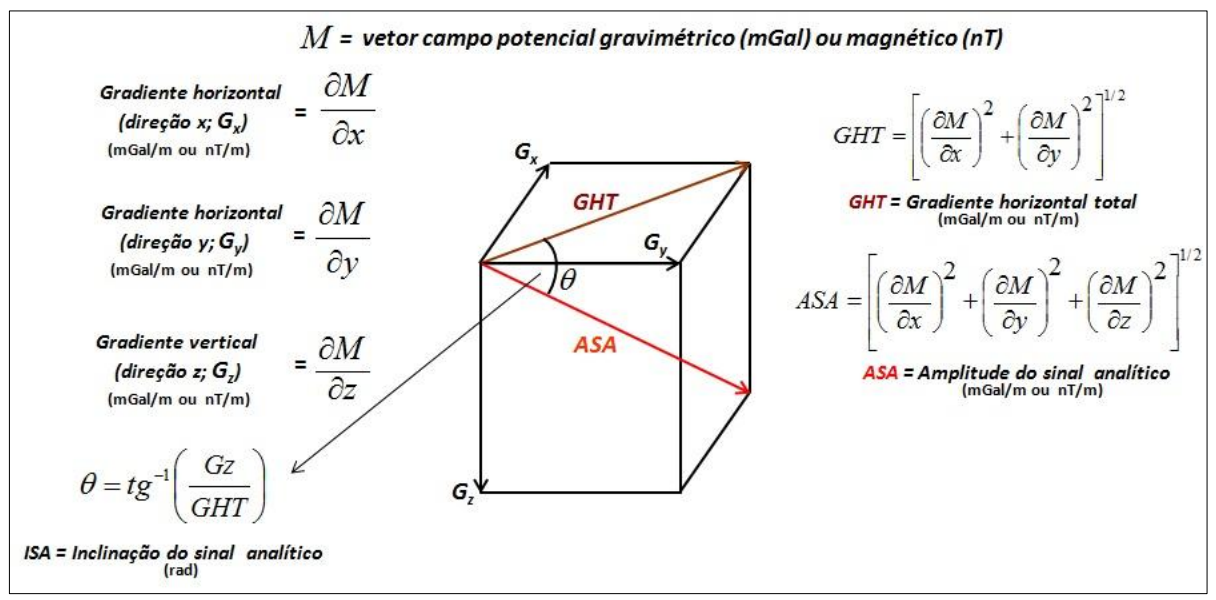

Figura 4.13 - Representação geométrica de ASA, ISA, derivadas e suas formulações (simplificado de Ferreira et al., 2010). 


\subsubsection{1- Inclinação do Sinal Analítico - ISA}

O método ISA (tilt angle method) normaliza a derivada vertical $(G z)$ pelo GHT (Miller \& Singh, 1994):

$$
\theta=\operatorname{tg}^{-1}\left(\frac{G z}{G H T}\right)
$$

o valor de $\theta$ permite a estimativa do mergulho da fonte e, consequentemente, o contraste local da propriedade física (susceptibilidade ou densidade).

A Figura 4.14 é um exemplo de ISA aplicado à redução ao polo de um prisma em três diferentes profundidades, crescente da esquerda para direita (Ferreira et al., 2010). Pode-se observar nesta figura o principal atributo desta técnica: máximos nos centros dos corpos (equalização das amplitudes).

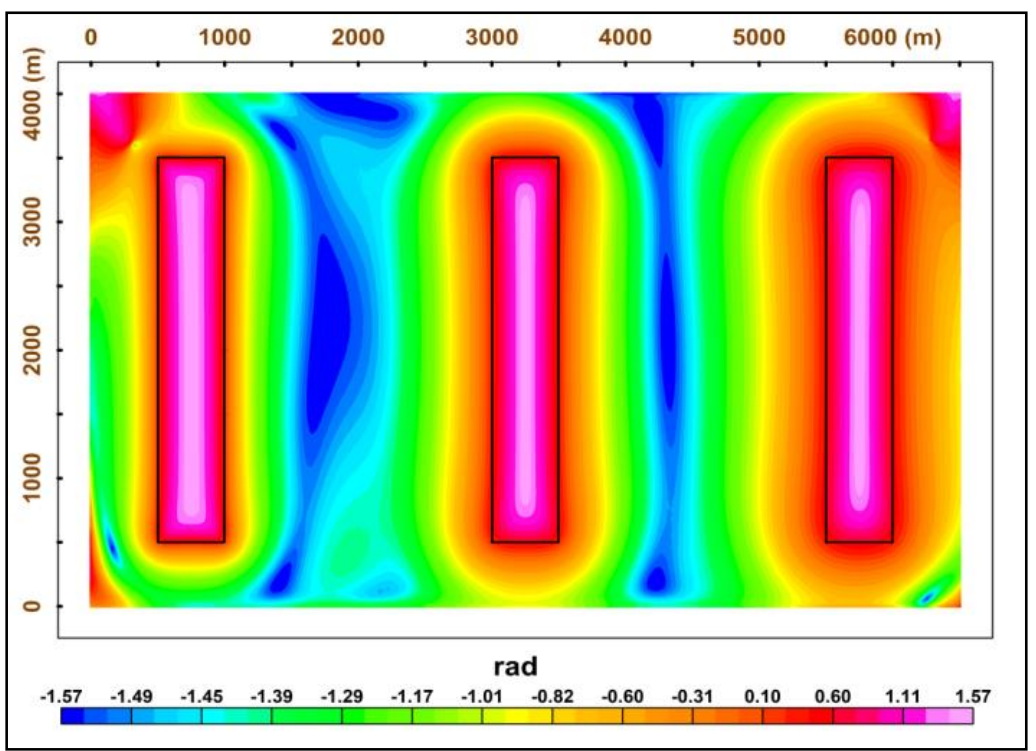

Figura 4.14 - Exemplo de aplicação da técnica ISA: máximos nos centros dos corpos, representados em um prisma, com magnetização reduzida ao polo, em profundidades diferentes (Ferreira et al., 2010). 


\subsection{6 - Deconvolução de Euler}

Visando a uma estimativa das profundidades, utilizou-se a técnica de Deconvolução de Euler. Esta técnica mapeia espacialmente as fontes anômalas de campo potencial baseando-se na equação de homogeneidade de Euler (Reid et al., 1990):

$$
x \frac{\partial P}{\partial x}+y \frac{\partial P}{\partial y}+z \frac{\partial P}{\partial z}=\eta P
$$

Considerando as coordenadas do centro da fonte, situada em $\mathrm{x}_{0}, \mathrm{y}_{0}, \mathrm{z}_{0}$, a anomalia magnética $P$ (ou gravimétrica), a equação 6 pode ser reescrita da seguinte forma (Kearey \& Brooks, 2002, p. 296):

$$
\left(x-x_{0}\right) \frac{\partial P}{\partial x}+\left(y-y_{0}\right) \frac{\partial P}{\partial y}+\left(z-z_{0}\right) \frac{\partial P}{\partial z}=\eta P
$$

Esta equação relaciona o campo potencial e os seus gradientes horizontal e vertical com a localização das fontes, com grau de homogeneidade $\eta$. Este grau é denominado de índice estrutural e pode ser definido pela medida da razão de mudança do campo potencial em relação distância (Kearey \& Brooks, 2002, p. 296). Estas soluções relacionadas aos índices (Quadro 4.1) são utilizadas para identificar e caracterizar uma gama de estruturas geológicas, como falhas, soleiras, pipe, contatos (Thompson, 1982, Reid et al., 1990).

Quadro 4.1 - Resumo de índices estruturais simples em um campo potencial (Geosoft, 2010, p.63).

\begin{tabular}{|c|c|c|}
\hline$\eta$ & Campo magnético & Campo gravimétrico \\
\hline 0.0 & Contato & Soleiras/diques/steps \\
\hline 0.5 & Thick step & Ribbom \\
\hline 1.0 & Soleira/dique & Tubo (pipe) \\
\hline 2.0 & Tubo (pipe) & Esfera \\
\hline 3.0 & Esfera & - \\
\hline
\end{tabular}

A equação de Euler é resolvida nesta técnica para cada posição da grade dentro de uma janela e as suas incertezas (desvios-padrão) são obtidas para um determinado índice estrutural, ambos predefinidos (Geosoft, 2010, p.63). Uma solução é computada se a incerteza da profundidade calculada é menor do que uma determinada tolerância, também especificada, e se está dentro de um raio de limitação do centro da janela (Geosoft, 2010, p.63). 


\subsection{7 - Modelagem Gravimetrica Direta 21/2D}

Na modelagem direta foi utilizado o programa GRAVMAG (Pedley et al., 1997). Esse programa permite que, a partir de um vetor de dados de campo potencial, no caso anomalia de gravidade, construam-se polígonos com diferentes formas e contrastes de densidade com relação à base, que representa a rocha encaixante, a fim de se reproduzir a anomalia observada. O programa utiliza, para o cálculo da gravidade, a teoria de Rasmussen \& Pederson (1979), ou seja, a contribuição de cada polígono para a anomalia de gravidade em cada ponto amostrado. A estratégia utilizada nessa modelagem é de tentativa e erro. Parte-se de um modelo grosseiro, que reproduz, em linhas gerais, a anomalia observada. Esse modelo, normalmente, requer o conhecimento prévio de vínculos geológicos e que seja considerada alguma informação a priori (Pedley et al., 1997). Passa-se por um processo interativo de refinamento geométrico e de propriedades em que se criam novos polígonos, novos vértices para os polígonos existentes, ajustam-se os contrastes de densidade e movem-se os vértices visando a um melhor ajuste das curvas de anomalia. Essa etapa já é fortemente influenciada pelo conhecimento geológico disponível, ajustando-o à resposta da anomalia Bouguer. Por fim, por meio de uma ferramenta de otimização iterativa, é possível implementar um ajuste fino de propriedades e posicionamento de vértices, chegando-se ao modelo gravimétrico final (Pedley et al., 1997). 


\section{CAPITULO 5}

\section{MATERIAIS E MÉTODOS}

\section{1 - Materiais}

A área de estudo e os equipamentos utilizados nos levantamentos terrestres constituem os materiais desta pesquisa, como se apresenta a seguir.

\subsection{1 - Área de estudo - localização}

A área de estudo localiza-se na região centro leste do Estado de São Paulo, município de Anhembi e arredores (Figura 5.1).

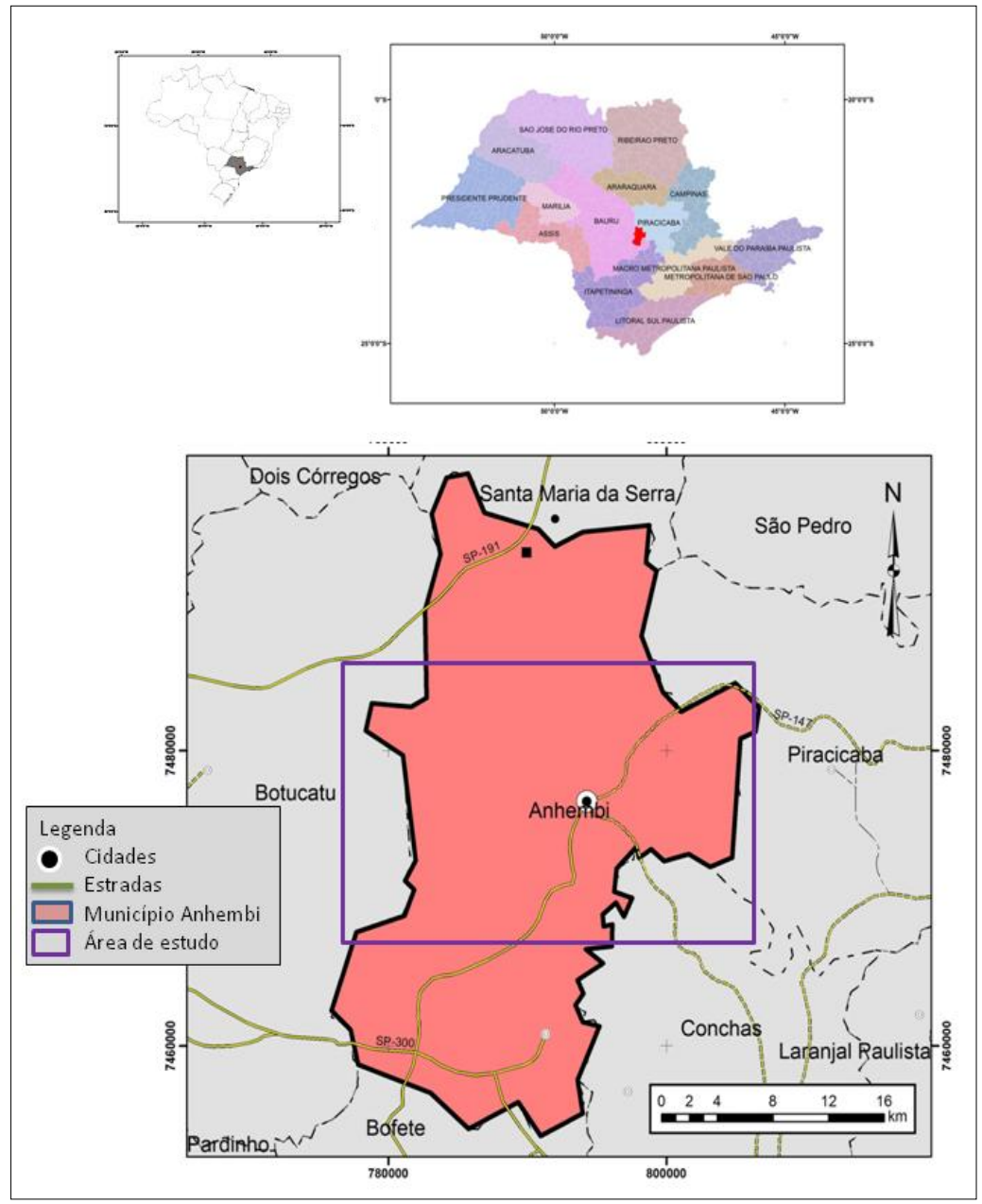

Figura 5.1 - Mapa de localização da área de estudo, retângulo em linhas azuis e em vermelho pode-se observar o município de Anhembi, onde se localiza o Alto Estrutural de Anhembi. 
O acesso pode ser feito a partir da cidade de São Paulo, pela Rodovia Castelo Branco (SP-280) e rodovia SP-147, até a cidade de Anhembi, ou então a partir de Piracicaba, via SP147, até Anhembi. Dentro da área de estudo, os acessos são feitos por estradas municipais e pertencentes às propriedades particulares, quando autorizados. A área de estudo abrange quase em totalidade a área do município de Anhembi, abrangendo também áreas do município de Botucatu a oeste, Santa Maria da Serra ao norte, Ibitiruna e Piracicaba a nordeste e Conchas a sudeste. A área de estudo tem uma extensão de aproximadamente de $1.050 \mathrm{Km}^{2}$ $(35 \times 30 \mathrm{~km})$.

\subsection{2 - Equipamentos}

Os levantamentos geofísicos foram executados com os seguintes equipamentos:

Magnetômetro GSM-19 com as seguintes características (Figura 5.2):

Resolução 0.01nT;

Precisão absoluta de 0.2 nT;

Intervalo: 15000 a $120000 \mathrm{nT}$;

Tolerância de gradiente: < 10000 nT/m;

Console com $16 \mathrm{Mb}$ de memória;

Amostragem em 5, 3, 2, 1, 0.5, 0.2 segundos;

Freqüência de amostragem superior a 5 leituras por segundo; RTT - transferência em tempo real e pós operação de coleta.

Operação manual: Coordenadas, tempo,datas e dados coletados são armazenados automaticamente num intervalo de 3 segundos; Acesso remoto: pode ser obtido usando a interface RS-232-C. Dados exportados no
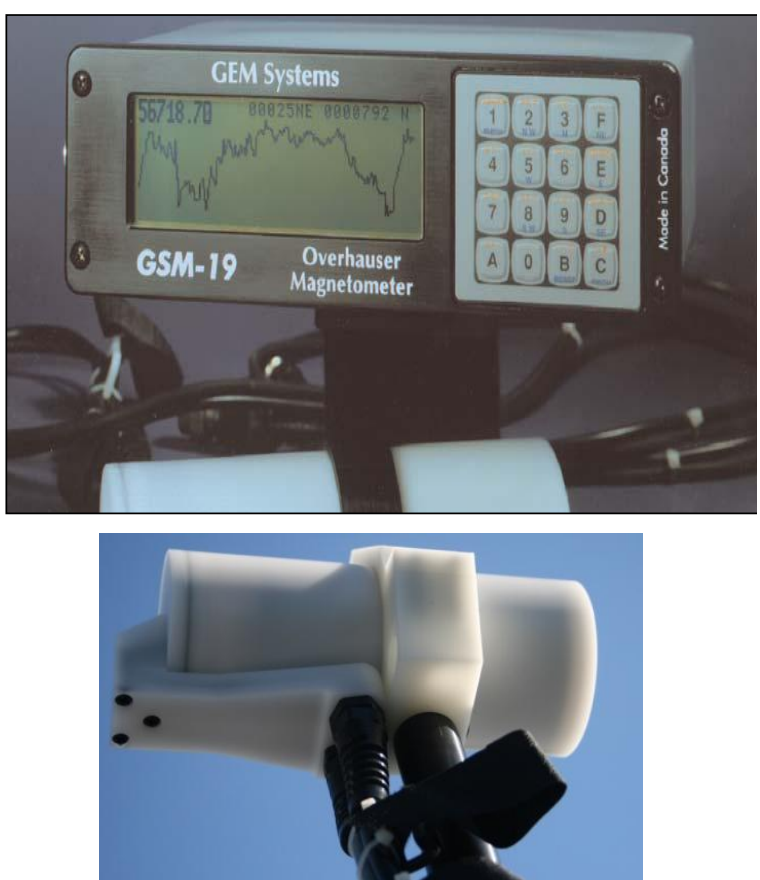

Figura 5.2 - Console Overhauser (GSM-19) com sensor e cabo. formato XYZ; 
Gravimetro CG5 - Scintrex com as seguintes características (Figura 5.3):

Resolução de medida: 1 microGal;

Repetibilidade padrão: $<5$ microGal;

Correções automatizadas: mares, inclinação do instrumento, temperatura, deriva, ruído da amostragem;

Temperatura de operação: $-40^{\circ} \mathrm{C}$ a $45^{\circ} \mathrm{C}$;

Bateria: 2 x 6.6 Ah (11.1V) recarregável (suficiente para um dia inteiro de trabalho); Possui GPS (12 canais) acoplado via porta RS-232.

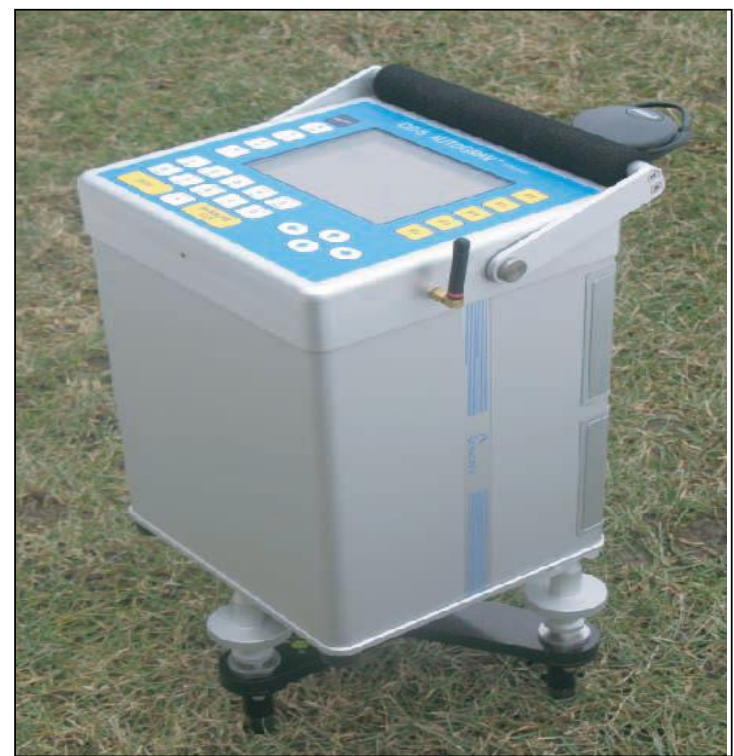

Figura 5.3 - Gravímetro Autograv Scintrex.

GPS RTK 5700 (L1 e L2) da Trimble com as seguintes características (Figura 5.4):

Trimble Recon Controller (coletor de dados)

Sistema operacional Windows Móbile 6;

Processador intel Xscale $400 \mathrm{MHz}$;

Tecnologia Bluetooth;

Bateria para o dia todo;

Memória flash de $128 \mathrm{MB}$;

Resistente e aprova d'água.

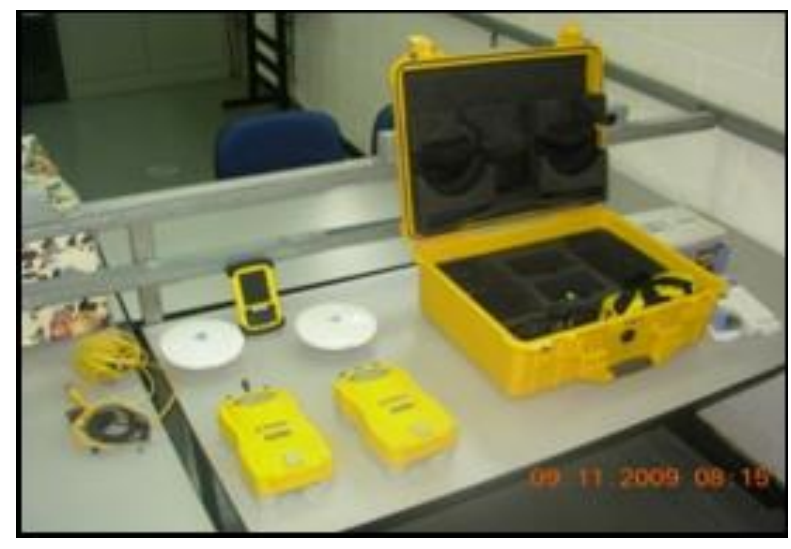

Receptor Trimble 5700 L1

Possui tecnologia Trimble Maxwell GPS;

Configuração e operação simples;

Precisão do equipamento para levantamento

GPS Estático:

Horizontal: $\pm 5 \mathrm{~mm}$;

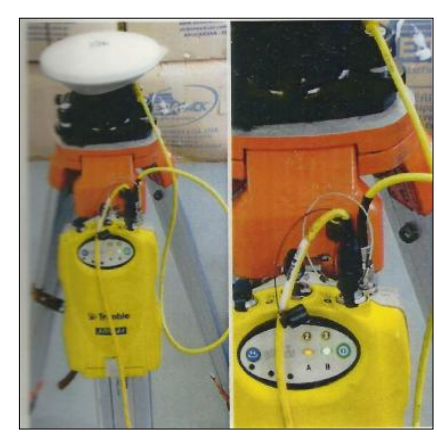

Vertical: $\quad \pm 5 \mathrm{~mm}$.

Figura 5.4 - GPS Trimble - Conjunto com coletor de dados receptor (5700 L1 e L2) e antenas. 
Magnetômetro SPINNER JR6 da AGICO (Figura 5.5):

Velocidade de rotação: $16.7 \mathrm{rps}$

Intervalo de medida: 0 a $12500 \mathrm{~A} / \mathrm{m}$ em 7 intervalos

Ruído: $2.4 \mu \mathrm{A} / \mathrm{m}$

Sensibilidade: $2.4 \mu \mathrm{A} / \mathrm{m}$

Precisão das componentes RM: $1 \%, 2.4 \mu \mathrm{A} / \mathrm{m}$

Parâmetros selecionáveis: velocidade de rotação, tipo de espécime, número de posições, tempo de integração e modo de medida.

Tamanho do espécime:

Diametro: $25.4 \mathrm{~mm}$

Comprimento: $22.2 \mathrm{~mm}$

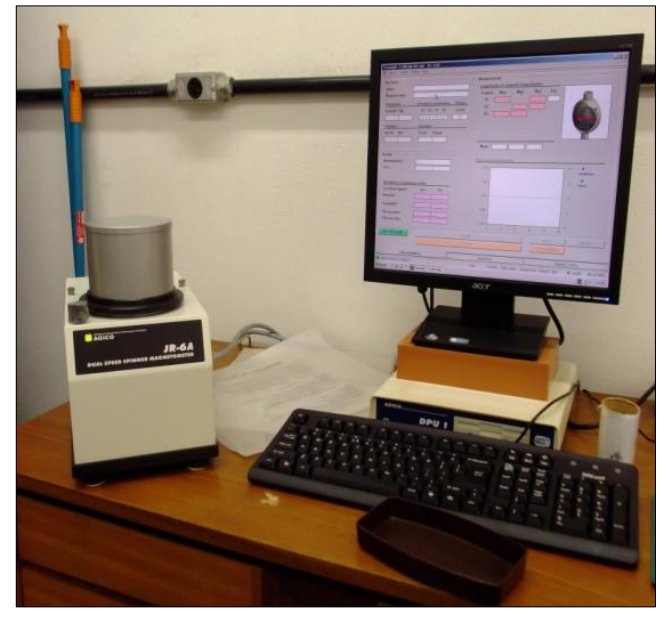

Figura 5.5 - Magnetômetro SPINNER JR6 conectado a computador do Laboratório de anisotropia magnética - LAM's.

Kappabridge LLY-4S - magnetic susceptibilitymeter da AGICO (Figura 5.6):

Volume nominal do espécime: $10 \mathrm{~cm}^{3}$

Frequência de operação: $875 \mathrm{~Hz}$

Intensidade do campo: 3 a $450 \mathrm{~A} / \mathrm{m}$ em 21 passos

Homogeneidade do campo: $0.2 \%$

Intervalo de medida: 0 a 0.2 (SI)

Sensibilidade $(300 \mathrm{~A} / \mathrm{m})$ :

Medida MAS: 2 × $10^{-8}(\mathrm{SI})$

Precisão dentro de um intervalo: $0.1 \%$

Tamanho do espécime:

Diametro: $25.4 \mathrm{~mm}$

Comprimento: $22.0 \mathrm{~mm}$

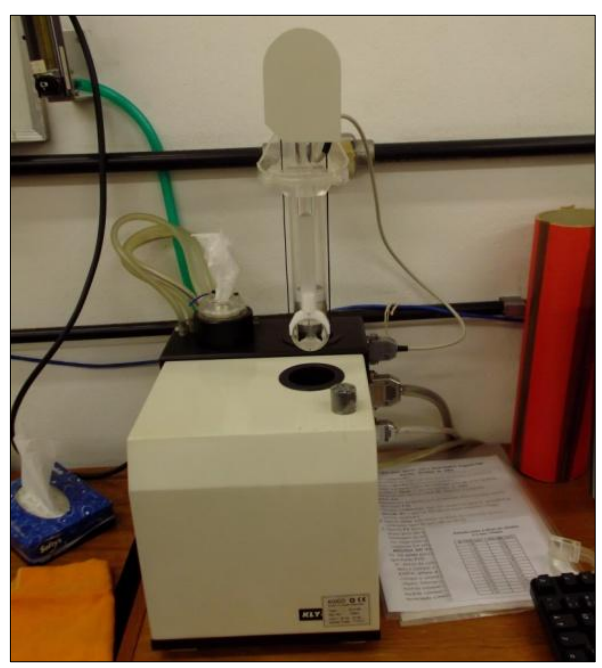

Figura 5.6 - Equipamento Kappabridge LLY-4S - magnetic susceptibility do Laboratório de anisotropia magnética LAM's. 


\section{2 - Métodos}

$\mathrm{Na}$ área de estudo, foram adquiridos dados gravimétricos e magnetométricos, através de levantamentos de campo. Também foram coletadas amostras de rochas para determinação de densidade, susceptibilidade e remanescência magnética. Estes valores calculados em laboratório são importantes no processamento dos dados gravimétricos e magnetométricos.

A área de estudo está contida basicamente no município de Anhembi - SP e recortado pelo rio Tietê na direção SE-NW. Para dar inicio ao levantamento gravimétrico, foi estabelecida a estação base, importante para as correções gravimétricas. Desta forma, foi realizada a transferência de $g$ absoluto de um ponto conhecido para a estação base. $\mathrm{O}$ levantamento gravimétrico foi acompanhado por levantamento planialtimétrico (Trimble R3 GPS System) utilizando duas bases, uma fixa e outra móvel, sendo a base fixa com o mesmo posicionamento da estação base fixa gravimétrica. Para o levantamento magnético foi também realizado por duas bases, sendo a base fixa estabelecida na zona rural do município de Anhembi, dentro da área de estudo, numa área apropriada, minimizando a influência de fontes ruidosas.

Os levantamentos gravimétricos e magnetométricos foram executados de forma independentes, com espaçamentos diferentes em semi detalhe para a área do Alto Estrutural de Anhembi e em detalhamento para a área de ocorrência de geiseritos.

Estes dados representam a interação de todas as litologias presentes na área, desde o embasamento, rochas sedimentares e vulcânicas básicas, observadas através de suas propriedades físicas, densidade e susceptibilidade magnética. Após o processamento e tratamento inicial, os dados são representados graficamente na forma de mapas de isovalores, com um espaçamento pré-determinado para o grid.

\subsection{1 - Transferência de $g$ absoluto}

A transferência, ou conexão gravimétrica, de um valor de ' $g$ ' absoluto, pertencente a uma estação estabelecida e com valor de ' $g$ ' absoluto conhecido, fez-se necessária a fim de se estabelecer a estação base, utilizada para as correções gravimétricas, para um ponto fixado na área do levantamento (Milson, 2003, p. 22). A estação escolhida, com valor de ' $g$ ' absoluto conhecido, é localizada na cidade de Laranjal Paulista - SP (Figura 5.7), distante $70 \mathrm{Km}$ da área de estudo, aproximadamente. Esta estação foi estabelecida por Dalpozzo et al. (2007), 
sendo uma estação de segunda ordem. Com base nesta estação, foi realizado o processo de transferência do valor de ' $g$ ' absoluto para a cidade de Anhembi, dentro da área de estudo, mais especificamente, em frente à igreja matriz de Anhembi (Figura 5.8). Foram realizadas 7 blocos de leituras, tendo 5 medidas de 120 segundos cada. A primeira e a última medida foram realizadas na cidade de Laranjal. O valor de $g$ transferido é igual a 978.631,57 mGal. As coordenadas são: UTM - Latitude $(Y)$ : 7476849.37 e Longitude $(X)$ : 794887.62, em metros, e geográficas - Latitude: $22^{\circ} 47^{\prime} 24.42^{\prime \prime} S$ e Longitude: $48^{\circ} 07^{\prime} 40.08 \mathrm{~W}$, com altitude: 468.44 metros.

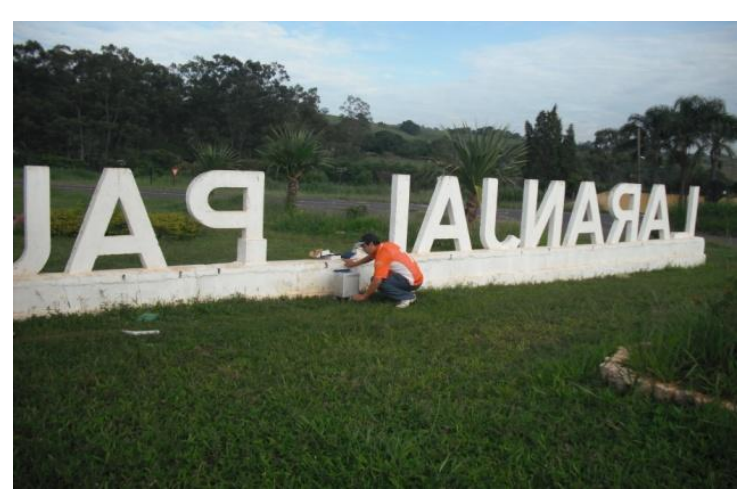

Figura 5.7 - Estação gravimétrica de Laranjal Paulista, de onde foi feita a transferência de ' $g$ ' absoluto para a área de estudo.

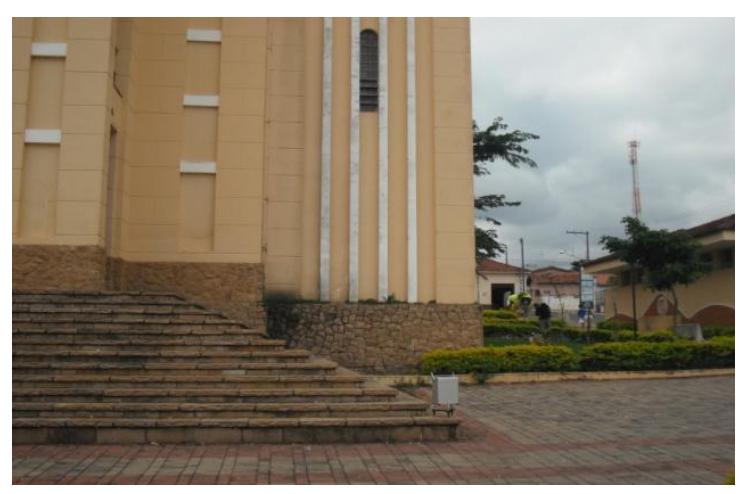

Figura 5.8 - Ponto na área de estudo (igreja matriz de Anhembi) para onde foi transferido o valor de ' $g$ ' absoluto de Laranjal Paulista.

\subsection{2 - Levantamento Planialtimétrico}

A execução deste levantamento foi realizada com o equipamento Trimble R3 GPS System com a utilização de dois receptores, sendo um posicionado numa base fixa, ponto conhecido, e um móvel que mede posições desconhecidas dentro de um raio de alcance da base. O tipo de levantamento utilizado foi o estático-rápido pós-processado que requer períodos mais longos de ocupação para cada ponto a ser levantado, porém isto promove resultados mais precisos. As coordenadas precisas para pontos levantados não são disponíveis durante o levantamento de campo. Para gerar linhas de base e coordenadas precisas os dados coletados devem ser pós-processados usando o software do fabricante, Trimble ${ }^{\circledR}$ Business Center - TBC (TBC, 2008). Este programa fez a correção da base fixa utilizando duas bases conhecidas do IBGE, uma localizada dentro da USP, denominada POLI, e a outra em São José do Rio Preto, SJRP (Figura 5.9). 

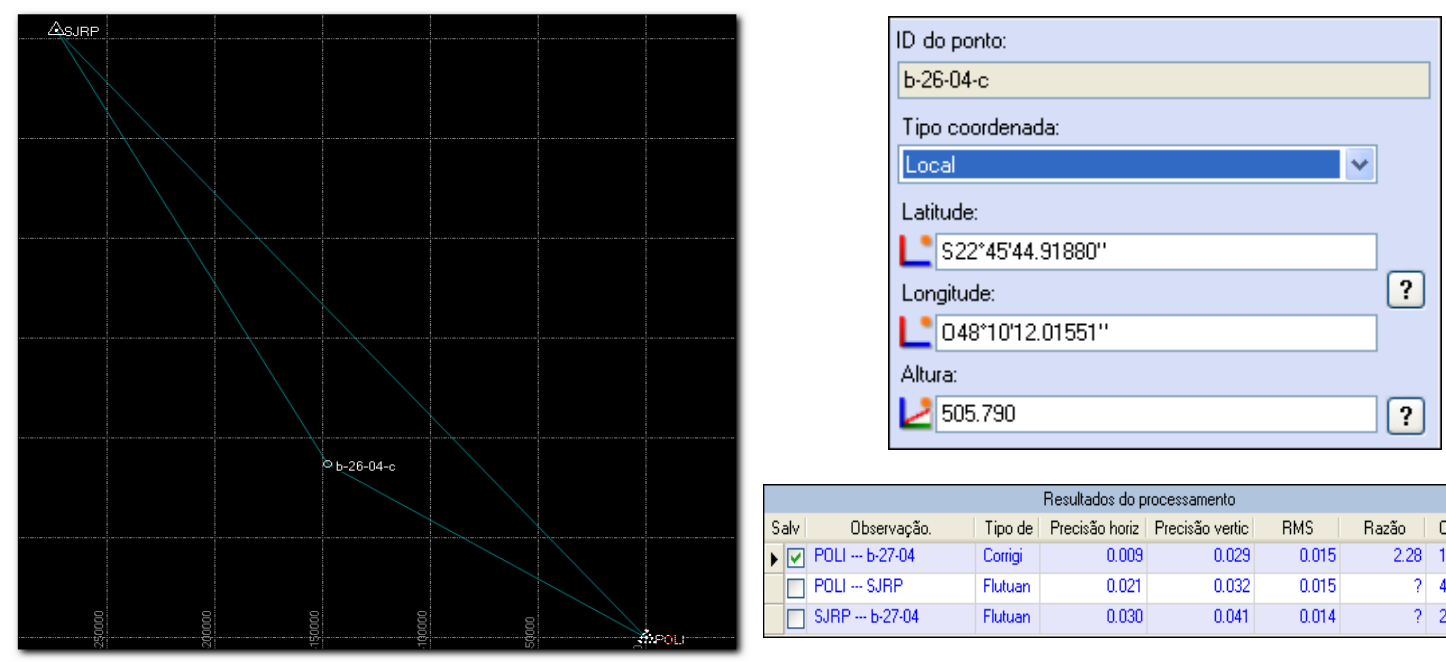

\begin{tabular}{|c|c|c|c|c|c|c|}
\hline \multicolumn{7}{|c|}{ Resultados do processamento } \\
\hline Observação. & Tipo de & Precisão horiz & Precisão vertic & RMS & Razão & Comprime \\
\hline P POLI -..b-27-04 & Corrigi & 0.009 & 0.029 & 0.015 & 2.28 & 171624.23 \\
\hline$\square$ POLI … S.JRP & Flutuan & 0.021 & 0.032 & 0.015 & $?$ & 409392.66 \\
\hline$\square$ S.JRP … b-27.04 & Flutuan & 0.030 & 0.041 & 0.014 & $?$ & 251124.17 \\
\hline
\end{tabular}

Figura 5.9 - Imagem ilustrativa de correção de posicionamento da base fixa do Trimble R3 GPS System (ID: b26-04-c) utilizando o software do fabricante, Trimble ${ }^{\circledR}$ Business Center - TBC.

O posicionamento dos pontos medidos pelo receptor móvel é processado (corrigido) e apresentado num relatório (Figura 5.10), onde é mostrada a precisão horizontal e vertical e se o ponto foi corrigido de forma satisfatória ou não (tipo de solução). Os pontos assinalados como flutuantes foram descartados na maioria das vezes por apresentar precisão vertical maior que 0.1 metros.

\begin{tabular}{|c|c|c|c|c|c|c|c|c|}
\hline Salvar & Observação. & Tipo de solução & & Precisão horiz (95\%) & Precisão vertical (95\%) & RiMS & Razão & Comprimento \\
\hline , & $b \cdot 26 \cdot 04 \cdot c-\cdots$ & Corrigido & & 0.010 & 0.018 & 0.786 & 2.61 & 8824.663 \\
\hline$\nabla$ & b-26-04-c - - lev-m-26-4:01 & Corrigido & & 0.029 & 0.056 & 0.022 & 3.72 & 8826.346 \\
\hline 田 & b-26-04-c - - lev-m-26-4.02 & Corrigido & & 0.029 & 0.056 & 0.021 & 3.72 & 8848.162 \\
\hline 田 & b-26-04-c - - lev-m-26-4-03 & Corrigido & & 0.023 & 0.042 & 0.030 & 2.01 & 8868.722 \\
\hline 田 & b-26-04-c $\cdots$ lev-m-26-4.04 & Corrigido & & 0.025 & 0.049 & 0.019 & 2.01 & 8891.600 \\
\hline 田 & b-26-04-c $\cdots$ lev-m-26-4-05 & Corrigido & & 0.026 & 0.052 & 0.014 & 2.09 & 8904.660 \\
\hline 田 & b-26-04-c - - lev-m-26-4.06 & Corrigido & & 0.022 & 0.052 & 0.012 & 7.72 & 8923.178 \\
\hline 田 & b-26-04-c - - lev-m-26-4-07 & Corrigido & & 0.023 & 0.044 & 0.029 & 5.28 & 8964.796 \\
\hline 田 & b-26-04-c $\cdots$ lev-m-26-4.08 & Corrigido & & 0.019 & 0.045 & 0.044 & 3.31 & 9037.006 \\
\hline 四 & b-26-04-c ‥ley-m-26-4-09 & Corrigido & & 0.021 & 0.042 & 0.040 & 2.17 & 9096.318 \\
\hline$\square$ & b-26-04-c $\cdots$ lev-m-26-4-10 & Flutuante & & 0.023 & 0.054 & 0.078 & ? & 9166.584 \\
\hline$\square$ & b-26-04-c c- lev-m-26-4-11 & Flutuante & & 0.027 & 0.066 & 0.071 & ? & 9164.702 \\
\hline 四 & b-26-04-c $\cdots$ lev-m-26-4-12 & Corrigido & & 0.025 & 0.058 & 0.043 & 2.91 & 9163.130 \\
\hline$\square$ & b-26-04-c $\cdots$ lev-m-26-4-13 & Flutuante & p & $0.606 \vdash$ & 0.752 & 0.028 & ? & 8935.189 \\
\hline 四 & b-26-04-c - - lev-m-26-4-14 & Corrigido & & 0.018 & 0.053 & 0.026 & 4.51 & 8955.304 \\
\hline 田 & b-26-04-c - - lev-m-26-4-15 & Corrigido & & 0.021 & 0.058 & 0.031 & 5.28 & 8972.046 \\
\hline 田 & b-26-04-c - - lev-m-26-4-16 & Corrigido & & 0.022 & 0.062 & 0.035 & 5.28 & 8981.896 \\
\hline 田 & b-26-04-c $\cdots$ lev-m-26-4-17 & Corrigido & & 0.022 & 0.051 & 0.046 & 2.01 & 8989.542 \\
\hline 田 & b-26-04-c - lev-m-26-4-18 & Corrigido & & 0.029 & 0.068 & 0.024 & 5.28 & 9003.886 \\
\hline 田 & b-26-04-c $\cdots$ lev-m-26-4-19 & Corrigido & & 0.023 & 0.052 & 0.026 & 5.39 & 9022.175 \\
\hline 田 & b- $-26-04-c \cdots$ lev-m-26-4-20 & Corrigido & & 0.019 & 0.052 & 0.024 & 2.16 & 9035.648 \\
\hline 田 & b-26-04-c $\cdots$ lev-m-26-4-21 & Corrigido & & 0.019 & 0.056 & 0.031 & 2.04 & 9047.923 \\
\hline 田 & b-26-04-c $\cdots$ lev-m-26-4.22 & Corrigido & & 0.019 & 0.052 & 0.029 & 3.66 & 9062.536 \\
\hline 田 & b-26-04-c $\cdots$ lev-m-26-4-23 & Corrigido & & 0.022 & 0.056 & 0.025 & 3.92 & 9074.457 \\
\hline$\nabla$ & b-26-04-c - - lev-m-26-4-24 & Corrigido & & 0.019 & 0.059 & 0.010 & 3.32 & 9086.525 \\
\hline 田 & b-26-04-c - - lev-m-26-4-25 & Corrigido & & 0.020 & 0.049 & 0.016 & 2.06 & 9100.535 \\
\hline 田 & b-26-04-c $\cdots$ ley-m-26-4-26 & Corrigido & & 0.021 & 0.052 & 0.027 & 3.92 & 9113.944 \\
\hline 四 & b-26-04-c $\cdots$ lev-m-26-4-27 & Corrigido & & 0.022 & 0.054 & 0.030 & 3.92 & 9128.724 \\
\hline$\nabla$ & b-26-04-c - - lev-m-26-4-28 & Corrigido & & 0.023 & 0.057 & 0.032 & 3.92 & 9145.572 \\
\hline 田 & b-26-04-c - - lev-m-26-4-29 & Corrigido & & 0.025 & 0.061 & 0.041 & 3.92 & 9163.683 \\
\hline 田 & b-26-04-c $\cdots$ lev-m-26-4-30 & Corrigido & & 0.026 & 0.064 & 0.042 & 3.92 & 9183.125 \\
\hline$\square$ & b-26-04-c $\cdots$ lev-m-26-4.31 & Flutuante & $p$ & $0.829 \mp$ & 0.726 & 0.029 & ? & 9206.707 \\
\hline
\end{tabular}

Figura 5.10 - Imagem ilustrativa da correção de posicionamento dos pontos medidos. São listadas todas as bases processadas, especificando as precisões horizontais e verticais. A bandeira vermelha indica problemas com as correções. 


\section{Capítulo 6}

\section{RESULTADOS E DISCUSSÃO}

\section{1 - Resultados obtidos em laboratório}

\subsection{1 - Densidade de massa}

Foram coletadas amostras de rochas na área de estudo e adjacências para medição da densidade de massa (Quadro 6.1). A área de estudo possui poucos afloramentos de rochas frescas, por isso é importante salientar que as densidades das rochas obtidas foram utilizadas de forma qualitativa, uma referência para se identificar e diferenciar litotipos via densidades. Foram coletadas amostras representativas das formações Teresina e Pirambóia na área de estudo. As amostras de diabásio foram coletadas nas áreas NW e SW, únicas áreas onde afloram e que estavam acessíveis. O embasamento cristalino descrito no poço de pesquisa da Petrobras à 1650m (Figura 3.15) de profundidade é formado por uma rocha silicosa (quartzito), porém não é possível a determinação da procedência do litotipo, se do embasamento cristalino ou parte da bacia. Portanto, foram amostradas rochas do embasamento cristalino aflorante às margens da bacia do Paraná (as margens da rodovia Castelo Branco SP 280, nos km 69 e 70) visando à determinação de uma densidade mais representativa desta. Os valores obtidos estão coerentes com aqueles apresentados na literatura (Telford, 1990 - p 16).

Quadro 6.1 - Densidades medidas na área de estudo e adjacências.

\begin{tabular}{|l|c|}
\hline Rochas & densidades $-\mathrm{g} / \mathrm{cm}^{3}$ \\
\hline Diabásio & 2.76 a 3.04 \\
\hline Cristalino (gnaisse) & 2.64 a 2.97 \\
\hline Arenitos Pirambóia & 1.36 a 2.54 \\
\hline Siltitos e Lamitos - Teresina & 1.62 a 1.67 \\
\hline Silexito - geseritos & 2.39 a 2.52 \\
\hline
\end{tabular}




\subsection{2 - Magnetização Remanescente Natural e Susceptibilidade}

Foram utilizadas 15 amostras de rochas, coletadas na área de estudo, para medidas de susceptibilidade, Tabela 6.1. Nesta tabela são apresentadas as amostras de rochas e suas respectivas medidas de susceptibilidade e a média deste conjunto de dados. Quanto à MRN, foi utilizado um conjunto de 7 amostras, Tabela 6.2, onde são apresentados os valores obtidos de declinação, inclinação e intensidade magnética de cada amostra e a média destes parâmetros. O resultado do cálculo da direção média da área de estudo é apresentado, novamente, na Tabela 6.3, complementado pelos parâmetros: $N, R$ e $k$.

Tabela 6.1 - Susceptibilidade de amostras de rochas da área de estudo.

\begin{tabular}{lc}
\hline Amostras & Susceptibilidade (SI) \\
\hline AP1A1 & 0.11270 \\
\hline AP1A2 & 0.10660 \\
\hline AP1A3 & 0.08788 \\
\hline AP1B1 & 0.09646 \\
\hline AP1B2 & 0.09799 \\
\hline AP1C1 & 0.08745 \\
\hline AP1C2 & 0.10500 \\
\hline AP1C3 & 0.10350 \\
\hline AP1C4 & 0.10550 \\
\hline AP2A1 & 0.08160 \\
\hline AP2A2 & 0.09723 \\
\hline AP2B1 & 0.04340 \\
\hline AP2B2 & 0.05942 \\
\hline AP2C1 & 0.06912 \\
\hline AP2C2 & 0.05365 \\
\hline Média & $\mathbf{0 . 0 8 7 1 7}$ \\
\hline
\end{tabular}

Tabela 6.2 - Valores de MRN das amostras de rochas da área de estudo.

\begin{tabular}{cccc}
\hline Amostras & $\mathbf{D}\left({ }^{\mathbf{o}}\right)$ & $\mathbf{I}\left({ }^{\mathbf{}}\right)$ & Intensidade $(\mathbf{A} / \mathbf{m})$ \\
\hline AP3A1 & 348 & -37 & 3.163 \\
AP3B1 & 350 & -39 & 3.165 \\
AP3C1 & 6 & -42 & 3.527 \\
AP3D1 & 6 & -47 & 2.817 \\
AP3E2 & 1 & -43 & 3.043 \\
AP3G1 & 359 & -44 & 2.300 \\
AP3H1 & 343 & -38 & 2.431 \\
Média & $\mathbf{3 5 5 . 8}$ & $\mathbf{- 4 1 . 7}$ & $\mathbf{2 . 9 2 1}$ \\
\hline
\end{tabular}


Tabela 6.3 - Direção média da área de estudo. $N=$ número de vetores, $R=$ intensidade do vetor e $k=$ parâmetro de precisão.

\begin{tabular}{cccccc}
\hline $\mathbf{D}\left({ }^{\circ}\right)$ & $\mathbf{I}\left({ }^{\circ}\right)$ & $\mathbf{N}$ & $\mathbf{R}$ & $\mathbf{k}$ & $\alpha_{95}\left({ }^{\mathbf{o}}\right)$ \\
\hline 355.8 & -41.7 & $\mathbf{7}$ & $\mathbf{6 . 9 4 5}$ & $\mathbf{1 0 9 . 3}$ & $\mathbf{5 . 8}$ \\
\hline
\end{tabular}

A magnetização induzida da área de estudo, na época do levantamento, obtido no site do Observatório nacional $(\mathrm{ON}, 2012)$ é: declinação $=-19.91^{\circ}$, inclinação $=-33.37^{\circ} \mathrm{e}$ intensidade $=22929 \mathrm{nT}$.

Soma vetorial da magnetização induzida com a remanescente, isto é, magnetização total $\left(J=J_{i}+J_{r}\right)$ tem os seguintes valores: declinação $=347.5^{\circ}$ e inclinação $=-37.8^{\circ}$.

A anomalia magnética de campo total, da área de estudo, tem significativa influência da direção da magnetização remanescente, pois as rochas desta região apresentaram magnetização remanescente $\left(J_{\mathrm{r}}\right)$ expressiva comparada à magnetização induzida $\left(J_{i}\right)$, como é mostrado através da razão de Königsberger:

$$
\left(Q=J_{r} / J_{i}\right)=2.921 /(0.087 * 22929 / 400 \pi)=1.84
$$




\section{2 - Levantamento gravimétrico de semi-detalhe}

Araújo (2003, p.65) demonstrou a existência de uma anomalia gravimétrica na região do Alto Estrutural de Anhembi. Entretanto, a massa de dados obtidos foi muito baixa e, portanto, insuficiente para fins de interpretação da estrutura geológica subjacente. Assim, um adensamento de pontos de medidas gravimétricas foi realizado nesta área e adjacências. Para isso, foram consideradas todas as estradas existentes, bem como alguns caminhamentos ao longo de pastos, matas, canaviais, reflorestamentos e pomares de laranjas.

Para o levantamento gravimétrico terrestre foram realizadas 3486 medidas no total, distribuídas em toda a região do Alto Estrutural de Anhembi e adjacência, aproximadamente $35 \times 30 \mathrm{~km}$ (Figura 6.1). Esta figura mostra também as principais estradas, sendo duas rodovias (SP 147 e 192) e as principais estradas vicinais, dentro da área de estudo e o rio Tietê (represa de Barra Bonita). Os espaçamentos variaram de 200 a 500 metros para levantamento de semi-detalhe, 2718 medidas, com intervalo de tempo de cada coleta, numa determinada estação, de 120 segundos, sendo duas medidas por estação.

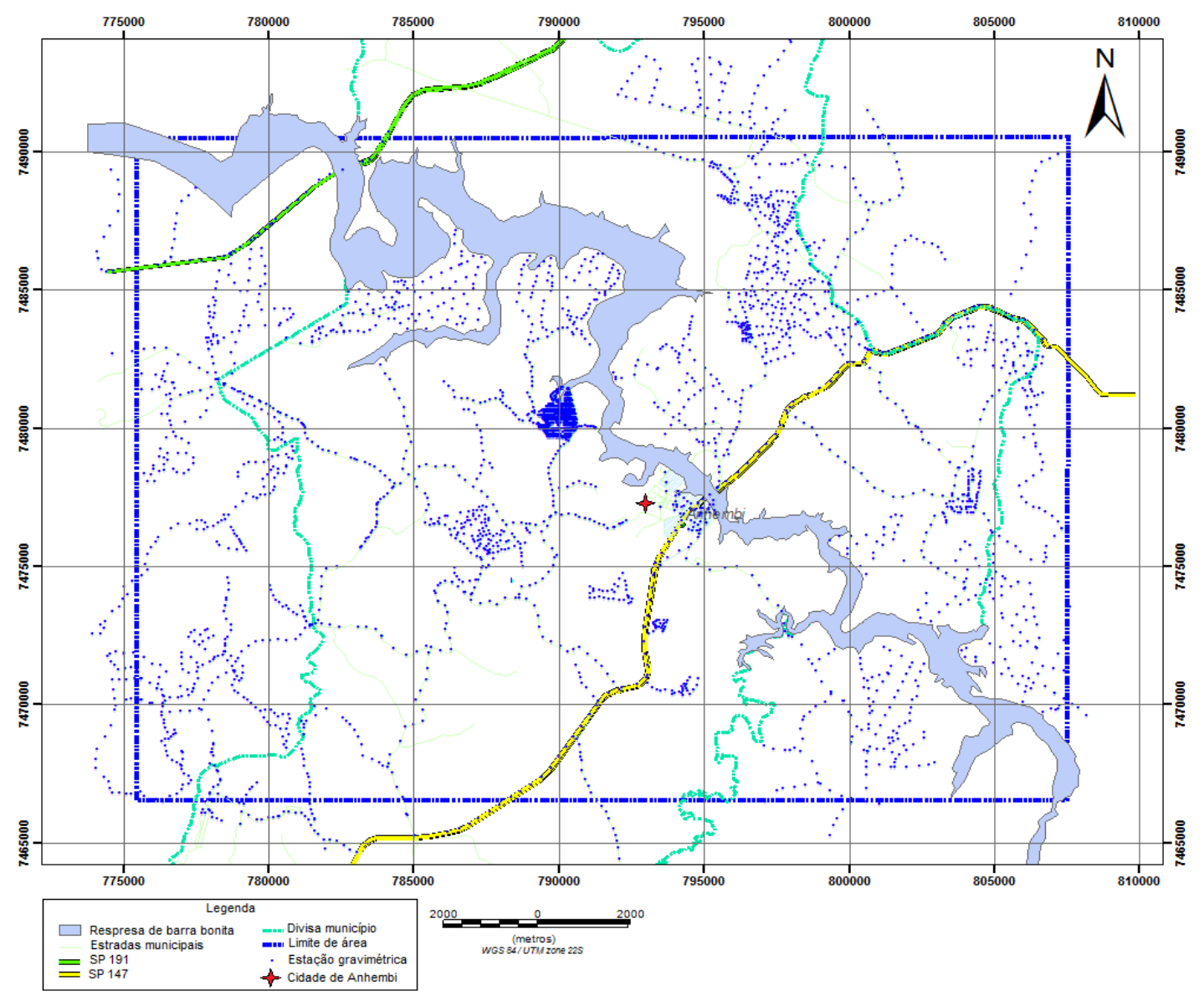

Figura 6.1 - Levantamento gravimétrico realizado no Domo de Anhembi com 3486 estações. 
Para a correção da deriva instrumental do gravímetro CG-5, durante a aquisição dos dados, utilizou-se o procedimento da linha gravimétrica fechada, onde o gravímetro é aferido numa base, com gravidade conhecida, antes e depois das leituras serem executadas. Esta base gravimétrica, localizada na igreja matriz de Anhembi, foi transferida a partir da base gravimétrica de Laranjal Paulista (item 5.2.1).

Os dados gravimétricos foram reduzidos através da rotina Gravity \& Terrain Correction do programa Oasis Montaj ${ }^{\mathrm{TM}}$ (Geosoft, 2006), que permite aplicação das correções e cálculo dos valores Ar-livre e Bouguer, integrando-os aos dados processados do levantamento planialtimétrico. Este programa permite também a confecção de mapas e aplicação de filtros especiais. O resumo destes processos pode ser vista na Figura 6.2, onde se mostra, de forma ilustrativa, os processos envolvidos e os respectivos produtos.

\subsection{1 - Mapa Bouguer do levantamento de semi-detalhe}

Para a confecção do mapa Bouguer, do levantamento de semi-detalhe, foi empregado o sistema de coordenadas UTM, zona 22 sul do meridiano de Greenwich. O elipsóide de referência utilizado foi o WGS 84. O mapa Bouguer foi confeccionado através de rotinas de interpolação do programa Oasis Montaj (Geosoft, 2005. p.92), baseada no método mínima curvatura (Briggs, 1994) com tamanho de célula de 100 metros, metade do menor espaçamento entre estações. O produto resultante da redução dos dados gravimétricos e da interpolação é apresentado na Figura 6.3. Onde é mostrado o mapa de Bouguer da área de estudo para levantamentos de semi-detalhe, tendo como referência o rio Tietê.

Este mapa representa a resultante de interação de todas as litologias presente na área, desde o embasamento, rochas sedimentares e vulcânicas básicas. Uma característica notável é que a anomalia apresenta uma tendência positiva para sudeste, sugerindo este gradiente a existência de uma feição geológica positiva em subsuperfície nesta direção. Este resultado, além de confirmar os trabalhos anteriores de Araújo et al. (2006), IPT (1979 e 2005) realizados na área de estudo, permitiu a definição mais precisa das anomalias quanto a suas localizações, formas e amplitudes, possibilitando o aperfeiçoamento do estudo tectonoestrutural da área de estudo.

A análise dos dados gravimétricos na área de estudo tem como objetivo principal o estudo do Alto Estrutural de Anhembi e sua correlação que possa existir com o embasamento. 


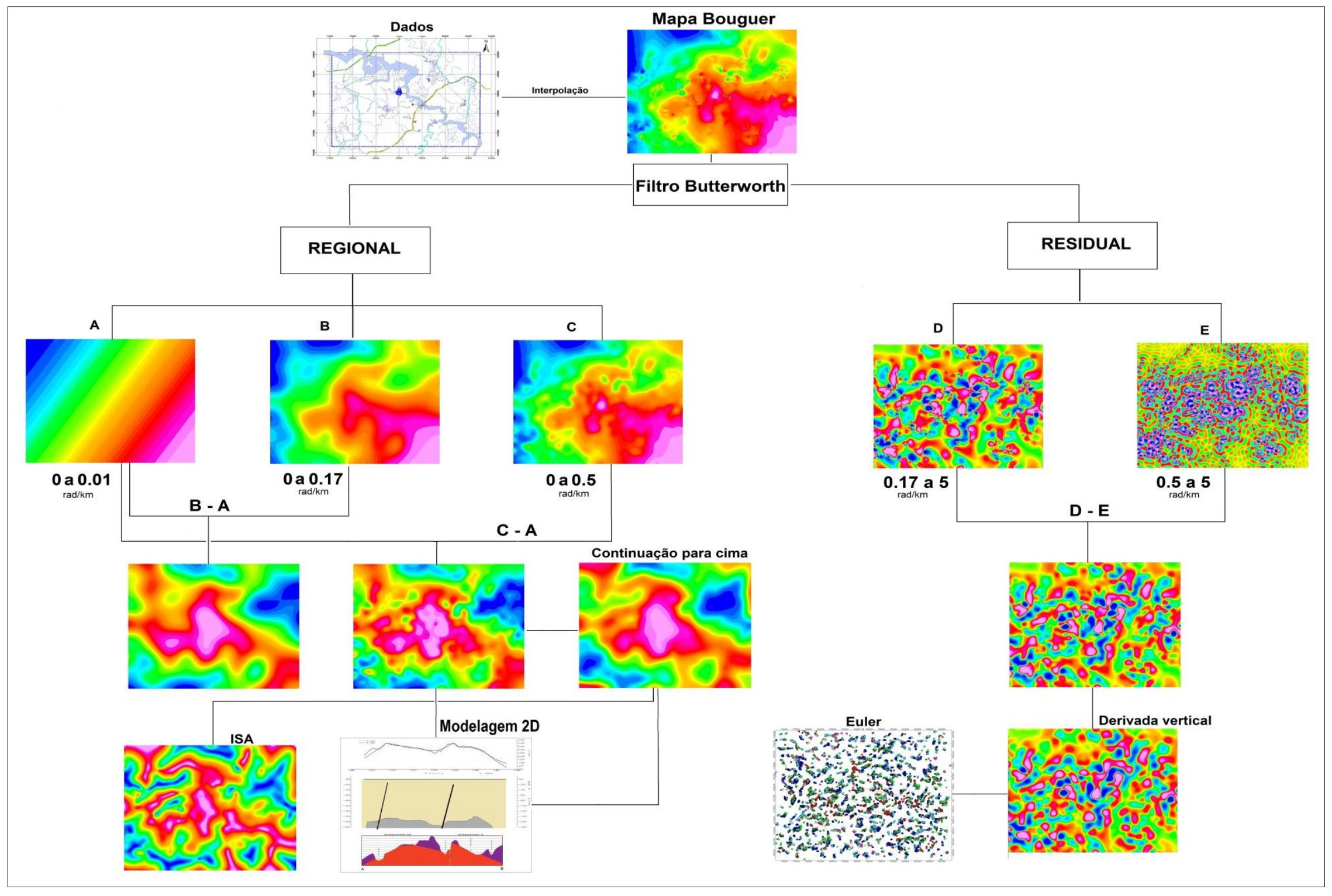

Figura 6.2- Diagrama ilustrativo da obtenção do mapa de Bouguer, levantamento de semi-detalhe, e produtos derivados. 


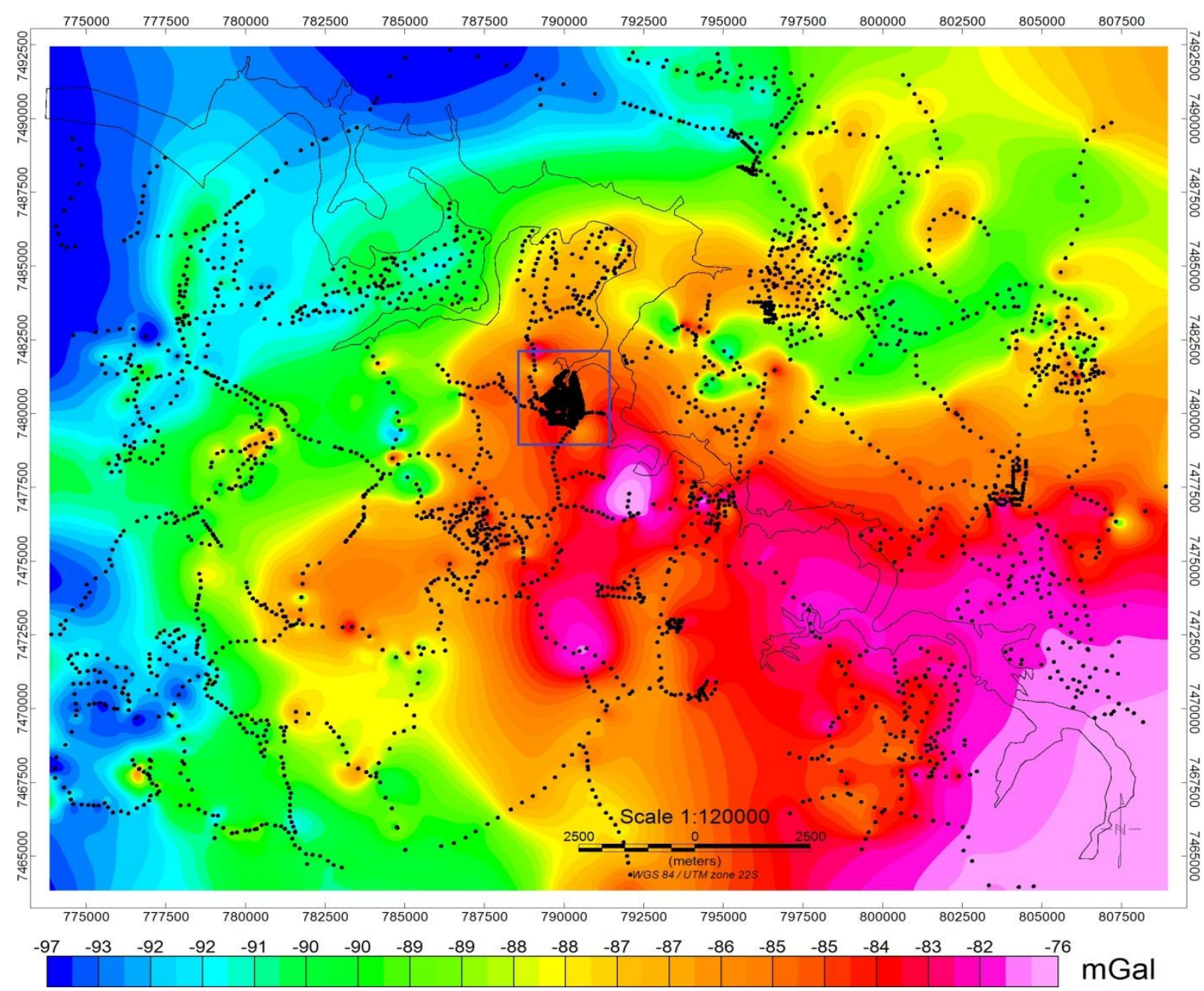

Figura 6.3 - Mapa de anomalia Bouguer da área de estudo com estações de medidas gravimétricas. A área assinalada no retângulo azul corresponde a área de ocorrência dos geiseritos.

\subsection{2 - Espectro de Potência aplicado aos dados gravimétricos de semi-detalhe}

Com a finalidade de se analisar a influência na anomalia gravimétrica dos litotipos localizados no embasamento, bem como dos litotipos no interior da bacia, procedeu-se a aplicação da técnica do Espectro de Potência Ponderado Radialmente ao mapa Bouguer (Figura 6.3) (Spector e Grant, 1970 e Geosoft, 2009. p. 28). A análise do espectro produzido pelo Geosoft $(2009$, p. 52) foi realizada através da transferência do arquivo de dados (formato ASC) que o compõem para o programa Excel da Microsoft ${ }^{\mathrm{TM}}$, onde se pode determinar com mais precisão os limites das componentes de interesse: fontes profundas, rasas e ruídos. A Tabela 6.4 apresenta as estatísticas desta análise para as componentes de fontes: profunda e rasa. O espectro apresentado na Figura 6.4 foi produzido com o conjunto de dados de profundidade estimadas baseadas em 5 pontos (Geosoft, 2009. p. 46) medidos do declive do espectro de energia (Spector e Grant, 1970 e Geosoft, 2009, p. 52). 
O espectro (Figura 6.4) apresenta duas partes distinguíveis da esquerda para a direita. A primeira parte, reta $1 \mathrm{em}$ verde, representa as fontes localizadas no embasamento, com profundidade média de 1800 metros.

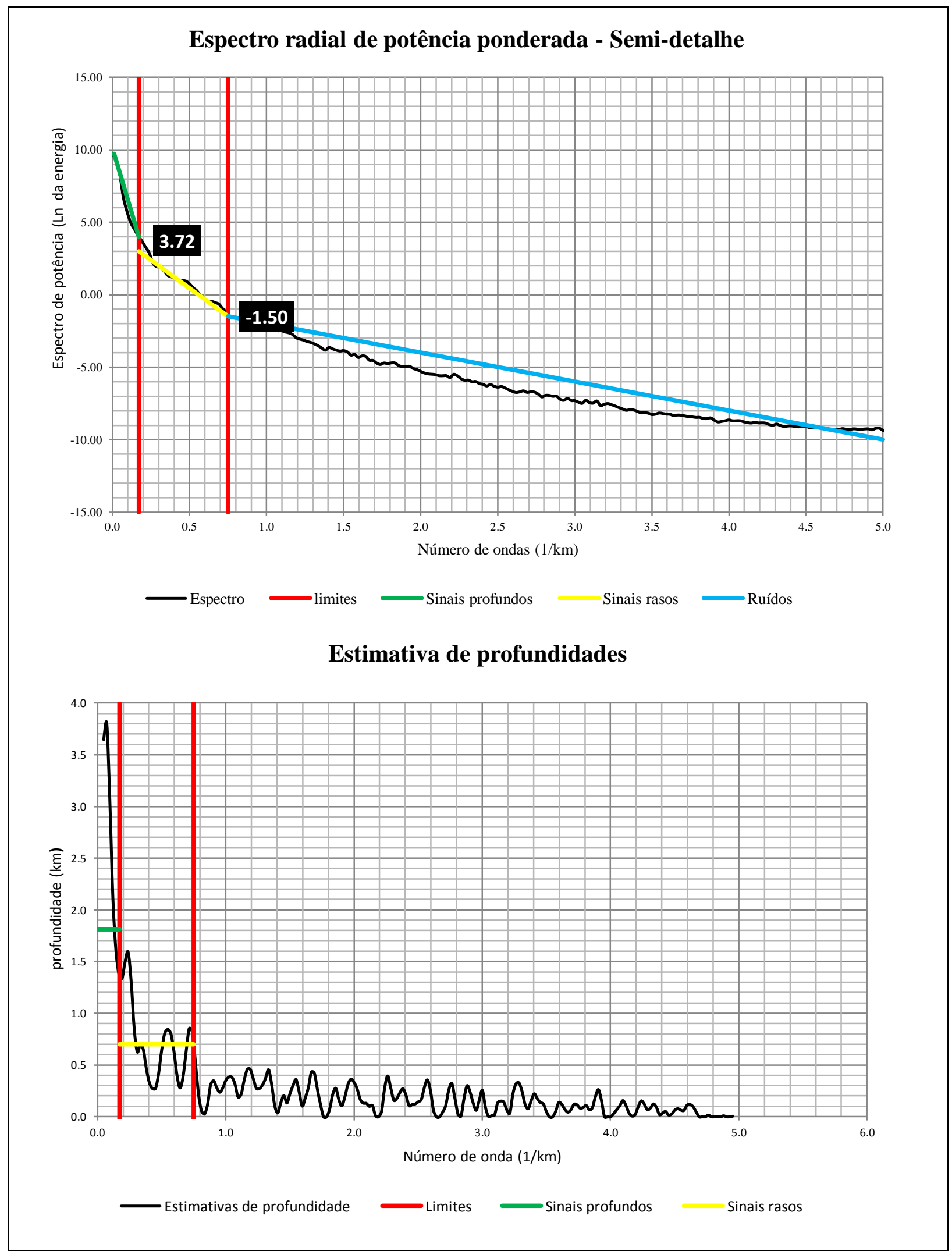

Figura 6.4 - Gráfico do espectro de potência radialmente ponderado gerado a partir do mapa Bouguer do levantamento de semi-detalhe, com indicação das profundidades médias das fontes. 
Adotou-se a profundidade, aproximada, de 1800 metros como contato entre a bacia e o embasamento cristalino, baseando-se nas informações do perfil do poço pioneiro exploratório 1-AB-1-SP, da Petrobras, existente na área de estudo e mostrado na Figura 3.15. Este perfil informa a profundidade de 1650 metros do embasamento. Levando em conta que este poço foi locado na parte mais alta do Alto Estrutural e que o perfil descreve o embasamento constituido por quartzito, adotou-se uma profundidade um pouco maior, aproximadamente 1800 metros. A segunda parte, reta 2 em amarelo, reflete fontes mais rasas, provavelmente, localizadas dentro da bacia. A partir de $0.5 \mathrm{rad} / \mathrm{km}$, aproximadamente, considerou-se ruído e foi descartado, reta azul. Desta forma, o mapa bouguer foi filtrado em dois intervalos, usando a profundidade de 1800 metros como referência. Acima deste valor, com intuito de analisar o embasamento e valores menores que este patamar até a superfície, visando, principalmente, as rochas básicas (diabásio).

Tabela 6.4 - Estatística descritiva do espectro da Figura 6.4.

\begin{tabular}{|c|c|c|c|}
\hline 5_DEPTH & Profundo & 5_DEPTH & Raso \\
\hline Média & 2.604473 & Média & 0.699864 \\
\hline Erro padrão & 0.427103 & Erro padrão & 0.076032 \\
\hline Mediana & 2.59353 & Mediana & 0.646531 \\
\hline Modo & \#N/D & Modo & $\# N / D$ \\
\hline Desvio padrão & 1.046184 & Desvio padrão & 0.364636 \\
\hline Variância da amostra & 1.0945 & Variância da amostra & 0.132959 \\
\hline Curtose & -2.38555 & Curtose & 1.006979 \\
\hline Assimetria & 0.004329 & Assimetria & 1.111178 \\
\hline Intervalo & 2.42854 & Intervalo & 1.319389 \\
\hline Mínimo & 1.37608 & Mínimo & 0.272741 \\
\hline Máximo & 3.80462 & Máximo & 1.59213 \\
\hline Soma & 15.62684 & Soma & 16.09687 \\
\hline Contagem & 6 & Contagem & 23 \\
\hline Nível de confiança $(95,0 \%)$ & 1.097902 & Nível de confiança $(95,0 \%)$ & 0.15768 \\
\hline
\end{tabular}

\subsection{3 - Aplicação do Filtro Butterworth aos dados gravimétricos de semi-detalhe}

A partir deste espectro da Figura 6.4 foi aplicado o filtro Passa-Banda (item 4.4.2.2) para testar esses intervalos, pois sua resposta é muita rápida e serve de parâmetro para utilização de outro filtro tão eficaz quanto. Porém, este filtro aplica um corte abrupto a um espectro, isto introduz, na maioria das vezes, um valor de ringing (fenômeno de Gibbs, 
Geosoft, 2009, p. 28) significativo. Assim, o filtro Butterworth (item 4.4.2.4), mais suave, foi usado em substituição ao filtro Passa-Banda (Geosoft, 2009. p. 57).

Os valores da anomalia Bouguer, no domínio do espaço, foram convertidos para o domínio da frequência espacial (número de onda) por meio da transformada rápida Fourier, utilizando o procedimento de filtragem interativa de espectros do programa do Oasis Montaj (Geosoft, 2010, p. 28). O filtro Butterworth foi aplicado em três intervalos de número de onda, com o parâmetro <<Regional>> selecionado, com base no espectro da Figura 6.4 e testado com o filtro Passa-Banda: A) 0.0 a $0.01 \mathrm{rad} / \mathrm{km}$; B) 0.0 . a $0.17 \mathrm{rad} / \mathrm{km}$; C) 0.0 a 0.5 $\mathrm{rad} / \mathrm{km}$. Utilizando parâmetro <<residual〉> selecionado, foram escolhidos mais dois intervalos: C) 0.17 a 5, final do espectro da Figura 6.5, D) 0.5 a $5 \mathrm{rad} / \mathrm{km}$, interpretado como ruído. Como o filtro Butterworth não trabalha de forma direta como o filtro Passa-Banda, os intervalos de interesse foram obtidos da seguinte forma (Figura 6.2):

- Passa-baixa (parâmetro <<regional〉> selecionado):

$1^{\circ}$ ) Intervalo: 0 a $0.01 \mathrm{rad} / \mathrm{km}=\operatorname{grid} A$;

$2^{\circ}$ ) Intervalo: 0 a $0.17 \mathrm{rad} / \mathrm{km}=\operatorname{grid} B$;

$\left.3^{\circ}\right)$ Intervalo: 0 a $0.5 \mathrm{rad} / \mathrm{km}=$ grid $C$;

Para os intervalos desejados fez-se a subtração:

grid $B-\operatorname{grid} A=0.01$ a $0.17 \mathrm{rad} / \mathrm{km}$;

grid $C-\operatorname{grid} A=0.01$ a $0.5 \mathrm{rad} / \mathrm{km}$;

- Passa-alta (parâmetro <<residual>> selecionado):

$4^{\circ}$ ) Intervalo: 0.17 a $5 \mathrm{rad} / \mathrm{km}=\operatorname{grid} D$;

$5^{\circ}$ ) Intervalo: 0.5 a $5 \mathrm{rad} / \mathrm{km}=$ grid $E$.

Para o intervalo desejado, fez-se a subtração:

grid $D-$ grid $E=0.17$ a $0.5 \mathrm{rad} / \mathrm{km}$;

Foram testados vários valores para o parâmetro <<grau da função〉> do filtro Butterworth (Geosoft, 2009, p. 57). O valor que forneceu a melhor resposta foi o grau 9, exemplificado na Figura 6.5. 
Figura 6.5 - Exemplo de aplicação do filtro Butterworth ao espectro de potência do levantamento de semidetalhe e seu respectivo valor de corte (linhas azuis). O espectro resultante é mostrado na linha de cor vermelha. $\mathrm{O}$ intervalo de corte foi 0.0 a $0.17 \mathrm{rad} / \mathrm{km}$ para profundidades maiores que 1800 metros, aproximadamente.

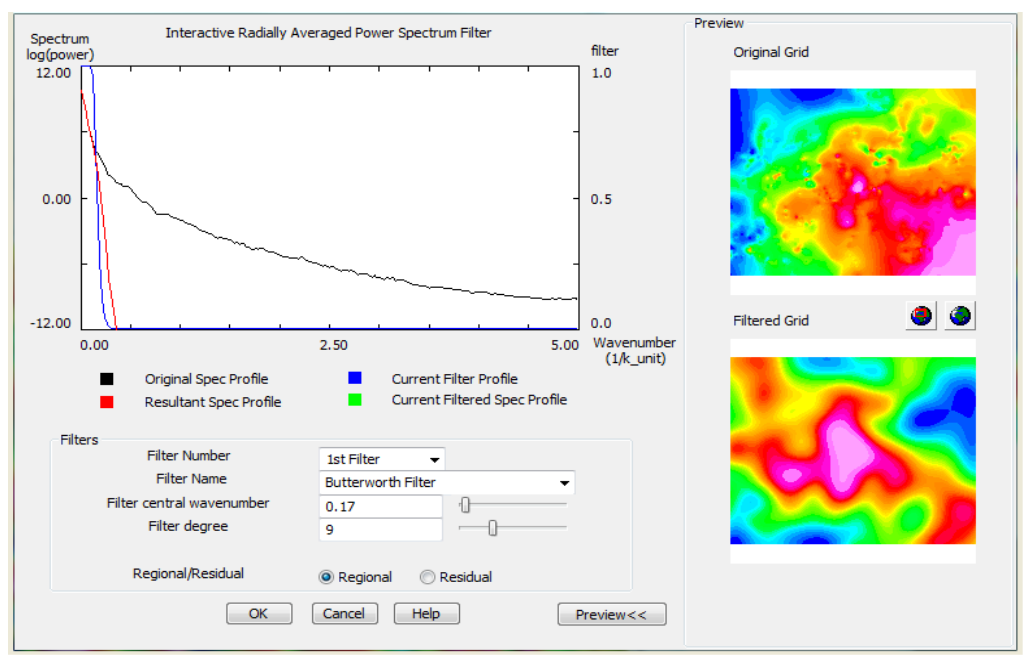

\subsection{4 - Resultados do Filtro Butterworth - parâmetro regional - aplicado aos} dados gravimétricos de semi-detalhe

O primeiro intervalo de 0.01 a $0.17 \mathrm{rad} / \mathrm{km}$, com profundidade aproximada de 1800 metros, foi interpretado como embasamento. $\mathrm{O}$ resultado da filtragem deste intervalo é mostrado na Figura 6.6. Nesta figura pode-se notar uma clara orientação da anomalia a NW. A Figura 6.6-A mostra a anomalia gravimétrica no embasamento com sobreposição do contorno do topo da Fm. Teresina e falhas descritas por IPT (1979). Usou-se para análise somente o contorno confeccionado por IPT (1979), pois se considerou o contorno estrutural da Fm. Teresina de Araújo et al. (2006) equivalente a este. Analisando a figura 6.6-A, pode-se verificar que, na área de ocorrência da Fm. Teresina, a estrutura dômica é marcada por uma anomalia gravimétrica positiva, mostrando a correlação do Alto Estrutural de Anhembi com uma feição do embasamento. Também se verifica a perfeita correlação com as falhas descritas por IPT (1979). A Figura 6.6-B apresenta a anomalia gravimétrica no embasamento sobreposto pela integração dos sistemas de falhas de IPT (2005) e Araújo (2006). Observamse duas direções relacionadas aos sistemas de falhas: NE e NW. Há uma boa relação com a anomalia gravimétrica positiva apresentada. Ainda nesta figura, observa-se o sistema escalonado tipo dominó, com mergulho para SW, como descrito por IPT (2005, p. 174). O IPT (1979) em seu trabalho realizado na área de estudo (Figura 3.16), confeccionou dois perfis geológicos (Figuras 3.17 e 3.18). Estes perfis foram modelados a partir de dois perfis traçados no mapa Bouguer residual, obtidos no intervalo de 0.01 a $0.5 \mathrm{rad} / \mathrm{km}$ (Figura 6.7) no filtro Butterworth (Figura 6.2). Os dois conjuntos de pontos, que representam estes perfis, foram utilizados para modelagem buscando o melhor ajuste. Este processo foi executado com 
o programa GRAVMAG (Pedley et al., 1997) e visou mostrar o topo do embasamento. As Figuras 6.8 e 6.9 mostram o melhor ajuste obtido, resultado desta modelagem e são comparadas aos perfis geológicos do IPT (1979), Figuras 3.17 e 3.18. Para as rochas da cobertura sedimentar foi utilizada a média de $2,40 \mathrm{~g} / \mathrm{cm}^{3}$, com base nos valores obtidos em laboratório e descritos na literatura (Telford et al., 1990, p.16), para densidades dos sedimentos arenosos predominantes nas formações geológicas da área de estudo. Também por ser valor obtido pelo melhor ajuste entre os dados observados e calculados. Nas rochas básicas (diabásio) utilizou o valor médio de $2,84 \mathrm{~g} / \mathrm{cm}^{3}$ para densidade. Da mesma forma, este valor foi obtido pelo melhor ajuste entre os dados observados e calculados. Quanto às rochas do embasamento cristalino utilizou o valor médio $2,80 \mathrm{~g} / \mathrm{cm}^{3}$ de densidade. Valor obtido através de amostragem coletada na borda da Bacia do Paraná. Nestes perfis pode-se observar que o embasamento da área de estudo tem características de horst/graben com blocos abatidos e que as falhas estão preenchidas por diques com alto mergulho. Outros dois perfis foram modelados somente com o conhecimento da forma da anomalia, cruzando-os nas orientações NW e NE para melhor caracterizá-la. Para isto foi aplicado o filtro continuação para cima no mapa residual gravimétrico, determinado pelo intervalo de 0.01 a $0.5 \mathrm{rad} / \mathrm{km}$ (Figura 6.7). $\mathrm{O}$ mapa resultante é mostrado na Figura 6.10. Nesta figura foram traçados dois perfis com orientações NE e NW, perfis $E F$ e $G H$, respectivamente. A continuação para cima foi testada para várias alturas, sendo que a altura selecionada foi a de 1000 metros, pois esta atenuou razoavelmente a influência das fontes rasas e preservou o formato da anomalia em geral. As Figuras 6.11 e 6.12 mostram o resultado desta modelagem. Procurou-se uma possível forma do topo do embasamento nestas direções, com a minimização das fontes rasas.

Fazendo uma comparação com estruturas vizinhas, Pitanga, Pau d'alho, Artemis e Jibóia, estudadas por Sousa (2002, p. 183), nota-se uma semelhança, quanto à tectônica. O Alto Estrutural de Anhembi está contido na zona de falha de Jacutinga (PT3, Soares, 1991), assim como as estruturas vizinhas aqui citadas. Soares et al. (1996) descrevem todas as estruturas desta zona de falha possuidoras de características semelhantes: alongadas e assimétricas com direção NE, cortados por estruturas NW.

Outra constatação é a existência de uma concordância da anomalia positiva gravimétrica com a direção do rio Tietê, ou seja, a noroeste, concordante com o Lineamento Estrutural do Tietê, descrito por Saad (1977, p.96) e Coimbra et al. (1977).

A Figura 6.13 apresenta o resultado da aplicação de um filtro de realce denominado inclinação do sinal analítico - ISA (Miller \& Singh, 1994), item 4.4.5.1, sobre a o mapa da Figura 6.10. Este filtro tem como principal atributo: máximos nos centros dos corpos equalização das amplitudes, realçando os picos da anomalia. Assim, é possível verificar nesta 
figura que o rio Tietê está sobre a anomalia gravimétrica positiva. A Figura 6.13 mostra uma separação entre uma região de baixo gravimétrico a nordeste, com uma faixa central orientada a noroeste-sudeste caracterizada como uma região de alto gravimétrico. Trata-se de um resultado extremamente importante no ponto de vista da estratigrafia da Bacia do Paraná, pois mostra a existência de um alto gravimétrico separando a ocorrência das formações Serra Alta, Teresina e Rio do Rasto, a sul do rio Tietê, da formação Corumbataí a norte do mesmo rio, como descrito por diversos autores (e.g. Schneider et al., 1974). Além disso, este alto gravimétrico confirma as observações de Coimbra et al. (1977), que baseando-se no mapa de isópacas do intervalo Irati-Serra Alta (conforme descritos por Northfleet et al. 1969, p. 117) concluem que o Lineamento Estrutural do Tietê representa o soerguimento que serviu de limite para a deposição dos sedimentos do intervalo Irati-Serra Alta. 

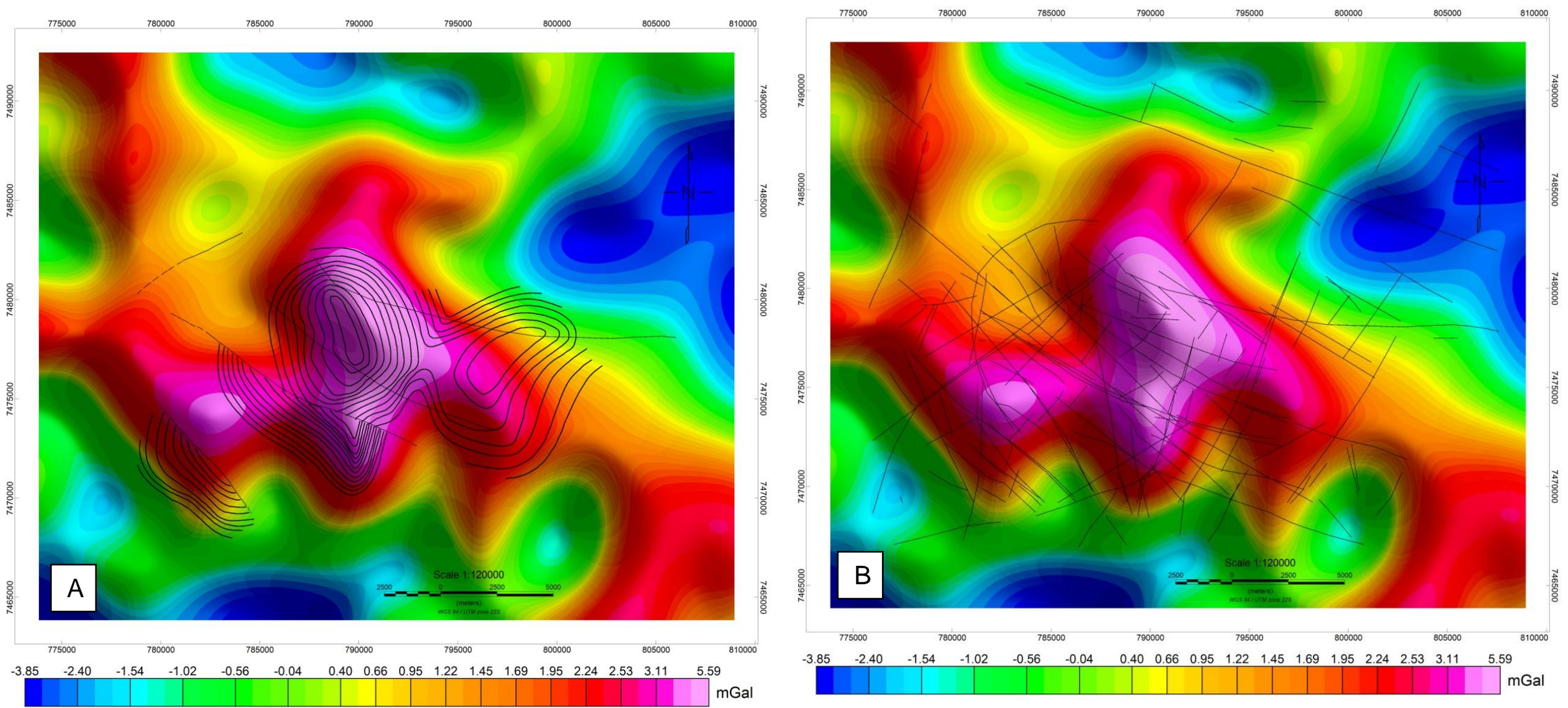

Figura 6.6 - Mapa filtrado do levantamento de semi-detalhe, sombreado, iluminação de $45^{\circ}$, elevação de $45^{\circ}$, com profundidade maior que 1800 metros. (A) - Embasamento com contorno estrutural da Fm. Teresina e falhas segundo IPT (1979). (B) Embasamento sobreposto pela integração dos sistemas de falhas de IPT (2005) e Araújo et al. (2006). 


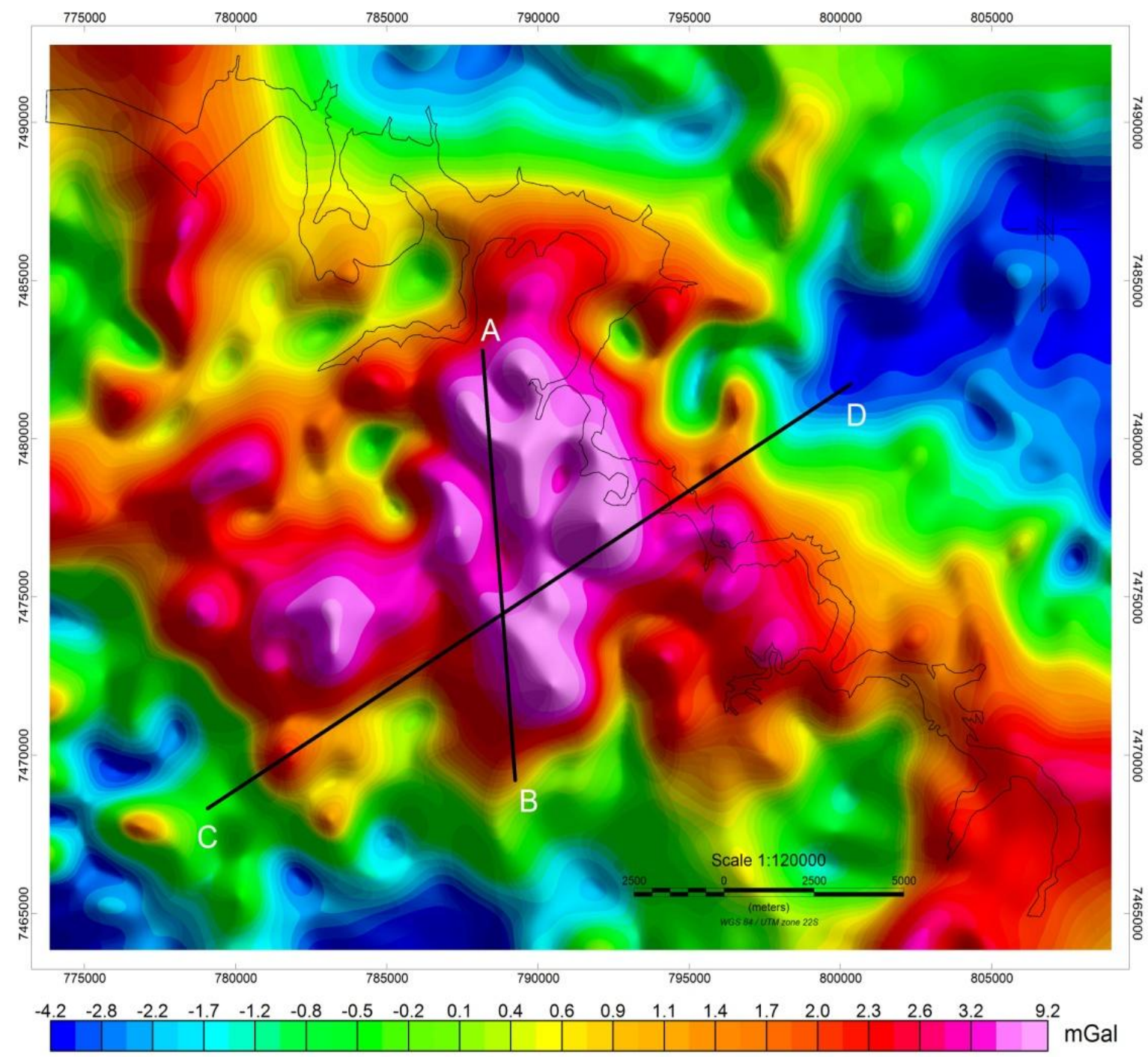

Figura 6.7 - Mapa residual gravimétrico, sombreado, iluminação de $45^{\circ}$, elevação de $45^{\circ}$, determinado pelo intervalo de $0.01 \mathrm{a} 0.5 \mathrm{rad} / \mathrm{km}$. Dois perfis estão representados: $A B$ e $C D$. Eles foram modelados utilizando o programa GRAVMAG. 


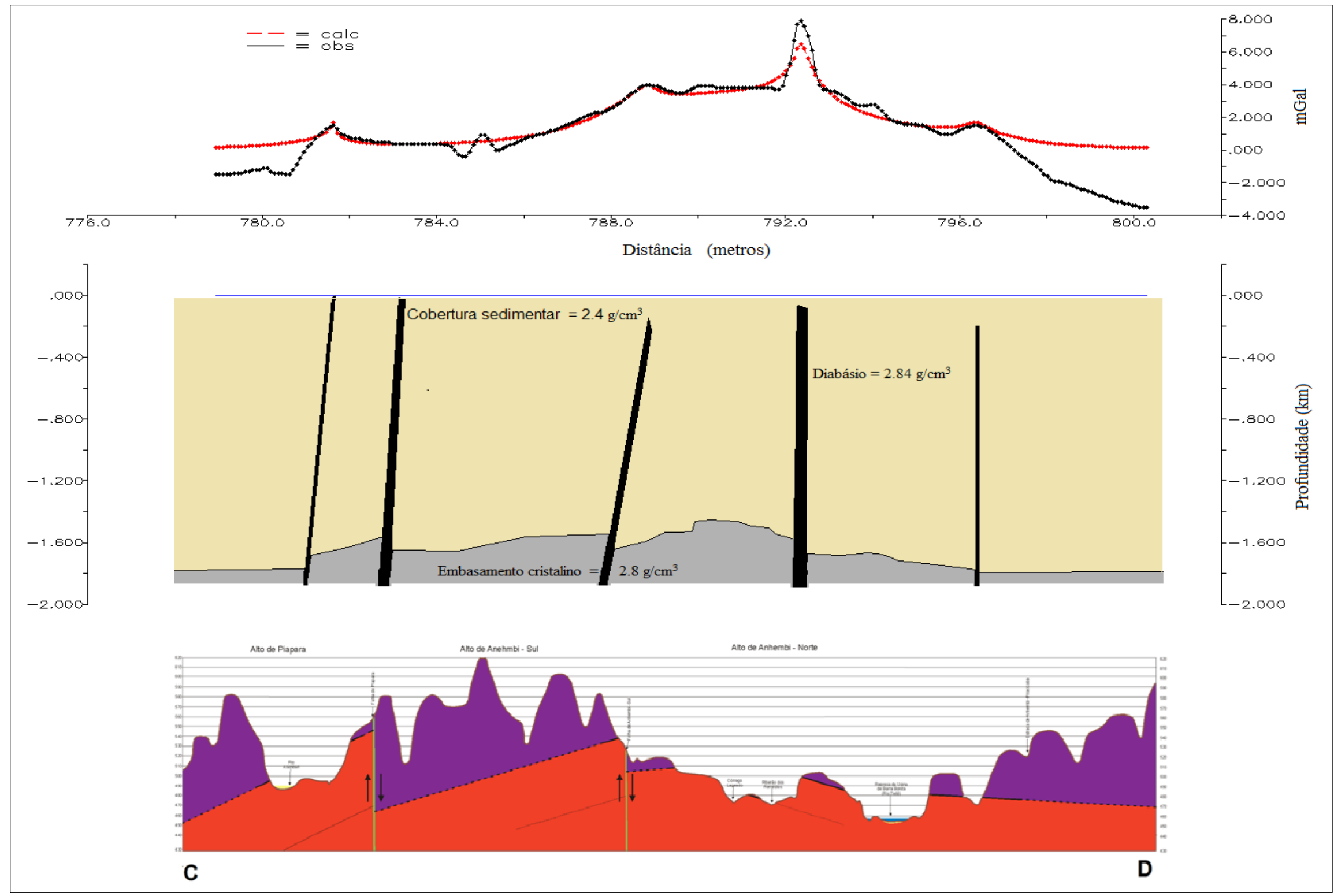

Figura 6.8 - Perfil geológico $C D$ pelo IPT (1979) modelado pelo programa GRAMAG. 


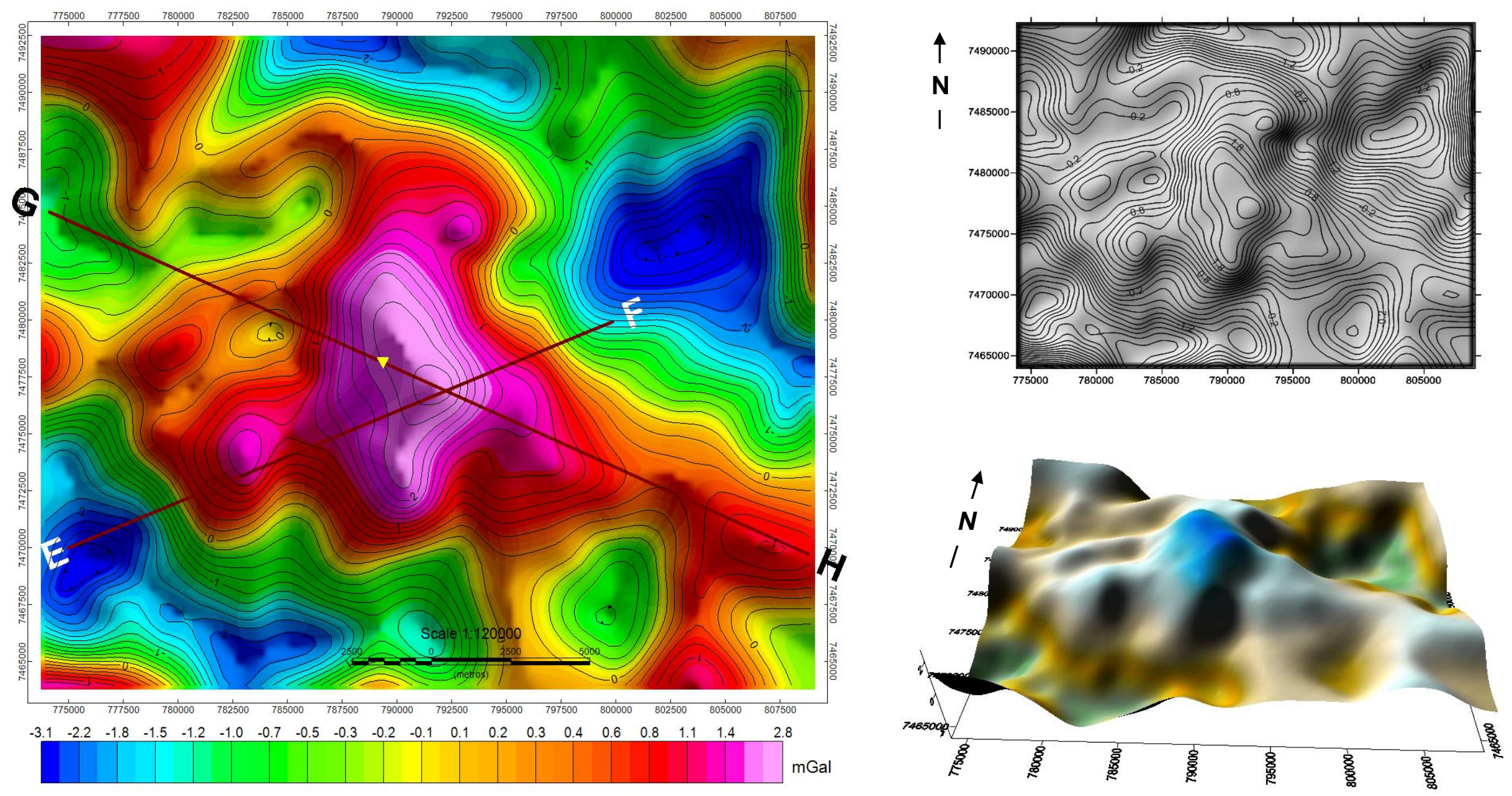

Figura 6.10 - Mapa continuado para cima (1000 metros) do mapa residual gravimétrico, determinado pelo intervalo de 0.01 a $0.5 \mathrm{rad} / \mathrm{km}$ (Figura 6.7), com curvas de contorno, intervalo de $0.2 \mathrm{mGal}$. Também está representado o poço pioneiro exploratório 1-AB-1-SP da Petrobras (triângulo amarelo invertido) e são traçados mais dois perfis $E F$ e $G H$, cruzando o Alto Estrutural de Anhembi. 


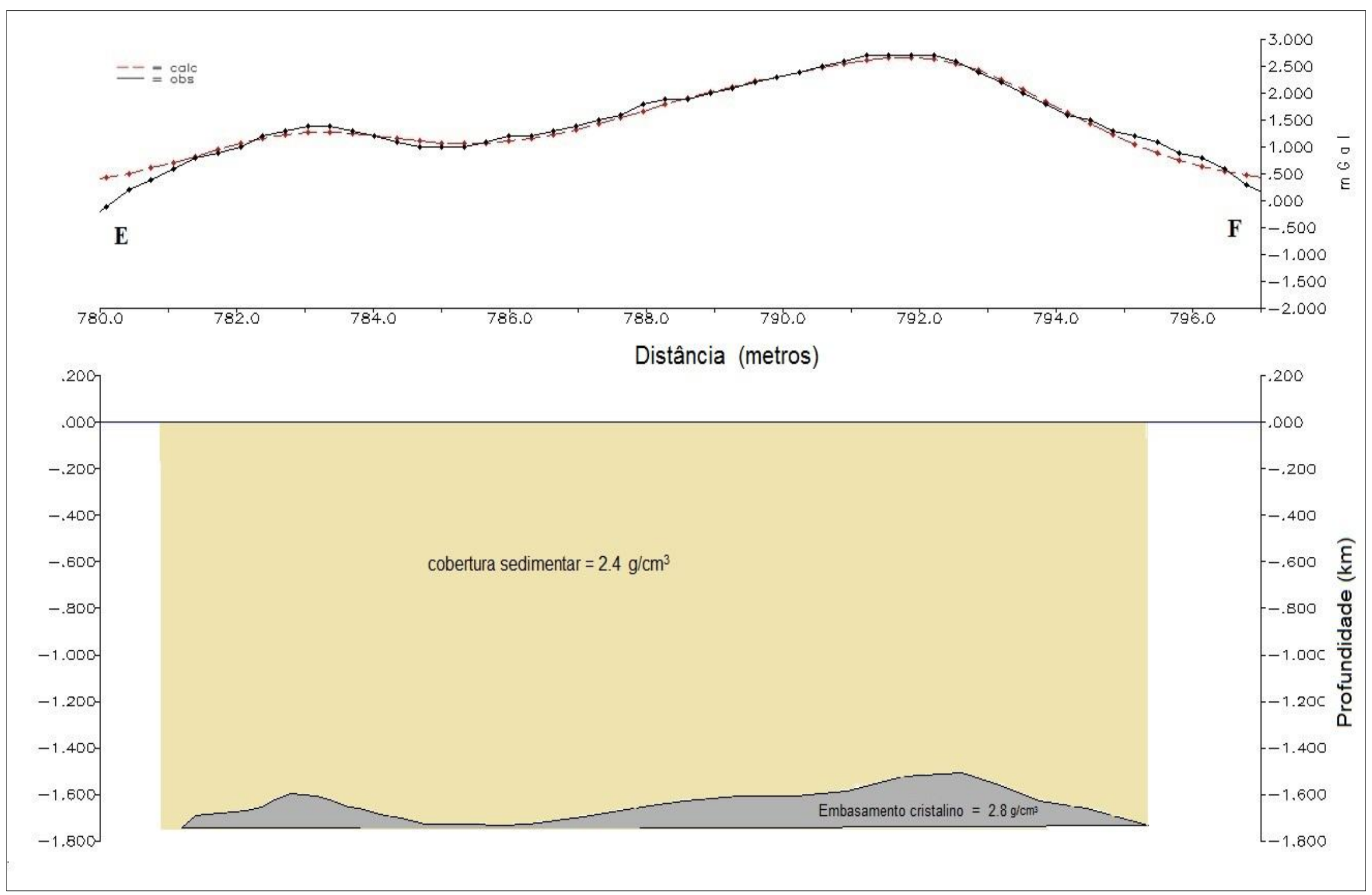

Figura 6.11 - Perfil EF modelado pelo programa GRAMAG do mapa continuado para cima à 1000 metros (Figura 6.10). 


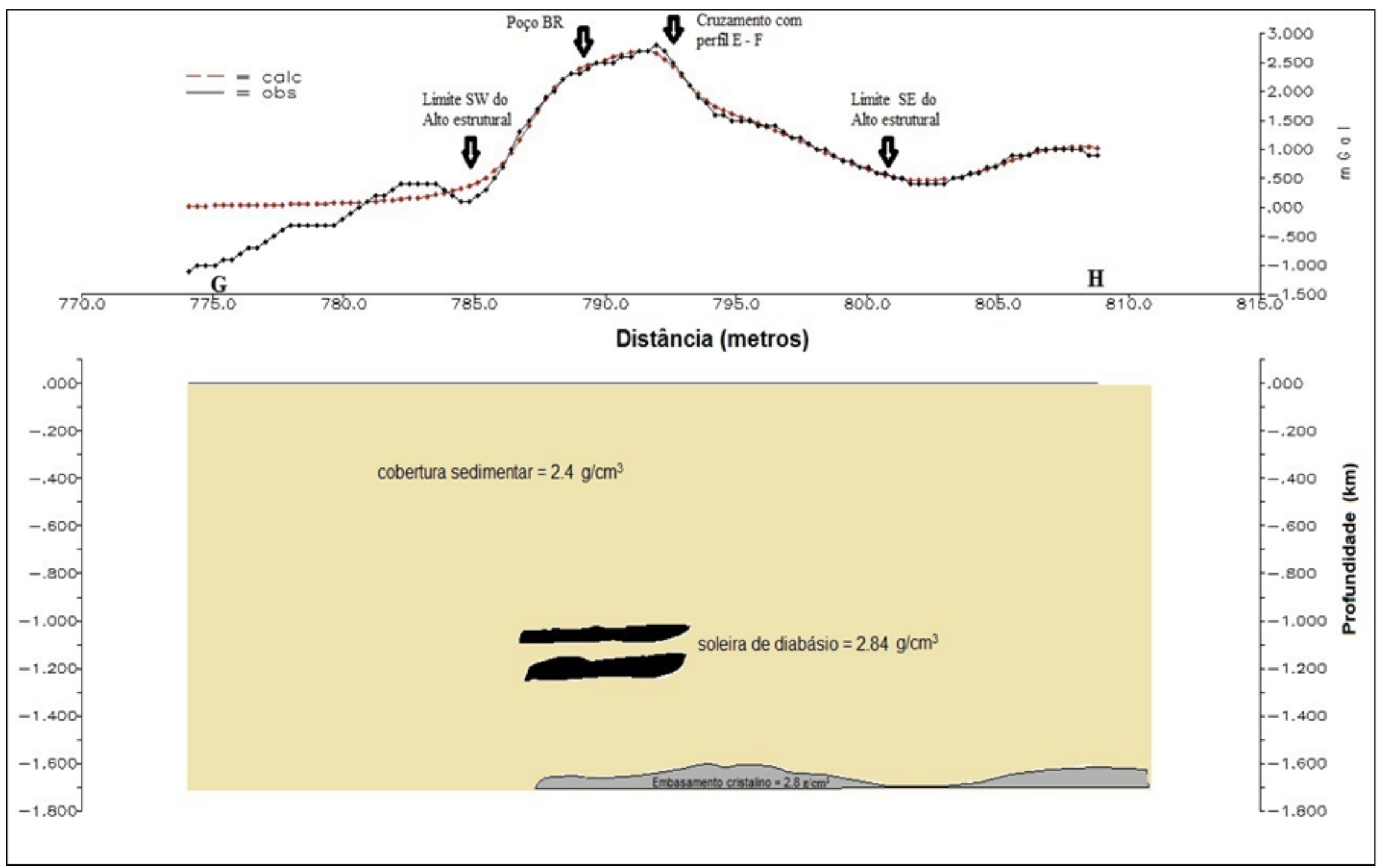

Figura 6.12 - Perfil GH modelado pelo programa GRAMAG do mapa continuado para cima à 1000 metros (Figura 6.10). 


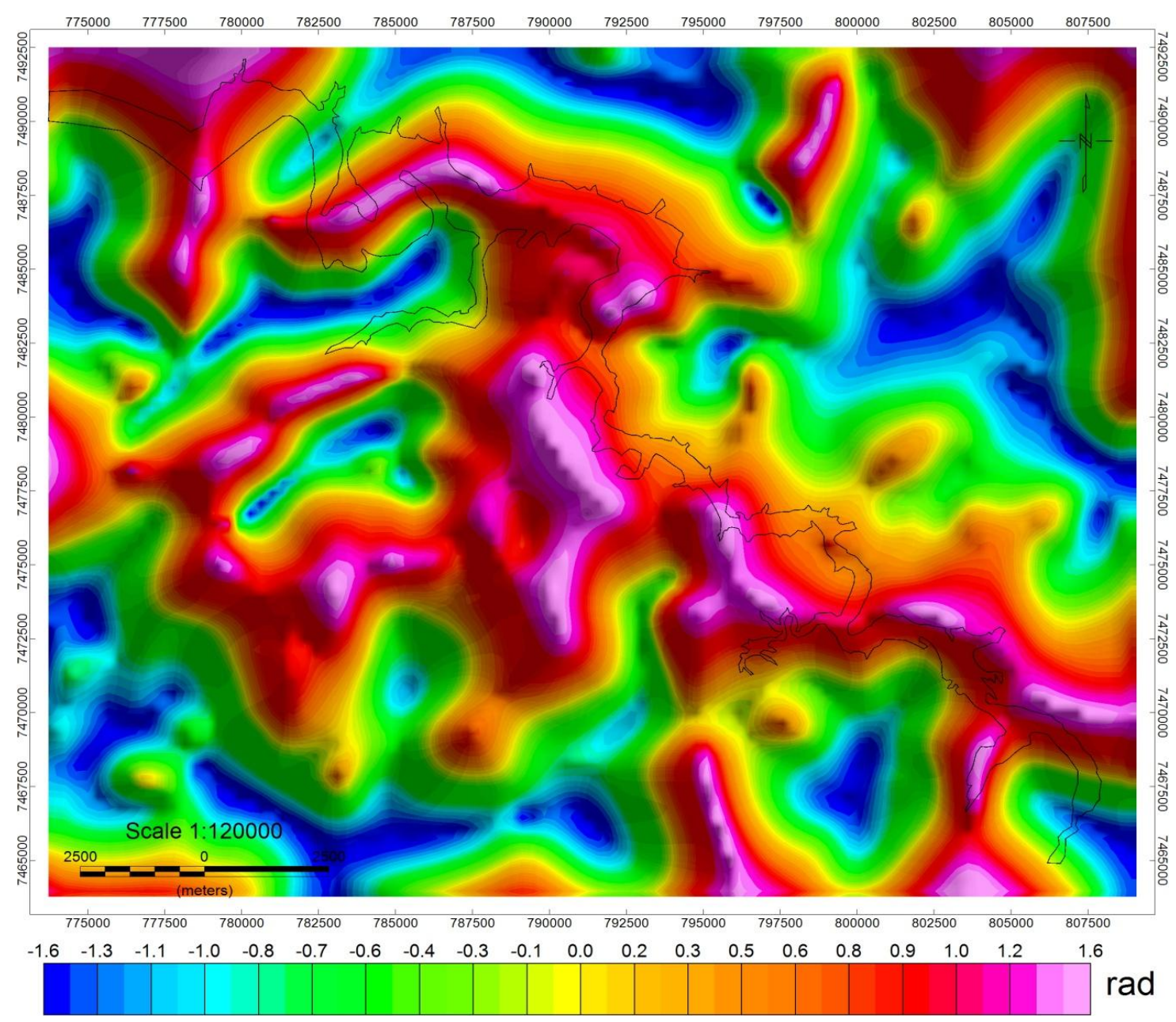

Figura 6.13 - Mapa da inclinação do sinal analítico - ISA, sombreado, iluminação de $45^{\circ}$, elevação de $45^{\circ}$, aplicado ao mapa gravimétrico resultante da aplicação do filtro Passa-Banda, para profundidades maiores que 1800 metros com sobreposição do rio Tietê.

\subsection{5 - Resultados do Filtro Butterworth - parâmetro residual - aplicado aos dados gravimétricos de semi-detalhe}

O segundo intervalo de 0.17 a $0.5 \mathrm{rad} / \mathrm{km}$ (Figura 6.2) é interpretado como rochas que estão dentro da bacia, acima de 1800 metros de profundidade. O produto desta filtragem é mostrado na Figura 6.14. A esta figura é sobreposta o contorno estrutural da Fm. Teresina e o sistema de falhas confeccionado pelo IPT (1979). As anomalias representadas neste mapa estariam relacionadas a rochas básicas (diabásios) localizadas na bacia. Uma característica interessante observada no relevo gravimétrico é a forma circular na área do Alto Estrutural de Anhembi, círculo branco na Figura 6.14-A. Esta estrutura circular está relacionada à interpretação morfoestrutural feita por Araújo (2006), Figura 6.14-B, isto é, esta anomalia morfoestrutural é reflexo da estruturação encontrada em subsuperfície.

A existência desta estrutura circular é consequência do encontro de dois sistemas de falhamentos: Jacutinga, atuando na direção NE e Tietê na direção NW. 
6.2.6 - Deconvolução de Euler aplicado aos dados gravimétricos de semidetalhe

Para uma estimativa de localização e profundidade destas fontes rasas utilizou a técnica da deconvolução de Euler (Reid et al. 1990), por meio de rotinas do programa Geosoft (2010, p. 11). Para o grid de entrada utilizou a primeira derivada vertical (Figura 6.15) do mapa residual gravimétrico (Figura 6.14-A). Desta forma, há um incremento da razão do decréscimo por uma potência, tornando o índice estrutural dos campos gravimétrico e magnético equivalentes, considerando ser o mesmo modelo de fontes Geosoft (2010, p. 64). Na prática, como os alvos são diques e soleiras, pode-se utilizar o índice estrutural de valor igual a 1. Assim, os melhores resultados para o conjunto de soluções de Euler foram $\mathrm{N}=1$, tamanho da janela $=3$ células e $4 \%$ de tolerância. A Figura 6.16 apresenta o resultado da deconvolução de Euler sobre mapa da derivada vertical. Vários intervalos de profundidade, de 0 a 1800 metros, estão representados, num total de 37396 soluções. As soluções possuem um valor mínimo de 209 e máximo de 1800 metros, média de 936 metros. Observa-se que 88.5\% das soluções estão a entre 600 a 1200 metros de profundidade.

Os intervalos de profundidades, em percentual, dos dados estão distribuídos da seguinte forma (Tabela 6.5):

Tabela 6.5 - Distribuição das profundidades, em porcentagem na deconvolução de Euler.

\begin{tabular}{|c|c|}
\hline Intervalos & Porcentagem (\%) \\
\hline 0 a 300 & 0.02 \\
\hline 300 a 400 & 0.17 \\
\hline 400 a 500 & 0.54 \\
\hline 500 a 600 & 1.77 \\
\hline 600 a 800 & 22.2 \\
\hline 800 a 900 & 21.8 \\
\hline 900 a 1000 & 20.4 \\
\hline 1000 a 1200 & 24.1 \\
\hline 1200 a 1400 & 6.70 \\
\hline 1400 a 1600 & 1.8 \\
\hline 1600 a 1800 & 0.5 \\
\hline $\begin{array}{r}\text { Mínima } \\
\text { Média } \\
\text { Máxima } \\
\mathbf{N}^{\mathbf{0}}\end{array}$ & $\begin{aligned} \text { de profundidade } & =209 \text { metros } \\
& =936 \text { metros } \\
& =1800 \text { metros } \\
\text { soluções } & =37396\end{aligned}$ \\
\hline
\end{tabular}




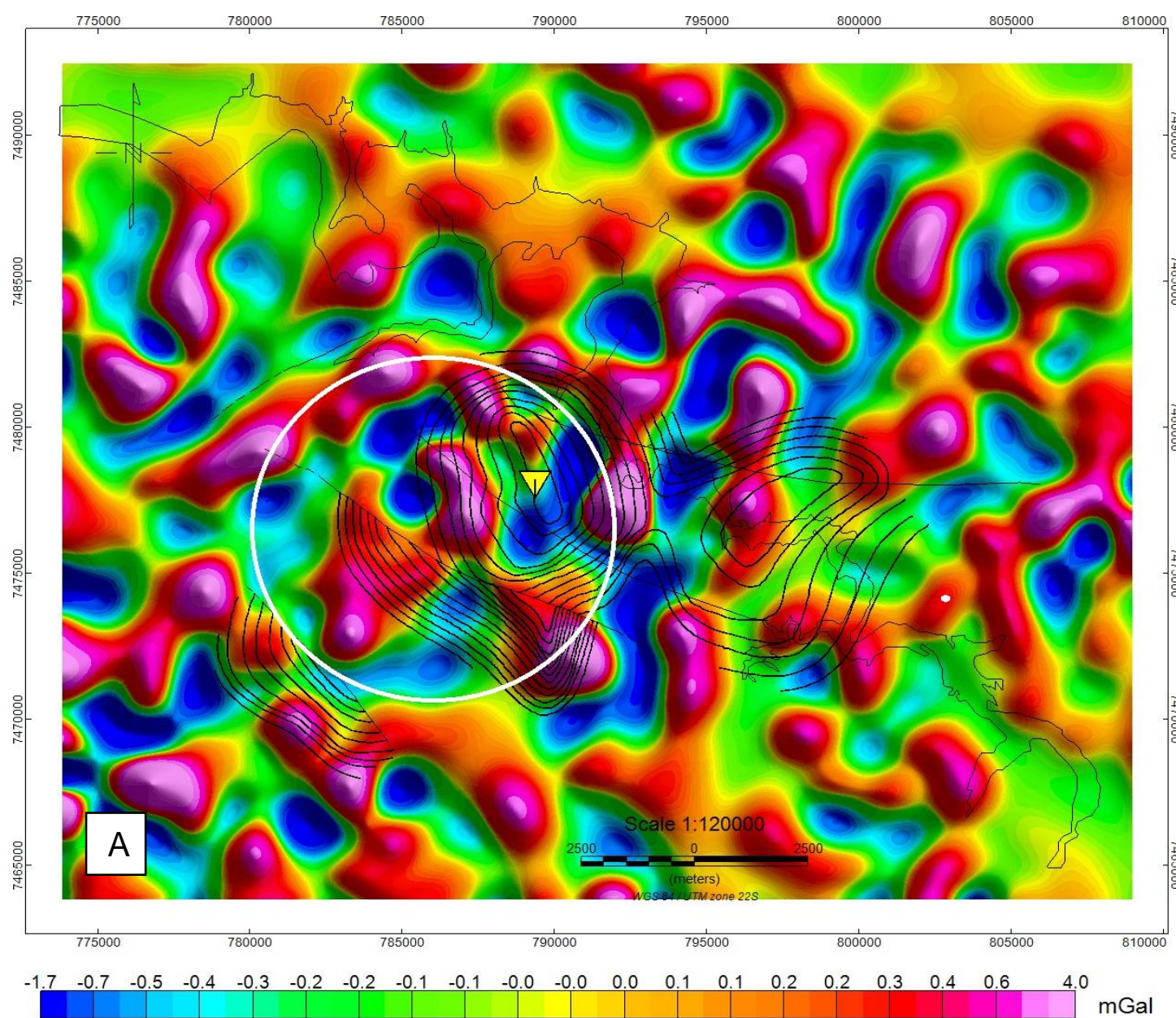

Figura 6.14 (A) - Mapa residual gravimétrico, sombreado, iluminação de $45^{\circ}$, elevação de $45^{\circ}$, com profundidade menor que 1800 metros, aproximadamente. O poço 1-AB-1-SP da Petrobras está representado com triângulo amarelo. Em branco é mostrado estruturas com formato circular.

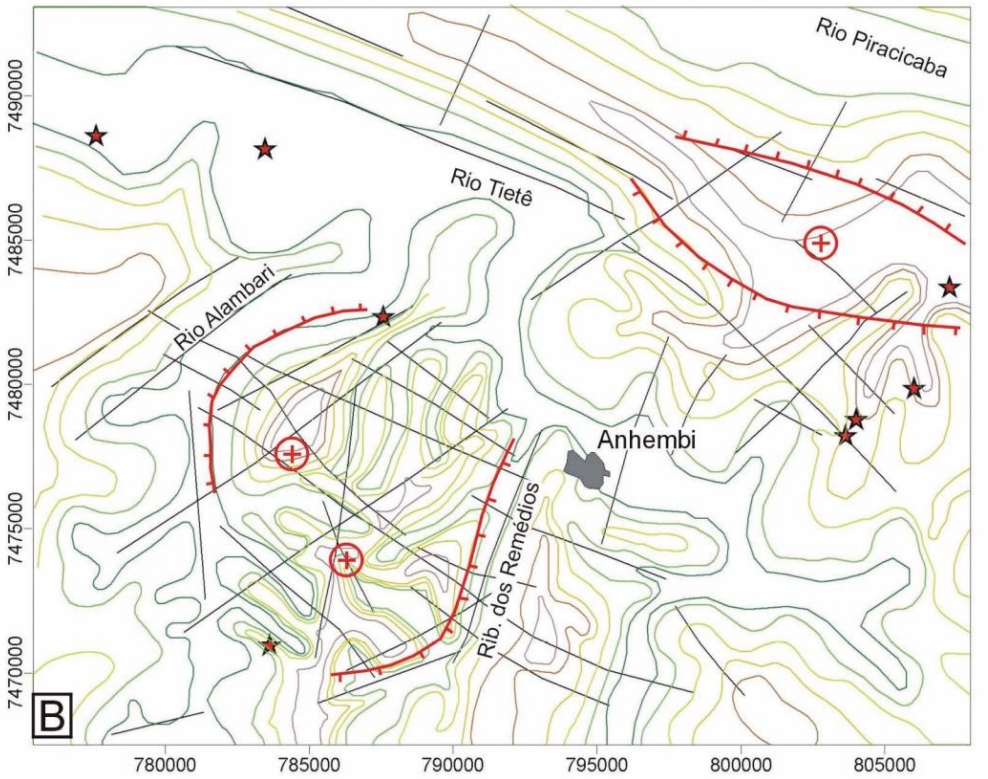

Figura 6.14 (B) - Curvas de isovalor com interpretação morfoestrutural na área de estudo (modificado de Araujo et al., 2006, p. 56). 


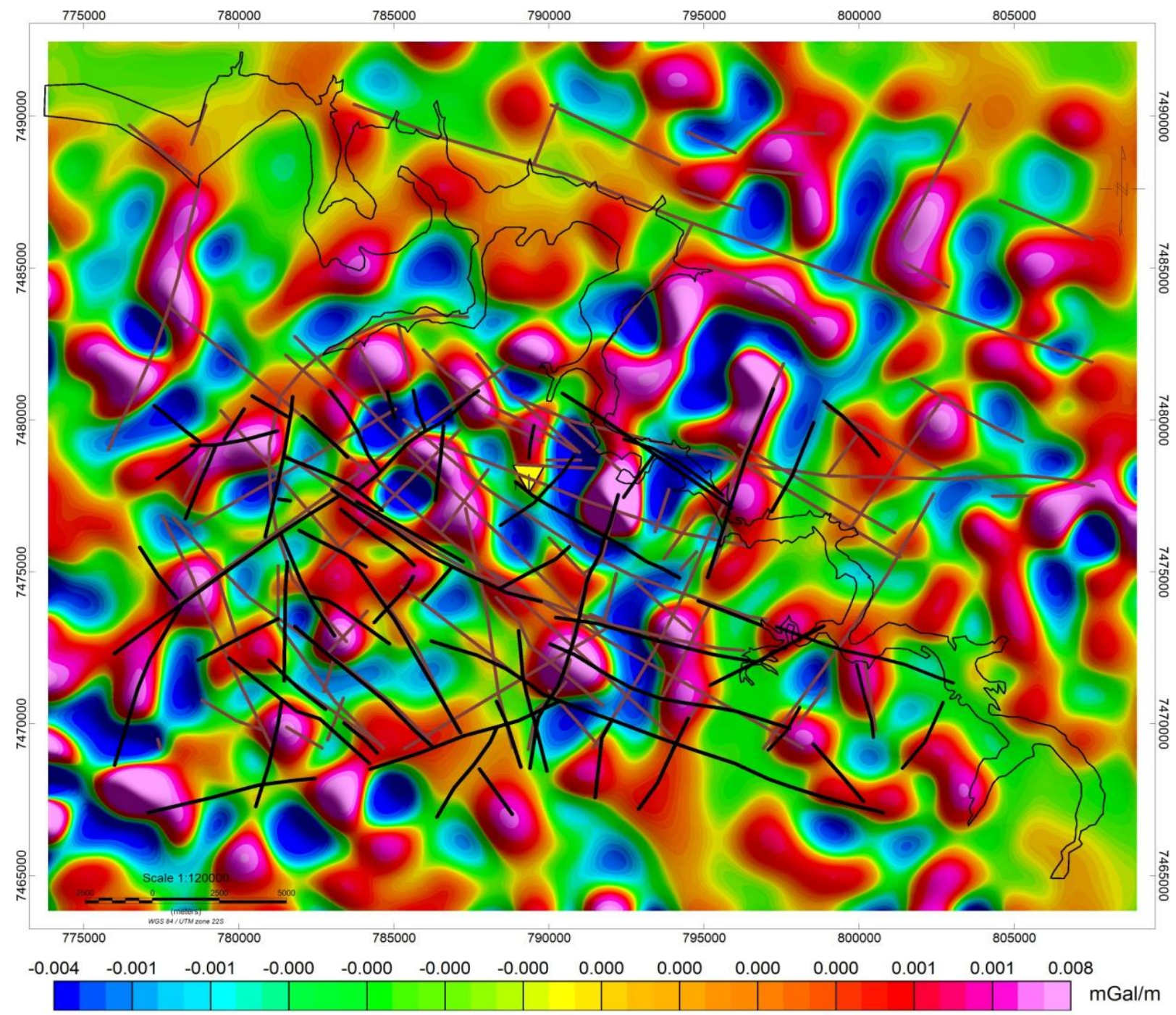

Figura 6.15 - Mapa da $1^{\text {a }}$ derivada vertical, sombreado, iluminação de $45^{\circ}$, elevação de $45^{\circ}$, do mapa residual gravimétrico (Figura 6.14), sobreposto por sistema de falhas de IPT (1979 e 2005, p.166), em preto e Araújo et al. (2006, p. 51), em marrom. 


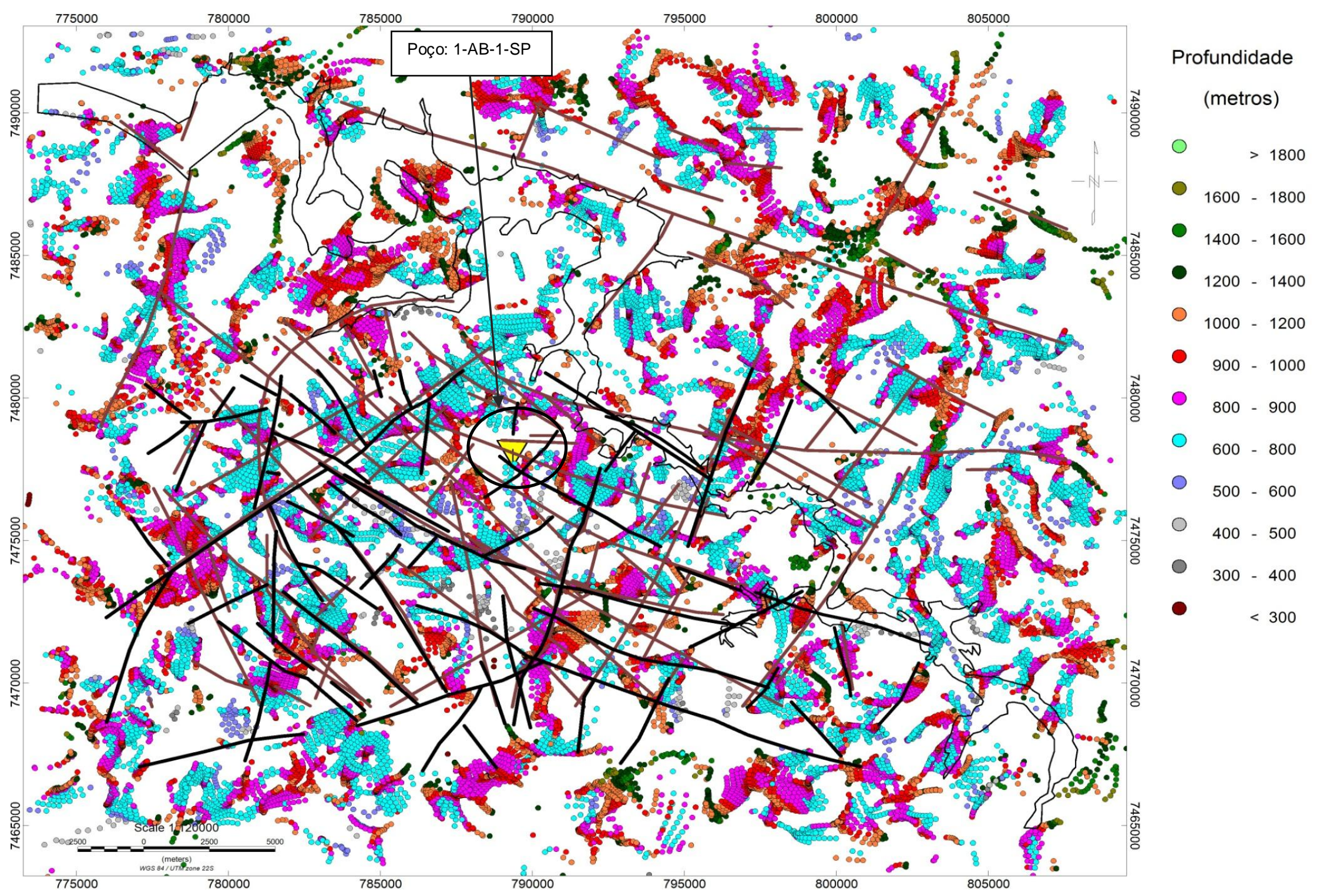

Figura 6.16 - Soluções de Euler calculado com base nos dados da Figura 6.15, sobrepostas ao sistema de falhas de e lineamentos de IPT (1979 e 2005, p.166) em preto e Araújo et al. (2006, p. 51) em marrom. 


\section{3 - Levantamento magnetométrico de semi-detalhe}

O levantamento magnetométrico de semi-detalhe realizado na área de estudo cobriu toda a área do Alto Estrutural de Anhembi e adjacências, numa área de 35 x $30 \mathrm{~km}$, aproximadamente, percorrendo as principais estradas (rodovias SP 147 e 193 mais as vicinais) e caminhos dentro da área de estudo, com 15868 pontos medidos. No total foram levantados 19047 pontos de medida válidos (300 pontos descartados, aproximadamente $2 \%$ do total, e 3479 relacionados ao levantamento de detalhe) num intervalo de leitura de 20 segundos cada, sendo duas medidas por ponto. Os espaçamentos variaram de 100 a 250 metros para os levantamentos de semi-detalhe (Figura 6.17). A localização dos pontos medidos foi feita automaticamente com o GPS acoplado no próprio magnetômetro. A partir dos valores de campo magnético total, depois da correção diurna, foi subtraído o IGRF (International Geomagnetic Reference Field) para área de estudo, apesar da variação de latitude ser de pouca significância, por ser uma área de pouca extensão. O valor do IGRF é disponibilizado pelo site http://www.ngdc.noaa.gov/seg/geomag/jsp/IGRF.jsp, acessado em junho de 2011.

Os dados magnetométricos foram processados através de rotinas do programa Oasis Montaj (Geosoft, 2005, p 76). que permite aplicação de correções, processamentos, confecção de mapas e aplicação de filtros especiais. O fluxo dos principais filtros aplicados aos dados magnetométricos pode ser vista na Figura 6.18, onde se mostra, de forma ilustrativa, os processos envolvidos e os respectivos produtos.

\subsection{1 - Mapa do Campo Magnético Total - CMT}

O mapa do campo magnético total - CMT - do levantamento de semi-detalhe foi produzido usando as rotinas do programa Geosoft (2005, p.92). O CMT foi gerado por interpolação baseado na mínima curvatura (Briggs, 1994) com tamanho de células de 100 metros. A localização geográfica das estações foi feita com base no sistema de coordenadas UTM, zona 22 sul do meridiano de Greenwich. O elipsóide de referência utilizado foi o WGS 84. O mapa resultante da interpolação pode ser visto na Figura 6.19, onde é mostrado o CMT da área do Alto Estrutural de Anhembi, sobreposto aos pontos de medidas magnetométricas. Assinalado num retângulo azul a área de ocorrência dos geiseritos. 
6.3.2 - Espectro de Potência aplicado aos dados magetométricos de semi-detalhe

A técnica do Espectro de Potência Ponderado Radialmente (Spector e Grant, 1970 e Geosoft, 2009. p. 28) foi aplicada ao mapa - CMT (Figura 6.19) com a finalidade de se separar o campo magnético residual - CMR - e retirar ruídos (Figura 6.20). De forma semelhante ao levantamento gravimétrico de semi-detalhe, a análise do espectro produzido pelo Geosoft (2009, p.28) foi realizada através da transferência do arquivo de dados calculados para o programa Excell da Microsoft ${ }^{\circledR}$. A Tabela 6.6 apresenta as estatísticas desta análise para as componentes de fontes: profunda e rasa. $\mathrm{O}$ espectro representado nesta figura apresenta duas partes representadas por retas, da esquerda para a direita. A primeira reta, em cor verde, tem uma profundidade média de 1400 metros $(0.23 \mathrm{rad} / \mathrm{km})$, já a segunda reta, em amarelo, possui em média 600 metros de profundidade (Figuras 6.20). Estas fontes magnéticas são constituídas por diabásios na forma de diques e soleiras (sills), conforme ocorrências em superfície, no caso de diques e informações do perfil do poço pioneiro exploratório 1-AB-1-SP, da Petrobras, para o caso de sill. Segundo este perfil, o sill é atingido na profundidade de 1015 metros, aproximadamente, e possui 200 metros de espessura. A partir de $0.65 \mathrm{rad} / \mathrm{km}$, aproximadamente, foi descartado e interpretado como ruído, reta azul.

Tabela 6.6 - Estatísticas descritivas do espectro da Figura 6.20.

\begin{tabular}{cccccc}
\hline 5_DEPTH & Profundo & & 5_DEPTH & Raso \\
\cline { 5 - 6 } \cline { 5 - 6 } Média & 1.471249 & & Média & 0.585913 \\
Erro padrão & 0.102276 & & Erro padrão & 0.043836 \\
Mediana & 1.39005 & & Mediana & 0.510268 \\
Modo & \#N/D & & Modo & \#N/D \\
Desvio padrão & 0.306829 & & Desvio padrão & 0.175344 \\
Variância da amostra & 0.094144 & & Variância da amostra & 0.030746 \\
Curtose & 0.824178 & & Curtose & -1.07818 \\
Assimetria & 1.135015 & & Assimetria & 0.53316 \\
Intervalo & 0.97034 & & Intervalo & 0.573277 \\
Mínimo & 1.11909 & & Mínimo & 0.336122 \\
Máximo & 2.08943 & & Máximo & 0.909399 \\
Soma & 13.24124 & & Soma & 9.374605 \\
Contagem & 9 & & Contagem & 16 \\
\cline { 5 - 6 } \cline { 5 - 6 } & & & &
\end{tabular}




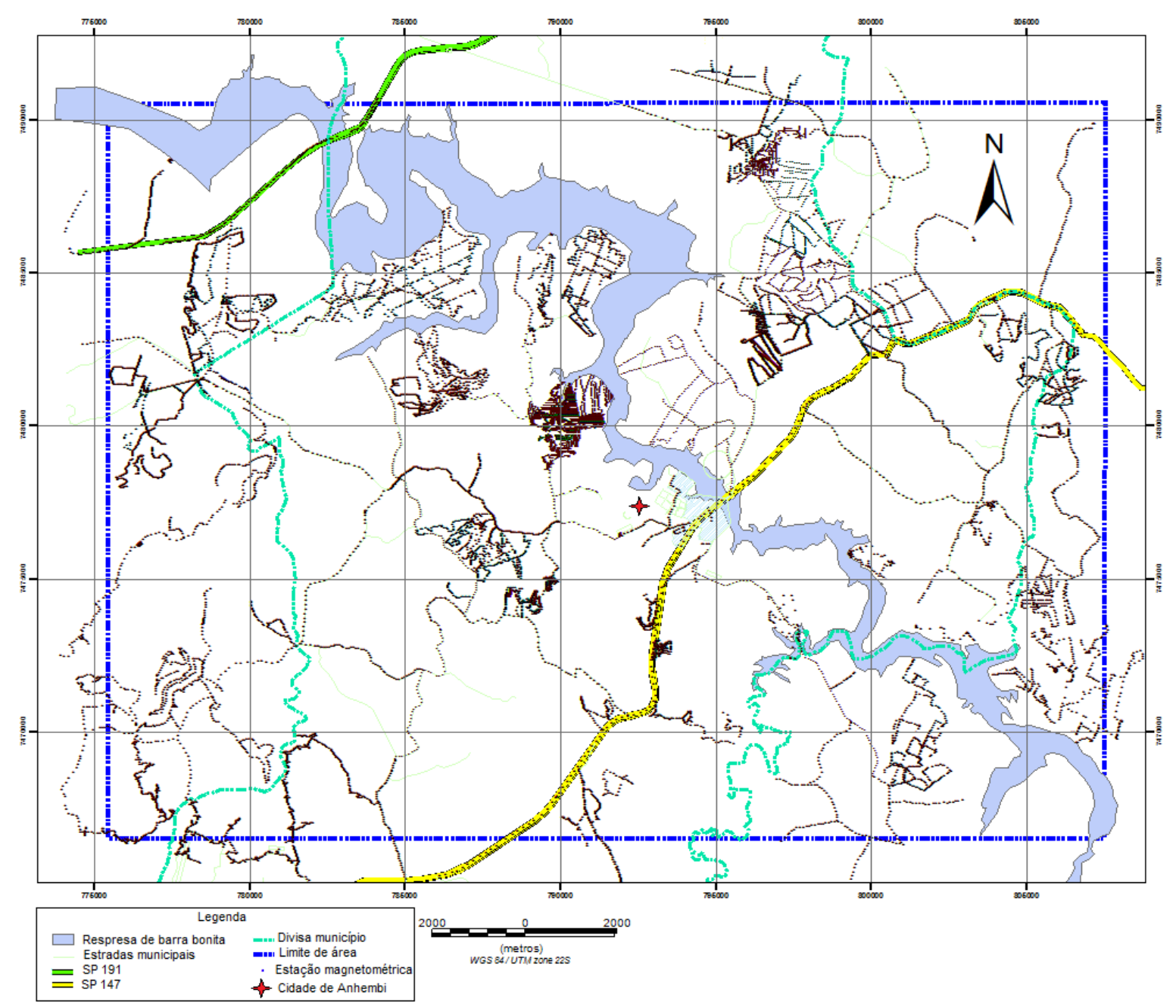

Figura 6.17 - Levantamento magnetométrico realizado no Alto Estrutural de Anhembi com 19047 medidas, sobreposto ao mapa de acessos na área de estudo, sendo 15868 medidas utilizadas para o levantamento de semidetalhe. 


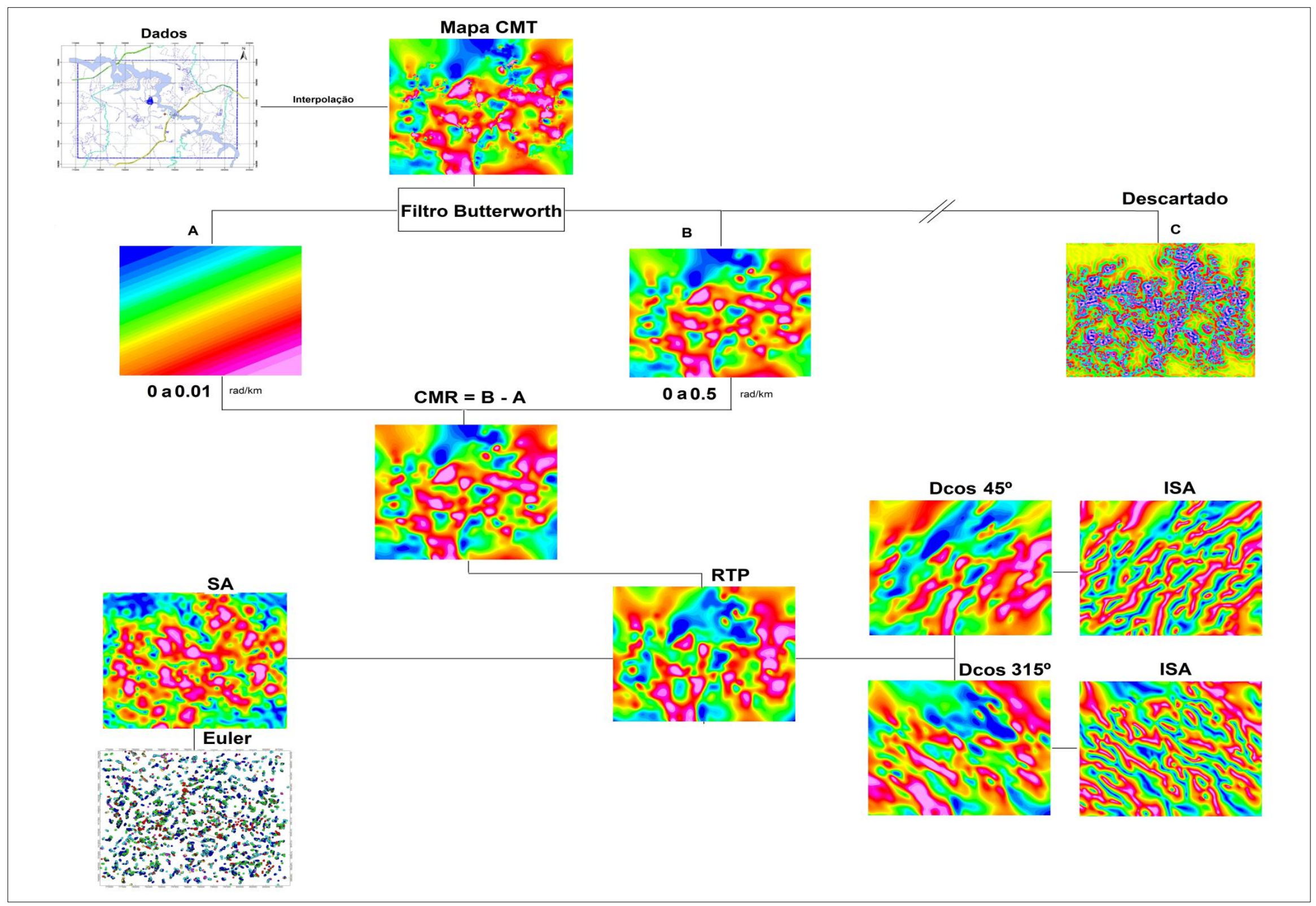

Figura 6.18- Diagrama ilustrativo da obtenção do mapa de Campo Magnético Total - CMT, levantamento de semi-detalhe, e produtos derivados. 


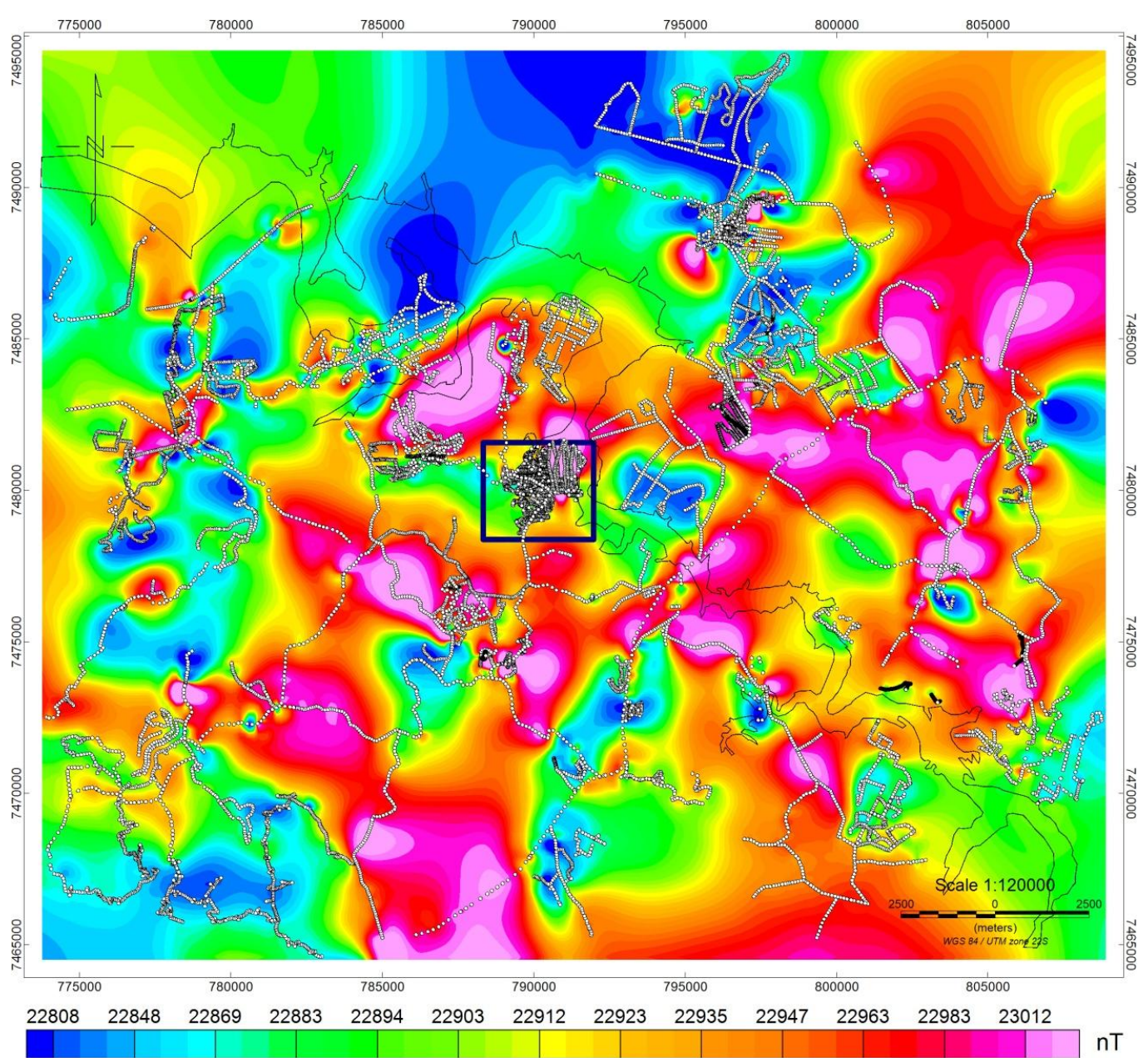

Figura 6.19 - Mapa do campo magnético total - CMT, sobreposto aos pontos de medida do levantamento de semi-detalhe. Área de ocorrência dos geiseritos está demarcada pelo retângulo azul, levantamento de detalhe.

\subsection{3 - Filtro Butterworth aplicado aos dados magnetométricos de semi- detalhe}

O filtro utilizado foi o Butterworth (item 4.4.2.4) usando o procedimento de filtragem interativa de espectros do programa do Oasis Montaj (Geosoft, 2009, p. 28).

Este filtro foi aplicado em dois intervalos de números de onda, com parâmetro <<regional>> selecionado, baseando-se nos valores encontrados no espectro de potência (Figura 6.20):

A) 0.0 a $0.01 \mathrm{rad} / \mathrm{km} ; B) 0.01$ a $0.65 \mathrm{rad} / \mathrm{km}$.

O intervalo de interesse foi obtido da seguinte forma (Figura 6.18).

Passa-baixa (parâmetro <<regional>> selecionado):

$1^{\circ}$ ) Intervalo: 0 a $0.01 \mathrm{rad} / \mathrm{km}=$ grid $A ; 2^{\circ}$ ) Intervalo: 0 a $0.65 \mathrm{rad} / \mathrm{km}=\operatorname{grid} B$;

Fez-se a subtração: grid $B$ - grid $A=0.01$ a $0.65 \mathrm{rad} / \mathrm{km}$;

O grid $C$ foi descartado: intervalos maiores que $0.65 \mathrm{rad} / \mathrm{km}$, interpretado como ruído. 
Foram testados vários valores para o parâmetro <<grau da função>> do filtro Butterworth (Geosoft, 2009, p. 57). O valor que forneceu a melhor resposta foi o grau 5, sendo o resultado da filtragem do intervalo 0.01 a $0.65 \mathrm{rad} / \mathrm{km}$ mostrado na Figura 6.21.

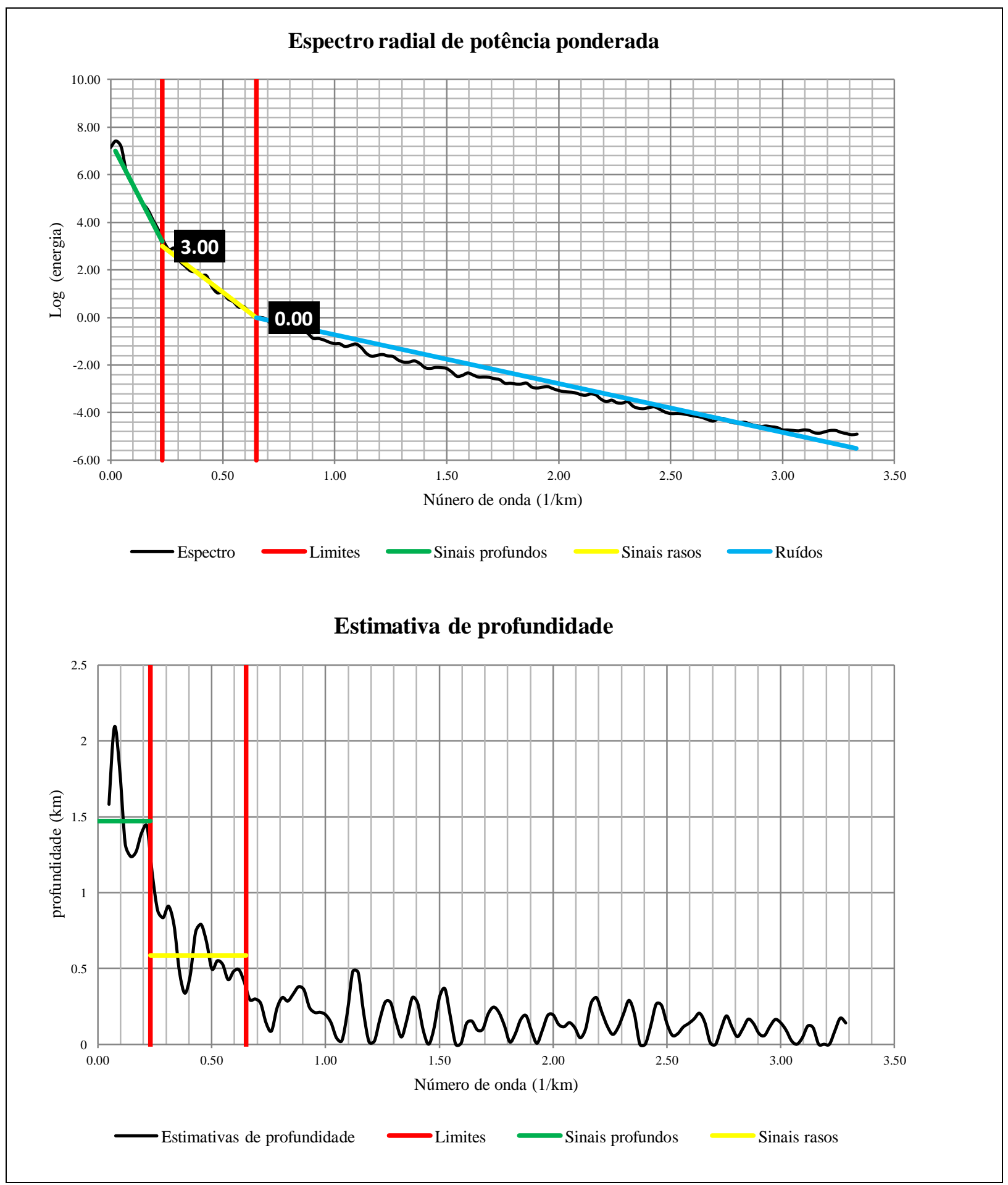

Figura 6.20 - Espectro de potência do levantamento de semi-detalhe, com indicações das profundidades médias das fontes e seus respectivos valores de cortes. 


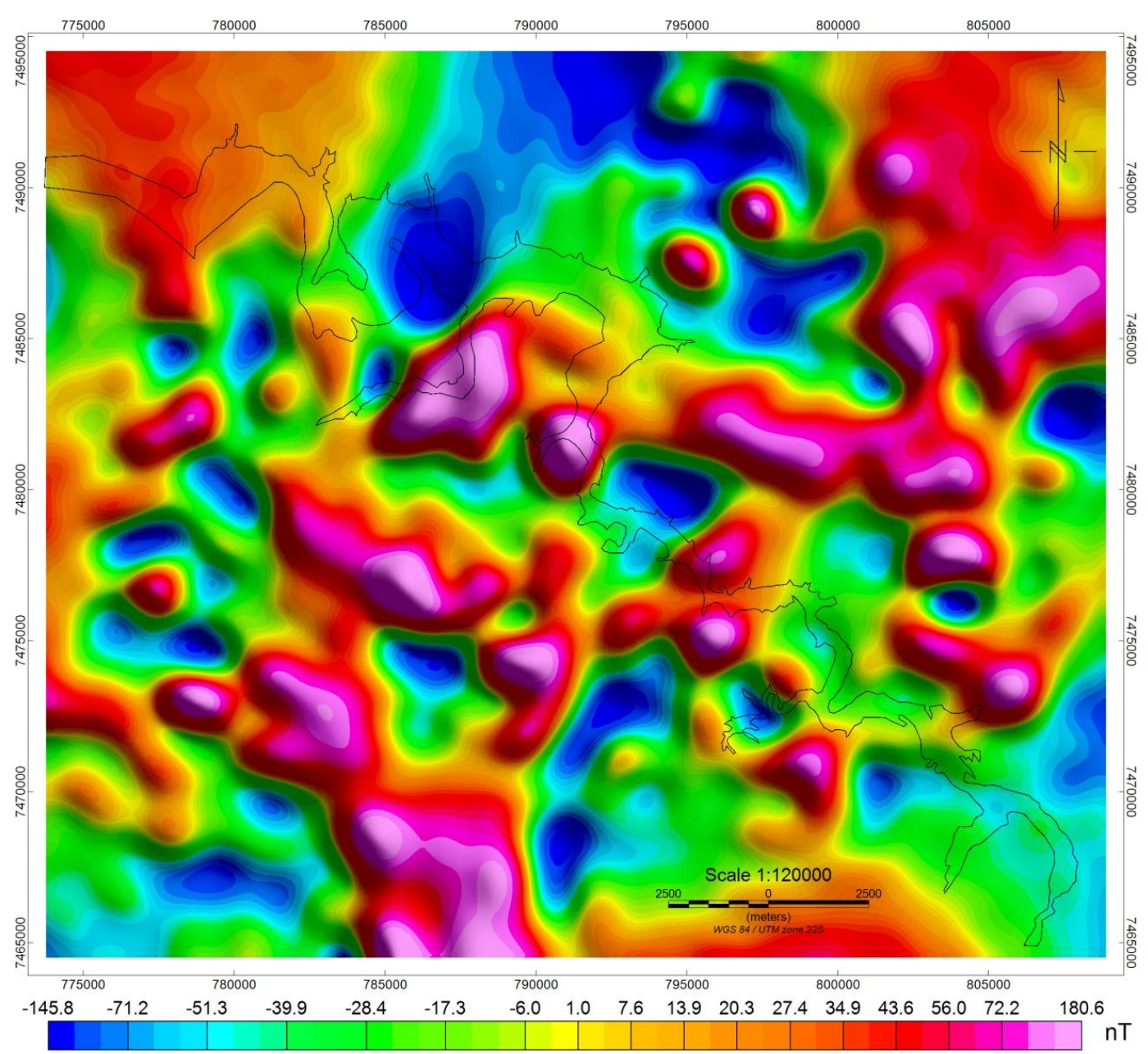

Figura 6.21 - Mapa do campo magnético residual - CMR, sombreado, iluminação de $45^{\circ}$, elevação de $45^{\circ}$.

6.3.4 - Resultados dos filtros aplicados aos dados magnetométricos de semidetalhe

A partir do mapa CMR (Figura 6.21) aplicou-se redução ao polo (Figura 6.22) por meio do algoritmo de Philips (2007, p.67). Observa-se que esse operador matemático centralizou os picos das anomalias magnéticas sobre suas fontes, facilitando a interpretação dessas anomalias. Como discutido no item 6.1.2, a MRN na área de estudo possui um valor considerável (razão de Königsberger $=1.84$ ). Desta forma, na utilização do operador redução ao polo considerou-se a soma vetorial da magnetização induzida com a remanescente, isto é, magnetização total $\left(J=J_{i}+J_{r}\right)$ : declinação $=347.5^{\circ}$ e inclinação $=-37.8^{\circ}$.

A figura 6.22 mostra sobreposição dos sistemas de falhamentos de IPT (1979 e 2005, p. 166), representada com linhas na cor preta, somadas a de Araújo et al. (2006, p.51), na cor marrom. Pode-se perceber que o conjunto de falhas se ajusta razoavelmente bem à assinatura magnética apresentada no mapa de redução ao polo. Há duas direções predominantes, NE e $\mathrm{NW}$, sendo a NW a mais marcante. A existência destes dois sistemas de falhas, 
aproximadamente a $90^{\circ}$, propiciou a formação da estrutura circular, observada no Alto Estrutural de Anhembi. A amplitude do sinal analítico - ASA (Figura 6.23) tem a vantagem de colocar a anomalia sobre a fonte ou sobre os limites dessa fonte (contato geológico), evidenciando de forma mais clara a direção NW. Também ficou evidente esta estrutura circular, assemelhando a Figura 6.14. Desta forma, pode-se relacionar o mapa residual gravimétrico (Figura 6.14-A), que representa fontes rasas, com os mapas de redução ao polo e sinal analítico, representados nas Figuras 6.22 e 6.23 , com a anomalia positiva morfoestrutural (Figura 6.14-B) identificada por Araújo et al. (2006). Segundo estes autores, a anomalia morfoestrutural encontrada reflete eventos permianos e jurássico-cretáceos em função da reativação do arcabouço preexistente. Descreve ainda uma anomalia, formadas pelo rio Alambari e pelo Ribeirão Bonito, com padrão circular, tendo drenagens radiais, características de áreas soerguidas.

Nos trabalhos de IPT (2005) e Araújo et al. (2006) as direções mais frequentes das falhas são: N50-60E, N20-30E, N30-50W e N10-30W. Com o intuito de observar melhor estas direções em relação à anomalia magnética encontrada, aplicou-se o filtro co-seno direcional, descrito no item 4.4.2.3, no mapa reduzido ao polo (Figura 6.22) em duas direções, N45E e N45W (Figura 6.18). A estes mapas foram aplicados o filtro ISA (Figuras 6.24 e 6.25), um para cada direção, e sobrepostos os sistemas de falhas determinados por IPT (1979 e 2005), linhas pretas, e Araújo et al. (2006, p. 51), linhas em marrom. Observando esta sobreposição de sistemas de falhas, nota-se uma correlação muito grande destes sistemas com as anomalias nas direções mais frequentes. O sistema de falhas determinado por IPT (2005, p. 166) correlacionam melhor com a direção noroeste, enquanto as determinadas por Araújo et al. (2006, p. 51) na direção nordeste. Esta sobreposição também foi feita com o mapa ASA, Figura 6.26, onde se observa uma boa associação destes sistemas de falhas com o resultado apresentado por este mapa.

Apesar de ocorrer um dique aflorante, de largura 5 a 10 metros, descrito por Araújo et al. (2006) e confirmado em campo, na área da anomalia positiva morfoestrutural, o causador desta anomalia é identificado como soerguimento e/ou abatimento de blocos, como descrito por IPT (1979), Soares (1974, p.118). Também se pode observar um paralelismo de falhas com rio Tietê, direção noroeste, sugerindo que estas pertençam ao complexo de falhas do Lineamento Tietê.

Ao mapa reduzido ao polo, Figura 6.22, é sobreposto locais de ocorrência de arenito asfáltico (Figura 6.27), mostrando sua distribuição em relação à anomalia magnética e sistema de falhamentos de IPT (1979 e 2005, p. 166) e Araújo et al. (2006, p. 51). 


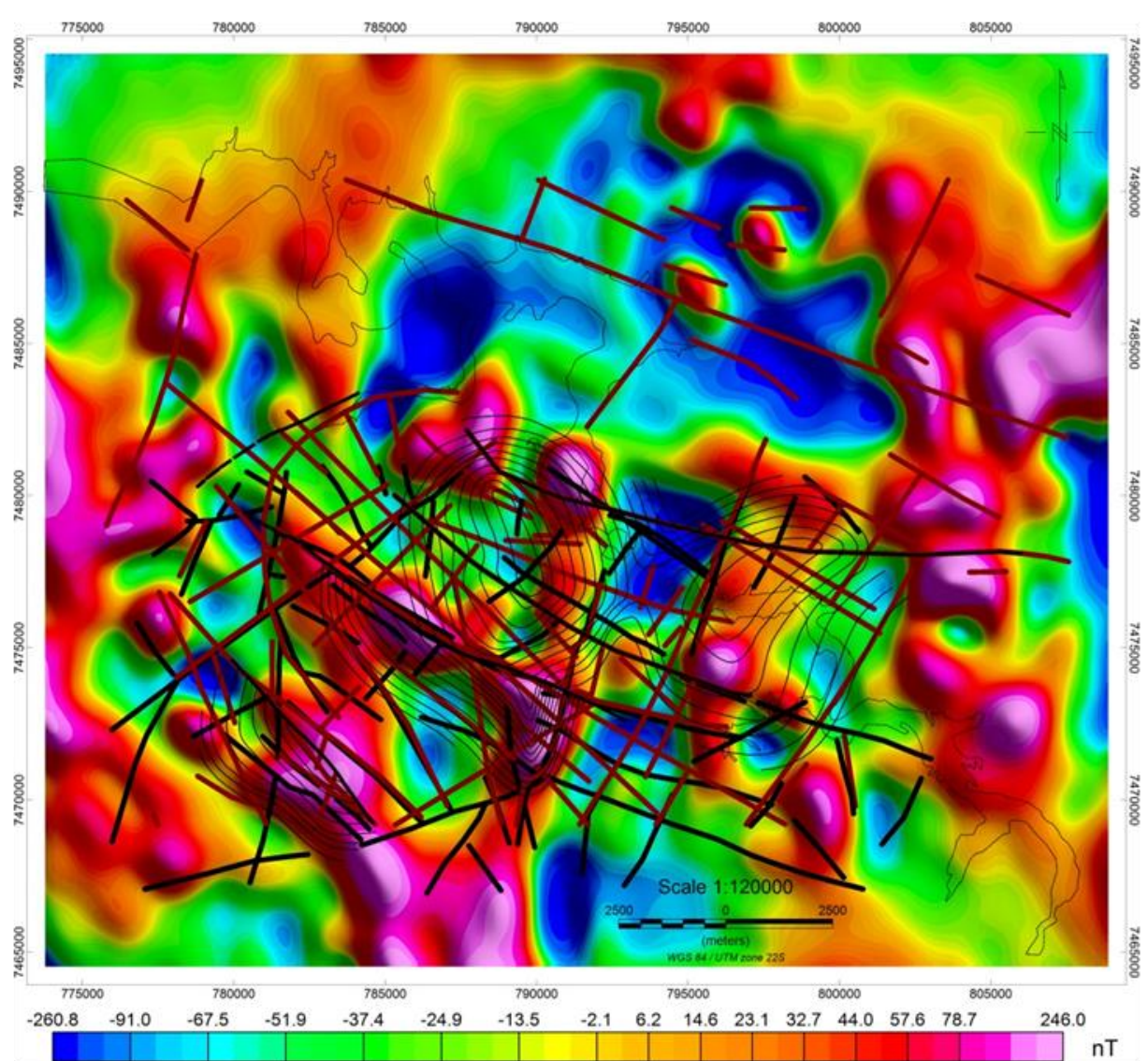

Figura 6.22 - Mapa redução ao polo, sombreado, iluminação de $45^{\circ}$, elevação de $45^{\circ}$, sobreposto pelo contorno estrutural da Fm. Teresina e o sistema de falhas de IPT (1979 e 2005, p. 166) e Araújo et al. (2006, p. 51).

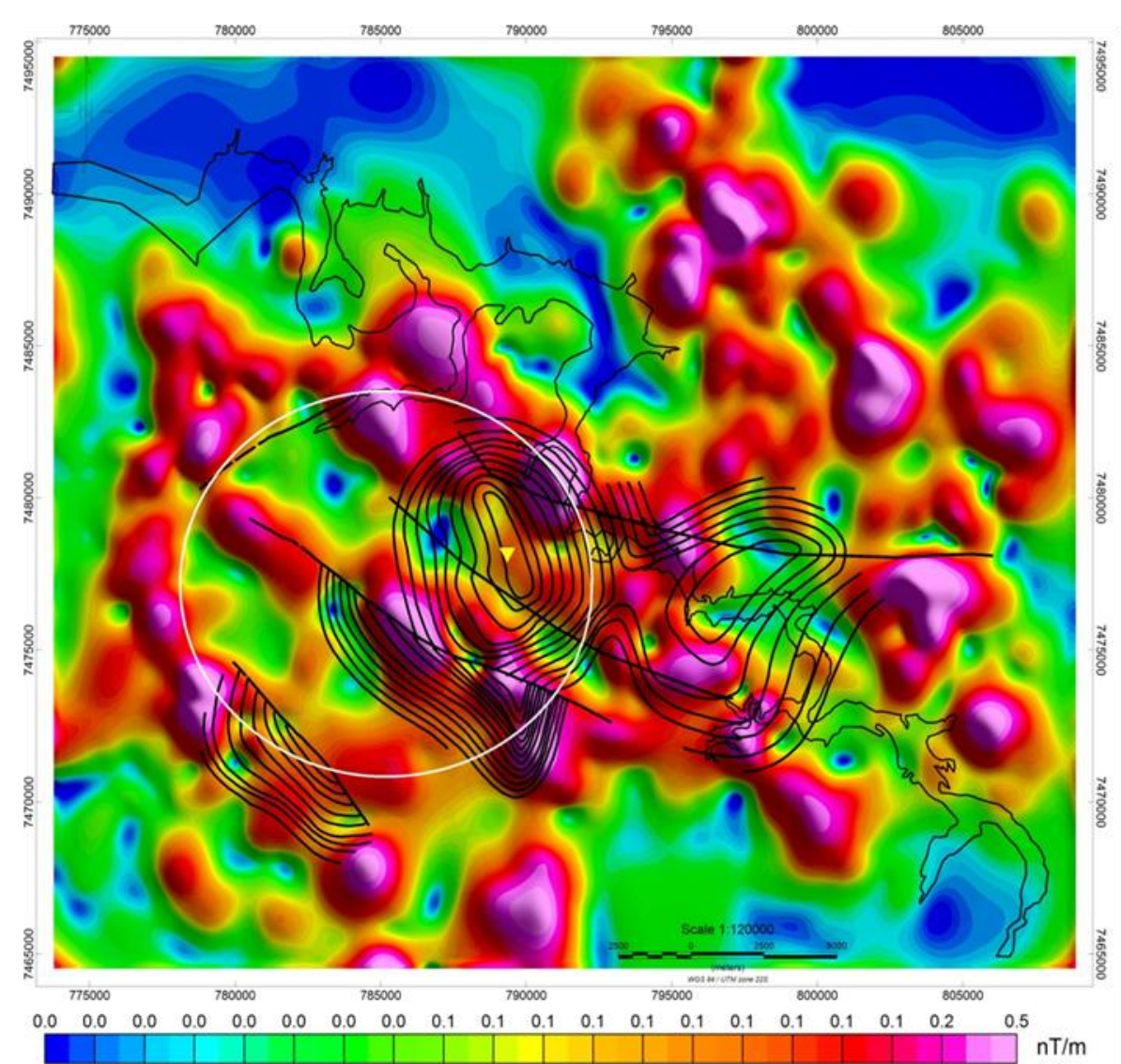

Figura 6.23 - Mapa de Amplitude do Sinal Analítco - ASA, sombreado, iluminação de $45^{\circ}$, elevação de $45^{\circ}$, sobreposto pelo contorno estrutural da Fm.Teresina e o sistema de falhas de IPT (1979) e Araújo et al. (2006, p .55). O circulo em branco indica uma possível estrutura circular no Alto Estrutural de Anhembi. 


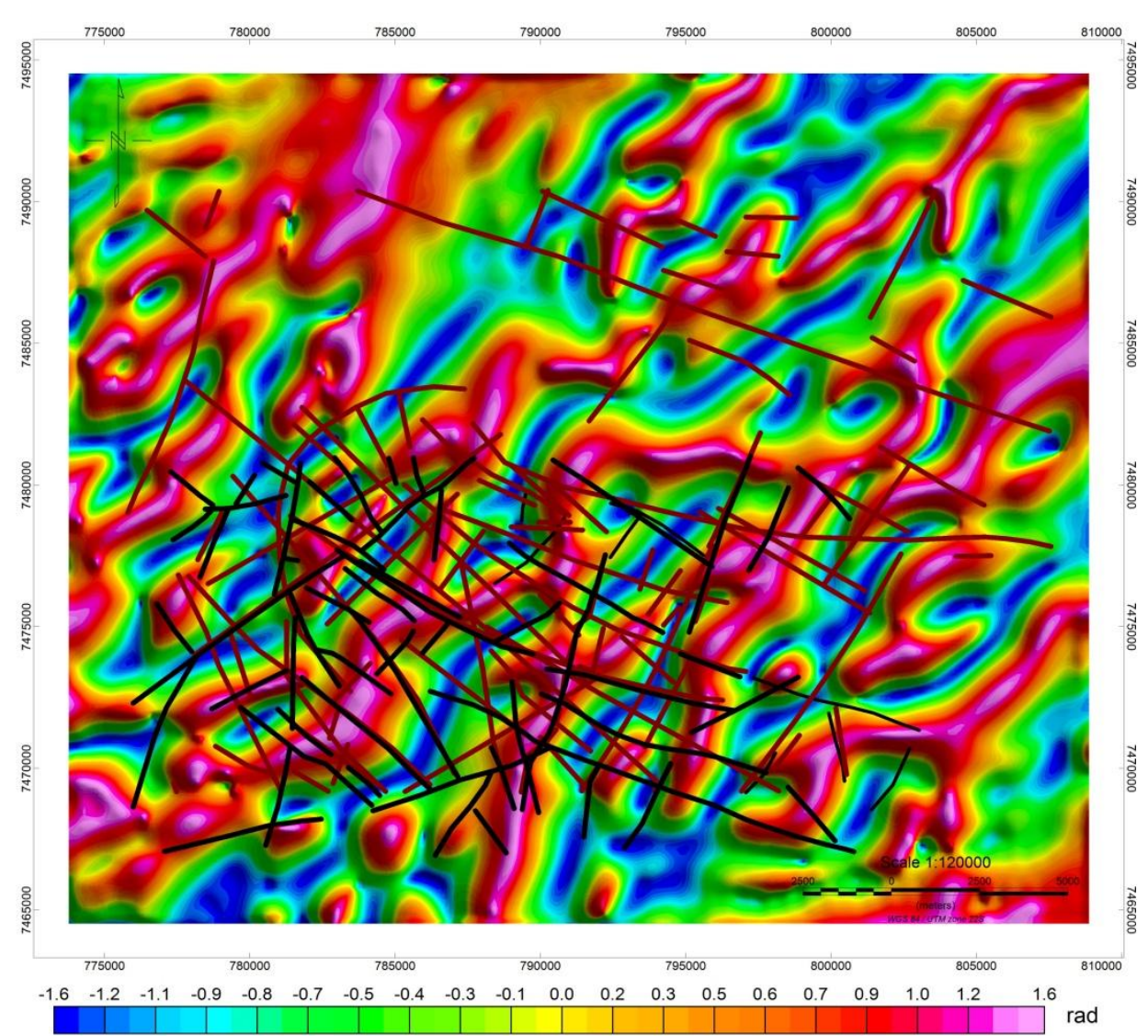

Figura 6.24 - Mapa ISA do cos-seno direcional, sombreado, iluminação de $45^{\circ}$, elevação de $45^{\circ}$, com direção N45E, com base no mapa de redução ao polo, sobreposto pelo sistema de falhas de IPT (1979 e 2005, p. 166), linhas em preto, e Araújo et al. (2006, p. 51), linhas em marrom.

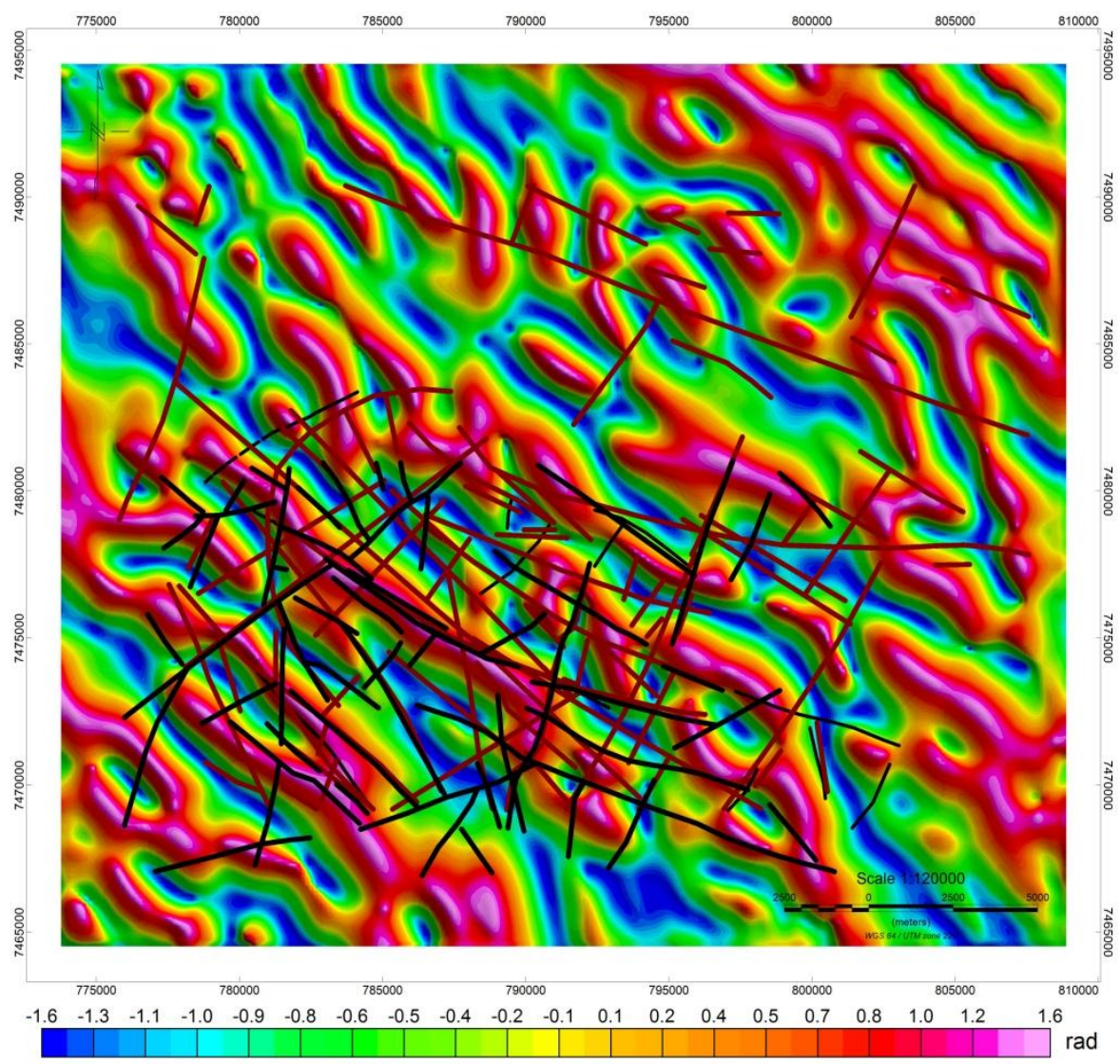

Figura 6.25 - Mapa ISA do cos-seno direcional, sombreado, iluminação de $45^{\circ}$, elevação de $45^{\circ}$, com direção $\mathrm{N} 45 \mathrm{~W}$, com base no mapa de redução ao polo, sobreposto pelo sistema de falhas IPT (1979 e 2005, p. 166), linhas em preto, e Araújo et al. (2006, p. 51), linhas em marrom. 


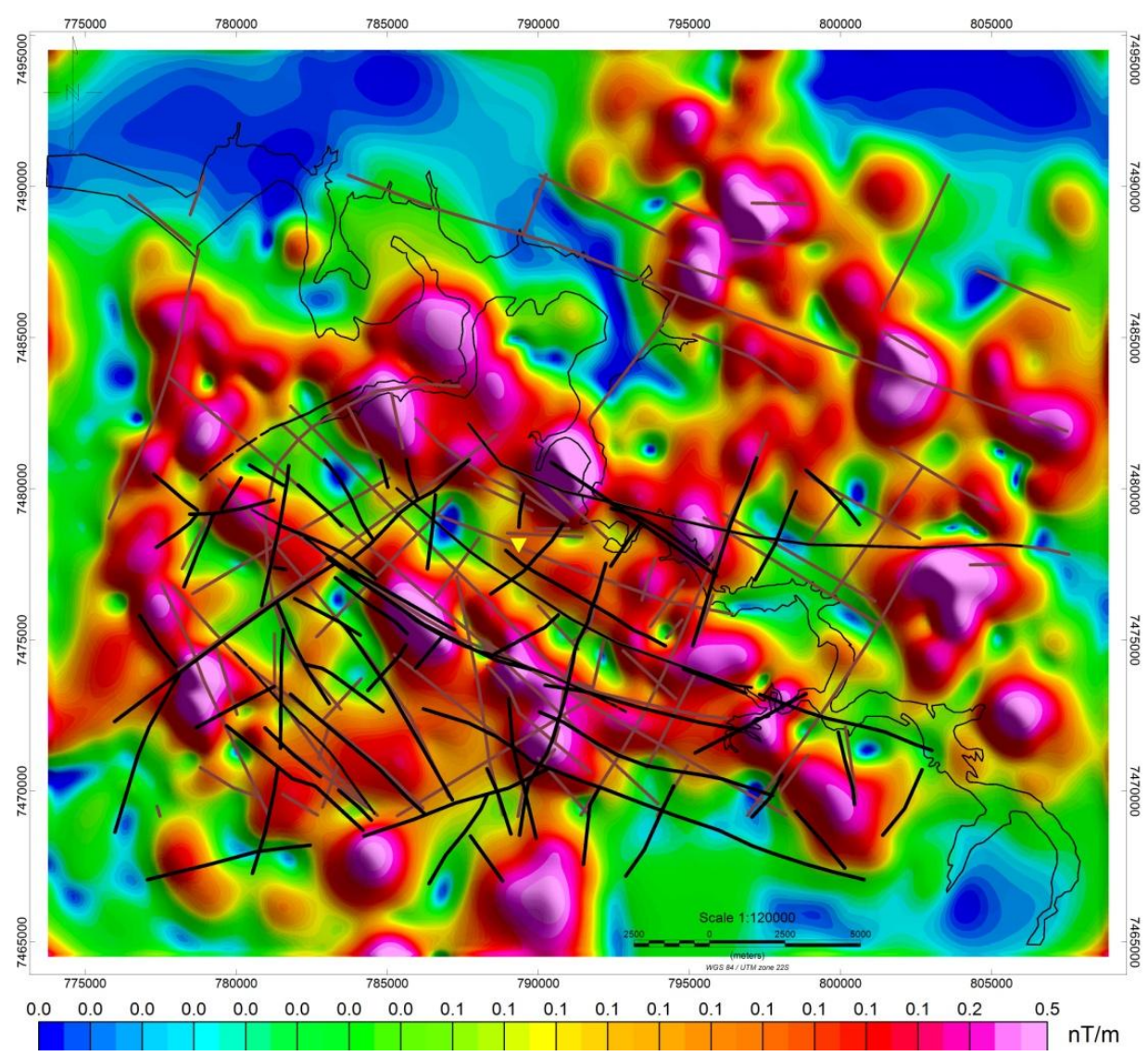

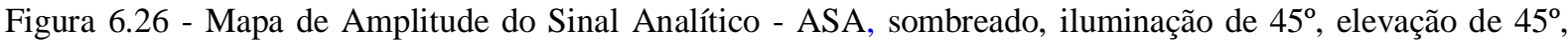
sobreposto ao sistema de falhas de IPT (1979 e 2005, p. 166), linhas em preto, e Araújo et al. (2006, p. 51), linhas em marrom.

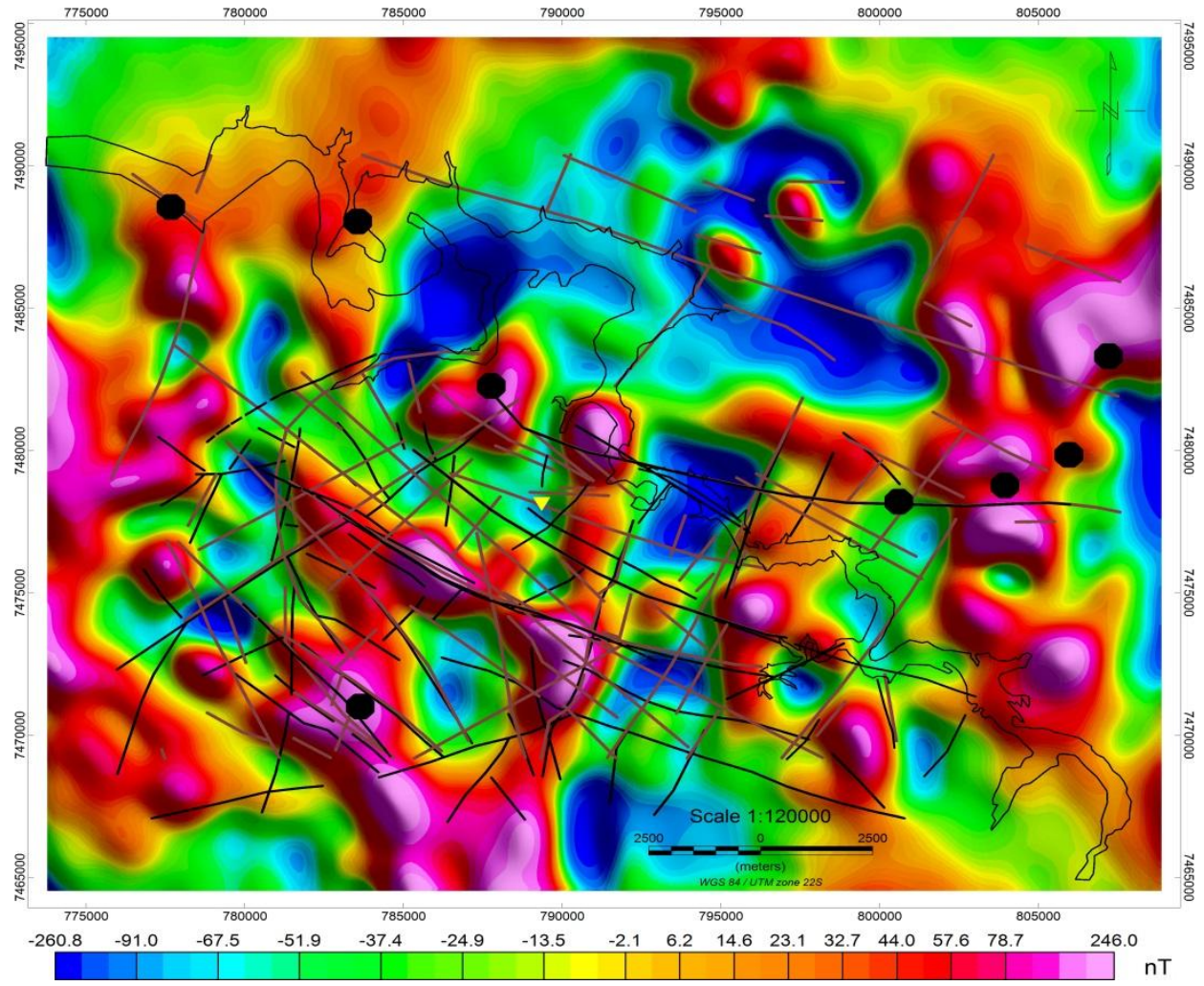

Figura 6.27 - Mapa de redução ao polo sobreposto à localização de ocorrência do arenito asfáltico, ponto pretos. sombreado, iluminação de $45^{\circ}$, elevação de $45^{\circ}$, sobreposto ao sistema de falhas de IPT (1979 e 2005, p. 166), linhas em preto, e Araújo et al. (2006, p. 51), linhas em marrom. 
6.3.5 - Deconvolução de Euler aplicado aos dados magnetométricos de semidetalhe

A técnica da deconvolução de Euler (Reid et al. 1990) foi utilizada para estimar a localização e profundidade das fontes magnéticas. O mapa do sinal analítico, Figura 6.26, foi inserido como grid de entrada para o cálculo. Assim, os melhores resultados para o conjunto de soluções de Euler foram $\mathrm{N}=1$, tamanho da janela $=3$ células e $5 \%$ de tolerância. A Figura 6.28 apresenta o resultado da Deconvolução de Euler sobre mapa do sinal analítico.

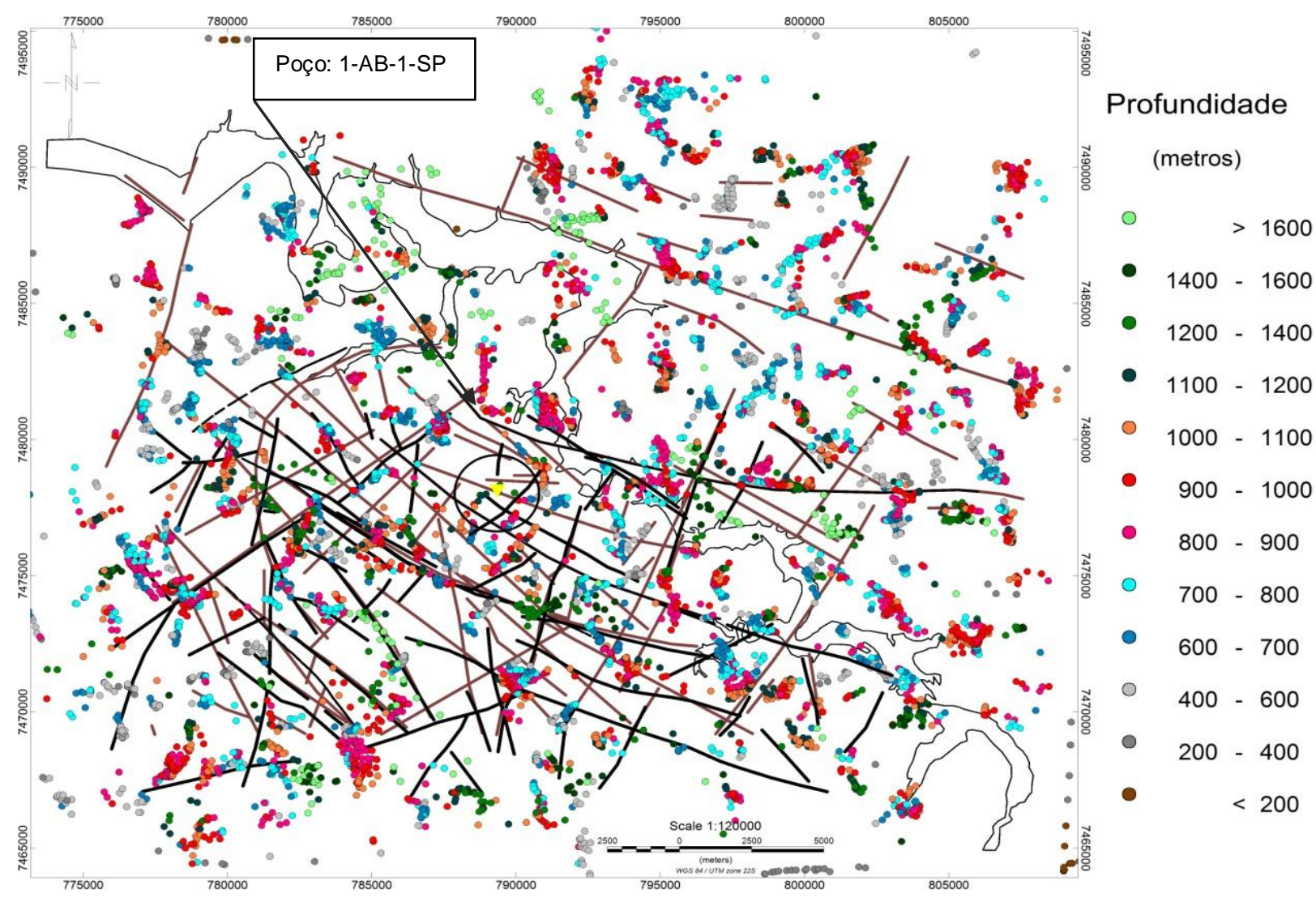

Figura 6.28 - Soluções de Euler calculado com base nos dados da Figura 6.26, sobrepostas ao sistema de falhas de IPT (1979 e 2005, p. 166), linhas em preto, e Araújo et al. (2006, p. 51), linhas em marrom.

Vários intervalos de profundidade, de 0 a 1650 metros, estão representados, num total de 6306 soluções. As soluções possuem um valor mínimo de 170 e máximo de 1648 metros, média de 875 metros. Observa-se que $81.3 \%$ das soluções estão distribuídas entre 400 a 1100 metros de profundidade, com pico no intervalo de 800 a 900 metros, na cor violeta. Nesta figura estão representados o poço pioneiro exploratório 1-AB-1-SP da Petrobras (triângulo amarelo invertido) e o sistema de falhas de IPT (1979, p. 166) e Araújo et al. (2006, p. 51). O poço 1 AB - 1 - SP foi utilizado como balizador para a escolha do conjunto de soluções da deconvolução de Euler, pois os valores que estão próximos a ele estão intervalo entre 1000 a 
1200 metros de profundidade. A profundidade do topo do diabásio está a 1015 metros. Os valores calculados estão compatíveis com os observados neste perfil. Verifica-se também que de forma geral, o conjunto de soluções de profundidades no intervalo entre 800 a 1100 metros está na direção noroeste. Os intervalos de profundidades, em porcentagem, dos dados estão distribuídos como mostra a tabela 6.7.

Tabela 6.7 - distribuição das profundidades, em porcentagem na deconvolução de Euler.

\begin{tabular}{|c|c|}
\hline intervalos & Porcentagem (\%) \\
\hline 0 a 200 & 0.03 \\
\hline 200 a 400 & 2.40 \\
\hline 400 a 600 & 10.0 \\
\hline 600 a 700 & 11.6 \\
\hline 700 a 800 & 14.0 \\
\hline 800 a 900 & 17.6 \\
\hline 900 a 1000 & 15.9 \\
\hline 1000 a 1100 & 12.2 \\
\hline 1100 a 1200 & 7.2 \\
\hline 1200 a 1400 & 5.9 \\
\hline 1400 a 1650 & 3.2 \\
\hline $\begin{array}{r}\text { Mínima } \\
\text { Média } \\
\text { Máxima } \\
\mathbf{N}^{\mathbf{0}}\end{array}$ & $\begin{aligned} \text { de profundidade } & =170 \text { metros } \\
& =875 \text { metros } \\
& =1648 \text { metros } \\
\text { soluções } & =6306\end{aligned}$ \\
\hline
\end{tabular}




\section{4 - Levantamento gravimétrico de detalhe}

$\mathrm{Na}$ área de ocorrência dos geiseritos foi executado um levantamento gravimétrico de detalhe, cobrindo toda a área de afloramento e circunvizinhas, aproximadamente $1.5 \mathrm{~km}^{2}$. A intenção foi tentar localizar uma possível rocha que agiu como fonte de calor para a formação dos geiseritos. Desta forma, foi executado o levantamento gravimétrico com espaçamento de 20 metros entre as estações, num total de 768 estações medidas. O intervalo de tempo de cada coleta, numa determinada estação, foi de 120 segundos, sendo duas medidas por estação.

De forma semelhante ao levantamento de semi-detalhe, os dados gravimétricos foram reduzidos através da rotina Gravity \& Terrain Correction do programa Oasis Montaj (Geosoft, 2006) e integrados aos dados processados do levantamento planialtimétrico. O fluxo dos principais filtros aplicados aos dados gravimétricos pode ser vista na Figura 6.29, onde se mostra, de forma ilustrativa, os processos envolvidos e os respectivos produtos.

\subsection{1 - Mapa Bouguer de detalhe}

Repetindo o procedimento aplicado ao levantamento de semi-detalhe, na confecção do mapa Bouguer também foi empregado o sistema de coordenadas UTM, zona 22 sul do meridiano de Greenwich. O elipsóide de referência utilizado foi o WGS 84 e as rotinas do programa Oasis Montaj foram utilizadas para a confecção do mapa Bouguer com base no método da mínima curvatura (Briggs, 1994) com tamanho de célula de 10 metros. O produto resultante da redução dos dados gravimétricos e da interpolação é apresentado na Figura 6.30, onde é mostrado o mapa de bouguer da área de estudo para levantamentos de detalhe, imagem da área de ocorrência dos geiseritos sobreposta com as estações gravimétricas.

\subsection{2 - Espectro de Potência aplicado aos dados gravimétricos de detalhe}

O espectro de potência (Figura 6.31) foi aplicado ao mapa Bouguer. A Tabela 6.8 apresenta as estatísticas da análise do espectro de potência para a componente de fonte em duas profundidades. $\mathrm{O}$ espectro apresentado na Figura 6.31 foi produzido pelo programa excel, da Microsoft ${ }^{\circledR}$, com o conjunto de dados de profundidades estimadas pelas rotinas do programa Oasis Montaj (Geosoft, 2010, p. 52). Pode-se observar que os dois grupos (dois 
segmentos) distintos representam fontes com profundidades médias de 125 e 50 metros. Analisando o espectro determinou-se o intervalo de 0.17 a $14.67 \mathrm{rad} / \mathrm{km}$.

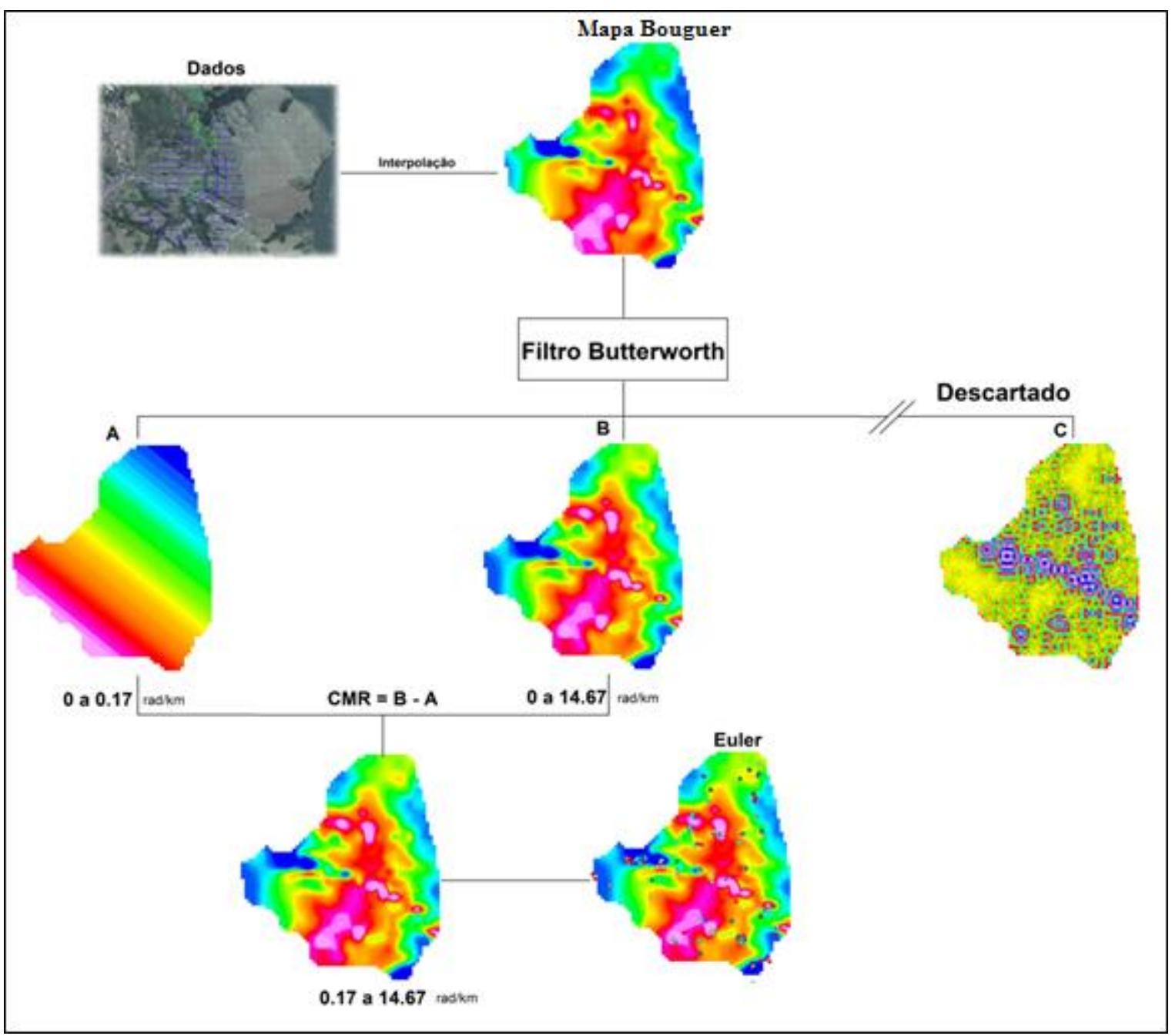

Figura 6.29 - Diagrama ilustrativo da obtenção do mapa Bouguer, do levantamento de detalhe, e seus produtos derivados.

6.4.3 - Filtro Butterworth aplicado aos dados gravimétricos de detalhe

O filtro Butterworth foi aplicado ao mapa de bouguer da seguinte forma:

- Passa-baixa (parâmetro <<regional>> selecionado):

$1^{\circ}$ ) Intervalo: 0 a $0.17 \mathrm{rad} / \mathrm{km}=$ grid $A ; 2^{\circ}$ ) Intervalo: 0 a $14.67 \mathrm{rad} / \mathrm{km}=$ grid $B$;

Para os intervalos desejados fez-se a subtração:

grid $B-\operatorname{grid} A=0.17$ a $14.67 \mathrm{rad} / \mathrm{km}$;

O resultado pode ser visto na Figura 6.32, onde está também representado a localização dos geiseritos e o córrego do Retiro, linha na cor azul. 

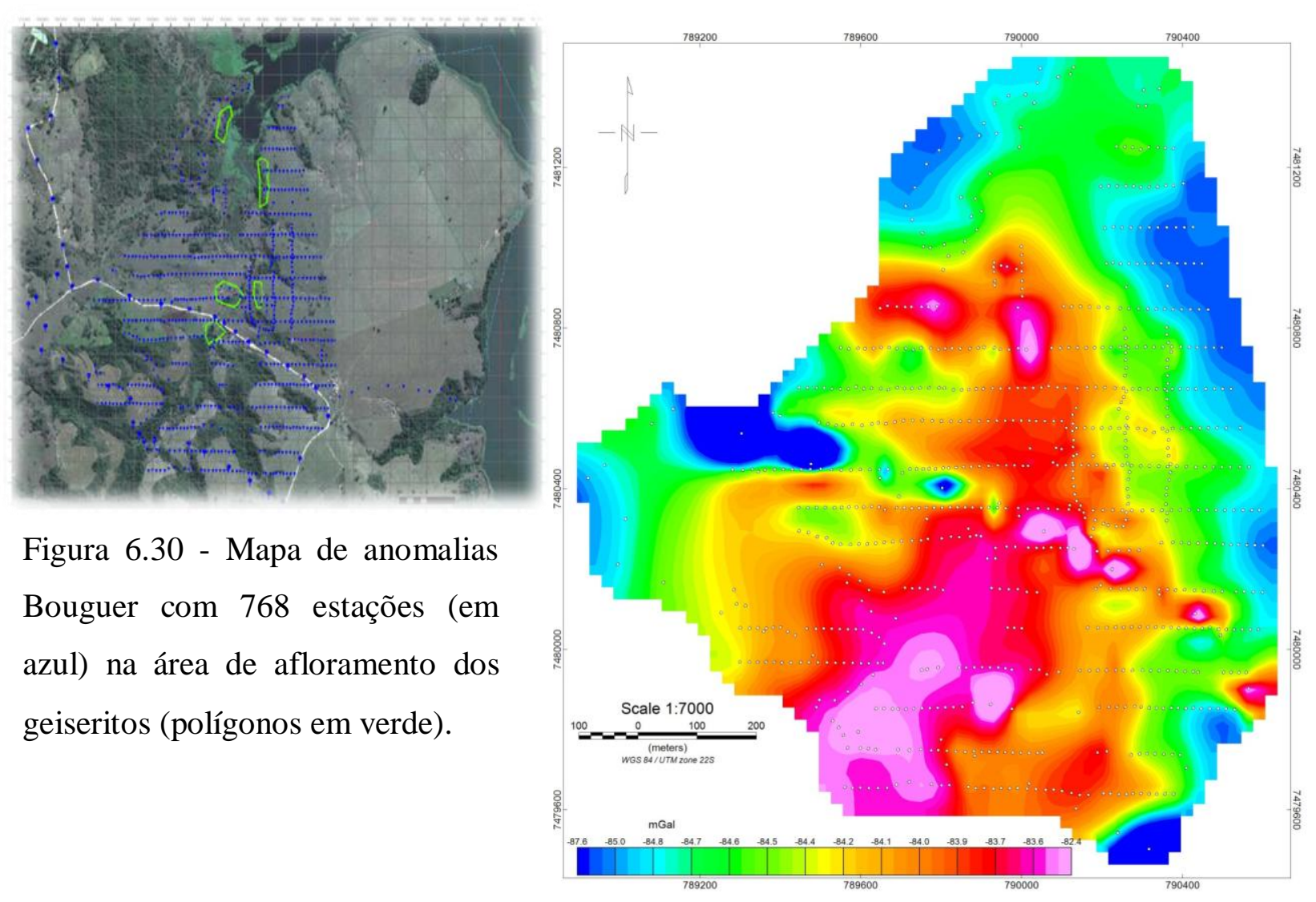

Figura 6.30 - Mapa de anomalias Bouguer com 768 estações (em azul) na área de afloramento dos geiseritos (polígonos em verde).

Tabela 6.8 - Estatísticas descritivas do espectro de potência da Figura 6.31.

\begin{tabular}{lr}
\hline \multicolumn{1}{c}{ 5_DEPTH } & Profundo \\
\hline Média & 0.120502 \\
Erro padrão & 0.003187 \\
Mediana & 0.123447 \\
Modo & \#N/D \\
Desvio padrão & 0.009016 \\
Variância da amostra & \multicolumn{1}{c}{$8.13 \mathrm{E}-05$} \\
Curtose & 0.718571 \\
Assimetria & -1.08362 \\
Intervalo & 0.02647 \\
Mínimo & 0.103008 \\
Máximo & 0.129478 \\
Soma & 0.964015 \\
\hline Contagem & 8 \\
\hline Nível de confiança (95,0\%) & 0.007537 \\
\hline
\end{tabular}

\begin{tabular}{lr}
\hline \multicolumn{1}{c}{ 5_DEPTH } & \multicolumn{1}{c}{ Raso } \\
\hline Média & 0.037253 \\
\hline Erro padrão & 0.003455 \\
Mediana & 0.037358 \\
Modo & \multicolumn{1}{c}{$\#$ N/D } \\
Desvio padrão & 0.018282 \\
Variância da amostra & 0.000334 \\
Curtose & -0.19299 \\
Assimetria & -0.47857 \\
Intervalo & 0.063169 \\
Mínimo & $7.86 \mathrm{E}-05$ \\
Máximo & 0.063248 \\
Soma & 1.043085 \\
Contagem & 28 \\
\hline Nível de confiança (95,0\%) & 0.007089 \\
\hline
\end{tabular}




\section{Espectro radial de potência ponderada}

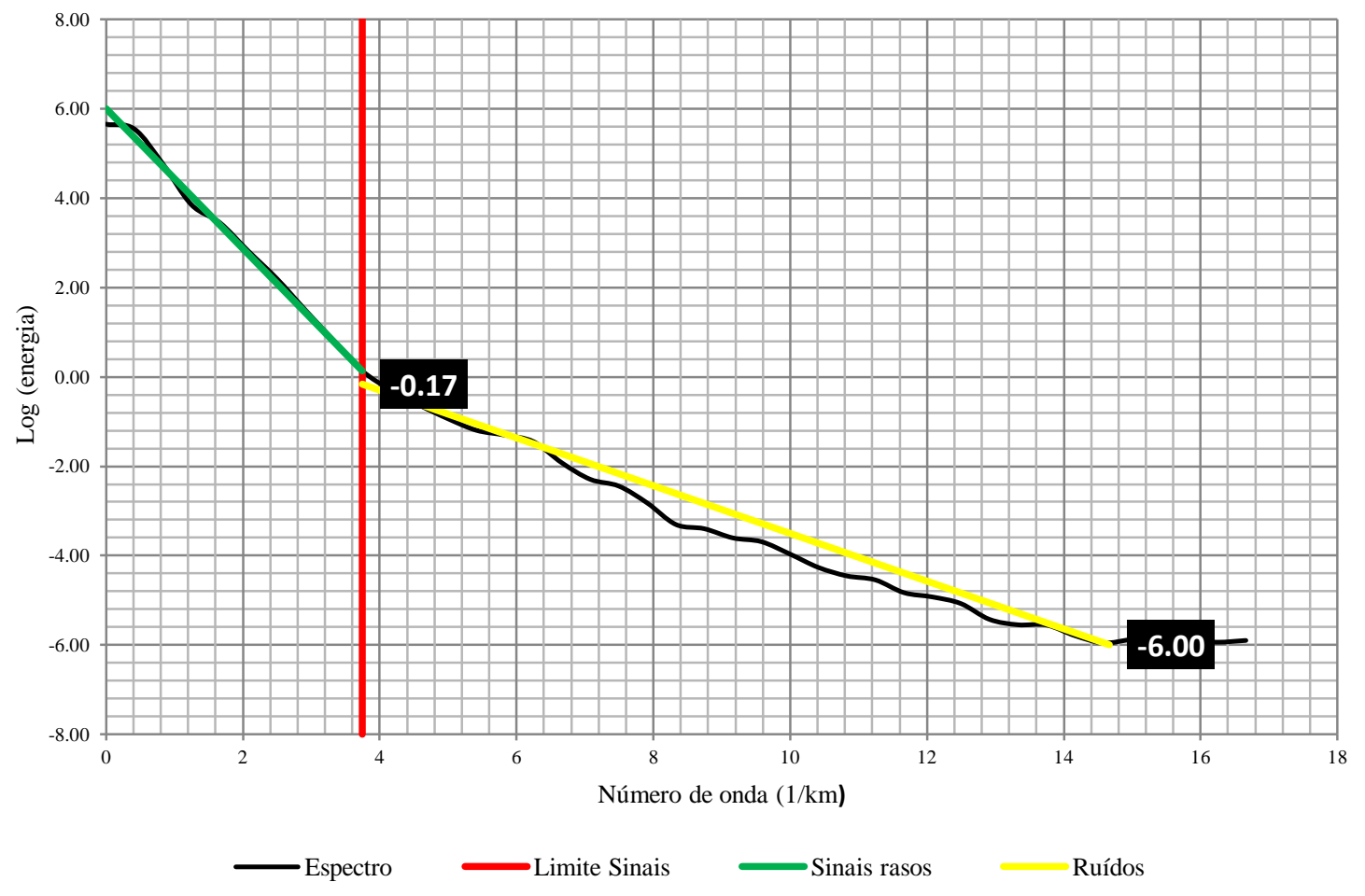

Estimativas de profundidades

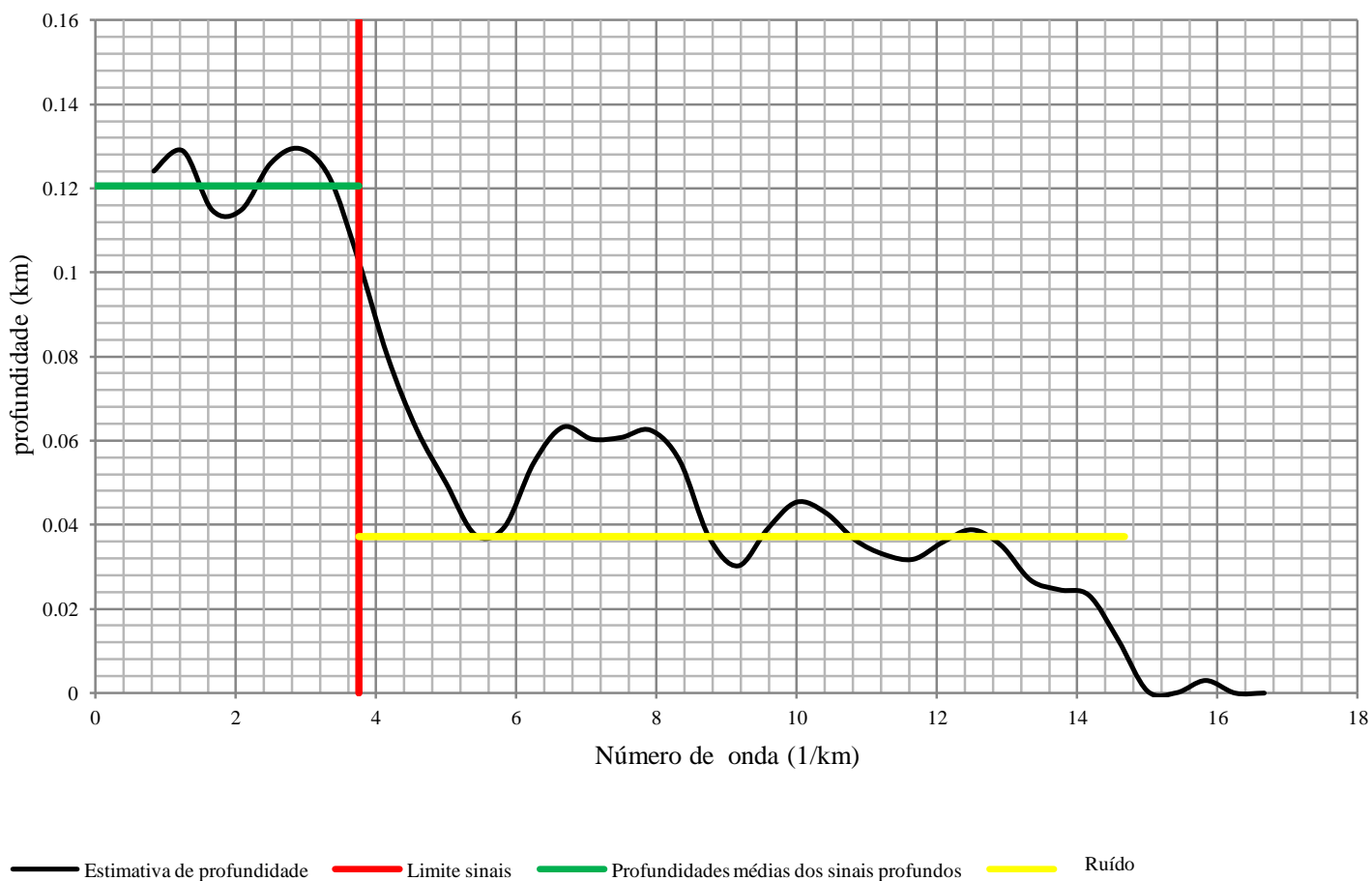

Figura 6.31 - Espectro de potência do levantamento de detalhe, com indicações das profundidades médias das fontes. 


\subsection{4 - Deconvolução de Euler aplicado aos dados gravimétricos de detalhe}

Para a estimativa de localização e profundidade das fontes rasas aplicou-se a técnica da deconvolução de Euler (Reid et al. 1990) ao mapa residual gravimétrico. Utilizou-se o índice estrutural de valor 0.5 (contatos, sills e diques). Assim, os melhores resultados para o conjunto de soluções de Euler foram $\mathrm{N}=0.5$, tamanho da janela $=3$ células e $10 \%$ de tolerância. A Figura 6.33 apresenta o resultado da deconvolução de Euler sobre mapa residual gravimétrico. Vários intervalos de profundidade, de 0 a 160 metros, estão representados, num total de 140 soluções. As soluções possuem um valor mínimo de 18 e máximo de 105 metros, média de 43 metros. Observa-se que $75.6 \%$ das soluções estão a menos de 50 metros de profundidade, sendo estas representadas numa escala de cor. Em percentual, os intervalos de profundidades dos dados estão distribuídos conforme mostrado na Tabela 6.9. As profundidades encontradas pela deconvolução de Euler estão próximas às médias encontradas pela técnica espectro de potência (Figura 6.31). Ainda na Figura 6.33, está representada a falha, na direção NW, determinada por Araújo et al. (2006), traço na cor preta. Os traços representados na cor marrom mostram os principais lineamentos gravimétricos reconhecidos na área dos geiseritos.

Tabela 6.9 - Distribuição das profundidades, em porcentagem na deconvolução de Euler.

\begin{tabular}{|c|c|}
\hline Intervalos & Porcentagem (\%) \\
\hline 0 a 20 & 3.5 \\
\hline 20 a 30 & 27.9 \\
\hline 30 a 40 & 22.1 \\
\hline 40 a 50 & 22.1 \\
\hline 50 a 60 & 8.6 \\
\hline 60 a 70 & 5.0 \\
\hline 70 a 80 & 2.9 \\
\hline 80 a 90 & 3.5 \\
\hline 90 a 100 & 2.9 \\
\hline 100 a 110 & 1.4 \\
\hline $\begin{array}{r}\text { Mínima } \\
\text { Média } \\
\text { Máxima } \\
\mathbf{N}^{\mathbf{0}}\end{array}$ & $\begin{aligned} \text { de profundidade } & =18 \text { metros } \\
& =43 \text { metros } \\
& =105 \text { metros } \\
\text { soluções } & =140\end{aligned}$ \\
\hline
\end{tabular}




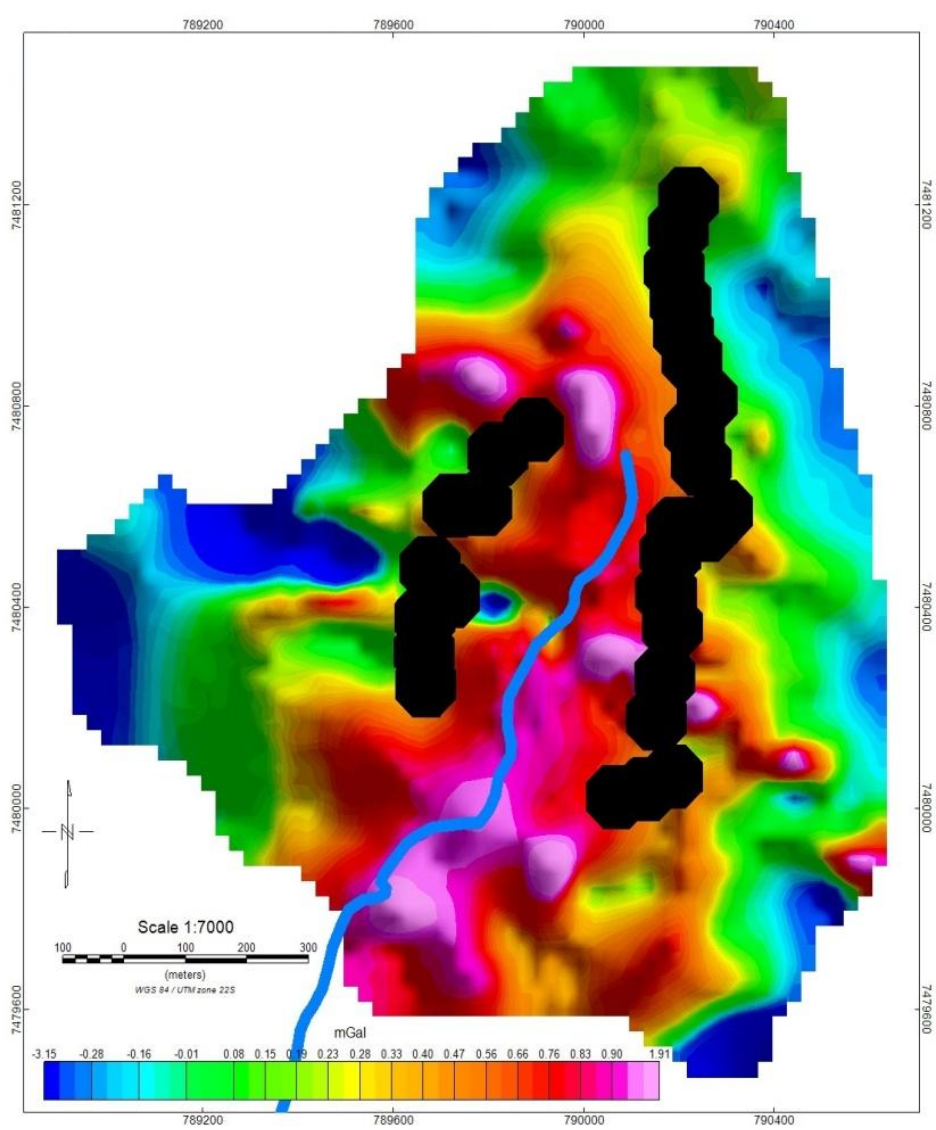

Figura 6.32- Mapa residual gravimétrico, sombreado, iluminação de $45^{\circ}$, elevação de $45^{\circ}$, com sobreposição de ocorrência de cones silicosos, em preto, e córrego do Retiro, linha azul.

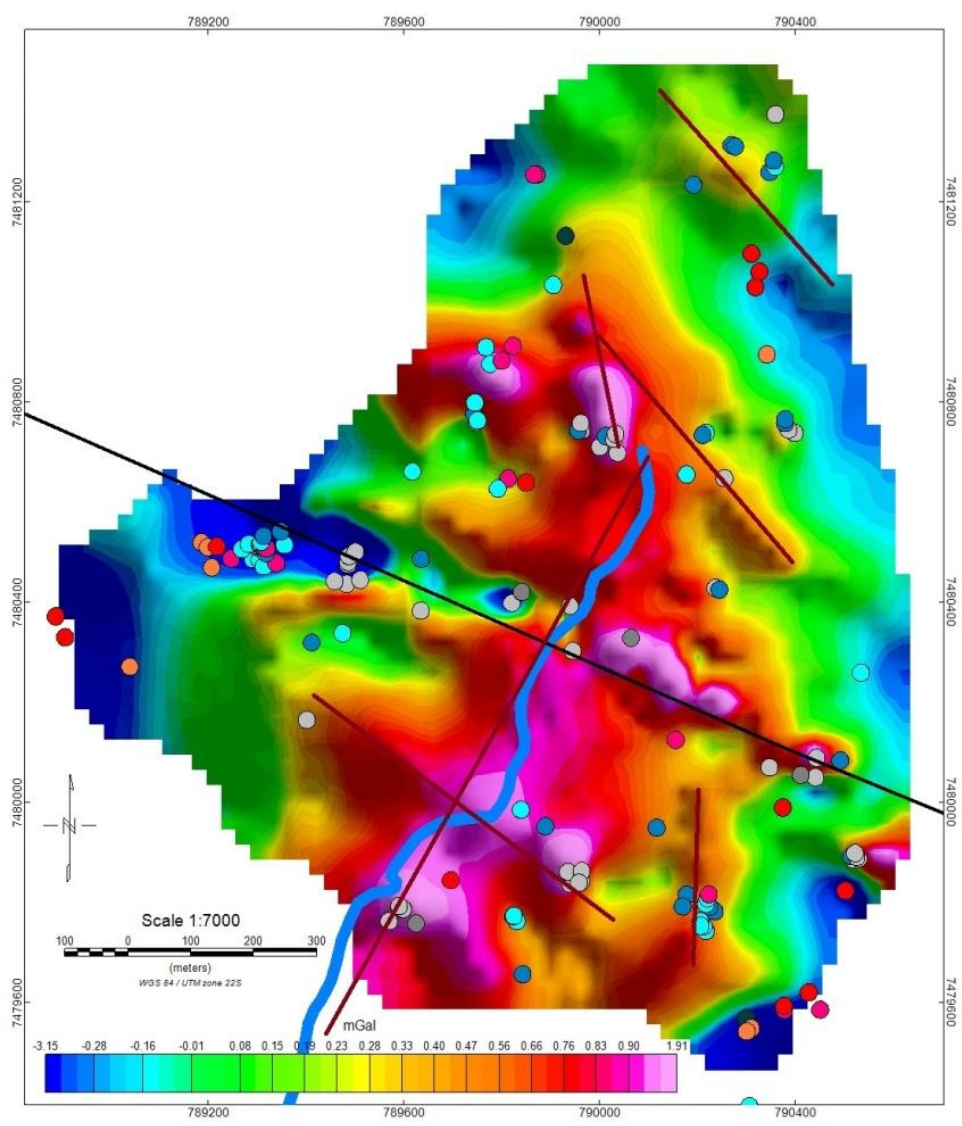

profundidade (metros)

O > 160

$140-160$

$120-140$

$100-120$

$80-100$

$60-80$

$50-60$

○ $40-50$

$30-40$

O $20-30$

○ $10-20$

$<10$

Figura 6.33 - Mapa residual gravimétrico, sombreado, iluminação de $45^{\circ}$, elevação de $45^{\circ}$, com sobreposição da soluções de Euler e principais lineamentos gravimétricos reconhecidos, linhas na cor marrom, na área de estudo. Linha em preto indica falha deterninada por Araújo et al. (2006). 


\section{5 - Levantamento magnetométrico de detalhe}

Paralelamente a gravimetria, foi executado o levantamento magnetométrico de detalhe na área de ocorrência dos geiseritos. A área coberta por este levantamento tem o triplo de tamanho em relação a gravimetria. Desta forma, foram obtidos 3479 pontos de medidas, com espaçamento entre os pontos de 20 metros. O intervalo de tempo de cada coleta, numa determinada estação, foi de 20 segundos cada, sendo duas medidas por ponto.

Os dados magnetométricos foram corrigidos através de rotinas do programa Oasis Montaj $^{\text {TM }}$ (Geosoft, 2005, p.43), de forma semelhante aos dados do levantamento de semidetalhe. Assim, as coordenadas dos pontos foram obtidas automaticamente com o GPS próprio do magnetômetro e a correção diurna e a subtração do IGRF (International Geomagnetic Reference Field) foi executada de forma já descrita no item 6.3. O fluxo dos principais filtros aplicados aos dados magnetométricos pode ser vista na Figura 6.34, onde se mostra, de forma ilustrativa, os processos envolvidos e os respectivos produtos.

\subsection{1 - Mapa do Campo Magnético Total - CMT - de detalhe}

Para a confecção do mapa CMT foi empregado o sistema de coordenadas UTM, zona 22 sul do meridiano de Greenwich, com base no WGS 84. O produto resultante da redução dos dados magnetométricos e da interpolação (mínima curvatura com célula de 10 metros) é apresentado na Figura 6.35, onde é mostrado o mapa CMT da área de ocorrência dos geiseritos, a imagem da área de ocorrência dos cones silicosos, com área ampliada, sobreposta com os pontos medidos. 
6.5.2 - Espectro de Potência Aplicado aos dados magetométricos de detalhe

A técnica do Espectro de Potência (Spector e Grant, 1970 e Geosoft, 2010. p. 28) foi aplicada ao mapa - CMT (Figura 6.35), separando o campo magnético residual - CMR - e subtraindo os ruídos (Figuras 6.34). A tabela 6.10 apresenta as estatísticas da análise do espectro de potência para as componentes de fontes rasas.

O espectro da Figura 6.36 apresenta duas partes representadas por retas, da esquerda para a direita. A primeira reta, em cor verde, tem uma profundidade média de 100 metros (3.7 $\mathrm{rad} / \mathrm{km}$ ), já a segunda reta, em amarelo, interpretado como ruído, foi descartada. Estas fontes magnéticas são constituídas por diabásios na forma de diques e soleiras (sills).

Tabela 6.10 - Estatísticas descritivas do espectro da Figura 6.36.

\begin{tabular}{lr}
\hline \multicolumn{1}{c}{ 5_DEPTH } & \multicolumn{1}{c}{ Fontes } \\
\hline Média & 0.104503 \\
Erro padrão & 0.018739 \\
Mediana & 0.095982 \\
\hline Modo & \multicolumn{1}{c}{$\#$ N/D } \\
Desvio padrão & 0.064912 \\
\hline Variância da amostra & 0.004214 \\
Curtose & -0.75974 \\
Assimetria & 0.203837 \\
Intervalo & 0.203999 \\
Mínimo & 0 \\
Máximo & 0.203999 \\
\hline Soma & 1.254032 \\
Contagem & 12 \\
\hline Nível de confiança (95,0\%) & 0.041243 \\
\hline
\end{tabular}




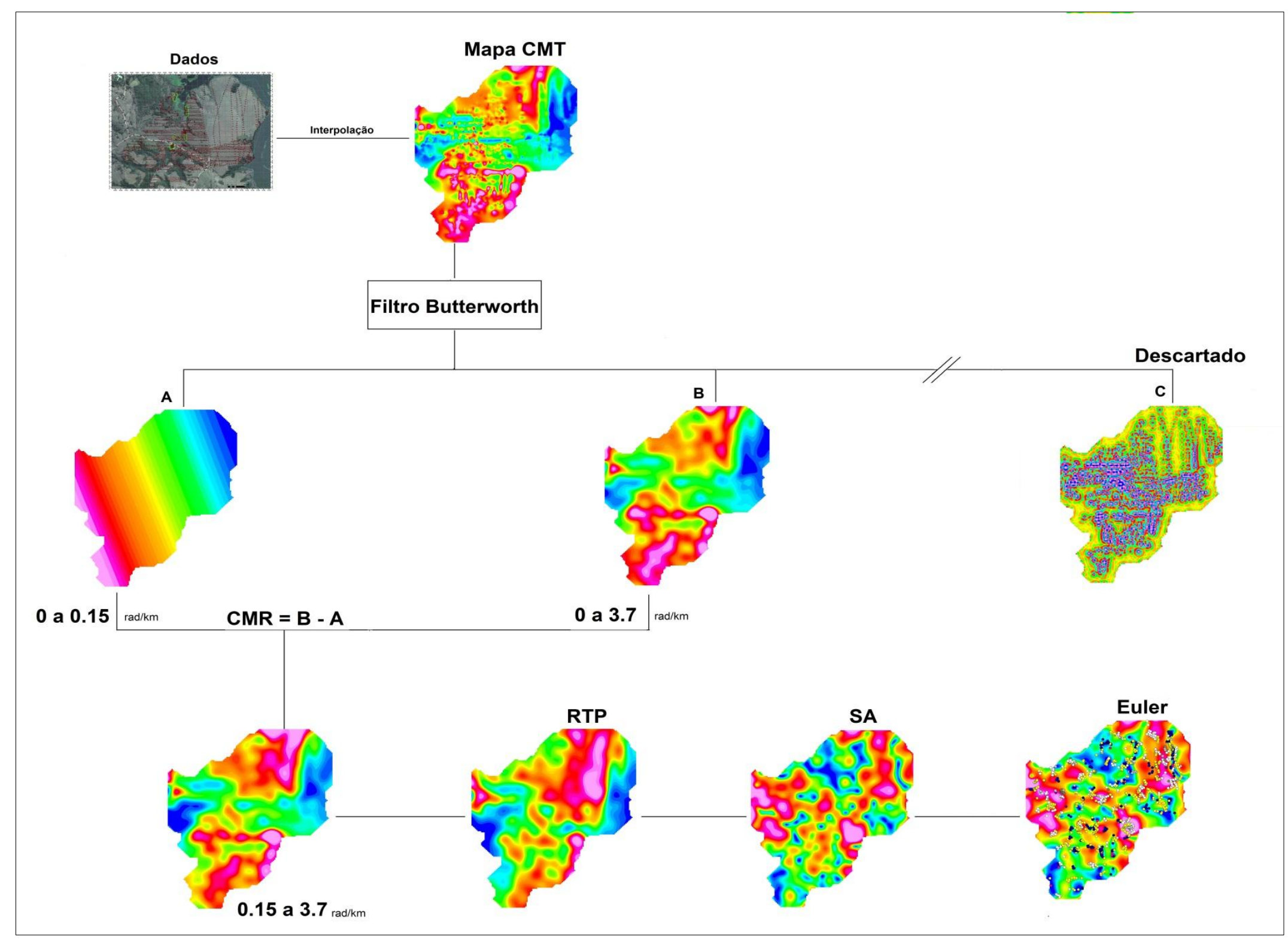

Figura 6.34 - Diagrama ilustrativo da obtenção do mapa CMT, levantamento de detalhe, e seus produtos derivados. 


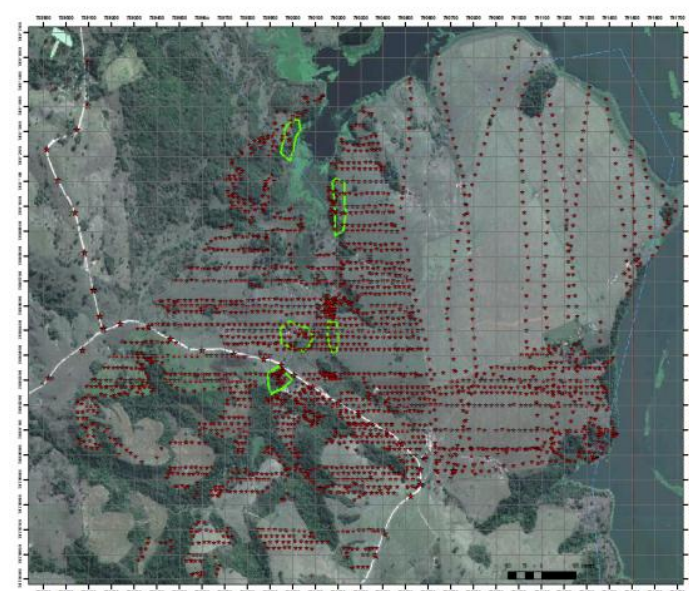

Figura 6.35 - Mapa do campo magnético total - CMT, sobreposto aos pontos de medida do levantamento de detalhe com 3.479 estações (em vermelho) na área de ocorrência dos geiseritos (polígonos em verde).

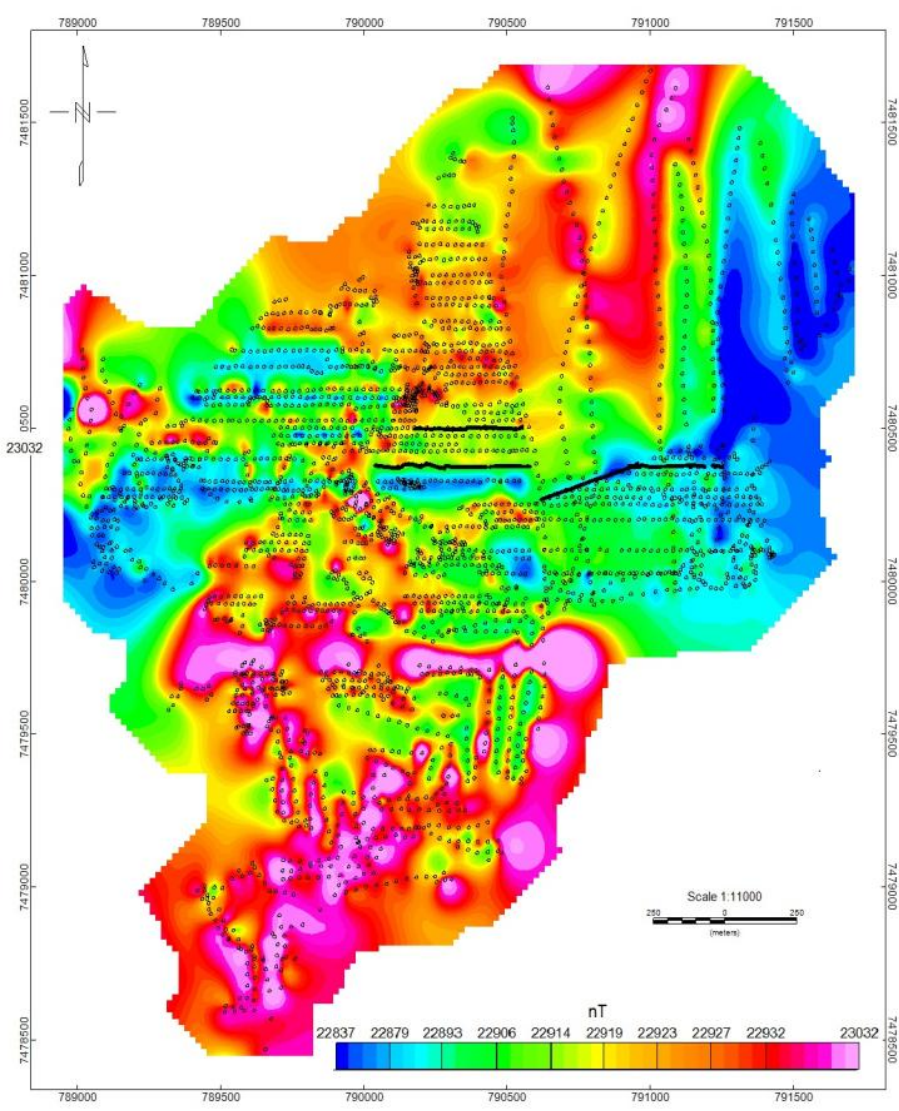

\subsection{3 - Filtro Butterworth aplicado aos dados magnetométricos de detalhe}

De forma semelhante aos outros levantamentos, o filtro utilizado foi o Butterworth (item 4.2.2.4). Este filtro foi aplicado em dois intervalos de números de onda, com parâmetro $<<$ regional>> selecionado, baseando-se nos valores encontrados no espectro de potência (Figura 6.36):

A) 0.0 a $0.25 \mathrm{rad} / \mathrm{km} \mathrm{e} B$ ) 0.0 a $3.70 \mathrm{rad} / \mathrm{km}$.

O intervalo de interesse foi obtido da seguinte forma (Figura 6.34):

Passa-baixa (parâmetro <<regional>> selecionado):

$1^{\circ}$ ) Intervalo: 0 a $0.25 \mathrm{rad} / \mathrm{km}=$ grid $A ; 2^{\circ}$ ) Intervalo: 0 a $3.7 \mathrm{rad} / \mathrm{km}=$ grid $B$;

Fez-se a subtração: grid $B$ - grid $A=0.25$ a $3.7 \mathrm{rad} / \mathrm{km}$;

O valor adotado, dentre vários testados, para o parâmetro <<grau da função >> do filtro

Butterworth (Geosoft, 2009, p. 57) foi o grau 6, sendo o resultado da filtragem do intervalo 0.25 a $3.7 \mathrm{rad} / \mathrm{km}$ mostrado na Figura 6.37 . 


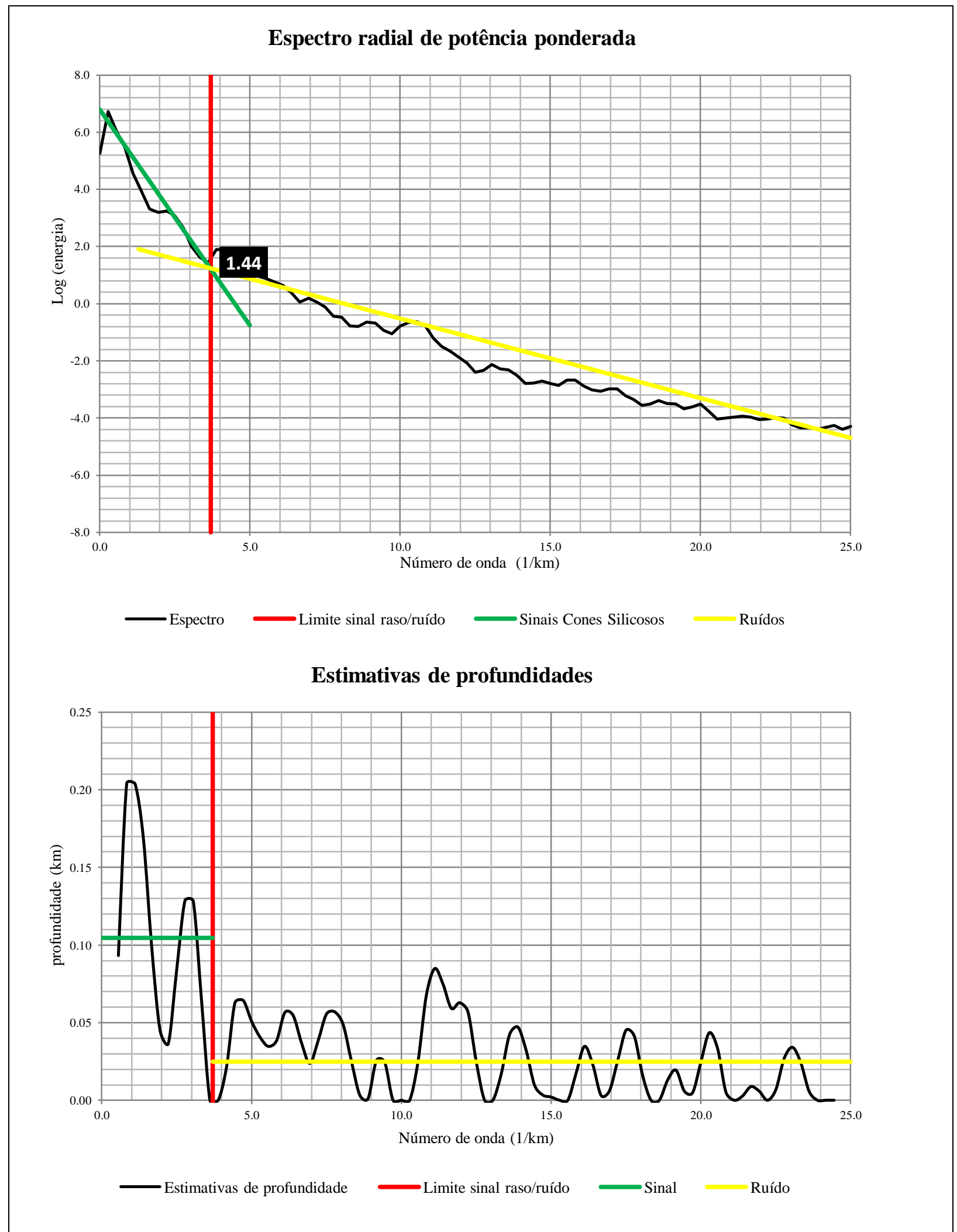

Figura 6.36 - Espectro de potência do levantamento de detalhe, com indicações das profundidades médias das fontes e seus respectivos valores de cortes, linhas azuis e espectro resultante, linha vermelha. 


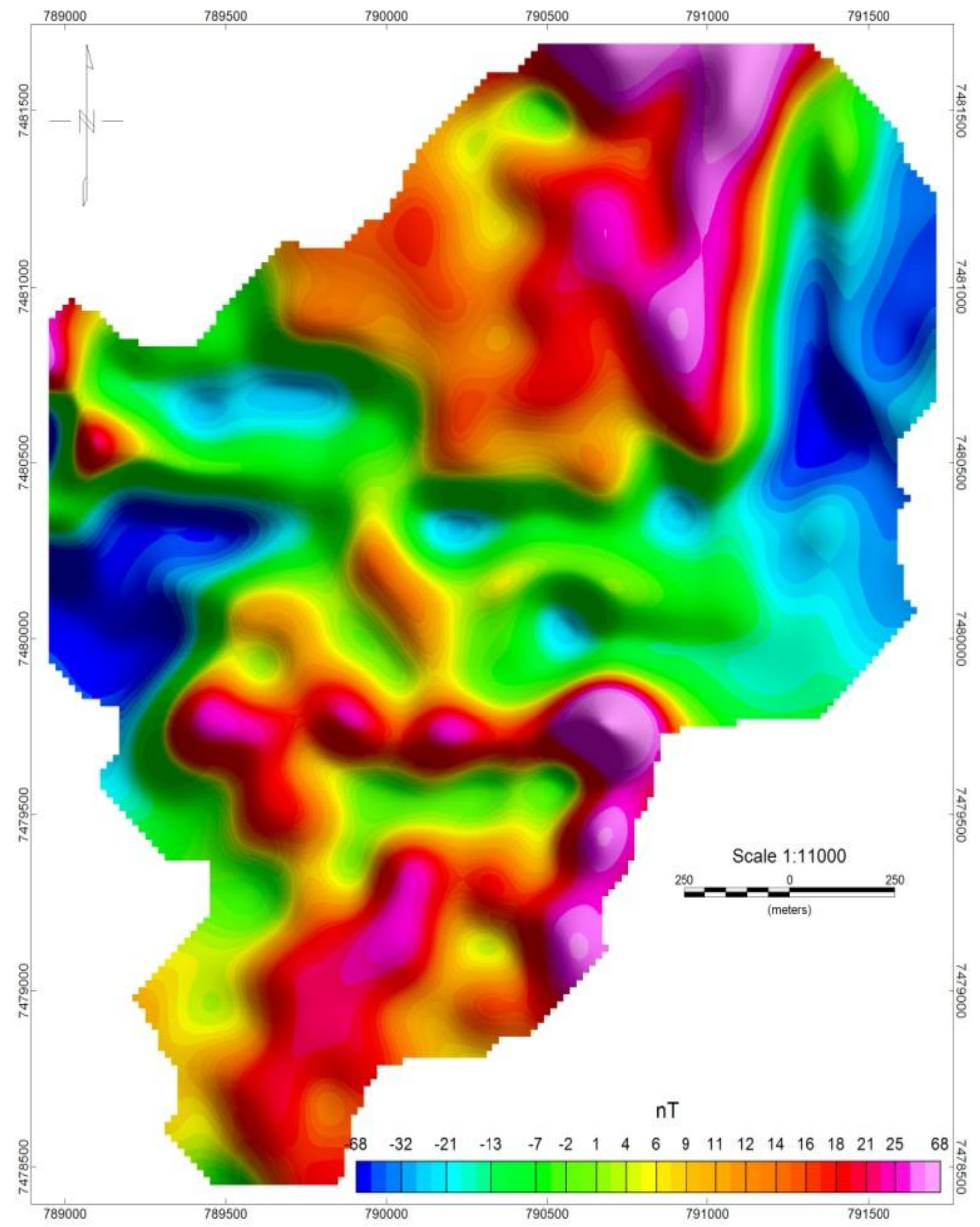

Figura 6.37 - Mapa do campo magnético residual - CMR, sombreado, iluminação de $45^{\circ}$, elevação de $45^{\circ}$.

6.5.4 - Resultados dos Filtros aplicados aos dados magnetométricos de detalhe

Ao mapa CMR (Figura 6.37) foi aplicado o operador redução ao polo de forma semelhante ao levantamento de semi-detalhe, item 6.3, utilizando algoritmo de Philips (2007, p.67). Desta forma, foram utilizados os mesmos valores de magnetização total, ou seja: declinação $=347.5^{\circ}$ e inclinação $=-37.8^{\circ}$, obtidos com medições em laboratório de MRN e susceptibilidade, discutidos no item 6.1.2. O resultado desta operação é mostrado na Figura 6.38. Nesta figura está representado uma grande falha, determinada por Araújo et al. (2006, p.55), cortando a área na direção noroeste a sudeste, bem como lineamentos magnéticos interpretados neste trabalho. 


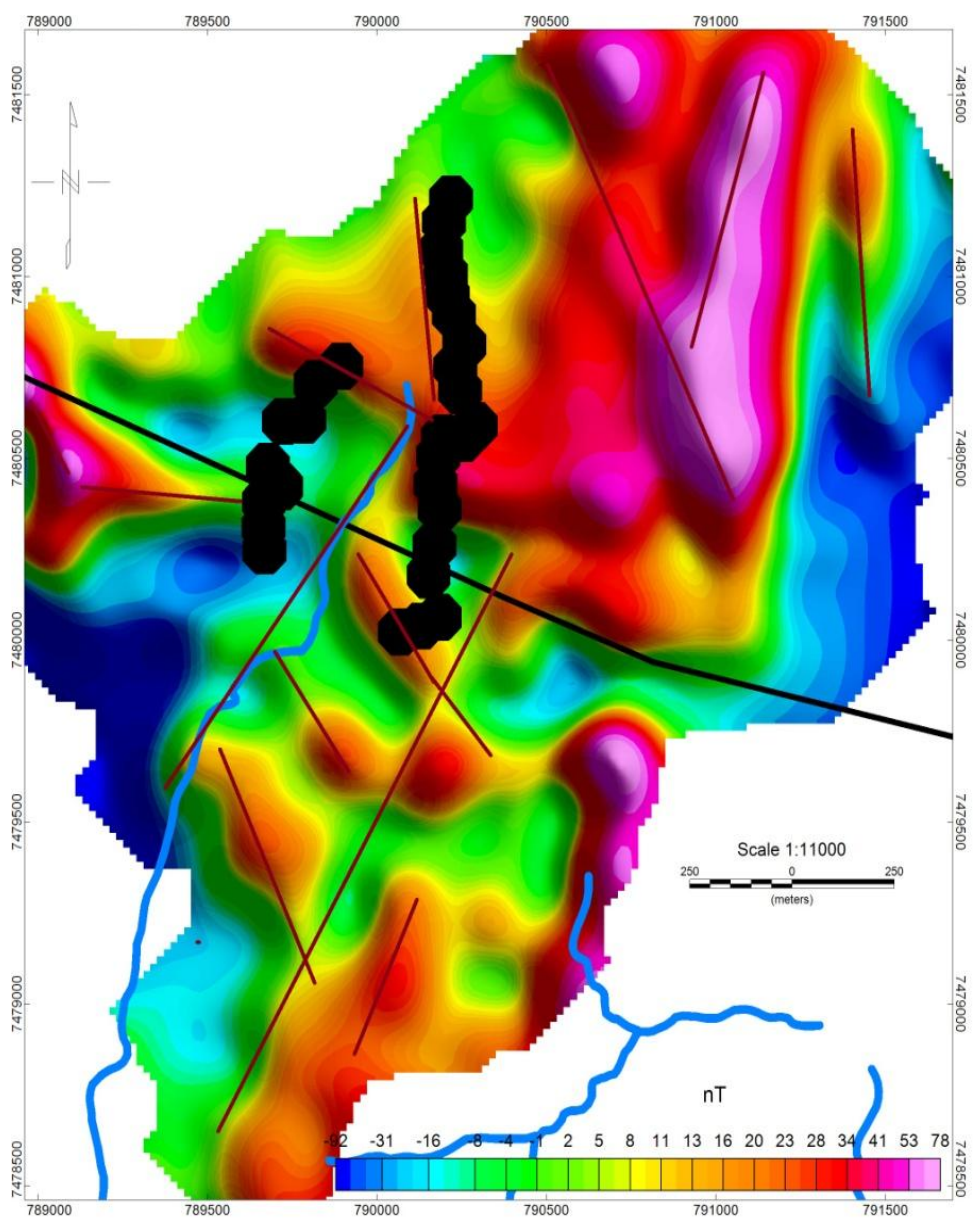

Figura 6.38 - Mapa redução ao polo, sombreado, iluminação de $45^{\circ}$, elevação de $45^{\circ}$, sobreposto por falha determinada por Araújo et al. (2006, p.55), segmento na cor preta, pela localização da área de ocorrência dos cones silicosos, sequência de pontos pretos, cortado pelo córrego do Retiro, segmento em azul. Os segmentos em marrom representam principais lineamentos magnetométricos reconhecidos neste mapa.

Ao mapa redução ao polo foi aplicado a amplitude do sinal analítico - ASA (Figura 6.39). Nesta figura foram marcados os principais lineamentos magnetométricos reconhecidos. A falha determinada por Araújo et al. (2006, p. 55) está sobreposta a este mapa e mostra uma boa correlação com este. 
6.5.5 - Deconvolução de Euler aplicado aos dados magnetométricos de detalhe

O mapa amplitude do sinal analítico (Figura 6.39) foi utilizado para a estimativa de profundidade da técnica deconvolução de Euler (Reid et al. 1990). Como o alvo são diques e sills, foi utilizado o índice estrutural de valor 1. Os melhores resultados para o conjunto de soluções de Euler, utilizando $\mathrm{N}=1$, índice estrutural, são: tamanho da janela = 3 células e $4 \%$ de tolerância. A Figura 6.40 apresenta o resultado da deconvolução de Euler sobre mapa ASA. Vários intervalos de profundidade, de 0 a 210 metros, estão representados, num total de 1478 soluções. As soluções possuem um valor mínimo de 22 e máximo de 227 metros, média de 104 metros. Observa-se que $95.4 \%$ das soluções estão a menos de 150 metros de profundidade. Os valores dos intervalos de profundidades estão descritos na tabela 6.11. As profundidades encontradas pela deconvolução de Euler estão dentro do intervalo de profundidades médias calculada pela técnica espectro de potência (Figura 6.36).

Tabela 6.11- Distribuição das profundidades, em porcentagem na deconvolução de Euler.

\begin{tabular}{|c|c|}
\hline intervalos & Porcentagem (\%) \\
\hline 0 a 50 & 1.8 \\
\hline 50 a 80 & 18.0 \\
\hline 80 a 110 & 42.5 \\
\hline 110 a 150 & 33.0 \\
\hline 150 a 180 & 3.0 \\
\hline 180 a 210 & 1.5 \\
\hline$>210$ & 0.2 \\
\hline $\begin{array}{r}\text { Mínima } \\
\text { Média } \\
\text { Máxima } \\
\mathbf{N}^{\mathbf{0}}\end{array}$ & $\begin{aligned} \text { de profundidade } & =22 \text { metros } \\
& =104 \text { metros } \\
& =227 \text { metros } \\
\text { soluções } & =1478\end{aligned}$ \\
\hline
\end{tabular}




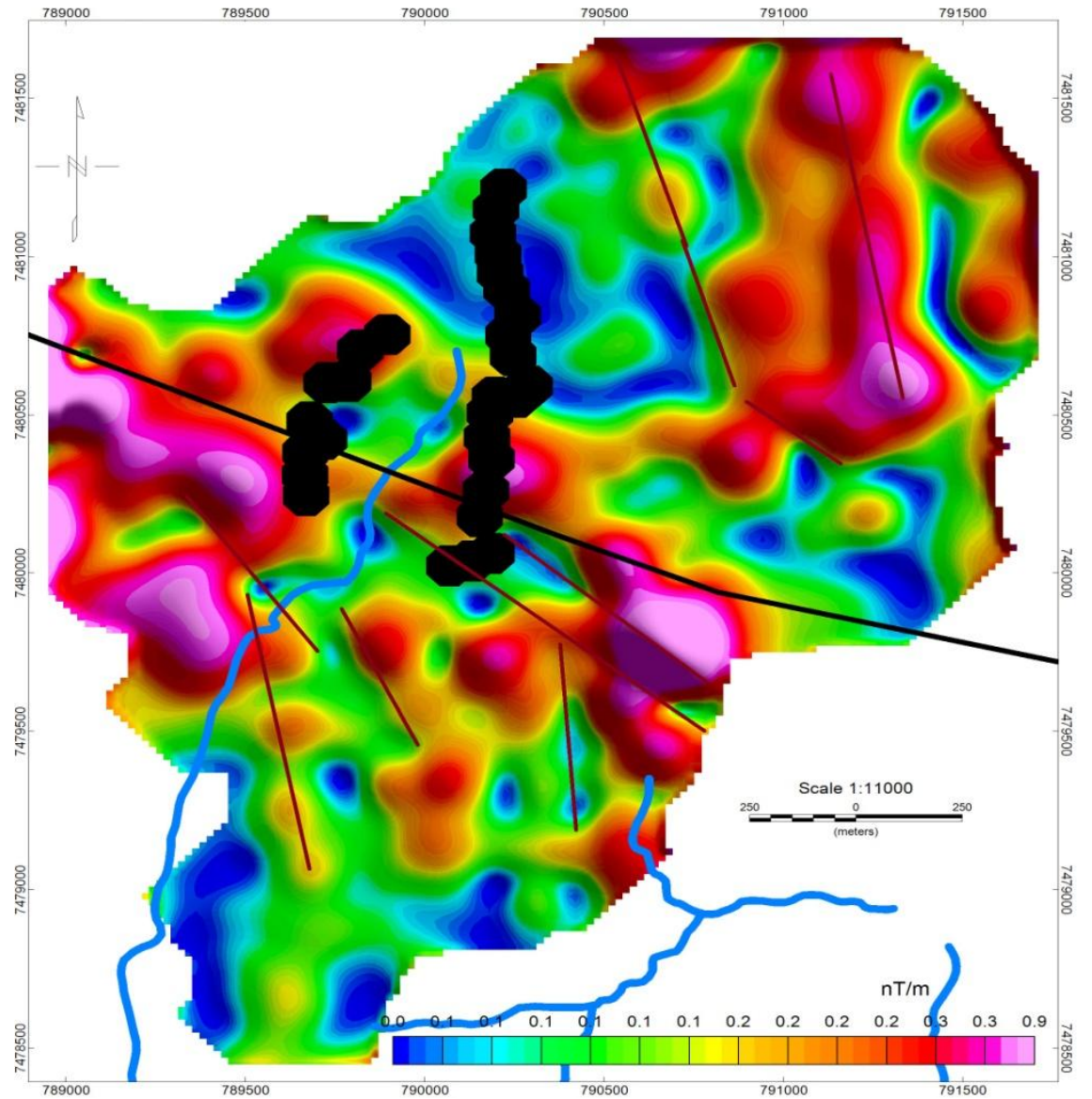

Figura 6.39 - Mapa Amplitude do Sinal Analítico - ASA, sombreado, iluminação de $45^{\circ}$, elevação de $45^{\circ}$, sobreposto por falha determinada por Araújo et al. (2006, p 55), segmento na cor preta, pela localização da área de ocorrência dos cones silicosos, sequência de pontos pretos, cortado pelo córrego do Retiro, segmento em azul. Os segmentos em marrom representam principais lineamentos magnetométricos reconhecidos neste mapa.

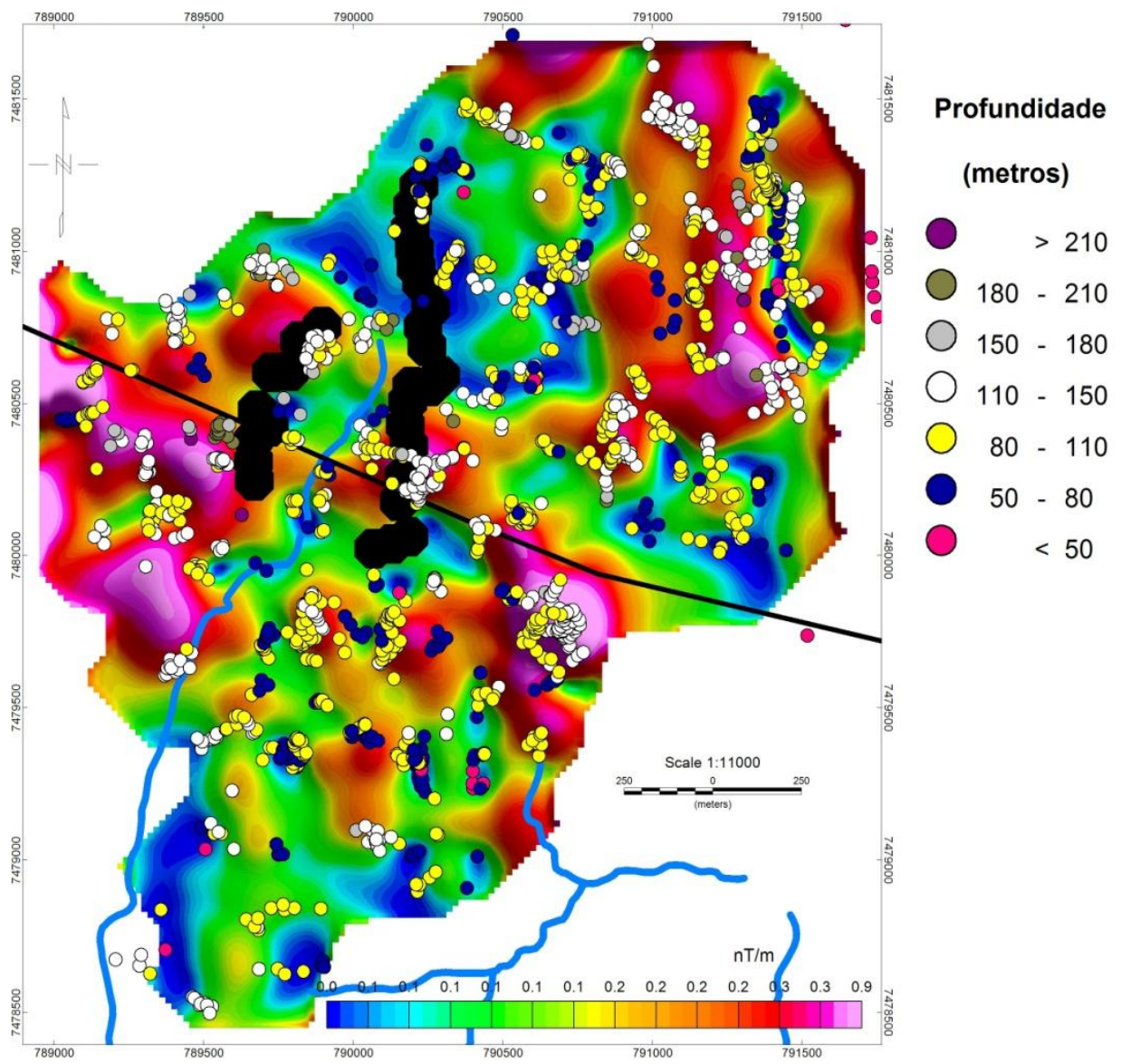

Figura 6.40 - Representação das soluções da deconvolução de Euler sobreposto ao mapa de Amplitude do Sinal Analítico - ASA, sombreado, iluminação de 45, elevação de $45^{\circ}$, e por falha determinada por Araújo et al. $(2006$, p. 55). 


\section{Capitulo 7}

\section{CONSIDERAÇÕES FINAIS}

Os principais produtos obtidos nesta pesquisa apresentam uma série de evidências tectônicas e estratigráficas no Alto Estrutural de Anhembi, inclusive em relação à ocorrência de geiseritos, bem como os arenitos asfálticos, conforme sumariados graficamente na Figura 7.1.

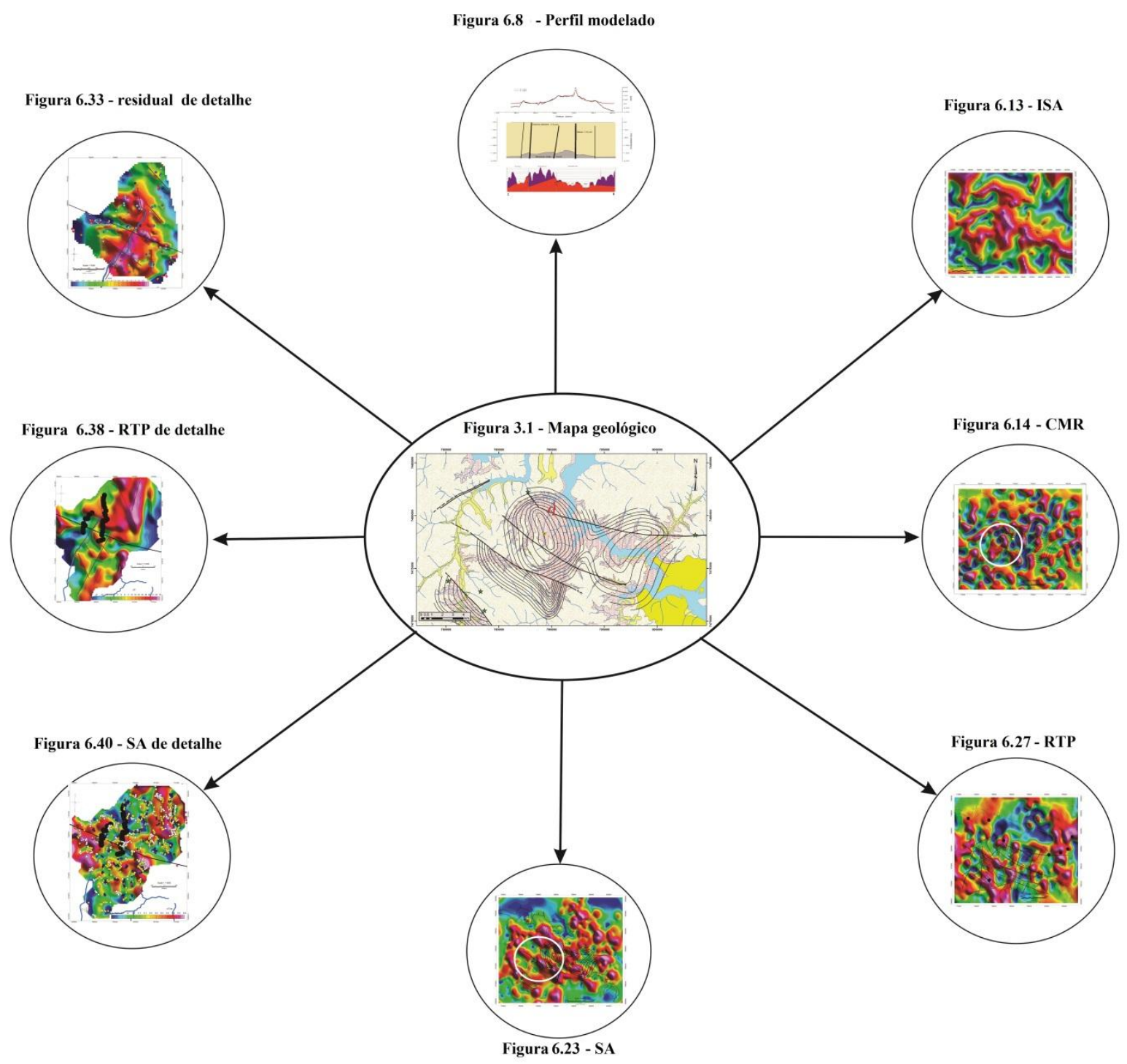

Figura 7.1 - Diagrama ilustrativo dos resultados obtidos. 
A Figura 3.1 apresenta o mapa geológico atualizado da área de estudo, o qual é uma síntese dos trabalhos de campo realizados por Araújo (2006, p. 55 e IPT, 1979).

O mapa de Inclinação do Sinal Analítico - ISA (Figura 6.13) identifica uma anomalia positiva com direção NW-SE, sobreposta ao rio Tietê, indicando uma forte correlação com o Lineamento Tietê, que por sua vez explicaria o alto estrutural separando as ocorrências das formações Serra Alta, Teresina e Rio do Rasto, a sul do rio Tietê, da formação Corumbataí a norte do mesmo rio, como descrito por diversos autores (e.g. Schneider et al., 1974). Trata-se de um resultado importante, pois confirma a existência desta feição estrutural à época da sedimentação do Grupo Passa Dois no final do Permiano.

A anomalia gravimétrica encontrada (Figura 6.13) está fortemente relacionada com o embasamento e confirma as observações realizadas em campo por Soares (1974), Araújo (2006) e IPT (1979 e 2005), tanto em relação ao afloramento da Fm. Teresina (Figura 3.1) quanto à descrição de blocos com mergulho a sudoeste e bloco baixo voltado a nordeste, constituindo de um sistema escalonado, tipo dominó.

A Figura 6.14 indica que a estruturação observada no embasamento é refletida na superfície, através dos sistemas de falhas e lineamentos, descritos por IPT (2005) e Araújo et al. (2006), e por uma feição circular coincidindo com a morfoestrutura descrita por Araújo et al. (2006). Este reflexo pode também ser verificado nos resultados do levantamento magnetométrico de semi-detalhe (Figura 6.23). O modelo estrutural apresentado assemelha-se ao proposto por Soares (1991) e ampliado por Etchebehere et al. (2007), mostrado na Figura 7.2 com o formato de bloco diagrama. Estes autores destacam que o conjunto de falhas e fraturas observadas na superfície é reflexo do movimento rúptil do embasamento, ou seja, descontinuidades estruturais geradas no embasamento que sofreram reativações ao longo do tempo. Desta forma, esta feição circular sugere que esta estrutura é de idade mais antiga que as idades atribuidas a Fm. Serra Geral, isto é, uma estrutura muito antiga e relacionada com o Lineamento Tietê. As modelagens de perfis gravimétricos reforçam a constatação discutida no parágrafo anterior, representada neste capitulo pela Figura 6.8. A modelagem gravimétrica mostrou blocos com características de horst/graben com blocos abatidos e que as falhas estão preenchidas por diques.

A Figura 6.23, sinal analítico, mostra que a estruturação das fontes magnéticas possue uma direção preferêncial NW, de forma geral e que abaixo do alto estrutural há uma feição circular, à semelhança da Figura 6.14, indicando que os derrames da Fm. Serra Geral se alojaram no sistema de falhas preexistente. As Figuras 6.27 e 6.23 sobrepostas aos sistemas de falhas descritos por Araújo (2006) e IPT (1979 e 2005) sugerem esta direção. 


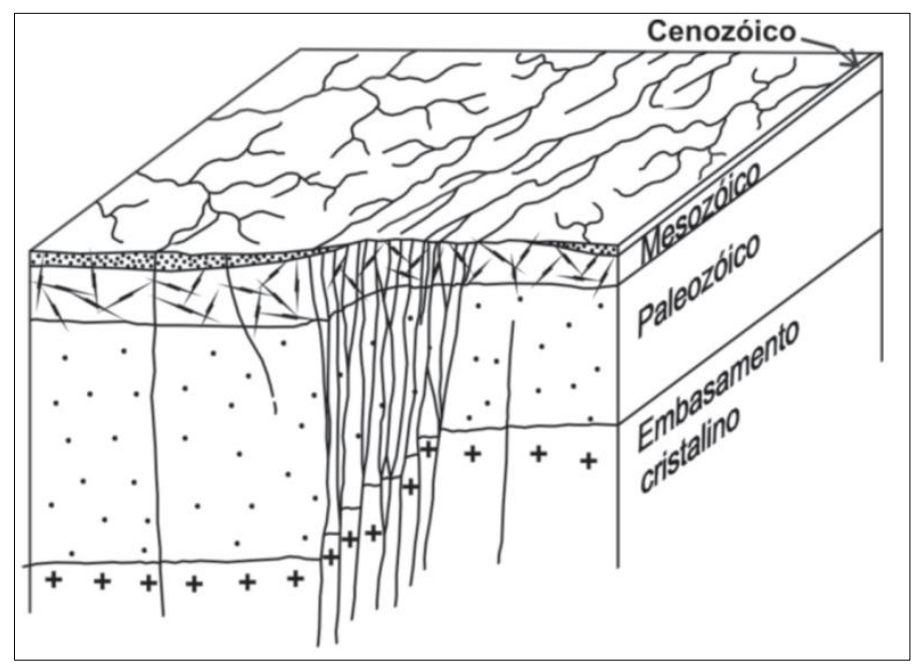

Figura 7.2 - Modelo de limite de blocos estruturais de Soares (1991) e ampliado por Etchebehere et al. (2007). Falhas e fraturas observadas em superfície refletem as descontinuidades existentes no embasamento.

O levantamento gravimétrico de detalhe mapeou o silexito, rocha que constitui os geiseritos (Figura 6.33). Essa anomalia tem a mesma direção do córrego do Retiro, interpretado como uma falha, recortado por uma falha descrita por Araújo (2006) e por outras falhas menores, inferidas neste trabalho. As profundidades encontradas pela convolução de Euler mostram que as rochas estão no máximo a 50 metros $(79.1 \%)$ dentro da Fm. Teresina. A mesma análise foi realizada em relação à anomália magnética de detalhe (Figura 6.40). Aparentemente, os corpos magnéticos, diabásio, estão localizados na área dos geiseritos em falhas, preenchedo-as, e na forma sills num intervalo de profundidade maior (50 a 150 metros, 93.5\% das soluções de Euler) que os encontrados pela gravimetria. Estes valores estão compatíveis às médias encontradas por análise de espectros de potência, com as descrições do perfil confeccionado por IPT (1979) e modelado (Figura 6.13) neste trabalho e com o que foi observado em campo, nas margens leste e oeste do córrego do Retiro (cota 515 metros), a montante do mesmo córrego (cota 530 metros), Figura 3.16, e na margem leste do Ribeirão dos Remédios (cota 490 metros).

A interpretação, baseada nos levantamentos de detalhe e semi-detalhe não indicaram a existência de uma rocha que exerceu o papel de fonte de calor próximo à superfície, relacionada à gênese dos geiseritos. Os resultados sugerem que as falhas (Figuras 6.33 e 6.38), principalmente a falha na direção do córrego do Retiro, funcionou como conduto para água quente vindo do embasamento, aproximadamente a 1650 metros, como mostrou as análises dos geiseritos por inclusões fluidas realizadas por Nomura $(2012$, p. 122) e que esta possível fonte de calor teria como origem a energia térmica resultante dos vários processos de 
deformação dúctil no interior da crosta e manto superior, decorrentes da longa história de deformação pela qual passou a falha de Jacutinga (Soares et al., 1996). A Figura 7.3 apresenta um modelo genérico de um sistema hidrotermal em profundidade que poderia ter características parecidas ao sistema de gênese dos geiseritos.

Os afloramentos conhecidos de arenitos asfálticos na região do Domo de Anhembi ocorrem restritos à borda desta estrutura (Figura 6.31) mostrando que estes estão localizados na base da Fm. Pirambóia. Na verdade, Thomas Filho et al,. (2008) demonstrou que os arenitos asfálticos sempre ocorrem associados a diques de diabásio que funcionaram como condutos do óleo gerado nos folhelhos da Formação Irati com o seu armazenamento em arenitos da Formação Pirambóia.

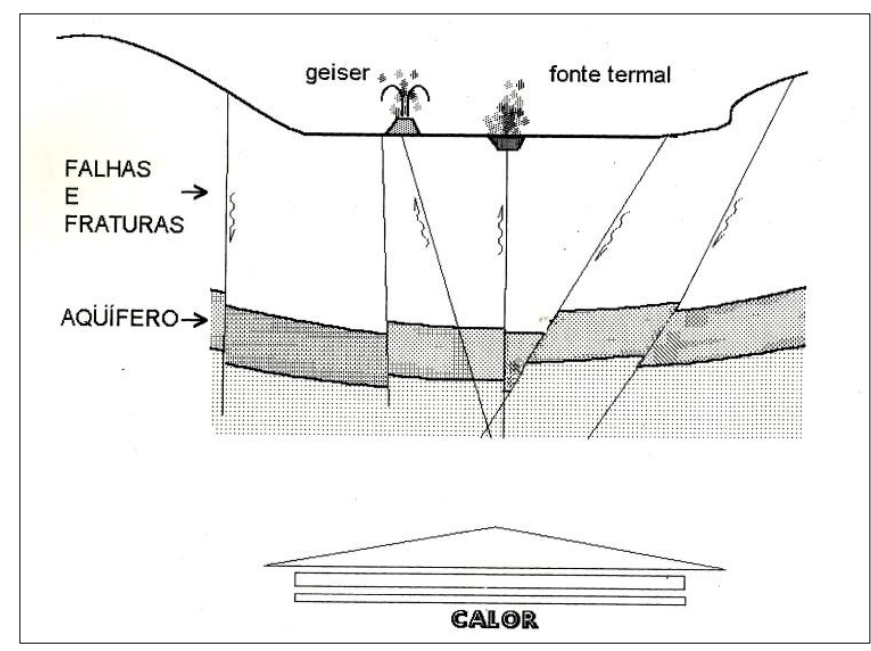

Figura 7.3 - Modelo genérico de um sistema hidrotermal em profundidade, que poderia representar a gênese dos geiseritos (Matos, 1995, p.75). As setas indicam um possível padrão de circulação de água no sistema. Neste modelo não houve preocupação com a geometria das falhas e com a proporcionalidade. 


\section{REFERÊNCIAS BIBLIOGRÁFICAS}

AGICO, JR6 - SPINNER MAGNETOMETER, 2004. User's Manual. 48 p.

AGICO, Kappabridge KLY-4, 2004. User's Guide. 77 p.

ANP, 2010. Acessado em junho/2012.

http://www.brasil-rounds.gov.br/round10/portugues/seminarios.asp\#Workshop_Academicos

Almeida, F. F. M.; Melo, M. S., 1981. A Bacia do Paraná e o vulcanismo mesozóico. In: Mapa Geológico do Estado de São Paulo, escala 1:50.000. São Paulo, IPT, v.1, p. 46-81.

Araújo, C.C., 2003. Gênese das ocorrências de arenito asfáltico da borda leste da Bacia do Paraná, SP. Instituto de Geociências-USP. Tese de Doutoramento. 135p.

Araújo, C. C., Yamamoto, J. K., Rostirolla, S. P., Madrucci, V, Tankard, A., 2005. Tar sandstones in the Paraná Basin of Brazil: structural and magmatic controls of hydrocarbon charge. Marine and Petroleum Geology, Guildford, v. 22, n. 5, p. 671-685.

Araújo, C.C., Yamamoto, J.K., Rostirolla, S.P., 2006. Arenitos asfálticos na B. Paraná: estudo das ocorrências no Alto Estrutural de Anhembi. B. Geo. Petrobrás, v.14 (1): 47-70.

Assine, M. L., Soares, P. C., 1995. Interação flúvio-eólica na Formação Piramboia. In: SIMPÓSIO DE GEOLOGIA DO SUDESTE Águasde São Pedro. Boletim... Águas de São Pedro: SBG, 1995. 4, p.65.

Assine, M. L.; Piranha, J. M.; Carneiro, C. D. R., 2004.Os paleodesertos Pirambóia e Botucatu. Geologia do Continente Sul- Americano - Evolução da Obra de Fernando Flávio Marques de Almeida. São Paulo: Beca. Produções Culturais Ltda., p. 77-92.

Baronov, W., 1957. A New method for Interpretation of aeromagnetic Maps: PseudoGravimetric Anomalies. Geophysics, 22: 359-383.

Baronov, W., 1975. Potencial fields and their transformations in Applied Geophysics. Berlin, Gebruder Bortraeger, $121 \mathrm{p}$.

Bateman, H., 1946. Some integral Equations of potencial Theory. J. of Appl. Physics, 17: 91102.

Bhattacharyya, B.K.,1965. Two-Dimensional Harmonic Analysis as a Tool for Magnetic Interpretation. Geophisics, 30: 829-857.

Blakely, R. J., 1996. Potential theory in gravity and magnetic applications. Cambridge University Press, 441 p.

Briggs I.C. 1974. Machine contouring using minimum curvature. Geophysics, 39(1):39- 48.

Briguetti, J. M. P., 1994. Faciologia dos sedimentos da Formação Pirambóia na Região de Rio Claro (SP). Rio Claro, IGCE/UNESP, Dissertação de Mestrado, 124p. 
Butler, R. F., 1992. Paleomagnetism: Magnetic Domains to Geologic Terranes. Blackwell Scientific Publications, $2^{\text {nd }}$ edition, 319p.

Caetano-Chang, M.R., 1993. Estado d'arte dos conhecimentos sedimentológicos/ estratigráficos das Formações Pirambóia e Botucatu no Estado de São Paulo. In: Sim. Cronoest. da Bacia Do Paraná,1, Rio Claro, SP. Bol. Res. Expandidos. Rio Claro,UNESP-SBG, p.84-85.

Caetano-Chang, M. R., WU, F. T., 1995. As formações Pirambóia e Botucatu no Estado de São Paulo. In: Simpósio de Geologia do Sudeste, Água de São Pedro. SBG, 1995. p.64.

Cooley, J.W., Tuckey, J.W., 1965. An Algorithm for the Machine calculation of Complex fourier series. Math. of Comp 45, 297-301.

Cordani U. G., Brito Neves B. B., Fuck, R. A., Porto, R., Thomaz Filho, A., Cunha F. M. B., 1984. Estudo preliminar de integração do Pré - Cambriano com os eventos tectônicos das bacias sedimentares brasileiras. Rio de Janeiro, Petrobras (CENPES/SINTEP), 70p (Série Ciência-Técnica-Petróleo. Seção: Exploração de Petróleo. Publ. no 15).

Cordani, R., Shukowsky W., 2009. Magnetização Remanescente: um parâmetro crucial para a interpretação e modelamento de anomalias magnéticas em território brasileiro. Revista Brasileira de Geofísica, vol. 27(4).

CPRM (Serviço Geológico do Brasil), 2001. Mapa geológico do Brasil. In: Geologia, Tectônica e Recursos Minerais do Brasil: Sistema de Informações Geográficas - SIG e Mapas na escala 1:2.500.000. CD-Rom 3.

Coimbra, A.M.; Brandt Neto, M; Petri, S. 1977. O alinhamentoestrutural do Tietê. In: Simpósio de Geologia Regional. Sociedade Brasileira de Geologia. Atas. São Paulo, p 145-152.

Dalpozzo, H.A.P., Shukowsky, W, Molina, E.C. 2007. Tietê Airborne Gravity Test Área. Tenth International Congress of the Brazilian Geophysical Society.

DNPM, 1988. Relatório final da Comissão de Estudos das Minas de Carvão de Pedra do Brasil. Rio de Janeiro: Parte I, p: 1-300; Parte II, p: 301-617.

Elkins, T.A., 1951. The second Derivative Method of Gravity Interpretation. Geophysics, 16: 29-50.

Etchebehere, M. L. C., Saad, A. R., Fulfaro, V. J., 2007. Análise de bacia aplicada à prospecção de água subterrânea no planalto ocidental paulista, SP. Rev. Geociências, v.26, no 3: p. 229-247.

Ferreira, F. J. F., Souza, J., Bongiolo, A. B. S., 2013. Castro, L. G. Enhancement of the total horizontal gradient of magnetic anomalies using the tilt angle. Geophysics, 78: 33-41.

Fowler, C. M. R., 2001. The Solid Eath. Cambridge Univ. Press, $2^{\text {rd }}$ ed. 472 p.

Fulfaro, V. J., Saad, A. R., Santos, S. M. V., Vianna, R. B., 1982. Compartimentação e evolução tectônica da Bacia do Paraná. Revista Brasileira de Geociências, São Paulo, v. 12, n. 4, p. 590-611.

Geosoft 2005. Mapping and processing system. Tutorial and User Guide - V6.1. Geosoft, Inc., Toronto. 271p. 
Geosoft, 2006. Montaj Gravity \& Terrain Correction - Tutorial and User Guide - V6.3. Geosoft, Inc., Toronto. 49p.

Geosoft, 2009. Filtragem montaj MAGMAP: Processamento de dados de campos potenciais no domínio da frequência. V7.1. Geososft, Inc., Toronto. 77 p.

Geosoft, 2010. Montaj Grav/Mag interpretation: Sistema de Processamento, análise e visualização para inversão 3D de dados de campos potenciais. V7.1. Geososft, Inc., Toronto. $73 \mathrm{p}$.

Giannini, P.C.F., Sawakuchi, A.O., Fernandes, L.A., \& Donatti, L.M., 2004. Paleoventos e paleocorrentes subaquosas do Sistema Deposicional Pirambóia nos estados de São paulo e Paraná, Bacia do Paraná: estudo baseado em análise estatística de dados azimutais. Revista Brasileira de Geociências, 34 (2), 282-292.

Godoy, D. F., Hackpacher, P. C., Guedes, S, Hadler, J, C, N., 2006. Reconhecimento da Tectônica Mesozóica-Cenozóica na borda leste da Bacia do Paraná através da aplicação de traços de fissão em apatitas no domo de pitanga (sudoeste de Rio Claro, SP). Revista de Geociências, UNESP - São Paulo, v. 25, nº 1, p. 151-164.

Gunn, P.J.,1974. Linear Transformations of Gravity and Magnetic field. Geophys. Prosp., 23: 300-312.

Gunn, P; Meixner, T., Milligan, P, Mackey, T., 1998. Interpretation of airborne magnetic and radiometric surveys. Camberra: Australian Geological Survey Organization. Airborne geophysics group, $113 \mathrm{p}$.

Hachiro, J., 1991. Litotipos, associações faciológicas e sistemas deposicionais da Formação Irati no Estado de São Paulo. 175 p. Dissertação (Mestrado em Geociências) - Instituto de Geociências, Universidade de São Paulo, São Paulo.

Hartmann, G.A. \& Pacca, I.G., 2009. Time evolution of the South Atlantic Magnetic Anomaly. Anais da Academia Brasileira de Ciências, 81(2):243-255.

Henderson, R.G., Zietz, I., 1949. The Computation of Second Vertical Derivatives of Geomagnet fields. Geophysics, 14: 508-516.

Hinze, W. J., 2003. Bouguer reduction density, why 2.67? Geophysics, 68, 1559-1560.

Holz, M., França, A.B., Souza, P.A., Iannuzzi, R., \& Rohn, R. 2010. A stratigraphic chart of the Late Carboniferous/Permian succession of the eastern border of the Paraná Basin,Brazil, South America. Journal of South American Earth Sciences, 29, 381-399.

IPT - Instituto de Pesquisas Tecnológicas do Estado de São Paulo, 1981. Mapa Geomorfológico do Estado de São Paulo, v. 1, IPT.

IPT - Instituto de Pesquisas Tecnológicas do Estado de São Paulo. 1979. Geologia do Alto Estrutural de anhembi . Relatório BP-002/79. 25p.

IPT - Instituto de Pesquisas Tecnológicas do Estado de São Paulo. 2005. Estocagem Subterrânea de Gás Natural - Tecnologia para Suporte ao Crescimento do Setor de Gás Natural no Brasil. Publicação IPT 3002. 226p. 
Kearey, P., Brooks, M., 2002. An introduction to Geophysical exploration. Boston, Blackwell Sci. Publ. 296 p.

Landim, P. M. B.; Soares, P. C.; Gama Jr., 1980. E. Estratigrafia do nordeste da Bacia do Rio Paraná. Rio Claro: IPT/UNESP. 45p.

Li, X., 2008. Magnetic reduction-to-the-pole at low latitudes: Observations and considerations. Leading Edge, 990-1002.

Lowrie, W., 2007. Fundamentals of Geophysics. Cambridge Univ. Press, $2^{\text {nd }}$ ed. 375 p.

Luiz, J. G., Costa e Silva, L. M., 1995. Geofísica de Prospecção. Ed. Univ. UFPA, 311p.

Mantovani, M. S. M., Quintas, M.C.L., Shukowsky, W. \& Brito Neves, B. B.,2005. The Paranapanema Lithospheric Block: It's Importance for Proterozoic (Rodinia, Gondwana) Supercontinent Theories. In: Gondwana Research, v. 8, n. 3, p. 303-315.

Matos, S. L. F., 1995. O contato entre o Grupo Passa Dois e a Formação Pirambóia na borda leste da Bacia do Paraná no Estado de São Paulo. São Paulo: Universidade de São Paulo. Dissertação Mestrado. 75p.

Meglhioratti, T. 2006. Estratigrafia de seqüências das formações Serra Alta, Teresina e Rio do Rasto (Permiano, Bacia do Paraná) na porção nordeste do Paraná e centro-sul de São Paulo. Rio Claro, Instituto de Geociências e Ciências Exatas, Universidade Estadual Paulista, Dissertação de Mestrado, 169 p.

Milani, E. J. \& Ramos V. A., 1998. Orogenias Paleozóicas no Domínio Sul-Ocidental do Gondwana e os Ciclos de Subsidência da Bacia do Paraná - Revista Brasileira de Geociências. v. 28 n. 4, p. 473-484.

Milani, E. J., Zalán, P. V., 1999. An outline of the geology and petroleum systems of the Paleozoic interior basins of South America. Episodes, Ottawa, v. 22, n. 3, p. 199-205.

Milani, E.L., Melo, J.H.G., Souza, P.A., Fernandes, L.A. \& França, A.B., 2007. Cartas Estratigráficas - Bacia do Paraná". Boletim de Geociências da Petrobrás 15 (2), 265-287.

Miller, H. G., and V. Singh, 1994, Potential field tilt - A new concept for location of potential field sources: Journal of Applied Geophysics, 32, no. 2-3, 213-217.

Milsom, J., 2003. Field Geophisics. Jonh Wiley \& Sons Ltd, $3^{\text {nd }}$ ed. 229 p.

Nabighian, M. N., 1972. The analytic signal of two dimensional magnetic bodies with polygonal crossection: Its properties and use for automated anomaly interpretation: Geophysics, 37, 507.

Nabighian, M. N., 1984. Toward a three-dimensional automatic interpretation of potential eld data via generalized Hilbert transforms: Fundamental relations: Geophysics, 49, 780.

Northfleet, A.A., Medeiros, R.A. e Muhlmann, H., 1969 - Reavaliação dos dados geológicos da Bacia do paraná. Bol. Técn. Petrobrás, vol. 12, n. 3, p. 291-346. 
Nomura, S., F., 2012. Hidrotermalismo evidenciado por minerais autigênicos e inclusões fluidas da formação Teresina, Bacia do Paraná. Instituto de Geociências, Universidade de São Paulo, Dissertação de Mestrado. 149 p.

ON, 2012. http://www.on.br/conteudo/modelo.php?endereco=servicos/servicos.html. Acessado em outubro de 2012.

Paterson, N. R., Reeves, C. V., 1985. Applications of gravity and magnetic survey: The stateof-the-art in 1985. Geophysics, 50: 2558-2594.

Penteado, M. M.,1976. Geomorfologia do setor centro-ocidental da Depressão Periférica Paulista. São Paulo, IGEOG/USP. 86p (Série Teses e Monografias, 22).

Peate, D.W., 1997, The Paraná-Etendeka Province, in Mahoney, J.J., and Coffi n, M.F., eds., Large igneous provinces: Continental, oceanic, and planetary flood volcanism: American Geophysical Union Geophysical Monograph 100, p. 217-245.

Pedley, R. C., Busby, J. P., Dabek, Z. K., 1997. GRAVMAG User manual: interative 2.5D gravity and magnetic modeling. British Geological Survey. 73 p.

Peters, L. J., 1949. The Direct Approach to Magnetic Interpretation and Its Practical Application. Geophysiscs, 14: 290-320.

Petri, S., \& Coimbra, A.M. 1982. Estruturas sedimentares das formações Irati e Estrada Nova (Permiano) e sua contribuição para elucidação dos seus paleoambientes geradores. $5^{\circ}$ Congr. Latinoamericano de Geologia, v.2, Buenos Aires, 353-371.

Philips, J.D. 2007. Geosoft eXecutables (GX's) developed by the U.S. Geological Survey, Version 2.0, with notes on GX development from FORTRAN code (Open-File Report 2007-1355), 111p.

Quintas, M.C., 1995. O embasamento da Bacia do Paraná: reconstrução geofísica de seu arcabouço. São Paulo. Tese Doutorado - Instituto Astronômico e Geofísico, Universidade de São Paulo, 253 p.

Rasmussen, R. \& Pederson, L. B., 1979. End corrections pontecial field modeling. Geophysical Prospecting. 27: 749-760.

Reid, A. B., Allsop, J. M., Granser, h., Millett, A, J., Somerton, I. W., 1990. Magnetic interpretation in three dimensions using Euler deconvolution. Geophysics, 55: 80-91.

Renne, P.R., Ernesto, M., and Milner, S.C., 1997, Geochronology of the Paraná-Etendeka magmatic province: Eos (Transactions, American Geophysical Union), v. 78, p. F742.

Riccomini. C., 1995. Tectonismo gerador e deformador dos depósitos sedimentares pósgondwânicos da porção centro-oriental do Estado de São Paulo e áreas vizinhas. Livre Docência - Instituto de Geociências, Universidade de São Paulo, 100 p.

Riccomini, C., 1997. Considerações sobre a posição estratigráfica e tectonismo deformador da Formação Itaqueri na porção centro-leste do Estado de São Paulo. São Paulo: Revista IG, v. 18, n. 1/2: p. 41-48. 
Riccomini, C., Almeida, R. P., Turra, B. B., Chamani, M A. C., Fairchild, T. R., Hachiro, J., 2005. Reativação de falha do Embasamento Causa Sismicidade no Permotriássico da Bacia do Paraná. In: X SNET (Simpósio Nacional de Estudos Tectônicos) Boletim de Resumos Expandidos, Curitiba, SBG-Núcleo Paraná, 18-20.

Rosenbach, O., 1953. A Contribuition to the computation of the second vertical derivative from Gravity data. Geophysics, 18: 894-912.

Rohn, R. 2001. A estratigrafia da Formação Teresina (Permiano, bacia do Paraná) de acordo com furos de sondagem entre Anhembi (SP) e Ortigueira (PR). Correlação de Seqüências Paleozóicas Sul-americanas, 20, 209-218.

Rugenski, A., 2006. Investigação geofísica dos complexos alcalinos do Sul e Sudeste do Brasil. Instituto de Astronomia, Geofísica e Ciências Atmosféricas - USP. Tese de Doutorado. 352p.

Saad, A.R., 1977 - Estratigrafia do subgrupo Itararé no Centro Sul do Estado de São Paulo Dissertação de mestrado, Instituto Geociências, USP, 107p.

Schneider, R.L., Mühlmann, H., Tommasi, E., Medeiros, R.A., Daemon, R.F., \& Nogueira, A.A. 1974. Revisão estratigráfica da Bacia do Paraná. In: Congresso Brasileiro de Geologia, XXVIII, 1974, Porto Alegre. Anais, Sociedade Brasileira de Geologia, Porto Alegre, vol. 1, 41- 66.

Silva, D. R. A, 2006. Aplicação de métodos radiométricos (Rb-Sr e Sm_Nd) na análise de bacias sedimentares o exemplo da Bacia do Paraná. Instituto de Geociências - UFRGS, Rio Grande do Sul, Dissertação de Mestrado, 132p.

Soares, P.C., 1973. O Mezosóico Gonduânico no Estado de São Paulo. Departamento de Geologia e Mineralogia da Faculdade de Filosofia, Ciências e Letras de Rio Claro, Rio Claro, Tese de Doutorado, 512 p.

Soares, P. C., 1974, Elementos estruturais da parte nordeste da Bacia do Paraná: Classificação e Gênese. In: Congresso Brasileiro Geologia, 28, 1974, Porto Alegre. Anais São Paulo: Sociedade Brasileira de Geologia, v. 4, p. 107-121.

Soares, P. C.; Landim, P. M. B., 1976. Depósitos Cenozóicos na Região Centro - Sul do Brasil. Notícia Geomorfológica, Campinas, n. 16, p. 17-39.

Soares, P.C., 1991. Tectônica sin-sedimentar cíclica na Bacia do Paraná - controles. Curitiba. Tese Professor Titular - Departamento de Geologia, Universidade Federal do Paraná.

Soares, P.C.; Rostirolla, S.P.; Ferreira, F.J.F.;Stevanato, R. O., 1996. Alto Estrutural Pitanga Quatiguá-Jacutinga na Bacia do Paraná: Uma estrutura litosférica. In: Congresso Brasileiro de Geologia, 39, Salvador- BA. Anais. Salvador: Sociedade Brasileira de Geologia, v. 5, p. 411-414.

Sousa, S.H., Suguio, K., \& Castro, J.C. 1991. Sedimentary facies of the Estrada Nova and Corumbataí Formation (Late Paleozoic of the Paraná Basin) in the state of São Paulo, Brazil. In: International Gondwana Symposium, VII, São Paulo, 1988. Proceedings, 161172. 
Sousa, M. O. L., 2002 - Evolução Tectônica Dos Altos Estruturais de Pitanga, Artemis, Pau d'Álho e Jibóia - Centro do Estado de São Paulo. Tese Doutorado - Instituto de Geociencias, Universidade Estadual Paulista, Rio Claro. 206 p.

Spector, A. \& Grant, F.S. 1970. Statistical models for interpreting aeromagnetic data. Geophysics, 35(2):293-302.

Stewart, K., Turner, S., Kelley, S., Hawkesworth, C., Kirstein, L., and Mantovani, M., 1996, 3 D, 40Ar-39Ar geochronology in the Paraná continental fl ood basalt province: Earth and Planetary Science Letters, v. 143, p. 95-109.

TBC - Trimble Business Center, 2008. User guide. Versão 1.2. 473 p.

Telford, W.M., Geldart, L.P., Sheriff, R.E. 1990. Applied Geophysics. Cambridge Univ. Press, $2^{\text {nd }}$ edition, $770 \mathrm{p}$.

Thiede, D. S., Vasconcelos, P. M., 2010 Paraná flood basalts: Rapid extrusion hypothesis confirmed by new ${ }^{40} \mathrm{Ar} /{ }^{39} \mathrm{Ar}$ results. Geological Society of America. Geology, 38, issue 8, $747-750$.

Thomaz-Filho A. 1982. Ocorrência de Arenito Betuminoso em Anhembi (SP) - Cubagem e Condicionamento Geológico. In: Congr.Bras.Geologia, 32, Salvador, Anais, 5:2344-2348.

Thomaz-Filho A., Mizusaki, A. M. P., Antonioli, L. 2008. Magmatismo nas bacias sedimentares brasileiras e sua inflência na geologia do petróleo. RBG. 32. 128-137.

Thompson D.T. 1982. EULDPH: A new technique for making computerassisted depth estimates from magnetic data. Geophysics, 47(1): 31-37.

Thurston, J. B., R. S. Smith, 1997, Automatic conversion of magnetic data to depth, dip, and susceptibility contrast using the SPI_TM_method: Geophysics, 62, 807-813.

Turner, S., Regelous, M., Kelley, S., Hawkesworth, C., and Mantovani, M., 1994, Magmatism and continental break-up in the South Atlantic: High precision 40Ar-39Ar geochronology: Earth and Planetary Science Letters, v. 121, p. 333- 348.

Zaine, M. F. 1980. Uma barreira geográfica no Paleozóico Superior na região de Fartura, SP. Instituto de Geociências, Universidade de São Paulo, Dissertação de mestrado, 89 p.

Zalán, P. V., Wolff, S., Conceição, J. C. J., Marques, A., Altolfi, M. A. M., Vieira, I. S., Appi, V. T., Zanotto, O. A., 1990. Bacia do Paraná. In: Origem e Evolução de Bacias Sedimentares - Gabaglia, G. P. R. \& Milani, E. J. - Petrobrás, p. 135- 168.

Zalán, P. V., Wolff, S., Conceição, J. C. J., Astolfi, M. A. M., Vieira, I. S., Appi, V. T., Zanotto, A.; Marques, A., 1991. Tectonics and sedimentation of the Paraná Basin. In: GONDWANA SYMPOSIUM, 7, São Paulo, Proceedings... São Paulo: Universidade de São Paulo. p. 83-117.

Yamamoto, J.K., Fairchild, T.R., Boggiani, P.C., Montanheiro, T.J., Araújo, C.C., Kiyohara, P.K., Matos, S.L.F., Soares, P.C. 2005. A Record of Permian subaqueous vent activity in southeastern Brazil. Nature, 438: 205-207. 